\title{
Remediation theory and practice : transforming at-risk medical students
}

Citation for published version (APA):

Winston, K. (2013). Remediation theory and practice : transforming at-risk medical students. [Doctoral Thesis, Maastricht University]. Datawyse / Universitaire Pers Maastricht. https://doi.org/10.26481/dis.20131212kw

Document status and date:

Published: 01/01/2013

DOI:

10.26481/dis.20131212kw

Document Version:

Publisher's PDF, also known as Version of record

\section{Please check the document version of this publication:}

- A submitted manuscript is the version of the article upon submission and before peer-review. There can be important differences between the submitted version and the official published version of record.

People interested in the research are advised to contact the author for the final version of the publication, or visit the DOI to the publisher's website.

- The final author version and the galley proof are versions of the publication after peer review.

- The final published version features the final layout of the paper including the volume, issue and page numbers.

Link to publication

\footnotetext{
General rights rights.

- You may freely distribute the URL identifying the publication in the public portal. please follow below link for the End User Agreement:

www.umlib.nl/taverne-license

Take down policy

If you believe that this document breaches copyright please contact us at:

repository@maastrichtuniversity.nl

providing details and we will investigate your claim.
}

Copyright and moral rights for the publications made accessible in the public portal are retained by the authors and/or other copyright owners and it is a condition of accessing publications that users recognise and abide by the legal requirements associated with these

- Users may download and print one copy of any publication from the public portal for the purpose of private study or research.

- You may not further distribute the material or use it for any profit-making activity or commercial gain

If the publication is distributed under the terms of Article $25 \mathrm{fa}$ of the Dutch Copyright Act, indicated by the "Taverne" license above, 


\section{Remediation Theory and Practice}

Transforming At-Risk Medical Students

Kalman Winston 
The research reported here was carried out at

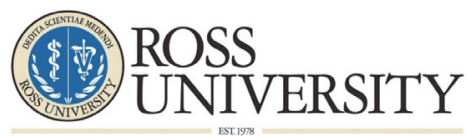

SCHOOL OF MEDICINE

And

Maastricht University in Leamingy!

in the School of Health Professions Education

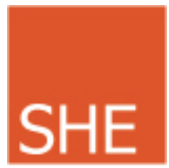

ISBN 9789461592835

(C) Kalman Winston, Maastricht 2013

Cover design: Kalman Winston

Printing: Datawyse / Universitaire Pers Maastricht 


\section{Remediation Theory and Practice}

\section{Transforming At-Risk Medical Students}

\section{DISSERTATION}

to obtain the degree of Doctor at Maastricht University, on the authority of the Rector Magnificus Prof. dr. L.LG. Soete, in accordance with the decision of the Board of Deans, to be defended in public on

Thursday, December 12, 2013 at 16.00 hours.

by

\section{Kalman Winston}

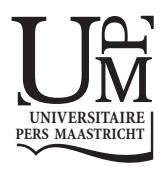




\section{Supervisors}

Prof.dr. A.J.J.A. Scherpbier

Prof.dr. C.P.M. van der Vleuten

\section{Assessment Committee}

Prof.dr. A.F.P.M. de Goeij (chair)

Dr. N. van Dijk, AMC-UvA

Prof.dr. A.D.C. Jaarsma, AMC-UvA

Prof.dr. J.P. Kooman

Dr. G.M.H. Tans 
for Diana 



\section{CONTENTS}

$\begin{array}{ll}\text { Chapter } 1 \text { - Introduction } & 9\end{array}$

Chapter 2 - An investigation into the design and effectiveness 33 of a mandatory cognitive skills programme for at-risk medical students

Published in Medical Teacher, 2010, 32(3):236-243

Chapter 2a - Essential Lifelong Learning Skills (ELLS) course handbook

Chapter 3 - At-risk medical students: implications of students' voice for the theory and practice of remediation

Published in Medical Education, 2010, 44:1038-1047

Chapter 4 - The role of the teacher in remediating at-risk medical students

Published in Medical Teacher, 2012, 34(11):e732-42

Chapter 5 - Prediction and prevention of failure: an early intervention to assist at-risk medical students Published in Medical Teacher, 2013, (0), 1-7

Chapter 6 - Remediation of at-risk medical students: theory in action

Published in BMC Medical Education, 2013, 13:132

Chapter 7 - Discussion

Summary

Samenvatting

Acknowledgements

Biosketch

SHE Dissertation Series 

CHAPTER 1

Introduction 
The widening access agenda is changing the face of higher education, with students increasing in both numbers and diversity. Medical education is also, quite appropriately, embracing diversification while expanding recruitment (AAMC 2006; Howe et al. 2008; AAMC, 2012), not least because of the growing shortfall of physicians (Dill \& Salsberg 2008). Inevitably, this means that there are more nontraditional students, from a wider range of socioeconomic, ethnic and linguistic backgrounds, many of whom are the first in their families to receive higher education, and often experience mismatch between the discourse practices of academia and the discourse practices of their homes. For many schools, the increased numbers are achieved by accepting students with lower entry grades (James et al, 2008), some of whom are less well-equipped for the rigour of academic work and may be unsure of what will be expected of them (Howe et al. 2008; Jolly et al. 2008; Fitzmaurice 2010). This raises concerns about increased dropout and failure rates (Howe et al, 2008; Thomas, 2012), and consequent waste of time and money by all stakeholders. If the competence of our graduates (and ultimately patient care) is not to be compromised, then institutions have an obligation to identify these poorly-prepared students and to provide the support necessary to help them adapt and develop the skills needed for success (Frellsen et al, 2008; Foster, 2010; Pell et al, 2012).

Essentially, there are two possible approaches to assisting these students: prediction and prevention of failure, or remediation after failure. There has been a great deal of work on identification of which students will struggle: the most consistent predictor for medical education appears to be a combination of prior GPA and cognitive tests such as the US Medical College Admission test (MCAT), but these only account for around $20 \%$ of the variance in medical school performance (Tinto, 1975; Ferguson et al, 2002; Donnon et al, 2007; Sui and Reiter, 2009; Callahan et al, 2010; Artino Jr. et al, 2012), and seem unable to predict either failure or dropout (Prideaux et al, 2011; McLaughlin, 2012; Shulruf et al, 2012). This difficulty of precise prediction is compounded by the risks of 'labelling' students incorrectly (Alexander et al, 2005), and the necessity for students to admit their need for help before it can be fully effective. Indeed, most reported efforts at preventing failure have shown no significant effect (Tekian and Hruska, 2004; Kies and Freund, 2005; Devoe et al. 2007), or short-term but no long-term effect (Kies and Martinsek, 2010; Stegers-Jager et al, 2013).

There has been relatively little work on strategies for effective remediation of struggling students, particularly within medical education. There is uncertainty about what kind of remediation works best (Hauer et al, 2009), and the work that has been done has resulted in calls for further research into the components of effective remedia- 
tion, how they work, and how they might be combined into an effective intervention (Saks and Karl, 2004; Kies and Freund, 2005; Paul et al, 2009; Cleland et al, 2010; O'Neill et al, 2011; Cleland et al, 2013). Thorough exploration and development of a theory and practice of remediation for at-risk medical students has the potential to positively impact the growth and diversification of the physician workforce and thus contribute to improved patient care.

\section{Research Aim}

The aim of this research project is to develop a practical theory of remediation for at-risk medical students. Learning proceeds by abstracting from specific cases to generalized categories (Hofstadter and Sander, 2013), and the development of any theory must originate in accumulated observation of practice (Dewey, 1929). Analogously, this project involves the development of a context-specific intervention, from which we hope to generalize towards a theory of remediation that may ultimately be applicable to the remediation of at-risk students in higher education disciplines beyond medicine. The design of this remedial intervention draws on a broad range of educational theory and literature, combined with extensive personal practical knowledge (Ben-Peretz, 2011), with the goal of creating a blend of pedagogic approaches that can enable at-risk students to become more proficient learners and achieve success in medical school. Thus the main research question is:

What are the ingredients of successful remediation, and how do these work to improve outcomes for at-risk medical students?

Answering this question is not trivial, and encompasses description, justification and clarification research (Cook et al, 2008) that attempts to understand the complexity of remediation in order to improve the quality of our interventions and enable transfer across contexts. The five studies reported in subsequent chapters each take on a different aspect of this overall aim, by focusing on various subquestions and perspectives. Before discussing remediation theory and practice in further detail, I offer a brief outline of the conceptual frameworks that have guided this work. 


\section{Conceptual Frameworks}

\section{The Researcher}

In any human endeavour, including research, objectivity is largely mythical (Denzin and Lincoln, 2005): what is observed depends on the paradigm of the observer (Dewey, 1929; Kuhn, 1996) and there are multiple ways to interpret any data set (Kuhn, 1996). Every step in research, from design to data collection to theory building (Mauthner \& Doucet 2003; Denzin \& Lincoln 2005; Bunniss and Kelly, 2010), depends on the conceptual frameworks used, making the researcher intrinsic to the methodology (Kvale, 1996). It is thus essential to be clear about myself as a researcher, my perspective, and my relationship to the research, so that readers are able to interpret the findings in light of this (Gill and Griffin, 2009).

First and foremost, I teach. I take a pragmatic view of education research: its ultimate value lies in its application, for the improvement of teaching and learning and for the dissemination of good practice. Developing wisdom of practice involves a constant interplay between reflection and action (Shulman, 2007): a full understanding of educational theory is essential to the development of good practice, and examination of practice is essential to the development of good theory (Gibbs et al, 2011). The oft-lamented gap between theory and practice (Sparapani et al. 1996) is partly due to outsider researchers' unfamiliarity with the context of their subjects, which can lead to misunderstandings (Maso, 2001; van Kruiningen, 2013) that serve to distance researchers from practitioners. The work of practitioner researchers can bring valuable perspectives to the theory of educational practice and the practice of educational theory: we are well-positioned to understand the nuances of our classrooms (Postholm, 2008) and contribute to theory development (van der Vleuten et al, 2000), while also being in a position to test those theories (Dewey, 1929) and adapt them to specific contexts. Indeed, from this perspective, the idea of a theory-practice gap involves the creation of a false dichotomy: they are interpenetrating and mutually constitutive, one cannot exist without the other (Dewey, 1929; Misawa, 2011).

\section{Research design}

This pragmatic, realist perspective requires the use of a variety of conceptual lenses (Bordage 2009) to explore remediation, which, like any educational intervention, is an inherently complex process (Jörg et al. 2007). The intent throughout has been to make use of mixed methodologies, to approach the research with a blend of methods 
that seem most likely to yield useful results, a 'whatever works' approach to explanation-building (Maudsley, 2011; Wong et al, 2012). I have employed both qualitative and quantitative methods, using insights from each to triangulate a range of perspectives (Kitto, 2008; Pope and Mays, 2009), to move towards a crystallization of multi-faceted understanding (Seltzer-Kelly, 2011).

The overall work may be loosely described as an extended case study of a design-based research project. Given the complexity and context-specificity of educational interventions, there is a strong argument for detailed case studies that exemplify, reflect upon and theorize practice (Shulman, 1986; Kannan and Miller, 2009), rich descriptions that allow readers to adapt and generalise the proffered experiences to their own situations (Cresswell and Miller, 2000; Postholm, 2008; Regehr, 2010). Design-based research involves the development and testing of theory-driven educational interventions in specific classroom contexts, with outcomes feeding back into iterative evolution of both theory and practice, (Joseph, 2004; Sandoval and Bell, 2004; Anderson and Shattuck, 2012). This methodology is wellsuited to the long-term study of a complex intervention in a single setting (Design-Based Research Collective, 2003), and also fits well with the ongoing theory-practice interplay in the world of a practitioner-researcher.

Inevitably, not every aspect of an intervention can be studied in a finite time, and a complete picture can never be fully explained: there are always selections to be made (Dewey, 1929), with some aspects explored in more detail than others. While the categories and labels used for description are necessarily inventions of the researcher rather than absolute properties of the phenomena described (Bateson, 1972; Greasley and Ashworth, 2007), hopefully there is enough here for the reader to gain some insight into the theory and practice of remediation.

\section{Research Context}

Context affects the details of design and outcomes for any educational practice (Shulman, 2005; Regehr, 2010; Wong et al, 2012), and it is this specificity that makes educational research so challenging (Gibbs et al, 2011). Here I offer a brief overview of the research context, with further details provided in subsequent chapters.

The work was carried out at Ross University, a private Caribbeanbased US medical school. The school is at the forefront of the widening access mission, accepting students, mostly US citizens, from diverse ethnic and socioeconomic backgrounds with a wide range of admission criteria: MCAT scores range from 12 to 36 . Most of these 
students have already failed to gain entry into mainland US medical schools, where the minimum MCAT requirement is around 27 (Coumarbatch et al, 2010), and many arrive in a 'strange foreign land' unprepared for both island life and the rigour of medical education. This is compounded by the school's accelerated curriculum - the four semesters of basic science are completed on island in 16 months ( 4 x 4-month semesters), compared to the US norm of 2 years, after which the students return to mainland USA for USMLE (United states Medical Licensing Exam) Step 1 exams and then clinical rotations. And the class sizes are large: the school accepts a new cohort of over 400 students each semester, three times a year. The accelerated curriculum means that students typically face twenty hours of lectures every week, as well as laboratory sessions - the pace is relentless, the volume of material often overwhelming. This learning environment, with its large class sizes, high contact hours, heavy workload, frequent high stakes exams, and underprepared students, encourages surface approaches to learning (Kember et al, 2008), and contributes to a $25 \%$ to $30 \%$ attrition rate.

Many of the students who fail one or more courses during a semester are allowed to repeat that semester on probation. Those who fail and repeat first semester, which is the one with the highest attrition, are the focus of this project, and are referred to subsequently as "at-risk students". Prior to this intervention, these students typically failed to seek help during their failing semester, and most of them again failed to seek help during their repeat semester. Data was clearly showing that students who had repeated a semester at the school were not graduating - the majority (62\%) either failing the repeating semester, failing a subsequent semester, or failing USMLE Step 1.

It was clear to me, in my new role as founder of the school's Centre for Teaching and Learning, that if the school was to continue taking money from these students, something needed to be done to help them make the most of their opportunity, and it needed to have a long-term effect on these students' success rates, since a shortterm fix risked simply extending their debt without increasing their likelihood of becoming physicians. We turn now to the first step in creating any educational intervention - a consideration of the learners who are its target.

\section{Reasons for struggling - 'at-risk-ness'}

Although the causes for students' academic difficulties are multifaceted and complex (Whitehead, 2012), a careful appraisal of the literature reveals a number of recurring, inter-related reasons for 
students failing at medical school. These generally include weakness in literacy, numeracy, study skills, test-taking strategies, background knowledge, critical thinking, domestic and emotional problems, confidence and self-esteem (Slotnick, 1981; Sayer et al, 2002; Alexander et al, 2005; Burns, 2006; Cleland et al, 2005; Winston and Houghton, 2006). While deeply personal issues can clearly affect student outcomes, they are beyond the scope of this intervention: it is important for teachers to recognize when a student's difficulty lies outside one's area of expertise, and to refer to the appropriate student support service. Here I give an overview of some of the most common relevant themes, which are dealt with further in subsequent sections and chapters.

'Study skills' is a broad, rather nebulous concept that can include a range of elements. Certainly, I have encountered medical students with surprising weaknesses in both numeracy and literacy that hamper their progress and understanding. Although we should not be too surprised that newcomers to medical discourse frequently misuse disciplinary language (Dewey, 1910; Anderberg et al, 2008; Sfard, 2010), a poor grasp of relatively ordinary vocabulary and basic mathematics is not uncommon. At-risk students commonly struggle to organize and integrate the large amount of information that is thrown at them (Paul et al. 2009), and are unable to differentiate between what is relevant and what is irrelevant (Sampson and Clark, 2008), with consequent problems with time management (Goldfinch and Hughes, 2007; Paul et al. 2009) leading to a reliance on handme-down notes that is negatively correlated with exam performance (Sleight and Mavis, 2009). Many of these students seem surprised at the high demands of their new learning environment (HaaralaMuhonen et al, 2011), and inflexibly stick to a single study strategy that may have served them well at previous levels of education. They fail to consider alternative active learning strategies, such as retrieval practice (Karpicke et al, 2009) or concept mapping, are commonly reluctant to participate in group discussions, and generally engage in passive learning behaviours that have been linked to weak performance (Dolan et al, 2002). Many have had success in the past by playing the 'classroom game' of correct answer production, rather than effortful sense-making (Hutchison and Hammer, 2010), which likely contributes to their unhelpfully low tolerance of uncertainty, also correlated with lower achievement (Bolhuis and Voeten, 2004).

Inexpertise in critical thinking is also a frequent trait of at-risk students. They tend to display weak problem-solving skills, faulty logic, avoid cognitive conflict (Yew and Schmidt, 2009; van Velzen, 2012), and have trouble identifying what was being asked in a problem (Geertsma, 1977). This often combines with unacknowledged insufficient background knowledge (Slotnick, 1981) - an 
illusion of knowing (Pashler et al, 2007) that can prevent appreciation of an 'at-risk' situation. This can lead to the classic overconfidence of those unable to recognize their incompetence (Kruger and Dunning, 1999; Cleland et al, 2005), a hallmark of a generation of students who are used to being told that they deserve to succeed (Twenge, 2009). Others, of course, see their weakness all too clearly, resulting in low self-esteem and a lack of confidence that prevents them asking questions (Muraskin, 1997) and may result in the avoidance of challenging situations (Fenollar et al. 2007) and high levels of anxiety that can adversely affect cognition and performance (Brown and Gray, 2008; Paul et al. 2009).

Many of the above problems can be related to difficulties with metacognition and self-regulation. Weak students are generally inaccurate at self-assessment (Kruger and Dunning, 1999), fail to plan well or monitor their own performance (Zimmerman, 2002) and rely more on external than internal feedback (Hattie and Timperley, 2007). This in turn correlates with lower exam scores and a resistance to seeking help (Weinsheimer, 1998; Artino et al, 2012); worse, students who are struggling often ignore communications from faculty offering assistance (Cleland et al, 2005). Equally problematic is that when these students do fail courses they choose to blame fixed personal attributes (Cleland et al. 2005), their teachers (Sandars and Cleary, 2011), the school (Frelin and Grannäs, 2010) or simply bad luck (Geary, 2008), rather than the more helpful attribution of failure to controllable causes (Ferla et al, 2008). Further, these students tend to lower their self-expectations after failure (Bandura, 1977), and to overgeneralize, believing that lack of success in one subject implies future lack of success in others (Dickhauser et al, 2009). And then, when they are allowed to repeat courses, they often simply work more intensively rather than try to change their approach, and thus fail again (Mattick and Knight 2007), in a cycle that can be difficult to break (Cleland et al. 2005, 2008).

While it is unlikely that any one student will exhibit all of the above, it is also true that most at-risk students turn out to face a combination of several of these challenges, regardless of which of them they may initially claim to present with. It is the task of remediation to help these novice learners unravel their own issues, and to help them transform into more expert students. We now turn to a brief review of attempts to do this.

\section{Remediation literature}

There is relatively little in the medical education literature that addresses the details of remediation (and there was even less when 
this project started 6 years ago). A survey of US and Canadian medical schools (Saks and Karl, 2004) showed that most do provide some form of academic support service, but these programmes tend to be variable in content, and the report concludes that further study is needed to determine how or whether these programs may influence academic success. Paul et al (2009) found a mismatch between needs and provision, with students mainly seeking help with organizing and integrating information but schools mostly offering mental health and disability support. Few programmes appear to be described in any detail in the medical education literature, but it seems that use of upper class students and individual sessions with academic support faculty are the most common form of intervention (Saks and Lebeau, 2006; Sayer et al, 2002), along with introductory workshops on study skills for new students (e.g. Texas Tech, Boonshoft, Robert Wood Johnson Medical Schools).

Many attempts at remediation have been shown to have only short-term effects (Cleland et al, 2013), setting these at-risk students up for further failure later in their careers. For example, there is no evidence that prematriculation programmes, which many schools run, have much impact on long-term outcomes (Tekian and Hruska, 2004; Kies and Freund, 2005; Lieberman et al, 2008), many other interventions, catering to only a handful of students, only report gains for the next exam, with no mention of long-term effects (Brown and Gray, 2008; Laatsch, 2009; White et al, 2009; Pell et al, 2012), while the use of students as tutors had either no effect (Devoe et al, 2007) or only a short-term effect (Stegers-Jager et al, 2013). Slightly more promising is a six week lifelong learning skills course for students performing poorly in their first exam, focusing on reading, notetaking, and classroom behaviour (Kies and Martinsek, 2010), but again only small short-term gains are reported, with little exploration of how this may have helped.

A number of schools provide decelerated programs that allow atrisk students to spend two years taking the first year, and report better outcomes for students in these programmes than for students who repeat (Ficklin et al, 1985; Kies and Freund, 2005). However, the majority of these are small scale, report sparse details and provide either minimal additional help or no other support than deceleration itself. Indeed, McGrath and McQuail (2004) question the value of deceleration and recommend that investigation into the effectiveness of additional support methods is needed.

Alexander et al (2005) describe a separate one-year intervention programme for 16 South-African students, with weekly tutorials focusing on academic concepts and skills development, in addition to PBL cases. Burch et al (2007) also report improved performance of at-risk students in PBL programs, but suggest further study is needed 
to identify the components of PBL that help at-risk students, and neither of these cases provide meaningful outcome measures. Likewise, Sayer et al (2002) provide up to a year of weekly tutorials for fourth and fifth years directed at diagnosis of causes of academic failure and negotiation of a management plan, with good short-term results, but again no long-term outcomes reported.

There is also a dearth of literature on the components of effective remediation. Several authors suggest that successful support programmes should focus on both 'skills development' and 'content boosting' (Saks \& Karl 2004; Brigman \& Webb 2007; Carroll \& Feltham 2007; Mattick \& Knight 2007). Hauer et al (2009b) recommend inclusion of diagnosis of problems, deliberate practice, feedback, and reflection, while Saxena et al (2009) favour a multimodal approach that addresses denial and involves authentic organized group activities. Looking beyond medical education, Muraskin's (1997) study describes five exemplary support programmes used in colleges and universities. These programmes focus less on studentled tutoring than other less successful programmes, and have in common a focus on group rather than individual interventions, as well as all having some control over student promotions and admissions.

Ultimately, remediation is complex (Hauer et al, 2009), teaching simply to pass the next test often results in repeated failure and could be considered unethical (Cleland et al, 2013) and there is an absence of guidelines about how best to accomplish remediation. The consensus appears to be that there is need for further research into details of effective, replicable strategies for remediation of struggling medical students (McGrath \& McQuail 2004; Saks \& Karl 2004; Kies \& Freund 2005; Burch et al. 2007; Paul et al. 2009; Saxena et al. 2009; Cleland et al. 2010; Cleland et al, 2013). Any specific context imposes certain constraints on what is possible (Ross University would not allow us, for example, to offer an extra year) but also offers advantages. At Ross, the numbers, diversity and fast throughput of students, affords a unique opportunity to explore remediation with large sample sizes and attention to long-term outcomes. The next section briefly outlines the first step in this process (further elaborated in chapter 2), the design of our intervention for repeating first semester students.

\section{Intervention design}

Instructional design necessarily enacts the theoretical beliefs of the designers. This intervention programme, labelled ELLS (Essential lifelong Learning Skills), draws upon a blend of complementary theoretical perspectives; no single theory provides a complete under- 
standing of education and learning: the power lies in their combination (Tetlock, 2005; Bordage, 2009; Chinn and Samarapungavan, 2009). ELLS is primarily based upon a constructivist, student-centred approach that focuses on learning through collaboration, dialogue, self-direction and reflection (Loyens et al, 2007; Bruner, 1999) while the effort to enculturate students into medical discourse and build their identities as medical students draws on sociocultural theories of learning (Lave and Wenger, 1991). Constructivism and socioculturalism can be seen as complementary, with the former discussing the individual processes and subject matter of learning while the latter provides social theories for the possibility of learning (Cobb, 1999); with respect to learners, constructivism looks from the inside out, while socioculturalism looks from the outside in - both are needed because both individual and environment matter. Complexity theory takes this further, seeing learning as becoming (Hager, 2008), with the learner and environment mutually constitutive, defining and changing each other (Maturana and Varela, 1987; Proulx, 2008). In this view, interaction and situation are inseparable (Dewey, 1938), attention to both participants and their environment is essential for the occurrence of meaningful learning (Durning and Artino, 2011), and the 'whole' of complex learning is more than the sum of its parts (van Merrienboer et al, 2002).

Of course, the main driver in ELLS has been the needs of the learners, as described above. Clearly, just telling students what to do, an information transfer approach to teaching study skills, cannot work (Bandura, 1977; McNamara, 2010) - skills must be applied to be learned (Goodyear and Zenios, 2007). It is essential to combine the teaching of process with content (Martin and Arendale, 1992; Wingate, 2006; Star and Hammer, 2007; Postholm, 2010), and in the ELLS course every lesson involves application of process skills to basic science course material, offering students a variety of ideas which they are encouraged to test and flexibly adapt (Muraskin, 1997; Alexander et al, 2005; Paul et al, 2009), with the goal of challenging students' conceptions of and approaches to learning (Mattick and Knight, 2007).

Broadly speaking, the course tackles cognitive, metacognitive and affective aspects of student learning, recognizing that these areas are inseparably intertwined (Lakoff and Johnson, 1999). Reflection on prior and current experiences is a cornerstone of the approach (Sargeant et al, 2009), as is the giving and receiving of feedback (Mattick and Knight, 2007), both of which are invaluable to the development of the disposition for critical thinking (Dewey, 1938; Tishman et al, 1992; Dyche and Epstein, 2011). Essentially, these atrisk students, having behaved like novice learners, need to become expert medical students who can learn the material however it may 
be presented to them. Expertise requires integration and organization of knowledge according to underlying principles (Glaser, 1999) and well-developed ability for self-regulation (Zimmerman, 2002; Mylopolous and Woods, 2009). Self-regulated learning encompasses the metacognitive processes that guide planning, monitoring and reflection on performance (Zimmerman, 2002; Sandars and Cleary, 2011; Durning et al, 2011), is closely related to both academic achievement and independent learning (Flavell, 1979; Kaufman, 2003; Ferla et al, 2008; Cleland et al, 2013), and provides a framework for approaching the variety of weaknesses shown by at-risk students.

Another key thread of the intervention is attention to discourse. Language is intimately connected to understanding (Dewey, 1910; Goodyear and Zenios, 2007; Kahneman, 2011) and needs to be used actively to become part of a person's available knowledge (Meyer and Land, 2003; Shotter, 2009). Dialogue and discourse are considered to be essential mediators of learning (Hicks, 2003; Mercer, 2000), fostering critical thinking (Freire and Macedo, 1999) and knowledge construction (Murphy, 1999). Working in small groups is thus a key element in the course, affording students the opportunity to use language as a tool for thinking (Dewey, 1910; Mercer 2000), to scaffold each other's learning (Machado 2003), to share ideas and be confronted with multiple viewpoints (Askell-Williams and Lawson, 2005), and to reflect on learning strategies through constructivist dialogue (Mercer 2000; Mackenzie 2007). The group setting also provides motivation and support (Postholm, 2008), maximises the capacity of scarce human resources and reinforces the message that receiving help is not a sign of weakness (Muraskin, 1997).

Given the aforementioned refusal of many at-risk students to seek help voluntarily, their tendency to attribute cause inappropriately and self-assess inaccurately, and the general reluctance of students to reflect on performance unless they are required to do so (Albanese, 2006), participation in this course has been made mandatory for repeating students. The hope was that students who have already failed are likely to be quite receptive to receiving assistance, since it's undeniable that something was not right during their first attempt at semester one. Another advantage of making attendance mandatory stems from the finding that increased attendance at support classes correlates with better outcomes (Muraskin, 1997), while required attendance also ensures a group stability likely to be helpful for constructive, collaborative dialogue.

Chapter $\mathbf{2}$ explores the efficacy of this intervention programme for at-risk medical students. Here the focus is on whether mandatory attendance in a cognitive skills programme for at-risk students can improve short- and long-term outcomes at medical school, and on 
describing the components of the programme, and the rationale for the inclusion of each. The most recent version of the full ELLS handbook, as provided to both students and teachers on the course, is included as an appendix, chapter $2 \mathrm{a}$.

Chapter 3 explores the students' views of the programme in order to clarify understanding of optimal remediation practice. Student surveys and focus groups are analysed for emergent themes in order to explore their perceptions of the programme, how it affects their understanding of their roles as medical students and which aspects of the programme students find most effective. The students' perspectives are used to inform and develop our knowledge of the theory and practice of remediation.

Chapter 4 takes a careful look at the role of the teachers in this programme. Extensive qualitative data from student surveys and indepth teacher interviews are used to produce a richer description of remediation processes, while further analysis of quantitative student performance data is used to identify differences in outcomes of students allocated to different teachers.

Chapter 5 takes advantage of a curricular change within the school to verify the value of a new early exam as a predictor of failure, and then takes ideas developed in the preceding chapters to explore a preventative intervention, and thus continue to develop our theory of remediation.

Chapter 6 picks up on emergent themes about the role of the teacher differences in remediation, while also bringing the emerging theory back to the classroom for deeper analysis. This paper focuses on direct observation of classroom teaching, drawing on recorded and transcribed samples of talk-in-context to demonstrate how the various elements of remediation play out in practice, highlighting aspects that are most effective, and identifying differences between experienced and novice teachers. This examination leads to further insights into the theory and practice of remediation.

Chapter 7 summarizes the work of the preceding chapters, discusses emergent themes and draws together various threads that run throughout the project to offer some conclusions about remediation for at-risk medical students. 
Readers are reminded that this thesis is based on journal articles, and therefore some repetition of content across chapters is unavoidable.

\section{References}

AAMC. 2006. AAMC Statement on the Physician Workforce. Association of American Medical Colleges. http://www.aamc.org/workforce/workforceposition.pdf

AAMC. 2012. Results of the 2011 Medical School Enrollment Survey. AAMC Centre for Workforce Studies. https://www.aamc.org/download/281126/data/enrollment2012.pdf

Albanese MA. 2006. Crafting the reflective lifelong learner: Why, what and how. Med Educ 40:288-290

Alexander R, Badenhorst E, Gibbs T. 2005. Intervention programme: A supported learning programme for educationally disadvantaged students. Med Teach 27(1):66-70

Anderberg E, Svensson L, Alvegård C, Johansson T. 2008. The epistemological role of language use in learning: A phenomenographic intentional-expressive approach. Educ Res Rev 3(1):14-29

Anderson T, Shattuck J 2012. Design-Based Research A Decade of Progress in Education Research? Educational Researcher, 41(1), 16-25

Artino AR, Gilliland WR, Waechter DM, Cruess D, Calloway M, Durning SJ. (2012). Does self-reported clinical experience predict performance in medical school and internship? Med Educ, 46(2):172-178

Askell-Williams $\mathrm{H}$, Lawson MJ. 2005. Students' knowledge about the value of discussions for teaching and learning. Social Psych Educ, 8(1):83-115

Bandura A. 1977. Self-efficacy: Toward a Unifying Theory of Behavioral Change. Psych Rev, 84(2):191-215

Bateson G. 1972. Steps to an Ecology of Mind. Chicago, IL: University of Chicago Press 469-70

Ben-Peretz M. 2011. Teacher knowledge: What is it? How do we uncover it? What are its implications for schooling? Teach Teach Educ 27(1):3-9

Bolhuis S, Voeten MJM. 2004. Teachers' conceptions of student learning and own learning. Teach Teach 10(1):77-98

Bordage G. 2009. Conceptual frameworks to illuminate and magnify. Med Educ 43:312-319

Brigman G, Webb L. 2007. Student success skills: Impacting achievement through large and small group work. Group Dyn: Theory Res Pract 11(4):283-292

Brown J, Gray LE. 2008. Helping students to gain confidence in personal performance. Med Educ 42:517-8 
Bruner, J. 1999. 'Culture, mind and education' in Moon \& Murphy (ed.) Curriculum in Context The Open University, Sage, London

Bunniss S, Kelly DR. 2010. Research paradigms in medical education research, Med Educ 44:358-366

Burch VC, Sikakana CNT, Yeld N, Seggie JL. 2007. Performance of academically at-risk medical students in a problem-based learning programme: A preliminary report. Adv Health Sci Educ Theory Pract 12(3):345-358

Burns ER. 2006. Learning syndromes afflicting beginning medical students: Identification and treatment - Reflections after forty years of teaching. Med Teach 28(3):230233

Callahan CA, Hojat M, Veloski J, Erdmann JB, Gonella JS. 2010. The predictive validity of three versions of the MCAT in relation to performance in medical school, residency, and licensing examinations: A longitudinal study of 36 classes of Jefferson Medical College. Acad Med, 85(6):980-987

Carroll S, Feltham M. 2007. Knowledge or Skills - The Way to a Meaningful Degree? An Investigation Into The Importance of Key Skills Within an Undergraduate Degree and The Effect This Has On Student Success. Bioscience Education 10

Chinn CA, Samarapungavan ALA. 2009. Conceptual change-multiple routes, multiple mechanisms: A commentary on Ohlsson. Educ Psychol 44(1):48-57

Cleland J, Arnold R, Chesser A. 2005. Failing finals is often a surprise for the student but not the teacher: Identifying difficulties and supporting students with academic difficulties. Med Teach 27(6):504-508

Cleland J, Milne A, Sinclair H, Lee AJ. 2008. Cohort study on predicting grades: Is performance on early MBChB assessments predictive of later undergraduate grades? Med Educ 42:676-683

Cleland J, Mackenzie RK, Ross S, Sinclair HK, Lee AJ. 2010. A remedial intervention linked to a formative assessment is effective in terms of improving student performance in subsequent degree examinations. Med Teach 32(4):e185-e190

Cleland J, Leggett H, Sandars J, Costa MJ, Patel R, Moffat M. 2013. The remediation challenge: theoretical and methodological insights from a systematic review. Med Educ, 47:242-251

Cobb, P. 1999. 'Where is the Mind?' in Murphy (ed) Learners, Learning \& Assessment The Open University, Sage, London

Cook DA, Bordage G, Schmidt HG. 2008. Description, justification and clarification: A framework for classifying the purposes of research in medical education. Med Educ 42:128-133

Coumarbatch J, Robinson L, Thomas R, Bridge PD. 201). Strategies for identifying students at risk for USMLE step 1 failure. Fam Med, 42(2):105-10

Creswell JW, Miller DL. 2000 Determining Validity in Qualitative Inquiry, Theory Into Practice, 39:3, 124-130 
Denzin NK, Lincoln YS. 2005. The Sage handbook of qualitative research. 3rd ed. Thousand Oaks, CA: Sage

Design-Based Research Collective. 2003. Design-based research: An emerging paradigm for educational inquiry. Educational Researcher, 5-8

Devoe P, Niles C, Andrews N, Benjamin A, Blacklock L, Brainard A, Colombo E, Dudley B, Koinis C, Osgood M. 2007. Lessons learned from a study-group pilot program for medical students perceived to be 'at risk'. Med Teach 29(2):e37-e40

Dewey J. 1910. How We Think. New York, NY: DC Heath \& Co

Dewey J. 1929. Experience and Nature. London, George Allen \& Unwin Ltd

Dewey J. 1938. Experience and Education. Touchstone, NY: Kappa Delta Pi

Dickhäuser O, Reinhard M, Diener C, Bertrams A. 2009. How need for cognition affects the processing of achievement-related information. Learn Indiv Diff 19(2):283-287

Dill MJ, Salsberg ES. 2008. The Complexities of Physician supply and Demand: Projections Through 2025. Center for Workforce Studies, Association of American Medical Colleges. http://www.mhc.org/mhc_images/phys_demand_2025.pdf

Dolan S, Mallott DB, Emery JA. 2002. Passive learning: A marker for the academically at risk. Med Teach 24(6):648-649

Donnon T, Paolucci EO, Violato C. 2007. The predictive validity of the MCAT for medical school performance and medical board licensing examinations: a meta-analysis of the published research. Acad Med, 82(1):100-106

Durning SJ, Artino AR. 2011. Situativity theory: A perspective on how participants and the environment can interact: AMEE Guide no. 52. Med Teach, 33(3):188-199

Dyche L, Epstein RM. 2011. Curiosity and medical education. Med Educ 45:663-668

Fenollar P, Roman S, Cuestas PJ. 2007. University students' academic performance: An integrative conceptual framework and empirical analysis. Br J Educ Psychol 77:873891

Ferguson E, James D, Madeley L. 2002. Factors associated with success in medical school: systematic review of the literature. BMJ, 324(7343):952-957

Ferla J, Valcke M, Schuyten G. 2008. Relationships between student cognitions and their effects on study strategies. Learn Indiv Differ 18(2):271-8

Ficklin FL, Hazelwood JD, Carter JE, Shellhamer RH. 1985. The reduced load as a remedial program to increase retention of first-year medical students. J Med Educ 60(5):406-408

Fitzmaurice M. 2010. Considering teaching in higher education as a practice. Teach High Educ 15(1):45-55

Flavell JH. 1979. Metacognition and cognitive monitoring: A new area of cognitivedevelopmental inquiry. Am Psychol 34:906-911 
Foster G. 2010. Teacher effects on student attrition and performance in mass-market tertiary education. High Educ 60(3):301-319

Freire P, Macedo DP. 1999. Pedagogy, culture, language and race: A dialogue. In: Leach Moon, editor. Learners and Pedagogy. London: Sage/The Open University. pp $46-58$

Frelin A, Grannäs J. 2010. 'Negotiations left behind: in-between spaces of teacherstudent negotiation and their significance for education', J Curriculum Studies, 42: 3, $353-369$

Frellsen SL, Baker EA, Papp KK, Durning SJ. 2008. Medical school policies regarding struggling medical students during the internal medicine clerkships: results of a national survey. Acad Med, 83 (9):876-81

Geary DC. 2008. An Evolutionarily Informed Education Science, Educ Psych,43(4):179195

Geertsma RH. 1977. A special tutorial for minority medical students: An account of a year's experience. Journal of Med Educ 52(5):396-403.

Gibbs T, Durning S, Van Der Vleuten C. 2011. Theories in medical education: Towards creating a union between educational practice and research traditions. Med Teach, 33(3): $183-187$

Gill D, Griffin AE. 2009. Reframing medical education research: let's make the publishable meaningful and the meaningful publishable. Med Educ, 43(10):933-935

Glaser, R. 1999. 'Expert Knowledge and Processes of Thinking' in McCormick and Paechter (eds) Learning and Knowledge The Open University, Sage, London

Goldfinch J, Hughes M. 2007. Skills, learning styles and success of first-year undergraduates. Active Learn High Educ 8(3):259-273

Goodyear P, Zenios M. 2007. Discussion, collaborative knowledge work and epistemic fluency. Br J Educ Stud 55(4):351-368

Greasley K, Ashworth P. 2007. The phenomenology of 'approach to studying': the university student's studies within the lifeworld. Br Educ Res J 33(6):819-43

Haarala-Muhonen A, Ruohoniemi M, Lindblom-Ylänne S. 2011. Factors affecting the study pace of first-year law students: in search of study counselling tools, Studies in Higher Education, 36:8, 911-922

Hager P. Learning and metaphors. 2008. Med Teach, 30(7):679-86

Hattie J, Timperley H. 2007. The power of feedback. Rev Educ Res 77(1):81-112

Hauer KE, Ciccone A, Henzel TR, Katsufrakis P, Miller SH, Norcross WA, Papadakis MA, Irby DM. 2009. Remediation of the deficiencies of physicians across the continuum from medical school to practice: a thematic review of the literature. Acad Med, 84(12):1822-1832

Hauer KE, Teherani A, Kerr KM, Irby DM, O'Sullivan PS. 2009b. Consequences within medical schools for students with poor performance on a medical school standardised patient comprehensive assessment. Acad Med 84(5):663-8 
Hicks D. 2003. Discourse, teaching and learning. In: Goodman S, Lillis T, Maybin J, Mercer $\mathrm{N}$, editors. Language, literacy and education: A reader. Stoke-on-Trent, UK: Trentham Books. pp 3-24

Hofstadter D, Sander E. 2013. Surfaces and Essences. New York, Basic Books

Howe A, Campion P, Searle J, Smith H. 2008. New perspectives - Approaches to medical education at four new UK medical schools. BMJ 329: 327-32

James D, Ferguson E, Powis D, Symonds I, Yates, J. 2008. Graduate entry to medicine: widening academic and socio-demographic access. Med Educ, 42(3), 294-300

Jolly P, Garrison G, Boulet JR, Levitan T, Cooper RA. 2008. Three pathways to a physician career: Applicants to U.S. MD and DO schools and U.S. citizen applicants to international medical schools. Acad Med 83(12):1125-1131

Jörg T, Davis B, Nickmans G. 2007. Towards a new, complexity science of learning and education. Educ Res Rev 2:145-156

Joseph D. 2004. The Practice of Design-Based Research: Uncovering the Interplay Between Design, Research, and the Real-World Context, Educational Psychologist, 39(4):235-242

Kahneman D. 2011. Thinking, Fast and Slow. Farrar, Straus and Giroux, New York

Kannan J, Miller JL. 2009. The positive role of negative emotions: fear, anxiety, conflict and resistance as productive experiences in academic study and in the emergence of learner autonomy. Int J Teach Learn High Educ, 20(2):144-54

Karpicke JD, Butler AC, Roediger III HL. 2009. Metacognitive strategies in student learning: Do students practise retrieval when they study on their own?', Memory, 17(4):471-479

Kaufman DM. 2003. ABC of learning and teaching in medicine: Applying educational theory in practice. BMJ 326:213-216

Kember D, Leung DYP, McNaught C. 2008. A workshop activity to demonstrate that approaches to learning are influenced by the teaching and learning environment. Active Learn High Educ 9(1):43-56

Kies SM, Freund GG. 2005. Medical Students who Decompress During the M-1 Year Outperform Those who Fail and Repeat it: A Study of M-1 Students at the University of Illinois College of Medicine at Urbana- Champaign 1988-2000. BMC Med Educ

Kies S, Martinsek A. 2010. Improving First-year Medical Student Performance with Individualized Learning Strategies. JIAMSE, 20(1):18-23

Kitto SC, Chesters J, Grbich C. 2008. Quality in qualitative research: Criteria for authors and assessors in the submission and assessment of qualitative research articles for the Medical Journal of Australia. MJA 188:243-246

Kruger J, Dunning D. 1999. Unskilled and Unaware of It: How Difficulties in Recognizing One's Own Incompetence Lead to Inflated Self-Assessments. J Personality and Soc Psych, 77(6):121-113 
Kuhn T. (1996). The structure of scientific revolutions. University of Chicago Press, 3rd ed

Kvale S. 1996. Interviews: An introduction to qualitative research interviewing. Thousand Oaks, CA: Sage

Laatsch L. 2009. Evaluation and treatment of students with difficulties passing the step examinations. Acad Med, 84(5), 677-683

Lakoff G, Johnson M. 1999. Philosophy in the flesh: The embodied mind and its challenge to western thought. New York, NY: Basic Books

Lave J, Wenger E. 1991. Situated Learning: Legitimate Peripheral Participation. Cambridge University Press, Cambridge

Lieberman SA, Ainsworth MA, Asimakis GK, Thomas L, Cain LD, Mancuso MG, Rabek JP, Zhang N, Frye AW. 2010. Effects of comprehensive educational reforms on academic success in a diverse student body. Med Educ, 44(12):1232-1240

Loyens SMM, Rikers RMJP, Schmidt HG. 2007. The impact of students' conceptions of constructivist assumptions on academic achievement and drop-out. Stud High Educ 32(5):581-602

Machado A. 2003. A Vygotskian approach to evaluation in foreign language learning contexts. In: Goodman S, Lillis T, Maybin J, Mercer N, editors. Language, literacy and education: A reader. Stoke-on-Trent, UK: Trentham Books. pp 55-64

Mackenzie J. 2007. Conceptual learning in higher education: Some philosophical points. Oxf Rev Educ, 34(1):75-87

Martin DC, Arendale DR. 1992. Supplemental instruction: Improving first year student success in high risk courses. The freshman year experience: Monograph series number 7. National Resource Center for the Freshman Year Experience, University of South Carolina

Maso I. 2001. Phenomenology and ethnography. chap 9 in Handbook of ethnography, Atkinson et al (Eds), pp.136-144 Sage Publications Limited

Mattick K, Knight L. 2007. High-quality learning: Harder to achieve than we think? Med Educ 41:638-644

Maturana HR, Varela FJ. 1987. The tree of knowledge. Boston, MA: Shambhala

Maudsley G. (2011). Mixing it but not mixed-up: Mixed methods research in medical education (a critical narrative review). Med Teach, 33(2):e92-e104

Mauthner NS, Doucet A. 2003. Reflexive accounts and accounts of reflexivity in qualitative data analysis. Sociology $37(3): 413-431$

McGrath B, McQuail D. 2004. Decelerated medical education. Med Teach 26(6):510513

McLaughlin K. 2012. Navigating in the fog of medical school admissions data. Adv in Health Sci Educ, 17:627-629 
McNamara DS. 2010. Strategies to read and learn: Overcoming learning by consumption. Med Educ, 44(4), 340-346

Mercer N. 2000. Words \& Minds: How we use language to think together. London: Routledge

Meyer J, Land R. 2003. Threshold concepts and troublesome knowledge: linkages to ways of thinking and practising within the disciplines. University of Edinburgh

Misawa K. (2011) The Hirst-Carr Debate Revisited: Beyond the Theory-Practice Dichotomy. J Phil Educ, 45(4):689-702

Muraskin L. 1997. "Best practices" in student support services: A study of five exemplary sites. Follow-up study of student support services programs. SMB Economic Research Inc. and US Department of Education

Murphy P. 1999. Supporting collaborative learning: A gender dimension. In: Murphy, editor. Learners, Learning \& Assessment. London: The Open University, Sage. pp 258276

Mylopoulos M, Woods NN. 2009. Having our cake and eating it too: seeking the best of both worlds in expertise research. Med Educ, 43(5), 406-413

O'Neill LD, Wallstedt B, Eika B, Hartvigsen J. 2011. Factors associated with dropout in medical education: a literature review. Medical Education, 45(5), 440-454

Pashler H, Bain PM, Bottge BA, Graesser A, Koedinger K, McDaniel M, Metcalfe J. 2007. Organizing Instruction and Study to Improve Student Learning. IES Practice Guide. US Department of Education

Paul G, Hinman G, Dottl S, Passon J. 2009. Academic development: A survey of academic difficulties experienced by medical students and support services provided. Teach Learn Med 21(3):254-260

Pell G, Fuller R, Homer M, Roberts T. 2012. Is short-term remediation after OSCE failure sustained? A retrospective analysis of the longitudinal attainment of underperforming students in OSCE assessments. Med Teach, 34(2):146-50

Pope C, Mays N. 2009. Critical reflections on the rise of qualitative research. BMJ 339:737-739

Postholm MB. 2008. Group work as a learning situation: A qualitative study in a university classroom. Teach Teach: Theory Pract 14(2):143-155

Postholm MB. 2010. Self-regulated pupils in teaching: Teachers' experiences. Teach Teach 16(4):491-505

Prideaux D, Roberts C, Eva K, Centeno A, Mccrori P, Mcmanus C, Patterson F, Powys D, Tekian A, Wilkinson D. 2011. Assessment for selection for the health care professions and specialty training: Consensus statement and recommendations from the Ottawa 2010 Conference. Med Teach, 33(3):215-223

Proulx J. 2008 Some Differences between Maturana and Varela's Theory of Cognition and Constructivism. Complicity: Int J Complexity Educ, 5(1):11-26 
Regehr G. 2010. It's NOT rocket science: rethinking our metaphors for research in health professions education. Med Educ, 44(1):31-39

Saks, NS and Karl, S 2004. 'Academic support services in U.S. and Canadian medical schools', Medical Education 9(6). http://www.med-ed-online.org/res00085.htm

Saks NS, Lebeau R. 2006. Evaluating an Academic Support Program: An Additional Component, Poster Presentation at IAMSE Conference, July 2006, Puerto Rico

Sampson V, Clark D. 2009. The impact of collaboration on the outcomes of scientific argumentation. Sci Educ, 93(3):448-84

Sandars J, Cleary TJ. 2011. Self-regulation theory: Applications to medical education: AMEE Guide No. 58. Med Teach, 33(11):875-886

Sandoval WA, Bell P. 2004. Design-based research methods for studying learning in context: Introduction. Educational Psychologist, 39(4), 199-201

Sargeant JM, Mann KV, van der Vleuten CP, Metsemakers JF. 2009. Reflection: a link between receiving and using assessment feedback. Adv Health Sci Educ, 14(3), 399410

Saxena V, O'Sullivan PS, Teherani A, Irby DM, Hauer KE. 2009. Remediation techniques for student performance problems after a comprehensive clinical skills assessment. Acad Med 84(5):669-676

Sayer M, Chaput de Saintonge M, Evans D, Wood D. 2002. Support for students with academic difficulties. Med Educ 36:643-650

Seltzer-Kelly DL, Cinnamon-Morrison S, Cunningham CA, Gurland ST, Jones K, Toth SL. (2011) (Re)Imagining Teacher Preparation for Conjoint Democratic Inquiry in Complex Classroom Ecologies. Complicity: Int J Complexity Educ, 8(1):5-27

Sfard A. 2010. A Theory Bite on Infinity: A Companion to Falk. Cogn and Instr, 28(2):210-218

Shotter J. 2009. Listening in a Way that Recognizes/Realizes the World of 'the Other, Int J Listening, 23(1):21-43

Shulman LS. 1986. Those who understand: Knowledge growth in teaching. Educ Researcher 15(2):4-14

Shulman LS. 2005. Excellence: An Immodest Proposal. Carnegie Perspectives. Carnegie Foundation for the Advancement of Teaching

Shulman LS. 2007. Practical wisdom in the service of professional practice. Educ Researcher 36(9):560-563

Shulruf B, Poole P, Wang GY, Rudland J, Wilkinson T. 2012. How well do selection tools predict performance later in a medical programme? Adv in Health Sci Educ, 17(5):615626

Sleight DA, Mavis BE. 2009. Study skills and academic performance among secondyear medical students in problem-based learning. Medical Education Online, 11 
Slotnick HB. 1981. Identifying and remediating specific deficiencies of entering medical students. J Med Educ 56(2):91-102

Sparapani EF, Abel FJ, Easton SE, Edwards P, Herbster DL. 1996. Action research: A strategy for bridging the gap between theory and practice, paper presented at the association of teacher educators 76th annual meeting, St Louis, MO

Star C, Hammer S. 2007. Teaching generic skills: eroding the higher purpose of universities, or an opportunity for renewal? Oxf Rev Educ, 34 (2):237-51

Stegers-Jager KM, Cohen-Schotanus J, Themmen APN. 2013. The effect of a short integrated study skills programme for first-year medical students at risk of failure: $A$ randomised controlled trial. Med Teach, 35(2):120-126

Sui E, Reiter HI. 2009. Overview: what's worked and what hasn't as a guide towards predictive admissions tool development, Adv in Health Sci Educ 14:759-775

Tekian A, Hruska L. 2004. A Review of Medical School Records to Investigate the Effectiveness of Enrichment Programs for "At Risk" Students, Teach Learn Med, $16(1): 28-33$

Tetlock PE. 2005. Expert political judgment: How good is it? How can we know? Princeton, NJ: Princeton University Press

Thomas L. 2012 Building student engagement and belonging in Higher Education at a time of change: final report from the What Works? Student Retention \& Success programme. Paul Hamlyn Foundation, HEA

Tinto V. 1975. Dropout from Higher Education: A Theoretical Synthesis of Recent Research. Rev Educ Res, 45(1):89-125

Tishman S, Jay E, Perkins DN. 1992. Teaching Thinking Dispositions: From Transmission to Enculturation, Harvard University

Twenge JM. 2009. Generational changes and their impact in the classroom: teaching Generation Me. Medical Education, 43(5), 398-405

Van der Vleuten CPM, Dolmans DHJM, Scherpbier AJJA. 2000. The need for evidence in education. Med Teach 22(3):246-250

Van Merriënboer JJ, Clark RE, De Croock MB. 2002. Blueprints for complex learning: The 4C/ID-model. Educational Technology Research and Development, 50(2), 39-61

van Kruiningen JF. 2013. Educational design as conversation: A conversation analytical perspective on teacher dialogue. Teach Teach Educ 29:110-121

van Velzen JH. 2012. Teaching metacognitive knowledge and developing expertise, Teach Teach: Theory and Practice, 18(3):365-380

Weinsheimer J. 1998. Providing effective tutorial services. Washington DC: Department of Education, National Council of Educational Opportunity Associations

White CB, Ross PT, Gruppen LD. 2009. Remediating students' failed OSCE performances at one school: The effects of self-assessment, reflection, and feedback. Acad Med, $84(5), 651-654$ 
Whitehead D. 2012. Do we give them a fair chance? Attrition among first year tertiary students, J Fur High Educ, 36(3):383-402

Wingate U. 2006. Doing away with 'study skills', Teach in Higher Educ, 11:4, 457-469

Winston K, Houghton K. 2006. Identifying and Resolving Problems with At-Risk Students, Poster Presentation at IAMSE Conference, July 2006, Puerto Rico

Wong G, Greenhalgh T, Westhorp G, Pawson R. 2012. Realist methods in medical education research: what are they and what can they contribute? Med Educ, 46(1):8996

Yew EH, Schmidt HG. 2009. Evidence for constructive, self-regulatory, and collaborative processes in problem-based learning. Adv in Health Sci Educ, 14(2):251-273

Zimmerman BJ. (2002) Becoming a Self-Regulated Learner: An Overview, Theory Into Practice, 41(2):64-70 



\section{CHAPTER 2}

\section{An Investigation into the Design and Effectiveness of a Mandatory Cognitive Skills Programme for At-Risk Medical Students}

Published as:

Winston KA, Van Der Vleuten CPM, and Scherpbier AJJA. 2010. "An Investigation Into the Design and Effectiveness of a Mandatory Cognitive Skills Programme For At-Risk Medical Students", Medical Teacher, 32(3):236-243 


\section{Background}

Recognition of the growing shortfall of physicians (Dill and Salsberg, 2008) has resulted in calls to increase the number of medical schools (AAMC, 2006; Howe et al, 2008). This rise in student numbers, along with attempts to broaden access to medical school, is resulting in admission of students from diverse, non-traditional backgrounds (Howe et al, 2008; Jolly et al, 2008), of varying levels of preparedness for a medical curriculum. This is particularly true of those attending less traditional schools, such as the Caribbean-based US medical school (hereafter called "the School") that is the locus of this project. This change in the student population is inevitably accompanied by increasing numbers of enthusiastic, but "at-risk", students, and there is a need for increased academic support to help them, once admitted, to become competent physicians.

A survey of US and Canadian medical schools (Saks and Karl, 2004) showed that most do provide some form of academic support service, in a variety of voluntary programmes. Few programmes appear to be described in any detail in the medical education literature, but it seems that use of upper class students and individual sessions with academic support faculty are the most common form of intervention (Saks and Lebeau, 2006; Sayer et al, 2002), along with introductory workshops on study skills for new students. At our School, we also offer voluntary cognitive skills classes, where students can work in small groups, guided by a faculty member, on cognitive and metacognitive skills (Flavell, 1979; Mevarech and Amrany, 2008). The results of this programme have been good: over the last 13 semesters, 1809 students have attended, $81 \%$ of whom have passed that semester. $56 \%$ of those that failed came too late or too infrequently (once) to make much difference.

A key problem with such voluntary programmes is that weak students who most need assistance often fail to seek it (Devoe et al, 2007; Judd, 1985; Weinsheimer, 1998), ignoring communications offering help (Cleland et al, 2005). Weaker students frequently regard themselves as competent students despite exam results suggesting otherwise, over-estimating their ability (Cleland et al, 2008), their performance (Albanese, 2006) and how well they have mastered the material (Pashler et al, 2007). Conversely, a lack of confidence can result in avoidance of challenging situations (Fenollar et al, 2007), especially when one's self-beliefs are challenged (Mackenzie, 2007). Thus, at-risk students often blame their failure on personal reasons rather than study skills (Cleland et al, 2005), or believe that simply putting more time into previously unsuccessful strategies will give better results (Loyens et al, 2007). And yet, regardless of their cited reasons, these students typically fail the same subjects (Sayer et al, 
2002), and, when allowed to repeat without remediation, often simply work more intensively rather than try to change their approach, and thus fail again (Mattick and Knight, 2007).

Our own experience mirrors these findings. At our School, a number of students fail one or more courses, and many are allowed to repeat the semester on probation. Typically, repeaters failed to seek help during their failing semester, and many again fail to seek help during their repeat semester. Data is showing that students who have repeated a semester at the school are not graduating - most of them either fail the repeating semester, fail a subsequent semester, or fail USMLE (United states Medical Licensing Exam) Step 1. Given the general success of the voluntary cognitive skills classes, in the May and September 2006 semesters, we strongly encouraged those students repeating first semester to attend our sessions. 37 first semester repeaters voluntarily attended: $83 \%$ of these passed that semester. 53 did not come: $58 \%$ of these passed. This was a significant effect (chi-squared, $\mathrm{p}<0.023$ ), but it is possible that the decision to attend voluntarily is simply indicative of the character and determination to succeed. Could mandatory attendance make a difference?

Devoe et al (2007) report a small pre-emptive mandatory intervention (13 students), with structured study groups led by upperlevel students, focusing on content rather than learning how to learn: results showed no significant improvements over controls, and they conclude that participation should not be mandated, although they still feel that intervention should happen pre-emptively. This is contradicted by Alexander et al (2005), who felt that preselection 'labelled' these students and resulted in antagonism towards the programme, concluding that, based on the crudity of attempts to predict failure, interventions are more effective once the need has become manifest.

Some schools provide decelerated programmes for at-risk students, although the majority of these provide no other support than deceleration itself (McGrath and McQuail, 2004), and continue to show high dismissal rates. A separate one-year intervention for 16 students, with weekly tutorials focusing on academic concepts and skills development reports improved performance of at-risk students (Alexander et al, 2005). Non-academic interventions typically fail to improve outcomes (Weinsheimer, 1998), and there seems to be a broad consensus that successful support programmes should focus on both skills development and content boosting (Saks and Karl, 2004; Brigman and Webb, 2007; Mattick and Knight, 2007; Carroll and Feltham, 2007). However, several of these studies recommend further investigation into whether these programmes influence academic success, and how specific components help at-risk medical students (Burch et al, 2007; McGrath and McQuail, 2004; Saks and 
Karl, 2004). Muraskin's (1997) study describes five exemplary support programmes used in (non-medical) colleges and universities. These programmes focus less on student-led tutoring than other less successful programmes, preferring to rely on skilled faculty than student tutors, and have in common a focus on group rather than individual interventions, as well as all having some control over student promotions and admissions.

Working with groups of students maximizes capacity of scarce human resources (Muraskin, 1997), and provides opportunities for emotional support: medical students commonly feel overwhelmed by the volume of material, unsupported, and socially isolated from tutors and peers (Boulos et al, 2006). Using groups also enables the collaboration that is widely touted as an effective tool for learning (Gokhale, 1995; Rogoff, 1999; Terenzini et al, 2001), allowing students to scaffold each other's learning (Machado, 2003), share ideas and reflect on learning strategies through constructivist dialogue (Mercer, 2000; Mackenzie, 2007) which promotes higher achievement, higher quality reasoning, more metacognition and more intrinsic motivation (Reynolds et al, 2002; Pegler, 2007). Furthermore, regular attendance promotes the group stability that is key to students and faculty building the mutual trust and understanding upon which the success of such programmes depends (Geertsma, 1977; Tekian et al, 2000).

Thus, we have concluded that, given the inaccuracy of predicting medical school success (the best appears to be undergraduate science performance, or MCAT (US Medical College Admissions Test) (Kies and Freund, 2005; Cariaga-Lo et al, 1997; Slotnick, 1981; Alexander et al, 2005)), and the reluctance of many at-risk students to seek help voluntarily, mandatory intervention for students who have failed their first semester is potentially an effective way to help students achieve success and help the school increase student retention.

\section{Aims}

This paper has two main aims. The first is to report on whether mandatory attendance in a cognitive skills programme for at-risk students can improve short- and long-term outcomes at medical school.

The second aim focuses on describing the components of such a programme, and the rationale for the inclusion of each. In order for any results to be generalizable, it is essential that the context is explicit, and that there is sufficient detail for the work to be reproducible (Bateson, 1972). This paper attempts to heed two common calls: the need to draw upon cross-disciplinary research (Eva, 2008), and 
the importance of bridging the gap between theory and practice (Sparapani et al, 1996; Lederman, 2008). Thus, the project employs practitioner-led research (Sparapani et al, 1996) in the search for and description of an optimal blend of learning tools and approaches (Clark, 2003) that will enable at-risk students to succeed in medical school.

\section{Methods}

\section{Research Setting and Methodology}

The School's IRB has approved this research project. All participating students sign an informed consent form before data collected from them during the programme is used for research purposes. Refusal to sign excludes use of that individual's data in published results, but does not provide exemption from participation in the programme itself. Identities have been kept confidential, and removed from all data presented.

The population under study, diverse in ethnicity, age, and background, with even gender distribution, is all students who repeat the first semester at the School ("repeaters") from 2007 onwards, which ranges from 20 to 50 students per semester. These "repeaters" now have, as a condition of their academic probation, a requirement to attend cognitive skills sessions. These students have reduced courseload, repeating 3 or 4 of the 5 first semester lecture-based courses. The repeaters are divided into small groups of 4 to 6 students, and the faculty of the Academic Success department each take responsibility for one or two of those groups each semester. Students are required to attend one session each week for 14 weeks, with each session lasting between one and two hours, following a specially designed course syllabus. Sessions are scheduled to fit around students' commitments to other classes.

The department faculty members, who are all experienced facilitators with mixed education and science backgrounds (although not considered 'content-experts'), act as mentors and guides for these students, and, if necessary, individual sessions are arranged as needed. Where appropriate, some students are also referred to the counselling department for non-academic assistance. The faculty members meet regularly to discuss student progress, and evaluate the efficacy and implementation of the syllabus. At the end of each semester, the syllabus is re-evaluated, and adjusted according to both faculty and student feedback.

The results presented in this paper deal with the quantitative analysis of student performance. For each cohort of repeating stu- 
dents, pass/fail data for the repeated semester is collected, and the students continue to be tracked as they progress through the four basic science semesters of the school. This data is aggregated for the performance of several cohorts of these students, and compared with similar data for previous cohorts of students who repeated first semester without the mandatory programme. The effect of the number of sessions attended is also explored. Thus the main independent variable is simply participation in mandatory cognitive skills groups, with number of cognitive skills sessions attended as a subset of this independent variable. The dependent variables are pass/fail for each of the four semesters. This nominal data is analysed using chisquared tests.

Before presenting the results obtained so far, a brief description of the actual programme is given.

\section{The Programme: Theory and Description}

The first step in course design has to be a good understanding of the learners. There seems to be agreement between the education literature and our own experience on the reasons for students failing at medical school. These include over-reliance on passive learning (Dolan et al, 2002; Burns, 2006), insufficient background and content knowledge (Slotnick, 1981), weakness in literacy, numeracy, study skills, test-taking strategies, and critical thinking, (Pelley, 2002; Sayer et al, 2002; Alexander et al, 2005; Winston and Houghton, 2006; Garrett et al, 2007) and a general lack of the self-regulatory and metacognitive skills that are correlated with academic success (Cleland et al, 2005; Goldfinch and Hughes, 2007; Brigman and Webb, 2007; Loyens et al, 2007; Cao and Nietfield, 2007; Carroll and Feltham, 2007).

Thus, at-risk students need to improve on these skills in order to become expert students, and to learn the course material however it may be presented to them. Expertise requires self-awareness, and organization of knowledge into large, meaningful patterns (Glaser, 1999). Bourdieu (1999) states that it is essential that learners acquire metacognitive skills, and pay attention to critical, deductive and reflective thought processes. However, such thinking dispositions cannot merely be transmitted - students need to become enculturated to their use if they are going to apply them habitually (Tishman et al, 1992). Thus, a remedial programme needs to challenge how individuals study and think (Mattick and Knight, 2007), regularly, over time.

Feedback is an essential part of this challenge, and is widely recognised as necessary for improving student learning (Mattick and Knight, 2007; Mullan and Hauge, 2007). However, it is impossible to 
give feedback unless students actively demonstrate their thought processes. This requires students to explain and justify their ideas (Hiebert et al, 1999), and is why dialogue and discourse are considered to be essential mediators of learning (Vygotsky, 1978; Hicks, 2003; Mercer, 2000), fostering critical thinking (Freire and Macedo, 1999) and knowledge construction (Murphy, 1999).

The recurrent themes are: self-regulation, metacognition and reflection; discourse and making reasoning explicit; active learning; giving and receiving feedback; focus on relevance to basic science course content; care with language and accuracy of thinking; and attention to affect and motivation. These skills can only be learned and demonstrated by doing, so the programme combines the development of skills with their application to relevant content (Mattick and Knight, 2007; Carroll and Feltham, 2007). What follows is an attempt, in broad terms, to describe how we address these issues.

Repeaters are initially emailed an invite to a 'large' group meeting of all first semester repeaters. This email includes a list of questions for reflection on feelings, reasons for past failures and successes, and effective/ineffective study methods. These questions form the basis for discussion at the large group meeting, where students gain some comfort from the realization that they are not alone in 'failure', and some solidarity quickly develops when they are given the opportunity to vent their feelings about their situation and the school. The session progresses towards positives about repeating, and an appreciative discussion of their motivations for studying medicine. Programme data is shared, and our expectations are made very clear. As well as weekly attendance, students have to complete weekly assignments relating to their basic science coursework, and be prepared to share and reflect on ideas with their colleagues. Indeed, it is this critiquing of each others' work that enables them to get a more objective view of their own work, an essential prerequisite for change and improvement (McConnell, 2002). It is also made quite clear to the students that we are not providing them with a "magic bullet": they are told that our objective is to present them with a smorgasbord of skills and techniques from which they can select the methods best suited to each particular person, subject and context. The session finishes with break-out into their assigned small groups, with their professor, to discuss the first assignment and arrange the time for the first small group session. From then on, we follow the syllabus, in small groups, week by week. The titles of the different handouts we use with the students are in italics.

Good Time Management is an important aspect of self-regulation, and has been shown to have a positive effect on exam scores (Vrugt and Oort, 2008). Students are asked to plan out their week in detail, and then record how they actually spend their week (Hammer and 
McCarthy, 2005). When the discrepancies are discussed in the group, failings are admitted, successes are acknowledged and adjustments can be made. This process gets repeated according to need and desire, and usually leads to a discussion on quality of time spent, as opposed to quantity, a common source of confusion for 'weak' students (Loyens et al, 2007). This handout, along with Study Tips, introduces the idea that short, repeated, distributed study sessions are far superior for learning and memory than multiple hours on the same topic (Thalheimer, 2003; Burns, 2006; Larsen et al, 2008).

Then we practice techniques to Preview for lectures, where the main goal is to stress the importance of linking new learning to prior knowledge (Harlen, 2003). How well prior material is understood is essential to building understanding of new material (Hay et al, 2008; Dewhurst et al, 2007)). When asked to clearly define terms they claim are 'previously known', students frequently struggle and are then forced to acknowledge they did not know as much as they thought, and here we begin to tackle the "illusion of knowing" so common to weak students (Pashler et al, 2007). This focus on the importance of definitions and the need to use language accurately will be important throughout their careers as physicians (Groopman, 2007), and is stressed repeatedly, most especially in work on Medical Terminology and Explain yourself, where students are asked for clear explanations of terms, supplemented with analogies. Commonly we discover that even when students appear comfortable using scientific language, when challenged it turns out that this "reproduction of disciplinary language does not guarantee understanding" (Anderberg et al, 2007). The use of analogy is an important aspect of getting at their thinking skills: making analogies has been claimed to be the "main business of human brains" (Hofstadter, 2007) - it deepens conceptual understanding, and certainly helps link new understanding to prior knowledge.

Similar themes of clarifying understanding by organizing knowledge structures are continued in Working With Handouts, Organizing Lists and Concept Mapping, which introduce ideas for making "study products", physical representations of knowledge that enable students to build conceptual relationships and contextualize their understanding (Pelley, 2002b; Torre et al, 2007). The collaborative construction of concept maps, and the sharing of each others' individual representations of the same lecture material (lists, summaries, tables, etc), opens these students to each other's ideas, and increases reflection on their own work. This introduction to various kinds of "study product" also helps these students learn to identify which facts are more or less important from the vast volume presented to them, a common difficulty for weak students (Garrett et al, 2007; Burns, 2006). 
The process of exploring content and thinking skills, with its direct and obvious relevance to the students' coursework, is continued in the exercise on Asking Questions, which draws on enquiry-based learning and Bloom's taxonomy to encourage students to make use of higher-level questioning to deepen their understanding (Harlen, 2003; Thalheimer, 2003; Pashler et al, 2007). Typically, these students fail to question their professors or the material (Muraskin, 1997), but here we make it clear that asking questions is not only okay, but essential for learning. Critical thinking skills are further developed as we explore Inferences and Assumptions. Success in problem-solving depends on the ability to think at the appropriate level of abstraction (Hofstadter, 2007), and in Generalizing the challenge is to move between levels of description, generalizing from specific examples in basic science coursework, and then finding new instances of the general rule. Other handouts include work on Memory (Ellis, 2003), Equations and Calculations, and Listening Style (Worthington, 2008).

There are a number of handouts that deal with different aspects of tackling multiple choice questions (MCQs): rephrasing questions to ensure the question is understood (Explicit Reasoning), explaining right and wrong choices, identifying key words, rewording questions to make alternate choices correct (Working with MCQs, MCQ learning), and writing their own MCQs (NBME guidelines), often creating clinical vignettes (Add Your Patient). US medical students are tested almost exclusively with MCQs from the beginning of medical school through to their licensing exams (USMLE), so the students see this as most relevant. Indeed, although repeaters are sometimes reluctant to admit other weaknesses, they are usually convinced that their main problem is the MCQ exams and test-taking skills. Thus, not only has working with practice questions been shown by much research to directly improve performance (Sivagnanam et al, 2006; Thalheimer, 2003; Gibbs and Simpson, 2004; Pashler et al, 2007; Marcell, 2008; Larsen et al, 2008), this also is a valuable way of exploring students' understanding, helping them to identify knowledge gaps, and persuading them that other elements of our programme can be brought to bear in improving their performance on MCQs. In many ways, it is through this work with MCQs that we draw the threads of our programme together and show these students how language, reasoning and metacognition directly affect their success at medical school.

\section{Results}

Six cohorts of first semester repeaters, with a total of 216 students, have now been through the programme. Table 1 compares their 
performance with historical controls - students who repeated first semester for the five years (15 cohorts) before the inception of the mandatory programme. It seems clear that huge short-term gains are made - repeaters do much better in their repeat semester with the programme than without, and this effect continues to be significant as students progress through the school.

Table 1: Academic progress of programme participants, compared to controls

\begin{tabular}{lcccc}
\hline & $\begin{array}{c}\text { reach } \\
\text { semester 2 }\end{array}$ & $\begin{array}{c}\text { reach } \\
\text { semester 3 }\end{array}$ & $\begin{array}{c}\text { reach } \\
\text { semester 4 }\end{array}$ & $\begin{array}{c}\text { reach } \\
\text { semester 5 }\end{array}$ \\
\hline $\begin{array}{l}\text { w/out mandatory cog skills } \\
(n=715)\end{array}$ & $58 \%$ & $47 \%$ & $42 \%$ & $37 \%$ \\
with mandatory cog skills & $91 \%$ & $79 \%$ & $64 \%$ & $55 \%$ \\
& $(196 / 216)$ & $(142 / 180)$ & $(83 / 130)$ & $(62 / 113)$ \\
Significant $(x 2)$ & $p<0.0001$ & $p<0.0001$ & $p<0.0001$ & $p<0.0005$ \\
\hline
\end{tabular}

As mentioned earlier, we have tweaked the syllabus each semester, and this appears to have had some effect, at least on short-term outcomes (table 2 ), with steadily climbing pass rates for the repeat semester (\% reaching sem 2 ).

Table 2: Academic progress of programme participants, by cohort

\begin{tabular}{lcccccc}
\hline & Jan07 & May07 & Sep07 & Jan08 & May08 & Sep08 \\
$\mathrm{N}$ & 25 & 50 & 38 & 17 & 50 & 36 \\
\hline \%reach sem 2 & $76 \%$ & $86 \%$ & $89 \%$ & $94 \%$ & $100 \%$ & $94 \%$ \\
\%reach sem3 & $68 \%$ & $72 \%$ & $79 \%$ & $94 \%$ & $88 \%$ & \\
\%reach sem4 & $52 \%$ & $70 \%$ & $76 \%$ & & & \\
\%reach sem 5 & $52 \%$ & $66 \%$ & & & & \\
\hline
\end{tabular}

Since we mandate attendance at one session per week, but encourage additional attendance at voluntary sessions, total number of sessions attended per student can vary quite widely. Given vagaries in scheduling, health, and other absences, the average number of sessions attended should be between 10 and 15 . However, the lowest has been 2 sessions, while the highest has been 38 sessions. There is thus an opportunity to compare progress against attendance, especially looking for longer term effects of this variation in behaviour (see table 3). While the sample size for this is still relatively low (75), the trend is very clear indeed: more attendance correlates with better results. 
Table 3: Academic progress of programme participants, by attendance

\begin{tabular}{lccc}
\hline Attendance & $\begin{array}{c}\text { No. of } \\
\text { students }\end{array}$ & $\begin{array}{c}\text { Reached } \\
\text { semester 5 }\end{array}$ & $\begin{array}{c}\text { Dismissed/withdrew } \\
\text { before semester 5 }\end{array}$ \\
\hline Attend $>15$ & 16 & $93 \%$ & $7 \%$ \\
Attend $10-15$ & 35 & $60 \%$ & $40 \%$ \\
Attend $<10$ & 24 & $42 \%$ & $58 \%$ \\
\hline
\end{tabular}

\section{Discussion}

The outcomes so far have been very encouraging, and have certainly made a difference to the progress of these at-risk students compared to controls, confirming the belief that approaches to learning can be taught (Lonka et al, 2008), especially when the skills are applied in situations that matter to the students (Goodyear and Zenios, 2007). There seems little doubt that this intervention, with a relatively large sample size compared to other studies $(216$, against <50) has already shown highly significant short-term gains.

A confounding variable is variation in course presentation for basic science courses over time. This, of course, is a problem for all educational research - it's hard to isolate the effects of one intervention among the myriad human interactions and courses undertaken at a large school. This problem is largely mitigated by the simple fact that if other changes do result in great improvements in student learning, we would expect the actual number of failing (and thus repeating) students to decrease steadily. As yet, there has been no such trend. However, we acknowledge that comparison with historical controls rather than the use of a randomized protocol could be a source of bias.

The replication of findings that increased attendance in support programmes correlates directly with improved outcomes (Muraskin, 1997) is important, and presentation of this data to students at the beginning of the programme may help to improve their attitudes and increase their attendance, with positive effect on long-term outcomes. Currently, poor attendance is addressed individually with the student, after which, failing improvement, professionalism cards have been given, which result in meetings with the Dean for Student Affairs. The exemplary programmes described by Muraskin (1997) all exert considerable control over promotions, with failure to attend leading to suspension from school, and it may be that ultimately we need to consider more serious consequences for non-attendees, although hopefully the softer, information-sharing approach can yield desirable results. 
A potential weakness of the programme is that it may be too short. Comparable interventions described in the literature are all one year long (Alexander et al, 2005; Burch et al, 2007; Ficklin et al, 1985), but ours is squeezed into 14 weeks. How long does it take to inculcate changes in underlying habits of mind in overworked, anxious medical students? This question is certainly worth exploration, but the answer probably varies between individual students.

The conventional wisdom is that the earlier the intervention the better (Burns, 2006; Devoe et al, 2007; Weinsheimer, 1998). This could be challenged on the basis that the further a student has progressed along the path to a medical career, the more they have invested and the more they have to lose, thus making later semester participants potentially more receptive to new ideas. Indeed, the School's data show that a failure in any semester is equally predictive of ultimate failure to graduate as a physician. Thus, another fruitful area of exploration may be to apply this methodology to students at different stages of the curriculum, from those predicted to be at risk before failure to those who have failed in the final semester.

It is worth noting that purely numerical data cannot tell the whole story. One advantage of the programme has been the development of the mentor-mentee relationship between faculty and students, and the early advising to change career that has occasionally ensued. This relationship tends to persist through the students' time at the School, and a topic for subsequent study is examination of this relationship, the precise role of the faculty in this programme, and to what extent the variations in personality, beliefs and skills of the faculty affect student outcomes. Similarly, a qualitative study into the perceptions and characteristics of the students is needed.

\section{Conclusion}

There is no doubt that any programme can be improved, and further work into finding the optimal blend of teaching/learning methods and cognitive/metacognitive skills for turning around the performance of at-risk medical students is necessary, along with research into the precise ways in which these methods can be applied. To do this, we need to remember that there is much valuable work done in fields beyond medical education (Eva, 2008), and continue to draw on this work to help our students. Hopefully, that relationship is reciprocal, and this project may be able to inform work with at-risk students in other fields. For now, the current results strongly suggest that the effect of a carefully designed, theory-driven, practical programme extends beyond the kind of student who would choose to attend 
voluntarily, and that a mandatory intervention can positively influence the performance of at-risk students.

\section{References}

AAMC. 2006. 'AAMC Statement on the Physician Workforce', Association of American Medical Colleges: http://www.aamc.org/workforce/workforceposition.pdf

Albanese MA. 2006. 'Crafting the reflective lifelong learner: why, what and how', Medical Education 40:288-290

Alexander R, Badenhorst E and Gibbs T. 2005. 'Intervention programme: a supported learning programme for educationally disadvantaged students', Medical Teacher 27(1):66-70

Anderberg E, Svensson L, Alvegård C, Johansson T. 2008. 'The epistemological role of language use in learning: A phenomenographic intentional-expressive approach', Educational Research Review 3:14-29

Bateson, G. 1972. Steps to an Ecology of Mind Chicago, University of Chicago Press

Boulos, M.N.K., Maramba, I., and Wheeler, S. 2006 'Wikis, blogs and podcasts: a new generation of Web-based tools for virtual collaborative clinical practice and education', BMC Medical Education, 6(41):1-8

Bourdieu, P. 1999. 'Principles for reflecting on the curriculum in France' in Moon \& Murphy (ed.) Curriculum in Context The Open University, Sage, London

Brigman G and Webb L. 2007. 'Student Success Skills: Impacting Achievement Through Large and Small Group Work', Group Dynamics: Theory, Research and Practice 11(4):283-292

Burch VC, Sikakana CNT, Yeld N and Seggie JL. 2007. 'Performance of Academically AtRisk Medical Students in a Problem-Based Learning Programme: A Preliminary Report', 12(3):345-358

Burns ER. 2006. 'Learning syndromes afflicting beginning medical students: identification and treatment--reflections after forty years of teaching', Medical Teacher 28(3): $230-233$

Cao L and Nietfield J. 2007. 'College Students' Metacognitive Awareness of Difficulties in Learning the Class Content Does Not Automatically Lead to Adjustment of Study Strategies', Australian Journal of Educational \& Developmental Psychology 7:31-46 Cariaga-Lo LD, Enarson CE, and Crandall SJ. 1997. Cognitive and Noncognitive Predictors of Academic Difficulty and Attrition. Academic Medicine 72(10):S69-71

Carroll S and Feltham M. 2007. 'Knowledge or Skills - The Way to a Meaningful Degree? An Investigation Into The Importance of Key Skills Within an Undergraduate Degree and The Effect This Has On Student Success', Bioscience Education ejournal, 10 http://www.bioscience.heacademy.ac.uk/journal/vol10/beej-10-7.aspx

Clark, D. 2003. Blended Learning, Epic White Paper

Cleland J, Arnold R and Chesser A. 2005. 'Failing finals is often a surprise for the student but not the teacher: identifying difficulties and supporting students with academic difficulties', Medical Teacher 27(6):504-508 
Cleland J, Milne A, Sinclair H and Lee AJ. 2008. 'Cohort study on predicting grades: is performance on early MBChB assessments predictive of later undergraduate grades?', Medical Education 42:676-683

Devoe P, Niles C, Andrews N, Benjamin A, Blacklock L, Brainard A, Colombo E, Dudley $B$, Koinis C and Osgood M. 2007. 'Lessons learned from a study-group pilot program for medical students perceived to be 'at risk", Medical Teacher 29(2):e37-e40

Dewhurst SA, Holmes SJ, Swannell ER, and Barry, C. 2007. 'Beyond the text: Illusions of recollection caused by script-based inferences', European Journal of Cognitive Psychology, 20(2)367-386

Dill MJ and Salsberg ES. 2008. 'The Complexities of Physician supply and Demand: Projections Through 2025', Center for Workforce Studies, Association of American Medical Colleges: http://www.mhc.org/mhc_images/phys_demand_2025.pdf

Dolan S, Mallott DB and Emery JA. 2002. 'Passive learning: a marker for the academically at risk', Medical Teacher 24(6):648-649

Ellis D. 2003. Becoming a Master Student, Houghton Mifflin Company, Boston

Eva KW. 2008. 'The cross-cutting edge: striving for symbiosis between medical education research and related disciplines', Medical Education 42:950-951

Fenollar P, Roman S and Cuestas PJ. 2007. 'University students' academic performance: An integrative conceptual framework and empirical analysis', British Journal of Educational Psychology 77:873-891

Ficklin FL, Hazelwood JD, Carter JE and Shellhamer RH. 1985. 'The Reduced Load as a Remedial Program to Increase Retention of First-year Medical Students', Journal of Medical Education, 60(5):406-408

Flavell JH. 1979. 'Metacognition and cognitive monitoring', American Psychologist 34: $906-911$

Freire P and Macedo DP. 1999. 'Pedagogy, Culture, Language and Race: a Dialogue' in Leach and Moon (eds) Learners and Pedagogy The Open University, Sage, London

Garrett J, Alman M, Gardner S and Born C. 2007. 'Assessing Students' Metacognitive Skills', American Journal of Pharmaceutical Education, 71(1)

Geertsma RH. 1977. 'A Special Tutorial for Minority Medical Students: An Account of a Year's Experience', Journal of Medical Education 52(5):396-403

Gibbs G. and Simpson, C. 2004. 'Conditions Under Which Assessment Supports Student Learning', Learning and Teaching in Higher Education, 1:3-31

Glaser R. 1999. 'Expert Knowledge and Processes of Thinking' in McCormick and Paechter (eds) Learning and Knowledge The Open University, Sage, London

Gokhale AA. 1995. 'Collaborative learning enhances critical thinking', Journal of Technology Education, 7(1):22-30

Goldfinch J and Hughes M. 2007. 'Skills, learning styles and success of first-year undergraduates', Active Learning in Higher Education, 8(3):259-273 
Goodyear P, and Zenios M. 2007. 'Discussion, Collaborative Knowledge Work and Epistemic Fluency', British Journal of Educational Studies, 55(4):351-368

Groopman J. 2008. How Doctors Think, Mariner Books, New York

Hammer L and McCarthy S. 2005. 'Study Smart', Learning and Teaching Support Services, University of Exeter, UK

Harlen W. 2003. Enhancing Enquiry Through Formative Assessment, Institute for Enquiry, Exploratorium, San Francisco.

Hay D, Kinchin I, and Lygo-Baker S. 2008. 'Making learning visible: the role of concept mapping in higher education', Studies in Higher Education, 33(3):295-311

Hicks D. 2003. 'Discourse, teaching and learning' in Goodman, S., Lillis, T., Maybin, J. and Mercer, N. (eds) Language, Literacy and Education: a reader, Stoke-on-Trent, Trentham Books

Hiebert J, Carpenter T, Fennema E, Fuson K, Human P, Murray H, Olivier A, and Wearne D. 1999. 'Problem Solving as a Basis for Reform in Curriculum and Instruction: the Case of Mathematics' in Murphy (ed) Learners, Learning \& Assessment The Open University, Sage, London

Hofstadter D. 2007. I Am A Strange Loop, Basic Books, New York

Howe A, Campion P, Searle J and Smith H. 2008. 'New perspectives-approaches to medical education at four new UK medical schools', British Medical Journal 329: 32732

Jolly P, Garrison G, Boulet JR, Levitan T, and Cooper RA. 2008. 'Three Pathways to a Physician Career: Applicants to U.S. MD and DO Schools and U.S. Citizen Applicants to International Medical Schools', Academic Medicine, 83(12):1125-1131

Jörg T, Davis B and Nickmans G. 2007. 'Towards a new, complexity science of learning and education', Educational Research Review 2:145-156

Judd TP. 1985. A Research Based Approach to Students in Academic Difficulty: Characteristics and Intervention. ASHE 1985 Annual Meeting Paper.

Kennedy TJT and Lingard LA. 2006. 'Making sense of grounded theory in medical education', Medical Education 40:101-108

Kies SM and Freund GG. 2005. 'Medical students who decompress during the M-1 year outperform those who fail and repeat it: A study of $M-1$ students at the University of Illinois College of Medicine at Urbana-Champaign 1988-2000' BMC Med Educ http://www.pubmedcentral.nih.gov/articlerender. fcgi?artid=1166556

Larsen DP, Butler AC and Roediger HL. 2008. 'Test-enhanced learning in medical education', Medical Education 42:959-966

Lederman D. 2008. 'Making Higher Ed Research Matter', Inside Higher Ed, http://www.insidehighered.com/news/2008/11/07/ashe

Lonka K, Sharafi P, Karlgren K, Masiello I, Nieminen J, BirgegÅrd G and Josephson A. 2008. 'MED NORD-A tool for measuring medical students' well-being and study orientations', Medical Teacher, 30(1):72-79 
Loyens SMM, Rikers RMJP, and Schmidt HG. 2007. 'The impact of students' conceptions of constructivist assumptions on academic achievement and drop-out', Studies in Higher Education, 32(5):581-602

Machado A. 2003. 'A Vygotskian approach to evaluation in foreign language learning contexts' in Goodman, S., Lillis, T., Maybin, J. and Mercer, N. (eds) Language, Literacy and Education: a reader, Stoke-on-Trent, Trentham Books

Mackenzie J. 2007. 'Conceptual learning in higher education: some philosophical points', Oxford Review of Education, 34(1):75-87

Marcell M. 2008. 'Effectiveness of Regular Online Quizzing in Increasing Class Participation and Preparation', International Journal for the Scholarship of Teaching and Learning 2(1)

Mattick K, Knight L. 2007. 'High-quality learning: harder to achieve than we think?', Medical Education 41:638-644

McConnell D. 2002. 'The Experience of Collaborative Assessment in e-Learning', Studies in Continuing Education, 24(1):73-92

McGrath B and McQuail D. 2004. 'Decelerated medical education', Medical Teacher 26(6):510-513

Mercer N. 2000. Words \& Minds - how we use language together, London, Routledge

Mevarech ZR and Amrany C. 2008. 'Immediate and delayed effects of meta-cognitive instruction on regulation of cognition and mathematics achievement', Metacognition and Learning 3:147-157

Mullan P and Hauge L. 2007. 'Providing Effective Feedback to Medical Students and Faculty', paper presented at AMEE conference, Trondheim, 2007

Muraskin L. 1997."Best Practices" in Student Support Services: A Study of Five Exemplary Sites. Followup Study of Student Support Services Programs." SMB Economic Research Inc, and US Dept of Education.

Murphy P. 1999. 'Supporting Collaborative Learning: a Gender Dimension' in Murphy (ed) Learners, Learning \& Assessment The Open University, Sage, London

Pashler H, Bain PM, Bottge BA, Graesser A, Koedinger K, McDaniel M and Metcalfe J. 2007. 'Organizing Instruction and Study to Improve Student Learning', IES Practice Guide, US Department of Education, http://ies.ed.gov/ncee/wwc/pdf/practiceguides/20072004.pdf

Pegler C. 2007. 'Collaboration and Social Software', H806 course materials, Open University, http://learn.open.ac.uk/mod/resourcepage/view.php?a=8904

Pelley JW. 2002a. 'Lifelong learning: Professional Tools for Professional Skills', TTHUSC School of Medicine Orientation Program

http://www.ttuhsc.edu/SOM/success/Life\%20Long\%20Learning\%20Orientation\%20Re cap.ppt

Pelley JW. 2002b. TTUHSC School of Medicine Program in Life-Long Learning Prematriculation Self Study Course, http://www.ttuhsc.edu/SOM/Success/Survival.htm 
Proulx J. 2008. 'Some Differences between Maturana and Varela's Theory of Cognition and Constructivism', Complicity: An International Journal of Complexity and Education 5(1):11-26

Reynolds J, Caley L, and Mason R. 2002. How do people learn? Chartered Institute of Personnel and Development Research Report, London

Rogoff B. 1999. 'Cognitive development through social interaction: Vygotsky and Piaget' in Murphy (ed) Learners, Learning \& Assessment The Open University, Sage, London

Saks NS and Karl S. 2004. 'Academic support services in U.S. and Canadian medical schools', Medical Education Online 9(6)

Saks NS and Lebeau R. 2006. 'Evaluating an Academic Support Program: An Additional Component', poster presentation at IAMSE conference, July 2006, Puerto Rico. Abstract available online: http://www.iamse.org/conf/conf10/general_2006.pdf

Sayer M, Chaput de Saintonge M, Evans, D and Wood D. 2002. 'Support for students with academic difficulties', Medical Education 36:643-650

Sivagnanam G, Sarawathi S, and Rajasekaran A. 2006. 'Student-led objective tutorial (SLOT) in medical education', Medical Education Online, 11(7):1-10

Slotnick HB. 1981. Identifying and Remediating Specific Deficiencies of Entering Medical Students. Journal of Medical Education 56(2):91-102

Sparapani EF, Abel FJ, Easton SE, Edwards P, and Herbster DL. 1996. 'Action Research: A Strategy for Bridging the Gap Between Theory and Practice', Paper presented at the Association of Teacher Educators $76^{\text {th }}$ Annual Meeting, St Louis, Missouri

Tekian A, Jalovecky MJ, and Hruska L. 2000. A Quantitative Assessment of "At Risk" Students and Medical School Performance: The Importance of Adequate Advising and Mentorship. Paper presented at annual meeting of American Educational Research Association, New Orleans.

Terenzini PT, Cabrera AF, Colbeck CL, Parente JM and Bjorklund SA. 2001. 'Collaborative learning vs. lecture/discussion: Students' reported learning gains', Journal of Engineering Education

Thalheimer W. 2003. The learning benefits of questions. http://www.worklearning.com/ma/PP_WP003.asp

Tishman S, Jay E and Perkins DN. 1992. 'Teaching Thinking Dispositions: From Transmission to Enculturation', Harvard University

http://learnweb.harvard.edu/ALPS/thinking/docs/article2.html

Torre DM, Daley B, Stark-Schweitzer T, Siddartha S, Petkova J, and Ziebert M. 2007. 'A qualitative evaluation of medical student learning with concept maps', Medical Teacher, 29(9):949-955

Vermunt J. 2005. 'Relations between student learning patterns and personal and contextual factors and academic performance', Higher Education 49

Vrugt A and Oort FJ. 2008. 'Metacognition, achievement goals, study strategies and academic achievement: pathways to achievement', Metacognition and Learning, 30: $123-146$

Vygotsky LS. 1978. Mind in society. Cambridge, MA: Harvard University Press. 
Weinsheimer J. 1998. 'Providing Effective Tutorial Services', National Council of Educational Opportunity Associations, Department of Education, Washington DC.

Winston K, and Houghton K. 2006. 'Identifying and Resolving Problems with At-Risk Students', poster presentation at IAMSE conference, July 2006, Puerto Rico. Abstract available online: http://www.iamse.org/conf/conf10/general_2006.pdf

Worthington D. 2008. 'Exploring the Relationship Between Listening Style and Need for Cognition', International Journal of Listening, 22(1):46-58 


\section{CHAPTER 2A}

\section{Essential Lifelong Learning Skills (ELLS) Course Handbook}

This handbook is issued to all ELLS students and teachers prior to the start of the course. It is included here as an appendix to chapter 2, for completeness. 


\section{Essentials Lifelong Learning Skills}

\section{Being a "repeater" - some questions for reflection}

How do you feel about repeating the semester?

Is it embarrassing?

Have you told your family? Your friends? Your classmates?

What went wrong last semester?

Were there personal reasons for your difficulties?

Were there academic reasons?

Do you have any ideas of what needs to change for you to succeed?

Do you think that simply repetition of the material will be enough for you to succeed in the longer term?

Is there any benefit to repeating?

What do you hope to achieve this semester?

Is there anything you believe you can learn or improve?

In the courses you passed last semester, what do you think enabled your performance?

Were they simply easier courses?

What did you do (or know) that helped you succeed?

What areas/topics/courses presented the most difficulty for you?

How, exactly, did you study that material?

What can you improve or change?

Describe one specific change you intend to make, and how you expect this to lead towards your stated goals.

\section{Expectations:}

1. Attendance: Twice per week, throughout the semester. (For absences, see syllabus.)

2. Portfolio: Each week, you will complete an assignment in preparation for the next session. At the end of the semester, you will hand in a portfolio containing your work for, and brief reflection on, each assignment.

3. Participation: Give feedback on your colleagues' work, and explain/critique your own work. Be prepared to explain in detail how you study/learn, including new strategies/methods you've tried (or re-tried), and why you think they do/don't help. 
Assignment - to be completed before your first small group meeting next week.

Complete PIP plan.

Read through the Study Tips handout.

Read through Time Management handout. Make a plan for the week on a blank schedule, and record what actually happens on another blank schedule. Be prepared to discuss differences between the two.

Please also bring to your first group meeting the course/lecture handouts for the following day.

\section{ELLS Course Outline}

We have found that most struggling students typically have similar problems, and the sessions outlined below are designed to help you. Remember, the plan is to identify possible weaknesses and develop strategies that address these difficulties.

The assignments are "cumulative" - you should be using the suggestions on a regular (daily) basis. Each week you are welcome to discuss examples of your use of the ideas from any of the earlier sessions, or ask any questions that have arisen during your studies.

1 Discuss Personal Improvement Projects. Share views on Study Tips and discuss details of Time Management assignment. Work through Previewing handout, using the ideas to preview one lecture for the coming week, using the lecture handout or relevant textbook reading.

Assignment: produce evidence (word lists) of previewing for at least two lectures between this and the next session.

2 Re-visit time management, if needed. Share preview word lists and comment on the value of previewing. Talk about the importance of organizing material after lectures, and the need to make study products. Work through Working with Handouts, applying it to a specific course handout. Finally, talk about the upcoming exams, referring to Test Tips.

Assignment: produce study products for two of your lectures between this and the next session. Be prepared to demonstrate that you have mastered the information in your own study products. Also, bring a challenging handout from the coming week to the next session. 
3 Share and critique study products produced during the past week. Try the Learning for Mastery section on a specific course handout. Then, asking questions as you study: discuss Asking Questions handout, and practice asking questions about the course material, with reference to a specific 'challenging' handout.

Assignment: Each choose one lecture from the week's course material, and prepare a set of questions (taken from each group on the handout) that fully explores the chosen lecture (the fewer questions needed to achieve this, the better).

4 Each student uses their prepared list of questions to quiz others on their chosen topic. Reflect on merits of asking higher order questions. Read Explicit Reasoning, and practice rephrasing the sample MCQs in that handout.

Assignment: Take a set of practice MCQs, and apply rephrasing and writing out your reasoning to at least three of those questions.

5 Share, critique and discuss the MCQs rephrased for the previous assignment. Work through Working with MCQs handout, and apply the ideas to a set of practice questions, paying particular attention to the formulation of learning issues.

Assignment: Take a set of practice MCQs, and reflect on why you find multiple choice questions difficult. What kinds of MCQs are problematic for you? Bring at least two examples of 'difficult' questions to the next session.

6 Discuss reflections on problematic MCQs. Apply the various ideas for playing with MCQs to the 'difficult' MCQs from the last assignment. Talk through the Working with Learning Objectives handout, working together to apply the ideas to a specific set of lecture objectives.

Assignment: Work with the learning objectives for your lectures this week. Bring concrete examples to demonstrate how you have used learning objectives in at least two different ways for this week's lectures.

7 Share and critique the various uses of lecture objectives. Use Explain Yourself handout: learn to define and explain clearly, using examples and analogy. Revisit the definitions of terms from other study products. Take a look at Medical terminology stressing the importance of using the language to aid understanding and memory.

Assignment: Explain at least three terms, as per Explain Your- 
self handout. Also, demonstrate use of medical terminology to understand some terms studied during the week.

8 Share explanations of terms, and discuss some terms you have understood by breaking them down into their word roots. Then work with Organizing Lists, demonstrating the use of 'chunking' with the carbohydrates list. Read and discuss Steps to Constructing a Concept Map.

Assignment: Create one complete list of terms covering a lecture handout studied this week, and try to create a concept map from that list. Bring both the word list and the concept map to the next session.

9 Share and critique concept maps. Select one of the shared concept maps and develop it further as a group during the session, focusing on the organization: relationships, branching, convergence, and crosslinks.

Assignment: Read Memory handout, reflect on the ideas, and be prepared to share one specific technique for remembering a particular concept/process from the week's course material. Read Listening Skills, and consider your strengths and weaknesses.

10 Share memory tips and thoughts on listening skills. Review progress on PIPs, and discuss any changes that need to be made. Then work through NBME Guidelines, with the group writing one or two MCQs together, collaborating to make them closer to NBME vignette style.

Assignment: Write three MCQs, and email to facilitator before session.

11 Work through some of the MCQs written by the group. Discuss Add Your Patient handout, and create patients for two diseases presented in recent lectures. Review progress on PIPs and portfolios, and discuss any changes that need to be made.

Assignment: Create two more patients, using the list of questions in the handout.

12 Discuss the patients created for the last assignment. Then explore critical reasoning handout(s) (Generalizing, Threshold Concepts).

Assignment: Apply the assignment from one of these handouts to current coursework.

13 Share and discuss the assignments. Some Math - Equations, Calculations handouts. Then do some physiology/genetics prob- 
lems.

Assignment: practice some questions involving equations and calculations, using techniques from the handout.

14 Share a description of an equation from coursework in as clear, non-technical language as possible. Discuss progress on PIPs and portfolio. Then work on practice MCQs.

Assignment: Look through CTL folders on G-drive, and select one handout not previously studied in these sessions that you feel is particularly helpful. Inform your facilitator, in advance of the session, of which handout you have chosen. Consider whether there are any handouts that don't appear to have any value for you.

15 Discuss chosen handouts, explaining why they might be helpful. Also share ideas on any handouts that seemed unhelpful. Hand in completed portfolios for final assessment and grading.

Assignment: Reflect on the whole course. What worked? What didn't? What did you learn - from faculty? From colleagues? From handouts? Write down your reflections.

16 Share and discuss reflections and final comments. Receive feedback on portfolios. 


\section{Getting The Most Out Of This Course}

Who is shaping your learning? You or your teachers?

In order to get the most out of this course, it helps to have a positive attitude and to know what you want. It is essential for you to take more effective control of your learning. Your teacher will certainly welcome your taking the initiative.

So, here are some questions to ask yourself, and a few suggestions.

$1 \quad$ Am I taking responsibility for my own learning?

- Make a learning plan, setting out clear targets. How can your teacher and your peers help you achieve these targets?

- Arrive at each session with a clear idea of what you want to achieve.

- Look in advance at the course material for each session.

- Identify questions you need to ask.

- If you make mistakes, admit to them early. Mistakes are a way of learning.

2 Am I making and taking opportunities to learn?

- Develop an appetite for learning.

- Make a habit of looking out for learning opportunities.

- Learn how to recognize a good technique.

- Look for the right moments to ask questions and seek advice.

- You can learn from other people's mistakes and successes as well as your own.

- Ask your teachers and peers for constructive feedback on your work.

3 Am I getting the most from my professors?

- When you need advice from a professor, think ahead and work out some possible answers to your questions, so that you can demonstrate that you've thought about it beforehand, and so that you can ask more penetrating questions.

- Remember, you learn more by allowing an expert to correct your thinking than by simply listening to an explanation. So, try to explain your understanding, and then ask your teacher to correct your errors. 
- Make note of any matters you should read up on later.

4 Am I really using the best study methods?

- Try following the suggested study techniques seriously.

- Just because an idea is difficult to follow, does not mean it is not worth following. Quite often, it is the most challenging ideas that can make the most difference.

- Be flexible - different techniques work best in different situations.

- Be creative - once you've mastered techniques, try adapting them and combining them, according to your needs and the material you are studying.

5 Am I learning through my relationships?

- Everyone you work with is potentially a source of learning. They all have skills they have mastered and knowledge to share. Treat them with the respect due to potential teachers.

- Listening is a difficult skill. When you ask questions or take part in discussions, listen very carefully to exactly what is said.

- You learn by teaching. Explain something you think you know to another person. You may find you understand it less well than you thought.

- Use your peers to talk through what you are studying - to ask you questions or correct your explanations. 


\section{Personal Improvement Project}

If you want to succeed in your medical education, you must improve the overall quality of your academic performance. This Personal Improvement Project (PIP) should become an integral part of your effort towards that goal. The aim of this assignment is to experiment with small changes that are under your personal control, and then to reflect on the effect of those changes on your overall performance and on the general challenge of changing habits.

Week 1 - before the large group meeting

- Following careful reflection on your performance last semester, identify at least two specific things that you believe need to change. Examples might include very specific study skills and habits, such as how long it takes to do study products, the number of practice questions you do each week, how many hours of sleep you get each night, how much time you spend online, etc. The items you choose to work on need to be as specific as possible and measurable.

- Given your performance on each of these items last semester, decide on a clear target for your future performance. State your aim for each as clearly as you can.

- What will be your change process? How will you achieve your aim? Consider the factors that may affect your performance, and how you will manage the process of change.

- How will you measure the change? How will you collect and record data?

You will need to be ready to discuss your responses to all of these ideas with your facilitator in your small group, at the end of the initial repeaters' meeting.

Week 2 - After that first meeting, write up a summary of your PIP, to include responses to all of the above. A copy of this should be handed in to your facilitator at the first small group meeting.

For the remaining weeks of the semester, monitor and record your progress. Each week, reflect on what is and is not working. You may find that you need to modify your plans, adjust your change process, resolve problems with data collection, tweak your goals, or even add new ones. At regular intervals throughout the semester, you will need to discuss your progress with your group and facilitator. 
Week 13

At the end of the semester, you must submit a report. This report should include your aims, a description of the processes you followed, and records of your data. The report should also include discussion of difficulties you have encountered and changes you have made to the project, along with reflection on how successful the project has been, and how you might take these ideas forward as you progress in your career. 


\section{Study Tips}

The following 'study tips' outline some essential aspects of successful study at medical school. Each of these points is expanded on in other handouts (referenced in italics), which can be found either in this packet or in the CTL folder on the G-drive.

- Healthy body, healthy mind - if you are not well, your brain won't function well. Sleep, exercise and good food are essential.

- Build up a routine. Study at regular times, in a regular place.

- Allocate time carefully. No one can focus fully for hours and hours at a time. Give each subject one hour, take a short break, then change subjects. Cover all the subjects. It doesn't matter if you haven't "finished" - you can come back to it later. Spacing out study time gives the material a chance to settle in your mind, and returning to a subject gives a chance to refresh and review. (Time Management)

- Previewing should become a regular part of your daily routine. Try to skim through handouts or textbook chapters before lectures - it's easier to focus and absorb when you have some idea of what's coming. Ask yourself "Why this lecture? Why now? How does it fit with this/other courses? What are the key concepts?" (Preparing for Lectures)

- Test yourself before each class by trying to summarize, orally or in writing, the main points of the previous class in that course.

- Make very brief notes during lectures - annotate, underline, link with arrows, use abbreviations. You don't have to write down every word the lecturer says.

- Find the learning objectives - read them, understand them. Think about which objective each point in the handout is related to. Plug the details into the big picture. Remember, the objectives are exactly what your professors expect you to know.

- Study from the handouts - read, think, question, organize. Use the textbooks for clarification when you don't understand. If there's conflicting information, your professors are right - they write your exams! (Working with Handouts) 
- Pay attention to definitions of all terms. Try to guess at the meaning of new words, and then use a dictionary. Bookmark an online dictionary in "My favourites" on your computer - for quick reference. (Medical Terminology, Language in Medicine)

- Be an active learner - produce something when you study. Reorganize the material: rephrase, summarize, draw charts, tables, diagrams, concept maps. Look for links between points in a lecture, between lectures in a discipline, and between disciplines. Draw ideas together into one product. The content needs to become a system of interconnected ideas. (Working with Handouts, Summary, Steps to Constructing a Concept Map)

- Discuss the material with colleagues. Never say "I know what you mean". Be explicit - that's when you identify misunderstandings. If you can't explain it, you don't know it. (Study Groups, Explain Yourself, Explicit Reasoning)

- Draw on your prior knowledge. Relate new material to things you already know: build connections with previous learning and experience and make use of analogy. (Explain Yourself)

- Ask questions. If you haven't got a question, you couldn't have understood the material. There is always more to learn. (Asking Questions)

- Use practice questions - regularly and often. A few days after studying a topic, answer some practice questions on it. You should spend more time trying to identify why you got questions wrong than you spend actually doing them. Use the questions to identify gaps in your knowledge, and go back to handouts and texts to plug those gaps. If you got a question right, you have just reviewed that material. (Learning through MCQs, Working with MCQs)

- Figure out your strengths and weaknesses. Make good use of your strengths, and practice any skills you are not good at whenever possible. 
Five point checklist for each lecture/handout

1 Preview (which includes review of content you should already know that the lecture will build upon)

2 Watch/attend lecture

3 Study handout/text and make product (chart, table, summary notes, concept map, etc)

$4 \quad$ MCQ practice (a few days later)

5 Review and redo product (at the weekend, ideally from memory, including additional details learned from MCQ study) 


\section{Time Management}

\section{Some Points to Ponder}

Effective time management is essential to success at medical school. There will always be more to do than you can handle, and if you don't organize yourself and your time carefully, there will be plenty that you don't manage to do.

We recommend that you read through these points on time management carefully. If something strikes you as valuable, please refer to the detailed handouts available in the CTL folder on the G drive.

1. Time management in medical school is not the same as it is in undergraduate or graduate school. This is arguably the most important time management you will ever be called on to do.

2. Set goals and evaluate and review them regularly. Have goals for the day, the week, the month, and the semester.

3. Plan and organize. No military campaign was ever won by bumbling through.

4. You must aim for excellence, not perfection. Pursuit of perfection is a waste of time.

5. You must overcome procrastination. Break a dreaded large task into smaller tasks that you tackle a little bit at a time. Start with the easier tasks, just to get you going.

6. Face each day with a "To Do List" created either the last thing at night or the first thing in the morning. Do not endlessly rewrite the list. Code each task and when it is completed, simply cross it out.

1 (must do)

2 (should do, but can survive the day without accomplishing it

3 (could do, but it's not crucial for today's goals)

7. Put first things first. Prioritize. The best time management principles can be shortened to one phrase: "Organize and execute around priorities." What are your priorities? 
8. Use the blank time schedule (attached) to plan out your week. First fill in your scheduled classes, then your personal and small group study times. Include time for breaks, exercise, eating, etc. As you go through the week, complete a second schedule showing how you actually used your time. At the end of the week, compare the two schedules (planned and actual). Do they match? If not (and none of us can keep perfectly to a schedule (see point 4, above)), why not? Was your plan unrealistic? Can you identify where and how you wasted time? Can you improve your schedule for the following week?

9. Avoid unplanned breaks and interruptions. It's okay to tell your friends and family that you are busy. You're supposed to be busy - you are at medical school. 


\section{Preparing for lectures}

\section{Previewing - 'Get Ahead and Stay Ahead'}

It is important to find time to do a little previewing before each lecture. In the long run, this will save you time, and help you to become a more efficient learner.

Think about this:

If you were going to a meeting, would you arrive with no idea what the meeting was about?

Or would you read over some materials to familiarize yourself with the topic of the meeting?

Why should lectures be any different?

"Pre-reading" will enable you to listen actively in the lecture, stay focused, and get the most from that time. For the prepared student, the lecture then becomes a review, not a first exposure to the content, and you are more likely to understand and retain the lecture material.

Here are a few simple steps you could follow:

1. Allocate some time for each of the lectures for the following day. As little as 10 minutes is helpful (by just following the bold terms in items $3,5,6$ and 7 ), up to $1 / 2$ an hour is ideal.

2. Use the handout. If you can't access the handout ahead of time, use the recommended reading from the textbook. Alternatively, you could use the relevant section of the departmental handout (e.g. biochemistry).

3. Do not worry too much about understanding. At this point you are not trying to master the material. You are simply trying to gain basic familiarity with the topic.

4. Look briefly at the objectives for that lecture, (found either on the lecture handout itself, the main course handout, on the Gdrive/scholars folder, or e-college).

5. Ask yourself "Why this lecture? Why now?" Think about how it fits in to the rest of the course, and how it relates to other lectures/courses. The objectives should help with this. 
6. Skim through the handout/chapter - look at headings, key words (often in bold or italics). Glance at the diagrams. Are there any terms that you know from other contexts, such as previous lectures? Do you remember them? Can you define them precisely? Now is a good time to go back and review these.

7. List all key terms as you skim, including both old and new terms. If you can't define it, it counts as new. Does the word itself suggest its meaning? Then look up the definition and paraphrase it - what does it mean to you? This list, adjusted during and after the lecture, can later become the basis for a concept map, an outline, or a self-test tool.

8. Think about what you already know that is related to each new term (from this or another course, or your own prior knowledge). For example, you have a lecture tomorrow on "smooth muscle function". Ask yourself how this might be different from skeletal muscle function. Consider what else you have learned in your lifetime about how muscles work.

9. Think of (and write down) some questions that you hope will be answered in the lecture.

If you can do any of this, it will help you get more from the lecture (whether live or media-site). Obviously, the more you can do, the better. 


\section{During the lecture}

This is the time where you find out what is important and what or how the lecturer wants you to learn. Therefore you need to give all your attention to the lecture and maximize what you can get from it. This will help you focus your study of the material for the exams.

1. Get to lectures early. This will ensure that you don't miss any important information, explanations, or questions asked by other students.

2. Have all the necessary tools ready (pens, pencils, highlighter etc). If you are looking around for something to write with while the lecturer is explaining, you will not get a full understanding of what is said.

3. Try to choose a good seat, from where you can clearly see the lecturer and have minimal distraction. This will help you maintain focus and attention

4. Pay Attention

a. Listen for the answers to questions you generated from your pre-viewing

b. Listen for the details you are expecting from your previewing

c. Listen actively (Listening handouts)

5. Write only what is necessary. It is virtually impossible to write as fast as the lecturer speaks: if you try, you may miss something important. Frequently, the information you are so eager to write down is already there in the handout, often on the very next slide. You may only need to add a couple of new words to your list, underline or highlight words or phrases the lecturer emphasizes, or briefly annotate what is in the handout. The key to learning from lectures is active listening, and you can't do that if you're busy trying to write every word the lecturer says.

6. Ask questions. There is no such thing as a stupid question. 


\section{Working With Handouts}

\section{After the lecture}

This is when you are going to put everything together. Sometimes you may feel the lecture and the handout seem to be disorganized or don't flow well. You need to remember that the way something is explained first time may not be the best way to remember it later: thorough explanations often require a roundabout route to make the point properly. It is your job to organize the material for learning: rearrange, group, or chunk information together so that you can get a better understanding.

How well you work with the handout after the lecture will determine how much work you will have to put into reviewing before exams. Here are a few tips to help you.

- Allow about 1 hour and 25 minutes to work with the handout for each hour of lecture. Your aim is to produce a 'study product' during this time.

- After 1 hour and 25 minutes (or 2 hours and 50 minutes for a 2 hour lecture), change subjects. If you didn't finish the packet, you can come back to it later. The break allows material to settle in your brain. Studying another handout may help you to see connections between subjects, and clarify points that were hard to understand. When you return to the unfinished handout, you'll be including a quick review of what you studied earlier.

- Did the main points emphasized in the lecture match your understanding from pre-reading? How do you now see the big picture for this topic? Can you summarize this in one or two sentences?

- Review the list of terms from your preview of the material. Are there any terms to add? Are there any that could be removed? How are they related?

[If you didn't make a list before, do it now. You should have marked (underlined/highlighted) key terms during the lecture.]

- Clarify the definitions of each term. What is it? Where is it found? When is it used? What does it do? Can you think of any causes and/or effects of each one? 
- Compare and contrast each term with one or more other terms. Think about what each term could be confused with. Taking the time to remind yourself not to confuse $X$ with $Y$ will make any possible confusion more real for you and help you to avoid it.

- Are there any sequences or processes described in the lecture? Explain the function of each step in the sequence/process. Try to sketch it out.

- What symptoms would be produced if (process, structure, etc) were defective? Defective structures and processes are what mini questions are made of.

- What would be the best way to organize the material for learning? Can you group terms into categories/classes? Is there a temporal sequence of events?

- What properties does each member of the category have in common? What distinguishes different categories/members of categories?

- How could you best represent this organization? A table? A concept map? A diagram? A brief paragraph/outline/summary? What columns would a table need? What kind of concept map would be most appropriate?

- Make a study product (table/concept map/etc) illustrating the organization of the material. Think carefully how each term/concept fits into the overall structure.

- Often, while you are working, you may feel that there is a better way to organize the material, or that some ideas don't fit with the way you have represented the material. That's okay. Start again, with your new organization plan. This is not wasted time - the new insights and the repetition are valuable aspects of learning.

- Do you have any questions about the material? If you've understood it well, you should be able to come up with a handful of questions that you'd like answered. Use the textbook, or colleagues, or a professor, to answer your questions. Add the answers to your study product in the appropriate place.

- After a couple of days, answer some multiple choice questions on the topic. Use the questions to identify any details you misunderstood or failed to include in your study product. Go back to the 
packet, find the necessary details, add them to your study product in the appropriate place, then return to the question to check your new understanding. In this way, you should return to the packet many times, each time looking for specific details that you may have missed previously.

- With the addition of new information, you may have to re-draw your study product. Again, this repetition and re-organization is invaluable for learning and memory. (You may find this is the best way to use weekend study time)

- Later, can you reproduce your study product (concept map, table, outline, etc) from memory? Can you explain it to a colleague? Can you simplify it or add to it in the light of new knowledge?

- Remember, these study products are dynamic works. You'll never finish learning, so you'll never have a "finished" product. As you learn more, you should see new ways to represent your knowledge, to consolidate your understanding, and to integrate material from different lectures and courses. 


\section{Test Tips}

- Rest well before exams - tired minds don't perform well, however much knowledge they hold.

- Last minute studying rarely helps, and often breeds anxiety. Spend at least the last hour before the exam doing something that calms you.

- When you do practice questions, time yourself - take no more than 15 minutes for every 10 questions. This is mental athletics - and athletes always train against the clock.

- Test anxiety - the more you know, the less anxious you are likely to be. However, if you feel you are suffering from serious test anxiety you might:

- practice meditation techniques (e.g. Mindfulness-based stress reduction)

- write down your concerns before exams (see pdf Writing to reduce test anxiety, at $\mathrm{G}: \backslash C T L \backslash$ cognitive skills $\backslash$ General Study Skills \& Test Tips)

- meet with a counsellor

- Don't rush in the exam. If you finish all the questions but misread half of them, you'll do worse than if you cover $80 \%$ and get most of those correct.

- Allow 25 minutes for each 20-question block.

- Don't assume any facts that are not given in the question.

- Don't ignore any facts that are given in the question.

- Read questions very carefully - the wording is very important. You need to know exactly what the question is asking.

- If you run into vague terminology, define it in your own terms.

- Pay attention to key words in both question stems and answer choices. However, be wary of making quick key word associations: sometimes the context, or another clue in the question, requires you to think beyond simple word association. Note 
that, as well as technical terms, small words like not, increase, never, etc, are also key - they are a major part of the context.

- Rephrase the question, making sure you understand exactly what is actually being asked, especially for less straightforward questions. Consider jotting down your rephrased question: it's easy to forget what you're aiming for as you think through lengthy or complex answer choices, and a quick note may save you time in the long run.

- Try to answer the question before reading the answer choices.

- Read each answer choice very carefully, rephrasing difficult ones, and try to rule in or out as you go - you don't have time to repeat yourself unnecessarily.

- If a question says "Which is correct/incorrect", change it to true/false. This avoids those pesky double negatives.

- Decide what you need to know to answer this question. Not everything related to the topic is going to be relevant.

- If you're unsure of the right answer, eliminate wrong answers first.

- When a question is hard, don't dwell on what you don't know. Think about what you do know about the topic, anything that's related, a definition, a concept, and work from there. Often, this can be enough to eliminate several answer choices and kick start your thinking on a question.

- If you've narrowed it down to a choice of 2 answers, re-read the question, remind yourself exactly what is being asked, and look for any clues you haven't yet used. Now re-read the 2 choices carefully, thinking about the wording, how each clue in the question relates to each choice, and how the choice relates to the question being asked.

- If you can't decide on an answer, flag your best guess, and move on. You can come back if you have time at the end of the block. Make sure you don't submit a block of answers until you've revisited the questions you flagged! 
- Some questions are supposed to be easy. Don't convince yourself you must be wrong just because the right answer seems obvious.

- Go through and pick off the easy questions in each block first - you get points in the bag, build confidence, and sometimes a later question can remind you of something you need for a question that seemed hard earlier.

- Don't change your answers without very good reason. Your first instinct is probably good. If you are going to change, you need to satisfy two conditions: you need a very good reason why your initial choice was wrong; and you need to be sure of a clear rationale for why your new choice is better.

- There are no patterns in MCQ exams. For example, just because several answers in a row are $C$, this does not mean the next answer cannot be $\mathrm{C}$.

- Trust yourself. Don't panic. If you find yourself losing focus, close your eyes and breathe deeply. Go to the bathroom if you need a break. 


\section{Asking Questions}

All subjects represent a systematic way of thinking, and critical thinking skills are essential to learning every subject. Thinking is not driven by answers but by questions. Had no questions been asked, each discipline - for example, Physics or Biology - would never have been developed in the first place. Furthermore, every field stays alive only to the extent that fresh questions are generated and taken seriously as the driving force in a process of research and thinking. To think through or rethink anything, one must ask questions that stimulate thought. This is why it is true that only students who have questions are really thinking and learning. If you haven't got a question, there must be a problem with your understanding - however much you know, there is always more to learn.

Perhaps one of the most common difficulties among students is recognizing what they don't know, and being able to ask appropriate questions to find out how deeply they understand material. It is important that while you are studying your course material, you constantly ask yourself (and anyone you may study with) questions that will probe the depth of your understanding and help prepare you for the kind of questions you can expect on exams.

Remember, specific questions are most valuable: they can be answered clearly, and they can help you to identify exactly what knowledge you are lacking. Inevitably, after spending time studying, you do know a lot of the material; the key to progress is not to keep repeating what you do know, but to use what you know to identify and explore what you don't know.

Any questions that you are unable to answer and explain with clarity, point you to material that needs reviewing. If you can't find the answers in the handouts or textbooks, perhaps you can work them out, starting from the facts that you do know. Or, having failed to satisfy yourself, you can discuss the ideas with colleagues, or go to a professor with a very specific question that she can answer quickly and easily.

To start with, there are the basic questions that can aid recall. These types of question ask for literal comprehension, requiring you to define, describe, rephrase. Professors assume that you know the answers to these questions very well, so you need to make sure that you do. Use words like:

What

When

Where 
Who

Which

How many

Having understood what is said, your next job is to think about the material a little more. The purpose here is to define relationships, make comparisons, draw distinctions, to begin to interpret the material. You should be thinking in terms of the following:

Why

How

What for

What are the similarities between

What are the differences

What links ... and ...

Which part

What is another example of

Then, you should be looking to apply what you learn, to push the boundaries of your understanding. The following question types are where you need to be to do well on the exams:

What if...?

How else might...?

What are the consequences of...?

How might ... appear in a patient?

Is there another way...?

What if this were changed to ...?

How could this be reversed?

What other factors...?

Under what other conditions...?

How does ... affect ...?

Answers to this kind of question will deepen your understanding, strengthen your memory of basic facts, and help prepare you for exams. Sometimes you'll be able to work out the answer, sometimes you'll need to ask, sometimes they will take you beyond the scope of your current courses. But, most importantly, they will help you identify gaps in your own knowledge, and improve your ability to reason. 
You should be asking these questions whenever you study, including when you look over practice questions. When you work through multiple-choice questions you have got wrong, it is again important to ask yourself very specific questions, so that you only need to review areas that you don't already know, rather than spending time on what you do know. Ask yourself: "What exactly did I need to know (or forget, or misunderstand) to be able to have got this question correct?" Then devote some time to finding out the answer, and thus focus your study on what you need most.

Finally, it is worth writing down your questions as they occur to you. This forces you to be explicit and accurate, and allows you to come back later to seek the answers. Make a habit of this, and you'll find yourself prepared to ask your most important questions whenever the appropriate opportunity arises, and you won't make the mistake of not asking exactly what you meant.

You could start by bringing a question to each cognitive skills session that you attend, and present it to the group for discussion. Group members should be able to identify one unanswered question each, and draft a research strategy for answering the question, returning the following week with an explanation for the group. 


\section{Explicit Reasoning}

One of the best ways to improve your reasoning skills is to make each step of your line of reasoning explicit. In our small group sessions we do this by talking through the problem, explaining our reasoning clearly enough for other group members to understand. In this way, we are able to check our own and each others' understanding. When working alone, this is much harder to do - no one is listening, and it can be easy to fool yourself into believing you have followed each step logically and methodically. After all, you know what you mean.

Perhaps the most effective way is to write down your reasoning as you work through a problem. This forces you to be explicit, and helps you to frame your understanding in terms that someone else could follow. Setting ideas on paper brings clarity and can help you see where you might have gone wrong. It allows you to come back to the problem later, when you may be able to spot something you missed first time. Also, you can then show your reasoning to someone else and get their opinion.

Writing it out makes it explicit, and plenty of research has shown that being explicit is the key to improving reasoning skills. You can do this with difficult sections of coursework, when trying to see "what would happen if...", or with practice questions.

So, here's an exercise to try.

Here are three multiple choice questions. Write down each step of your thought process as you work through the problems. Pay particular attention to rephrasing the question, so you are sure you understand it. Define any important terms. Write clear reasons why you think "wrong" choices are wrong, making the relationship to the question clear. Also write an explanation for why one choice is correct. Be as explicit as you can - make as few assumptions as possible. Write this for an audience - your tutor, for example, or a classmate. Is your writing clear enough for your reader to follow every step of your argument? 
1) Which of the following types of proteins are translated on ribosomes bound to the rough endoplasmic reticulum (RER) instead of being completely translated on the ribosomes free in the cytosol?
A) Cytoskeletal proteins
B) Mitochondrial proteins
C) Lysosomal proteins
D) Peroxisomal proteins
E) Nuclear proteins

2) Seizures are fundamentally the result of too much excitatory neuronal activity in the brain. Imagine that you wanted to design a new drug to reduce the severity of seizures. Which of the following approaches would make the most sense?

a) potentiate the effect of glutamate at glutamatergic receptors

b) block GABA receptors

c) open calcium channels

d) block the glial based uptake of glutamate from the synaptic cleft

e) open chloride channels

3) You have engineered a protein construct mRNA that will encode for a protein not normally found in nature. To a soluble protein that is normally a cytoplasmic protein you have added an ER signal sequence to its amino terminus, and an NLS to its carboxy terminus. There are no other targeting signals present in this protein. The final protein will be $100 \mathrm{kD}$ in size. After transfection into the cell, what is the final destination of the translated construct protein?
A) Cytoplasm
B) Lumen in the ER
C) Lumen of the Golgi
D) Secreted into the extracellular space
E) The nuclear interior

Have someone look through your work and discuss it with you. If you find yourself having to explain what you've written, then it might be worth trying again.

The more you practice this the better (faster) you will get at answering difficult questions during the exam.

So, we recommend that you try to write out your reasoning for any MCQs you haven't found easy, and, of course, we'll be happy to give feedback on any written work you do. 


\section{Working with MCQs}

Set aside an hour a day to do a few (perhaps 10) practice questions. Work on topics you studied a few days earlier. Use about 15 minutes for doing the questions, and 45 minutes for learning from them.

Doing the questions:

- When you do practice questions, time yourself - take no more than 15 minutes for every 10 questions. This is mental athletics and athletes always train against the clock.

- Read questions carefully. Rephrase in your own words, and be sure you know what is being asked.

- Practice as if it's a test. Skip hard questions, and return to them if you have time.

- If a question says "Which is correct/incorrect", change it to true/false. This avoids those pesky double negatives.

- Don't dwell on what you don't know. Think about what you do know about the topic, anything that's related, a definition, a concept, and work from there.

- Try to answer the question before reading the answer choices.

- Read answer choices carefully. How do they relate to the question? Look for key words (not, increase, never, etc).

- If the choices are long, break them down into parts. Often, a choice can be eliminated because one part of it is wrong.

- If you've narrowed it down to a choice of 2 answers, re-read the question, remind yourself exactly what is being asked, and look for any clues you haven't yet used. Now re-read the 2 choices carefully, thinking about the wording, how each clue in the question relates to each choice, and how the choice relates to the question being asked.

- It's worth thinking about what information is not given in the question. The absence of a clue is itself a clue. 
- When your time is up, give each question a confidence mark.

$$
1=\text { uncertain } \quad 2=\text { fairly sure } \quad 3=100 \% \text { sure }
$$

Learning from the questions:

- Before you check the answers, think about what would you need to know to change your confidence mark to a 3 . Write it down this is a specific learning issue for you. Go back to your notes and handouts, find the information you need, and then come back to the question; if necessary, revise your answer.

- Now check your answers. Score 1, 2 or 3 points, depending on your confidence mark, for each correct answer. Score 0, -2 , or -4 for incorrect confidence marks of 1,2 and 3 respectively. Work through the semester to improve your score (for 10 questions: maximum $=30$, minimum $=-40$ ).

- If there are explanations, don't read them yet - these might not help you understand why you may be wrong.

- Think about what you needed to know to get the right answer and to eliminate the wrong answers. Be very specific. If you were wrong, think carefully about why. Again, write down specific learning issues.

- Go and look up the answers to your learning issues. Are they actually in your study product (or notes), and you just forgot them? If not, go back to the handouts, textbooks, or ask colleagues or professors. If you've been specific enough, this won't take long: you do not need to read the whole packet/chapter again, just find the answer to a specific question. Add the answers to your learning issues to your original study product in the appropriate place.

- Having found the answers to your specific learning issues, go back to the original MCQ and check that you now fully understand the solution.

- For each answer choice, make sure that you can explain clearly why it is either right or wrong. Writing these explanations down really forces you to be accurate. If you can't, again make a specific learning issue, and follow the steps above. 
- Try changing the question to make alternative answer choices correct. Be very careful with the wording, so that no more than one choice is correct for your new question. This forces you to notice similarities and differences, and can prepare you for up to five exam questions for each one you study.

- Try writing your own MCQs. Again, this forces you to notice similarities and differences, and helps you understand how examiners think. Writing a good, challenging question is not easy. It helps to start with something fairly straightforward, and then work with colleagues on making it more complex.

- Remember, there are only 2 questions per lecture on the mini. Certain key concepts have to be tested - often, a professor simply has to change a few words to come up with a new question on the same topic. 


\section{Working with Learning Objectives}

When faced with the challenge of developing a curriculum, any medical school has to go through an exhaustive process of examining exactly what elements must be taught to ensure the proper education of a physician. That is no easy task.

As part of the process, faculty are charged with preparing learning objectives for each of their lectures, separating out the particular concepts essential for students' understanding of the whole. Since these objectives are the underpinning of each lecture, a careful consideration of them can often assist a student in organizing and understanding the material in a clear and workable pattern for learning. The objectives are frequently found on early slides within an individual lecture, and also on the $G$ drive in the learning objectives folders.

However, not all learning objectives are created equal. Some are expressed in very general, global terms that are open to a variety of interpretations. Others tend towards narrowly-focused, highlyspecific instructions for working through the material. How you use the learning objectives probably depends where on this spectrum they lie. Here we present some possibilities for making use of learning objectives in your studies.

Learning objectives can be useful for:

- Getting the 'big picture' - The objectives can show you the shape, the broad organizational structure of the lecture.

- Previewing - Read the learning objectives before lecture to get a good sense of topics/major points/questions that the lecturer will address.

- Organizing content and note-taking - Label lecture slides based on the learning objective(s) they address: write the learning objective number on each slide, noting which and how many learning objectives are related to each slide. You could also record your notes based on how the instructor addresses each learning objective, by printing out the objectives with enough space between each one for brief notes.

- Comparing and contrasting learning objectives - Consider how learning objectives are related to each other. Is the information pertaining to each objective in a lecture unique, or is there 
some overlap with other objectives? Have you noticed similar learning objectives in other lectures? For example, objectives about specific concepts may appear in more than one discipline, module and semester.

- Creating study products - Can you provide a short paragraph, diagram, flow chart or any helpful aid to address the learning objectives in your study product? Pay particular attention to the verbs used (e.g. 'list' is very different from 'explain'). Where possible, follow the instructions - if the objective says 'draw', then draw; if it says 'compare and contrast', then you might want something like a table. A good representation will aid your recall of the information.

- Linking learning objectives with MCQs - Can you find which learning objectives are linked to the MCQs you do? When working on a set of questions for a specific topic, try to tie a learning objective to each question. How many objectives can be linked to each question? Compare how the lecture information and MCQ stem address the learning objective.

- Creating questions - You may develop both open-ended and multiple-choice questions based on one or more learning objectives. Allow yourself to develop challenging questions and answer choices. You probably want a mix of primary, secondary and tertiary questions, especially when developing questions that address multiple objectives.

- Reviewing content - Test yourself by reading each objective and trying to recall as much relevant information as you can. This may be a good way to check your retention, especially if the objectives are detailed and specific. 


\section{Explain Yourself - Definition and Analogy}

The capacity to explain yourself with clarity and accuracy is crucial in any profession. The ability to explain ideas clearly and precisely helps with both understanding and memory, both crucial to success at medical school. If you can't explain it, you can't be sure that you know it.

It's impossible to reason with the material if you don't fully grasp what the terms mean. Students commonly hide behind terminology it's easy to say you understand an explanation if you assume you understand the jargon. However, this first assumption about the precise meanings of terms is exactly where so much reasoning goes wrong. Nurturing the skill of communicating in simple layman's terms avoids making this mistake, enables you to draw on prior knowledge, and will help you to clarify your understanding of basic definitions. Paying attention to definitions is what science is all about, and will inevitably improve your ability to reason through questions on exams.

Finally, in the field of medicine you will frequently need to explain things to patients who understand little of the jargon familiar to physicians. These patients will be from all sorts of backgrounds, and of very varied intellectual abilities. Being able to explain yourself clearly is a skill that will help improve your patients' outcomes throughout your career.

So, as an example, try to explain what "period" is.

How many meanings do you think there are? Are they related?

Is there one underlying concept shared by the different uses?

How about "cell"? What does cell mean?

Now, let's fix on the usage of cell most relevant to your studies. How would you explain this relatively trivial term? What exactly is a cell? Below is an example, which you may be able to improve upon:

cell: A cell is the smallest unit of living structure capable of independent existence. It is very small indeed - so small that you can't even see it without a microscope. A cell is capable of 'eating', excreting, storing energy, and controlling the things it needs to do: some creatures are actually made of only one cell (such as bacteria). Most creatures, however, including humans, are made up of millions of cells, each with its own specific job (blood cells, brain cells), and all working together for the benefit of the whole creature. It's a bit like 
lego: lots of little lego pieces can be put together to make one big thing. And, in the same way that there are different types of lego piece for different parts of the model, there are different types of cell performing different jobs within an organism.

\section{A clear explanation includes definition, classification, form,}

function, location (in time and space), uses simple language, and includes examples and analogy.

Next, everyone in the group should choose a word from one of your courses, and provide an explanation for it. Try to give a definition, put it into a category, and explain the word clearly, including both an example and an analogy.

How accurate are your explanations?

How far can your analogy be taken before it breaks down?

This ability to explain yourself is a skill that is necessary for deep learning, and requires constant practice. Whenever you come across unfamiliar terms, you should aim to explain them to yourself as clearly as possible.

As an exercise, you should choose at least one term from each of your other courses every week, and explain them as clearly and accurately as you can in proper English. Remember to write as though you were talking to a complete layman: keep it simple and avoid difficult language. Give a definition, classification, form, function, location, and use analogy and examples where appropriate.

Your professors also use analogy and metaphor to explain ideas. Pay attention to these analogies, collect them, and think about how well they fit the concepts they are used to explain, and about where these analogies break down. Share examples with your colleagues, and discuss how accurately the analogy reflects the concept.

You could take this even further. Try to use concepts learned earlier in the curriculum as an analogy to help you understand something in a later class. Can you think of any examples where a concept from one class can be used metaphorically to gain deeper understanding of a concept in another class? 


\section{Medical Terminology}

In medicine, word roots are combined with affixes to produce terms that provide very clear and precise descriptions of the intended meanings. Affixes attach to word roots to change, enhance or add to their meaning. Prefixes are added at the beginning, suffixes at the end.

The accompanying handouts (see $\mathrm{G}$ drive $\backslash \mathrm{CTL} \backslash$ medical terminology) provide lists of some of the medical word roots, prefixes and suffixes commonly used, and you'll probably find more comprehensive lists in your dictionary. At first glance, the lists may be seem long, but you should realise that a large number are in common use in everyday language (e.g. anti-, trans-), and that others are parts of words that you are familiar with (dentist, circumference): you already know their meanings. When you meet new terms, look for their constituent parts, and you'll soon get a good feel for how medical terminology works.

A medical term must have at least one root, but does not have to have a prefix and/or a suffix. An example of this is the term sternocleidomastoid, which is a muscle that has attachments at the sternum, the clavicle, and the mastoid. The term sternocleidomastoid can be divided into three parts (three roots, in this case): stern - $\mathbf{0}$ cleid - $\mathbf{0}$ - mastoid. Notice that there are vowels between the three roots. These are linking or combining vowels, which serve to make a term easier to pronounce. The vowel used most of the time is $\mathbf{0}$, but other vowels such as $\mathbf{i}$ and $\mathbf{a}$ are also used. Combining vowels are often used between roots and suffixes or roots and other roots, but they are NOT used between prefixes and roots.

Once you are comfortable with these terms, you should then be able to make an educated guess at the meaning of any other new terms that you come across, more easily recall the correct term for something you are thinking about, or even coin new terms yourself. Whenever you come across a new word, have a think, see if you can work out the meaning, and only then look it up in a medical dictionary.

For example, what do you think diplosomia means? Break it down into its constituents, check on the lists, and work it out.

What about hemospermia? Or splenomegaly?

Or rhizomeningomyelitis? 
The main point is to not be afraid of medical terms: they are mainly logical, and you will get used to them.

To help learn these, it may be useful to work with a partner and a dictionary. One of you finds a word, the other has to "guess" at the meaning. You can see how close you can get to the correct idea, then switch roles.

For more information and practice work through:

- a course in medical terminology

(http://www.dmu.edu/medterms/),

- some anatomical terminology

(http://www.uni-

mainz.de/FB/Medizin/Anatomie/workshop/Vokabular/1.html). 


\section{Organizing lists for memorization and understanding}

Take one minute to look at the following list. Then try to see how many items you can recall without looking.

Oligosaccharides

Glucose

Plant

Homopolysaccharides

Mannose

Cellobiose

Non-reducing

Starch

Lactose

Glucan

Heteropolysaccaride

Maltose

Monosaccarides

Carbohydrates

Isomaltose

Galactose

Disaccharides

Sucrose

Animal

Glycogen

Amylose

Glyceraldehyde

Fructose

Amylopectin

Polysaccarides

Reducing

Cellulose

How well did you do?

The above list is clearly not well-organized. See if you can group the elements of the list in a logical way: find category words, and group members of that category together.

Now try to recall the list. Is this an improvement?

Do you think this process can aid understanding? 
You might be tempted to think that the only reason this process aids recall is that you've simply spent longer working with the list of words. You might want to believe that simply spending the same amount of time reading or copying the list over and over will produce the same results. However, when you are faced with a large volume of material, you will find that organized lists are much easier to remember. The value of chunking for memory is well-researched, well-recognized, and known to be highly effective. 


\section{Steps to Constructing a Concept Map}

1. A concept map is a tool for organizing knowledge. Making a concept map requires three active learning steps:
a. Listing (concepts)
b. Identifying (categories)
c. Grouping or comparing for understanding (links)

2. Begin by creating a list of key terms from a single lecture handout (one of our tutors estimates that each packet has about 50 terms). Do not include definitions - but make sure you know them. You might also choose to do this as a way of integrating a group of lectures, as a review tool, by creating a list of concepts for the group of lectures.

3. Scan your list, and try to identify the broadest, most general concepts, terms that describe categories. Also note which terms can be grouped together, and mark them. The first level concepts are the most general and they will include all the remaining terms in the map, linked in a branching pattern beneath them.

4. Create a specific focus question, such as: What are the functions of enzymes? Or: How are the structure and function of enzymes related? Using a focus question helps you to capture the dynamic nature of the material, and go beyond mere listing. You end up with a study product that interconnects ideas.

5. Concept mapping is structured. Begin by placing the concept (or concepts) at the top in the center of a blank piece of paper (or on a whiteboard). In constructing a concept map you are identifying what you already know about the concept and then deciding how new information fits with the prior knowledge.

6. Most people like to use shapes and/or color for clarity. Start with the most general topic in, for example, an oval shape. Sub topics can be placed in rectangles or underlined. This step enables you to recognize instantly the category that shape represents, such as function or structure. If you prefer black and white and no bubbles, go for it. The main thing is to find what works for you.

7. The next active learning step is achieved by linking the topics. This is difficult, but it is a great help in checking your understanding. At this point you can see relationships. The decision about whether to use a simple line or an arrow for your links is im- 
portant to your understanding. Should the link be an arrow? Is there a causal or temporal relationship? Which direction should the arrow point? Does the link need a label?

8. Look for branching, ways to subdivide categories, and convergence, ways to connect subtopics. Identify cross-links between branches of your concept map. These are powerful for the development of integrative thinking. It is very common to have epiphanies at this point. Suddenly you appreciate a relationship that was not evident before. You may wish to redo the map. It requires time to do this, but the resulting clarity will save you time in the long run.

9. Later, try to draw your concept map from memory.

10. As you discover further relevant information (e.g. from subsequent lectures, or work with MCQs), you can add it to your map. Remember, concept mapping is a dynamic learning tool - your maps can always be improved, new cross-links can be identified, new information can be integrated. Don't be afraid to change them as you learn more and gain new insights. 


\section{Memory}

The volume of course material seems vast, and the task of remembering it all may seem insurmountable. You have to accept that you're unlikely to recall every single detail, and that you need to learn to work with what you can remember. However, there are ways of improving your memory.

Memory is the process of registering, consolidating, storing, and recalling information. Neurosurgeons and hypnotists have shown that memories do not disappear from our brains - forgetting is simply a failure to recall. So remember, "forget" is a misnomer - a more accurate term might be "can't find for the moment".

Imagine your memory is like a jungle. You need to find a particular rare plant. First time you visit the plant, you leave a faint trail. On each subsequent visit, the path becomes more trodden, more clear. If there are a number of different paths leading to the plant, you're more likely to get there. And, if you can recognize other plants growing nearby, they can serve as landmarks to help you.

And so we come to a number of techniques for aiding memory. These can be used in combination, or tried one at a time, or you may find that different ideas work best in different situations. Try them out, and find what works for you.

\section{Pay attention}

When you first encounter something, you need to be sure you know exactly what it is you want to remember, and why. Be sure you understand the information that you intend to commit to memory.

\section{The big picture}

Learn from the general to the specific, rather than focusing on the details first. Skim through all the material you plan to study in any one session when you start, so you get a sense of the overall picture. What are the key issues? How does it relate to other things you're learning? Then, as you work through details, keep asking yourself, "How does this relate to the big picture? How does it fit in? Why is it useful? Why do I need to know this? Which learning objectives does it address?" 


\section{Organize it}

Sorting and grouping are ways of categorizing data to provide memory traces to aid in recall. You should try to find major categories for grouping the material, and then think of subgroups for each of those categories. As well as making the information easier to recall, this can reduce your workload - each subgroup also possesses the properties of the larger group it belongs to, so you don't need to memorize those properties over and over. It may help to draw out your groupings as a flowchart, table or concept map. At the very least, you need to consider how best to classify your material as you try to learn it.

\section{Create Associations}

Trying to recall isolated information is like locating the proverbial 'needle in a haystack'. If, when placed into the haystack, the needle is tied to a reel of thread, a pair of scissors and a thimble, the needle will be much easier to find. So it is with data stored in your memory. As you learn something, think about how it relates to other things you already know - make the connections with your own previous knowledge and experience. Does the concept remind you of something? Can you think of an analogy? Does it evoke any connection with other things you've done or felt? Does it clarify something else in one of your courses? Or raise a new question about other material you've learned? You might also be able to find word associations. Look carefully at the language - is there a familiar word root? Does it remind you of another word you know? Look for as many links as you can - the more memory traces and connections you can associate with the new information, the more ways you have to recall that particular piece of information.

\section{Chunking}

Chunking is a term used to describe the process of grouping items into larger or smaller groups (or "chunks"). Chunking helps you to organise your thinking, and handle information. Psychologists have shown that the conscious can cope with between 5 and 9 pieces of information at any one time ("the magic number 7 "). If you think how you remember those useful phone numbers, you cluster the digits into groups. Chunking allows us to become more efficient at categorising information. Items can be classified into different groups moving from the general to the specific, and vice versa. When you are confronted with a task that seems daunting, chunk it down to find smaller, more manageable minitasks. When you are overwhelmed by details, chunk up to find the overall meaning or purpose to "get the big picture" or "see 
the wood for the trees". Basically, chunking (or grouping) information gives you much more chance of remembering it.

\section{Learn Actively}

Draw pictures, make up questions, produce charts and concept maps, rephrase in your own words, pace about, discuss with colleagues, note down ideas or questions that occur to you as you read. If you learn actively, you'll stop the boredom, become better focused, and create useful associations.

\section{Recite and Repeat}

Repetition helps you to hold information in your short term memory as your working memory organizes and integrates it into long term memory. And saying it out loud also helps - you get a physical memory of making the sounds, hearing it. You might even make up a rhyme or turn it into a song. As ever, the more ways you learn it, the more ways you have to recall it.

\section{Spacing out}

Spacing is the practice of leaving intervals between learning sessions in order to reinforce memory traces. Instead of doing long, marathon study sessions, try using shorter, more focused sessions, with regular breaks. Each time you return to the material, briefly review what you learned last time; you may find that this review even happens during your break. The more times you use the path, the clearer it becomes.

\section{Use it}

Often. Read it, write it, speak it, listen to it, apply it. Do practice questions regularly - they'll help you review and apply the knowledge, and show you bits you've missed. Discuss the material with your friends - if you can't explain it, there's something you don't understand or can't recall; once you've identified the gaps, you can fill them.

\section{Mnemonics}

To aid recall, you can use acronyms (e.g. IPMAT, stages of cell division - interphase, prophase, metaphase, anaphase, telophase), acrostics (which is the use of the first letters of words in a series to create a sentence, such as Every Good Boy Deserves Football), rhymes (30 days hath September....) and loci or peg systems (associating a series of things to be remembered with familiar locations, such as objects around your house or places on your route to school). However, be aware that mnemonics don't help with understanding or critical thinking, can be time- 
consuming to develop, and can themselves also be forgotten. But, a good mnemonic can be a powerful part of your memory tool kit.

\section{Attitude}

Positive attitude always helps. Remember, you can never really forget. Don't tell yourself "I never remember". You can choose to tell yourself something like "It will come to me" or "I never for-

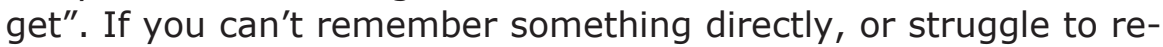
call a specific fact, try to recall something else that's associated with it. Is there an example that you can remember? Or anything at all that might be connected with it? Or can you start with defining a related term? Help yourself to jog your memory. Believe you can do it.

Finally...

It's hard to remember anything if you don't look after yourself remember the importance of food, sleep and exercise. Relax. Don't panic. Keep regular hours. Avoid distractions when you study. And don't lose sight of your own "big picture" - your purpose for choosing to study at all. 


\section{Listening Skills}

Ten bad listening habits, and how to remedy them

You can learn a lot through listening. In lecture, it is a prime source of information. Unfortunately, people do not instinctively listen well. Quite the reverse! Listening is a skill which must be developed. The business of becoming a good listener primarily consists of getting rid of bad listening habits and replacing them with their counterpart skills. If you understand the following bad habits, and consider their remedies, you will find yourself listening more effectively, both in class and out.

\section{Calling the Subject Dull}

Bad listeners often find a subject too dry and dusty to command their attention and they use this as an excuse to wander off on a mental tangent. Good listeners may have heard a dozen talks on the same subject before, but they quickly decide to see if the speaker has anything that can be of use to them.

The key to good listening is that little three-letter word use. Good listeners are sifters, screeners, and winnowers of the wheat from the chaff. They are always hunting for something practical or worthwhile to store in the back of their mind to put to work in the months and years ahead. G.K. Chesterton said many years ago that in all this world there is no such thing as an uninteresting subject, only uninterested people.

It helps to determine why what the speaker is saying is important to you. If you don't have an immediate, vivid reason for listening to a speaker, you are an unmotivated listener.

\section{Criticizing the Speaker}

It's the indoor sport of most bad listeners to find fault with the way a speaker looks, acts, and talks. Good listeners may make a few of the same criticisms but they quickly begin to pay attention to what is said, not how it is said. After a few minutes, good listeners become oblivious to the speaker's mannerisms or his/her faults in delivery. They know that the message is ten times as important as the clothing in which it comes garbed.

Remember: the responsibility for interest and understanding lies with you, not with the speaker. Learning is up to the learner. If you simply want to sit passively and blame the speaker for your lack of success, then you're not a serious learner. 


\section{Getting Over-stimulated}

Listening efficiency drops to zero when the listeners react so strongly to one part of the presentation that they miss what follows. Withhold evaluation until comprehension is complete -- hear the speaker out. It is important that we understand the speaker's point of view fully before we accept or reject it.

\section{Listening Only For Facts}

Almost without exception it is the poor listeners who say they listen for facts. They do get facts, but they garble a shocking number and completely lose most of them.

Good listeners listen for the main ideas in a speech or lecture and use them as connecting threads to give sense and system to the whole. In the end they have more facts appended to those connecting threads than the catalogers who listen only for facts. It isn't necessary to worry too much about facts as such, for facts have meaning only when principles supply the context.

Look for the speaker's pattern of organization. In a lecture, a speaker is generally referring to notes or some other source of information. You can understand much better if you are able to recognize what the speaker's driving at and how the speaker's getting there. Facts are important only as they support the speaker's main ideas.

\section{Trying To Outline Everything}

There's nothing wrong with making an outline of a speech -provided the speaker is following an outline method of presentation. But probably not more than a half or perhaps a third of all speeches given are built around a carefully prepared outline.

Good listeners are flexible. They adapt their note taking to the organizational pattern of the speaker-they may make an outline, they may write a summary, they may list facts and principles -- but whatever they do they are not rigid about it.

\section{Faking Attention}

The pose of chin propped on hand with gaze fixed on speaker does not guarantee good listening. Having adopted this pose, having shown the overt courtesy of appearing to listen to the speaker, the bad listener feels conscience free to take off on any of a thousand tangents.

Good listening is not relaxed and passive at all. It's dynamic; it's constructive; it's characterized by a slightly increased heart rate, quicker circulation of the blood, and a small rise in bodily temperature. It's energy consuming; it's plain hard work. 


\section{Tolerating Distraction}

Poor listeners are easily distracted and may even create disturbances that interfere with their own listening efficiency and that of others. They squirm, talk with their neighbors, or shuffle papers. They make little or no effort to conceal their boredom. Good listeners try to adjust to whatever distractions there are and soon find that they can ignore them. Certainly, they do not distract others.

If you can't hear, arrange things so you can. Move away from sources of noise - human or mechanical. Sit where you can see the speaker easily, and where other distractions are at a minimum.

\section{Choosing Only What's Easy}

Often we find the poor listeners have shunned listening to serious presentations on radio or television. There is plenty of easy listening available, and this has been their choice. The habit of avoiding even moderately difficult expository presentations in one's leisure-time listening can handicap anyone who needs to use listening as a learning tool.

\section{Letting Emotion-Laden Words Get In The Way}

It is a fact that some words carry such an emotional load that they cause some listeners to tune a speaker right out: such as, affirmative action and feminist - they are fighting words to some people.

Perhaps one of the most important studies that could be made would be the identification of the one hundred greatest troublemaking words in the English language. If we knew what these words were, we could bring them out into the open, discuss them, and get them behind us. It's so foolish to let a mere symbol for something stand between us and learning. Listen to what the speaker is saying. Don't tune the speaker out because you don't like something about the message. Be sure you understand something before you reject it.

\section{Wasting the Differential Between Speech and Thought Speed}

Americans speak at an average rate of 125 words per minute in ordinary conversation. A speaker before an audience slows down to about 100 words per minute. How fast do listeners listen? Or, to put the question in a better form, how many words a minute do people normally think as they listen? If all their thoughts were measurable in words per minute, the answer would seem to be that an audience of any size will average 400 to 500 words per minute as they listen.

Here is a problem. The differential between the speaker at 100 words per minute and the easy thought speed of the listener at 400 
or 500 words per minute is a snare and a pitfall. It lures the listener into a false sense of security and breeds mental tangents.

However, with training in listening, the difference between thought speed and speech speed can be made a source of tremendous power. Listeners can hear everything the speaker says and note what $\mathrm{s} / \mathrm{he}$ omits saying; they can listen between the lines and do some evaluating as the speech progresses. To do this, to exploit this power, good listeners must automatically practice three skills in concentration:

\section{Anticipating the next point}

Good listeners try to anticipate the points a speaker will make in developing a subject. If they guess right, the speaker's words reinforce their guesses. If they guess wrong, they'll have to do some thinking to discover why they and the speaker failed to agree. In either case, their chances of understanding and remembering what was said is nearly double what it would have been if they had simply listened passively.

\section{Identifying supporting material}

Good listeners try to identify a speaker's supporting material. After all, a person can't go on making points without giving listeners some of the evidence on which the conclusions are based, and the bricks and mortar that have been used to build up the argument should be examined for soundness.

\section{Recapitulating}

With the tremendous thought speed that everyone has, it is easy to summarize in about five seconds the highlights covered by a speaker in about five minutes. When the speaker stops to take a swallow of water or walks over to the blackboard to write something or even takes a deep breath, the experienced listener makes a mental summary. Half a dozen summaries of the highlights of a fifty-minute talk will easily double the understanding and retention important points in a talk.

References

Ralph G. Nichols, The Supervisor's Notebook, Vol. 22, No. 1, Spring 1960

(C)Academic Skills Center, Dartmouth College 2001 


\section{NBME Guidelines - What to Expect with Multiple Choice Ques- tions}

Writing MCQs is a valuable tool for learning, but students frequently write questions that are either too simplistic, involve only recall, or do not reflect the level of questions that appear on exams.

The NBME has extensive guidelines on writing MCQs. Although not all Ross faculty currently follow these guidelines perfectly, you can expect them to do so more and more.

Regardless of whether questions on Ross exams all currently adhere to these guidelines, ultimately you need to pass the USMLE Step 1 and NBME shelf exams. The questions on those exams do follow the guidelines, and we recommend that you get used to well-written questions. Indeed, we recommend that you write MCQs as a learning tool, and, when you do so, try to follow the NBME guidelines so that you are familiar with the way you will be tested.

The general NBME guidelines for writing questions are:-

- The stem of the item question should be long and the options short

- They should test important concepts, typically a common or potentially catastrophic clinical problem. Don't waste time testing trivial facts

- They should assess application of knowledge and not recall of an isolated fact. Avoid tricky and overly complex items

- They must pose a clear question, which should be possible to be answered without looking at the answer options.

- All distractors (incorrect options) should be homogeneous - They should all be grammatically consistent and they should be plausible and the same relative length as the answer.

- Avoid technical item flaws that provide special benefits to testwise examinees or that pose irrelevant difficulty. Avoid using 'always', 'never' and 'all' in the options as well as vague terms as 'usually' and 'frequently'.

\section{Some common flaws in MCQ item questions:}

- Grammatical cues - one or more distractors don't follow grammatically from the stem

- Logical cues - a subset of the options is collectively exhaustive

- Absolute terms- "always", "never" or "only" 
- Long correct answers - correct answer is longer and more specific or more complete than the other options

- Word repeat - a word or phase is included in the correct option that was in the stem

- Convergence strategy - the correct answer includes the most elements in common with the other options.

* These are good to remember, as they can help you answer flawed questions when/if they do appear.

\section{Presentation of item stems}

The NBME have found that vignette items tend to have fewer technical item flaws than typical non-vignette items, presumably because the vignettes follow a standard structure. The vignette consists of paragraph-length description of a clinical situation, followed by a question related to the basic sciences, diagnosis or next step in patient care. As such, these vignettes stress application of knowledge by asking examinees to make clinical decisions, rather than to simply recall isolated facts. They are designed to reflect "real life tasks" by challenging the examinee to first identify the findings that are important, then integrate those findings into a diagnosis or clinical action.

Studies have shown that low performing students are less likely to select the correct option in the vignette format. An item written in a non-vignette format typically is written from a "top-down" perspective (i.e. given a disease, what are the associated findings). To an expert (high performing student), items written in this manner appear identical to items written in a patient vignette. However to low performing students the items are not identical.

Likewise, short and long vignette formats were not markedly more difficult for high performing students, but were for the low performing students. 
The most likely renal abnormality in children with nephrotic syndrome and normal renal function is

A. acute poststreptococcal glomerulonephritis

$B$. hemolytic-uremic syndrome

${ }^{*} C$. minimal change nephrotic syndrome

D. nephrotic syndrome due to focal and segmental glomerulosclerosis

E. Schönlein-Henoch purpura with nephritis

\begin{tabular}{|l|l|l|l|l|l|}
\hline & A & B & C & D & E \\
\hline Hi & 1 & 0 & 99 & 0 & 0 \\
\hline Lo & 8 & 1 & 90 & 1 & 0 \\
\hline
\end{tabular}

\begin{tabular}{|l|l|l|l|l|l|}
\hline & A & B & C & D & E \\
\hline Hi & 0 & 0 & 98 & 2 & 0 \\
\hline Lo & 5 & 2 & 82 & 8 & 1 \\
\hline
\end{tabular}

A 2-year-old boy has a 1-week history of edema. His blood pressure is 100/60 mm $\mathrm{Hg}$, and there is a generalized edema and ascites. Serum concentrations are: creatinine $0.4 \mathrm{mg} / \mathrm{dL}$, albumin $1.4 \mathrm{~g} / \mathrm{dL}$, and cholesterol $569 \mathrm{mg} / \mathrm{dL}$. Urinalysis shows $4+$ protein and no blood. The most likely diagnosis is (same option list followed).

\begin{tabular}{|c|c|c|c|c|c|}
\hline & A & B & C & D & E \\
\hline Hi & 0 & 1 & 98 & 1 & 0 \\
\hline Lo & 10 & 9 & 66 & 10 & 5 \\
\hline
\end{tabular}

A 2-year-old black child developed swelling of his eyes and ankles over the past week. Blood pressure is $100 / 60 \mathrm{~mm} \mathrm{Hg}$, pulse $110 / \mathrm{min}$, and respirations $28 / \mathrm{min}$. In addition to swelling of his eyes and 2+ pitting edema of his ankles, he has abdominal distention with a positive fluid wave. Serum concentrations are: creatinine $0.4 \mathrm{mg} / \mathrm{dL}$, albumin $1.4 \mathrm{~g} / \mathrm{dL}$, and cholesterol 569 $\mathrm{mg} / \mathrm{dL}$. Urinalysis shows $4+$ protein and no blood. (Same lead-in and option list followed).

\section{How are the stems constructed?}

Have you noticed any particular order in which vignette stems are written?

The stem should begin with age/gender of patient, site of care, the presenting problem of a patient, followed by the history (including duration of signs and symptoms), physical findings, results of diagnostic studies, initial treatment, subsequent findings etc. Vignettes may include only a subset of this information, but the information should be provided in this specified order. The stem should have a single, clearly formulated problem and must pose a clear question so that the examinee can propose an answer without looking at the options. 
Good stem: this provides sufficient information and can be answered without referring to the options

A 52-year-old man has had increasing dyspnea and cough productive of purulent sputum for 2 days. He has smoked one pack of cigarettes daily for 30 years. His temperature is $37.2 \mathrm{C}(99 \mathrm{~F})$. Breath sounds are distant with a few rhonchi and wheezes. His leukocyte count is $9000 / \mathrm{mm}^{3}$ with a normal differential. Gram's stain of sputum shows numerous neutrophils and gram-negative diplococci. X-ray films of the chest show hyperinflation. Which of the following is the most likely diagnosis?

Stem testing isolated facts: insufficient information in order to answer the question; the examinee must use the options as a frame of reference.

Which of the following is true about pseudogout?

\section{What can I do with this knowledge?}

Use it!!

1. Study with application in mind:

a. How/what will a patient present with if they had $X$

b. What physical exam/diagnostic results would I expect to find if a patient had $X$

c. What is/are the possible treatments or next clinical step for a patient with $X$

2. Rewrite previous MCQ questions you have written to make them more application oriented

3. Write more application MCQs

\section{Reflection}

Are there any differences in terms of your understanding of the material now that you are thinking/studying for application and not just recall? 


\section{Add your Patient - complete your study}

Have you noticed that many exam questions involve a patient complaining of something, they then get examined, get some tests done, and then get treated with a drug? Does that sound familiar?

Patients do not go to their doctor saying, "Hi Doc, I have sickle cell anemia, what is the structural change affecting my RBCs?"

More likely, the patient will come to your office complaining of pain in a knee, etc (symptoms of a crisis). You will examine the patient and notice jaundice, swollen knees etc. You will request some blood tests (which ones?), and the results will show (what?), indicative of sickle cell anemia. You will then recommend treatment, such as drugs and/or change in eating habits and lifestyle.

This is how it normally happens, and this is how you will be tested. Increasingly, exam questions follow this "real life" format (see What to Expect with MCQs handout). So why not study in this format, the way you are being tested, the way you will function as a doctor?

Many lectures include diseases you are expected to learn and recall, as a way of demonstrating application of the basic science knowledge that is being taught. Many concepts can be illustrated more clearly by referring to a hypothetical patient. Pathways can be understood more deeply by imagining what would happen if they were not functioning normally (see Asking Questions handout).

An effective way to test your own understanding of material, and to improve your recall, is to Add Your Patient. After you have studied the information (handouts etc) and you think you know your stuff, try to create a patient to illustrate application of this newly acquired knowledge. To achieve this, here are some questions you need to answer:

1. How will a patient with disease $X$ appear?

2. Is age/sex/race etc important to disease $X$ ?

3. Is a particular lifestyle/environment a risk factor for disease $X$ ?

4. How common is this disease?

5. What will the patient herself complain about?

6. What significant findings will appear in the patient's history?

7. What significant findings will appear on physical exam?

8. What tests would you do and what results might be expected?

9. What underlying agent/cause is responsible for disease $X$ ?

10. What treatment (drug, surgery, lifestyle change, etc) might be needed to correct/prevent disease $X$ ? 
11. What is the prognosis of disease $X$ ?

12. What key point from the lecture is illustrated by disease $X$ ? What does it exemplify?

If you put all of this information together, you now have a patient. Indeed, you have just created a vignette that could be used as an exam question.

\section{Assignment}

Take today's course material and add patients to as many diseases as you can. Take note of any links that you have now made as a result of adding your patient that you hadn't noticed before. Does this help you to understand the material more clearly? Can you remember/recall more this way? 


\section{Level Crossing - Generalizing From Examples}

A common tool for clarifying ideas is to give examples or discuss specific situations. A common confusion among students seems to be in distinguishing the given examples from what those examples are trying to show: looking at the finger instead of where it is pointing. Clearly, when reading, it is important to understand why an author is using a particular example, what she is trying to show, and to think for yourself whether or not the inferences and conclusions she draws from her examples are valid. Similarly, when writing, it is often helpful to quote examples to make your argument more accessible, but, if you don't generalize somewhere, such as in the conclusion, or indicate explicitly what you're pointing to, readers may well misinterpret your main idea. The ability to generalize is crucial in so many situations, not least in cross-disciplinary work and the application of previously acquired knowledge to new contexts. This skill is tested frequently throughout your academic career, but is rarely taught explicitly. We are expected to learn this ability intuitively, or very early on in our lives; think back to when you heard fairy tales, and were expected to grasp the moral of the story. This is the same principle, just taken to a little more depth.

I do not doubt that, if given a topic, most students would find it relatively straightforward to think up some examples. However, it appears to be a somewhat harder task to go in the opposite direction.

For example, suppose your plumber tells you that you need a narrower pipe if you want to increase water pressure in your shower. Firstly, do you believe him? How will this affect your "shower experience"?

What general principle does this illustrate? One might try to describe this as "less space, more pressure", or "faster after bottleneck". Maybe you can describe it better.

Another example of this principle might be the effect on traffic speed when vehicles emerge from a single lane to a four lane highway. Or perhaps the blood pressure in a person with atherosclerosis.

Below are a few more 'examples'. Try to make generalizations from each of them, to draw valid inferences, without drifting too far into the realms of wild assumption. Then try to apply your generalized concept by citing a specific example from a different context. If a member of the group cites an example that you believe is not an illustration of the general concept, explain how it is "wrong".

1 The boy who cried wolf. 
2 It is easier to move your hand through air than it is to move your hand through water.

3 Lactate dehydrogenase is used to convert pyruvate to lactate.

4 When the temperature gets high enough, the heater switches off automatically.

5 Studies have shown that when a child chooses a toy for him- or herself, there is a very high chance that he or she will pick a toy that would have been traditionally assigned to their gender.

6 Maggie walker, a 33-year-old heroin addict desperately wants out. She is willing to "do anything to get clean", but there is no inpatient drug treatment available for addicts who have no means of payment. All that's available is a public methadone clinic. In five weeks, when her appointment at the clinic comes up, the moment will have passed, and she will be in no shape to take advantage of it.

7 Sherlock Holmes and $\operatorname{Dr}$ Watson are going camping. They pitch their tent under the stars and go to sleep. Sometime in the middle of the night Holmes wakes Watson up. "Watson, look up at the stars, and tell me what you deduce." Watson says, "I see millions of stars and even if a few of those have planets, it's quite likely there are some planets like Earth, and if there are a few planets like Earth out there, there might also be life." Holmes replied: "Watson, you idiot, somebody stole our tent!"

It is also worth thinking of counter-examples - specific cases that do not fit the general principle, with an explanation of why this is so.

Now try to apply these ideas to your coursework. First, cite an example, then describe the general principle that it is an example of. Then, provide another example of the general principle, and discuss how it differs from the first example. 


\section{Threshold Concepts}

Have you ever felt that your professors don't seem to understand why you find their material difficult? Why might this be so? After all, people become professors largely because they are interested in teaching...

It is commonly said that expertise in different academic disciplines requires ways of thinking that are specific to each discipline. If you are going to master the different courses presented at medical school, you need to develop the ability to see things in a manner that is most appropriate for each subject area. How can you do this?

Threshold concepts are classified as ideas/topics that can have a transformative, integrative effect on the understanding of a particular subject area. A threshold concept can be considered as akin to a portal, opening up a new and previously inaccessible way of thinking about something, often exposing previously hidden connections. It represents a paradigm shift, a transformed way of understanding or interpreting something without which a learner cannot progress. Such a transformed view may represent how people 'think' in a particular discipline, or how they perceive or experience particular phenomena within that discipline.

A core concept is a conceptual 'building block' that progresses understanding of a subject; it has to be understood but it does not necessarily lead to a qualitatively different view of subject matter. So, for example, the concept of gravity - the idea that any two bodies attract one another with a force that is proportional to the product of their masses and inversely proportional to the distance between them represents a threshold concept, whereas the concept of a centre of gravity does not, although the latter is a core concept in many of the applied sciences.

Threshold concepts often prove problematic for learners, since they involve knowledge that is conceptually difficult, or even counterintuitive. Once a threshold concept is understood, the transformation of perspective is likely to be irreversible, since the new viewpoint is unlikely to be forgotten. Indeed, experts may have difficulty looking back across thresholds they have long since crossed, finding it hard to understand (from their own transformed perspective) the difficulties faced from (untransformed) student perspectives. 
Clearly, then, special attention should be paid to threshold concepts, since they pave the way to mastery. As a learner, you should look out for ideas that may be key to understanding each subject and each course you take. Try to keep a list of threshold concepts, explore them, discuss them, and look for other ideas that are built upon them. If you can do this, you may find that your own understanding of medicine is irreversibly and integratively transformed.

Below are just three threshold concepts identified by Ross faculty. Take note of these, and, as you progress through your training, look for more.

Threshold Concept \# 1: Stereochemistry, (from Biochemistry)

"Stereochemistry" is a threshold concept for the entire science of biochemistry. This is because the three dimensional structure of biomolecules is often the critical factor in determining the biological function and role of those molecules. This idea gives insight into carbohydrate chemistry, amino acid chemistry, protein structure, protein-protein interaction, enzyme-substrate interactions, enzymeinhibitor interactions, enzyme kinetics, receptor-ligand interactions, the deleterious effects of gene mutations, drug targeting, drug specificity, drug potency, etc.

Threshold Concept \#2: Within-Group Variability Exceeds BetweenGroup Variability (from Behavioural Science)

Despite accepted professional practice of using categories to label patients, there is a great deal of variability among patients that carry a particular diagnostic label. In many cases, the differences among patients carrying the same Personality Disorder diagnosis are greater than the differences between different diagnoses. In this sense, the diagnostic categories can be viewed as artificial labels that we place on patients. Indeed, each of the diagnoses can be given when patients exhibit only a subset of symptoms from among a pool of possibilities (e.g., "Five of the following nine...'). While the language of labels helps us communicate about patients and guide research and practice, they do not serve us well as detailed descriptions of individuals, since no two people are alike, even if they have the same diagnosis. If students examine patients' behaviors with an agenda of fitting them neatly and definitively into one category, exactly like all others in that category, they can become rather frustrated. Understanding this threshold concept allows students to accept and appreciate the variability within categories, and the associated ambiguity of the behavioral sciences 
Threshold Concept \#3: Apoptosis (from Pathology)

Apoptosis is a prearranged pathway of cell death triggered by a variety of extracellular and intracellular signals. The threshold concept of apoptosis bridges the disciplines of physiology, embryology, histology and pathology: it occurs normally both during fetal development and throughout adulthood, and serves to eliminate unwanted, aged or potentially harmful cells, and it is also a pathologic event when diseased cells become damaged beyond repair and are eliminated. Apoptosis is a genetically programmed type of cell death affecting individual cells and acting as opposite to mitosis. It is a "threshold" concept central to pathophysiology that apoptosis is planned to perform as nature's surgical knife: it acts swiftly and quietly to maintain the balance between the life and death of cells.. 


\section{Equations}

Medical students need to remember a number of equations, particularly in the physiology and pharmacology courses. If you are able to gain an intuitive grasp of what the equations mean, your task of recalling them becomes much easier. You also need to understand elementary algebra to be able to manipulate these equations efficiently during exams.

Here are a few simple steps to help you learn and use equations.

1 What is the equation describing? If you can't answer this, you won't recognize which equation you need in which situations. This should be apparent from the context: what was the professor/handout discussing when the equation was introduced?

2 Can you define all the terms? This is not just recognizing what the symbols stand for, but also knowing the definitions of those terms.

3 Consider the units each term is measured in. Does this make sense with your definition?

4 Consider the subject of the equation (the term before the $=$ sign). From your understanding of the subject matter, and from common sense, what factors are likely to affect this? Try to describe this in as simple terms as you can, perhaps with the aid of an analogy.

5 Does your understanding from item 4 above match the actual equation?

6 Now, describe the relationship expressed in the equation in the simplest language you can. If the equation makes sense to you, it will be easier to recall, and to know when to use it.

7 Practice re-arranging the equation, making each term the subject in turn.

8 Play with it. What happens to the subject when you hold all variables constant except one? Does it increase, or decrease? Is that what you would expect from your intuitive understanding of the topic? Can you think of a clinical situation where such changes might actually take place? 
An example will probably help.

Take this simple equation: $\mathrm{CO}=\mathrm{HR} \times \mathrm{SV}$

This is describing how much blood the heart can pump out (eject). It makes sense to standardize this by measuring over a certain time. In this case, we measure cardiac output as a volume for each minute $(\mathrm{L} / \mathrm{min}) . \mathrm{HR}$ is heart rate, the number of times the heart beats per minute. SV, stroke volume, is the volume of blood ejected per heart beat. Now, what would you expect to affect the amount of blood pumped out of the heart? How often it pumps and how much it pumps each time are likely to be important factors. (Factors that affect these two will help you to understand other cardiac equations.) Clearly, if you eject 'SV' litres in one beat, you eject 2 times SV in 2 beats, etc. For each minute you have 'HR' beats. So, the cardiac output, volume of blood ejected each minute, must be HR x SV.

If we increase the heart rate, keeping stroke volume constant, what happens to the cardiac output? Under what circumstances might this actually happen?

If we increase the heart rate, keeping cardiac output constant, what happens to the stroke volume? Under what circumstances might this actually happen?

How about this one, given in physiology right at the beginning of semester 1:

Fick's law is $\mathbf{J}_{\mathbf{x}}=\mathbf{P}_{\mathbf{x}} \mathbf{A}\left(\left[\mathbf{X}_{\mathrm{o}}\right]-\left[\mathbf{X}_{\mathbf{I}}\right]\right)$

What is this equation trying to describe?

What do you think are factors likely to affect the rate of diffusion of a substance across a membrane? (Is there an analogy that may help here?)

Follow each of the steps 1 through 8 above, and then decide whether you think this equation makes sense.

Can you think of any other equations you are supposed to remember?

Try this method for each equation you come across during your studies. 
Clearly, this is only part of the battle. Knowing when to use particular equations, and doing so efficiently, is also important. However, learning equations in this way will help.

So, on to application. Some basic steps to follow are:

1 Rephrase the question to find what is being asked for.

2 Remind yourself of the definition of that term, and what factors affect it.

3 Recall any equations that include it. If you're lucky, the term in question will be the subject of an equation, but it may not be, in which case you'll need to rearrange the equation to make the term being asked for into the subject.

4 Look at the other terms in each equation. How many of them have you been given values for? If you have values for all the other terms in one of your equations, then all you have to do now is plug numbers in. If not, continue...

5 If there is just one other term in one of the equations for which you haven't been given a value, can you think of another equation containing that term? Have you been given values for the other variables in that second equation?

6 Solve the second equation for the term you need, and plug that result back into your first equation. 
Here is an example question from physiology.

What would be the effect of reduced total peripheral resistance (TPR) on mean arterial pressure if heart rate and stroke volume remain unchanged?

A) Increased twice as much as normal.

B) Remain normal.

C) Reduced below normal.

D) Increased by the power of 4.

E) No change if the body fluid remains unchanged.

Try to reword this question, and find what is actually being asked for.

We're looking for the effect (of something) on mean arterial pressure (if other things are kept constant). The subject is mean arterial pressure (MAP).

Next step is to remind yourself of what MAP is, and to think of any equation involving this MAP.

You should recall MAP $=\mathrm{CO} \times \mathrm{TPR}$

We know TPR is reduced, but the question doesn't mention CO (cardiac output).

But, we also know $\mathrm{CO}=\mathrm{HR} \times \mathrm{SV}$. Since heart rate and stroke volume are kept constant, we know that $\mathrm{CO}$ remains unchanged.

Coming back to the first equation, we can see that if TPR is smaller, then CO x TPR is also smaller.

Thus, MAP will also be reduced (answer choice C).

Now, find other questions that involve equations, and try to apply this method. The more you practice, the easier it gets. 


\section{Calculations}

Basic numeracy is a prerequisite for all medical professionals. As a physician, you really don't want to prescribe the wrong dose of a drug, or draw the wrong conclusions from an ECG. As a medical student, you will be expected to perform simple calculations during exams, without the aid of a calculator. If numeracy is a weakness of yours, you will waste valuable time on exams, and miss out on relatively easy marks.

Here we offer some basic tips on performing calculations. If you find any of this difficult, please visit the CTL department, where you can get help resolving these issues.

Firstly, it is quite common to hear someone say, "I can't do math." But, is innumeracy really any more acceptable than illiteracy?

Further, if you are capable of mastering the vast amounts of material you're required to learn in medical school, is it really possible that you can't learn a few basic number facts?

If you've learned a language as complex as English, then you must be capable of learning basic math. You have to believe this.

Firstly, you need to know:

- multiplication tables (up to $9 \times 9$ is enough)

- addition and subtraction of single digit numbers

- multiplication and division by factors of 10 (adding or removing zeros)

All else follows from these basic facts.

For example, multiplying a single digit by a double digit number.

Let's take $6 \times 14$.

This is the same as $6 \times 10$ plus $6 \times 4$.

Or $7 \times 38$

This is $(7 \times 30)+(7 \times 8)$.

And $7 \times 30=7 \times 3 \times 10$. Can you do that in your head?

Are you comfortable with fractions? (You'll need them for genetics, and physiology).

How about $2 / 3 \times 3 / 8$ ? Write down how you would do this.

Did you include a step that had 6/24? 
Or did you see that the 3 's cancel out, and that $2 / 8$ simplifies to $1 / 4$ ?

A golden rule in all calculation is simplify, whenever you can.

Another example. You measure from an ECG that a man's heart beats once every 0.72 seconds. What is his heart rate (beats/min) ?

You know there are 60 seconds in a minute.

So, in 1 minute, his heart will beat $60 \div 0.72$ times.

How would you approach this calculation?

(Do it first, before looking at the next page.)

Did you do this: $\frac{60}{72}$, as a long division calculation ?

Or did you first remove the decimal point by multiplying by 100 to get $6000 / 72$ ?

Did you notice that both 60 and 72 are divisible by 12 ?

So that $6000 / 72$ becomes $500 / 6$. Is this easier to work with?

Another useful rule is approximate first, make a "guesstimate" of the answer.

Before diving in to a calculation, make a rough estimate of what the answer should be. This will at least tell you if your final answer is in the right ball park. Indeed, after making your "guesstimate", have a look at the answer choices (if it's a multiple-choice question). It often happens that your estimate is close enough to select the correct answer.

For example, after plugging numbers into an equation, you may be faced with:

$(195 \div 11) \times 2.9$

What's your first step?

A good idea is to call this $(200 \div 10) \times 3=20 \times 3=60$.

Is this estimate high or low? How can you tell?

20 is higher than 195 , while 10 is less than 11 . So, $200 \div 10$ must be more than $195 \div 11$. And, multiplying by 3 is a little more than multiplying by 2.9. So, you know that your answer of 60 is a bit higher than the correct answer. If there is only once answer choice in the fifties, your job is done. 
Another example:

An arteriole with a resistance of $4 \mathrm{~mm} \mathrm{Hg} / \mathrm{L} / \mathrm{min}$ divides into three capillary branches with resistances of 2, 1 and 4, respectively. These capillaries combine into a single venule with a resistance of 1 . Which of the following values most closely represents the total resistance of this vascular bed?
A) 0.6
B) 1.7
C) 5.6
D) 6.6
E) 7.7

Here you need only know that resistance in series is mere addition, while resistance in parallel requires Rtot $=1 /\left(1 / R_{1}+1 / R_{2}+1 / R_{3}\right)$.

So we need to work out $4+1 /(1 / 2+1+1 / 4)+1$

Before you start, you can eliminate choices A and B, since you know the total is greater than 5 .

Now, the piece in the middle. The denominator is $1 / 2+1+1 / 4$. This is obviously greater than 1 . So, when we take $1 /(1 / 2+1+1 / 4)$, we know it's less than 1.

Which is the correct answer choice?

You will also be expected to find the square root of simple numbers, especially in genetics. If you know your multiplication tables, this shouldn't present a problem.

First, look at the first one or two digits of the number. Can you see the square root of that? Then, for each pair of zeros, add one zero to that simple square root.

For example: Find $\sqrt{ } 900$. Okay, first $\sqrt{ } 9=3$. There are two 0 's, so we need to add one 0 to the 3 , giving $\sqrt{ } 900=30$.

Or, find $\sqrt{ } 2500$. $\sqrt{ } 25=5$. one pair of zeros, so add one 0 . So, $\sqrt{ } 2500$ $=50$.

Or, find $\sqrt{ } 1000000 . \sqrt{ } 1=1$. Three pairs of zeros, so add three 0 's. So, $\sqrt{ } 1000000=1000$.

What is $\sqrt{ } 640000$ ? 
Some calculations in physiology and pharmacology require a basic understanding of logarithms. What is a logarithm?

The logarithm of a number $\mathrm{n}$ is defined as the power to which 10 needs to be raised to get $\mathrm{n}$. That is:

$$
\text { If } 10^{x}=n \text { then } \log n=x
$$

So, what is $\log 100$ ? Ask, if $10^{x}=100$, then what is $x$ ?

$10^{2}=100$. So, $\log 100=2$.

Or, if $\log n=-1$, what is $n ? n=10^{-1}=1 / 10$. So, $n=0.1$

Finally, if any step of this is not really simple for you, remember that you are not alone. This handout was developed from examples of issues regularly seen in Ross students. If working with numbers (at any level) is a problem area for you, please do bring calculation problems to some cognitive skills sessions, where you can learn to improve both the speed and accuracy of your number work. 



\section{CHAPTER 3}

\section{At-Risk Medical Students: Implications of Students' Voice for the Theory and Practice of Remediation}

Published as:

Winston KA, Van Der Vleuten CPM, and Scherpbier AJJA. 2010. "At-risk medical students: implications of students' voice for the theory and practice of remediation", Medical Education, 44:1038-1047 


\section{Introduction}

The education literature provides a clear catalogue of the reasons some students struggle at medical school: problems with time management (Paul et al, 2009), over-reliance on passive learning (Dolan et al, 2002; Burns, 2006), insufficient background and content knowledge (Slotnick, 1981), weakness in literacy, numeracy, study skills, test-taking strategies, and critical thinking (Sayer et al, 2002; Alexander et al, 2005), and a general lack of the self-regulatory and metacognitive skills that are correlated with academic success (Cleland et al, 2005; Brigman and Webb, 2007; Loyens et al, 2007; Cao and Nietfield, 2007). And yet, these weak students tend to avoid seeking assistance (Devoe et al, 2007; Judd, 1985; Weinsheimer, 1998).

There are relatively few examples in the medical education literature of how to remediate these difficulties, perhaps because medical schools are uncertain of effective strategies (Hauer et al, 2009), and there have been calls for further research into optimal methods for remediating at-risk medical students (Paul et al, 2009; Frellsen et al, 2008; Saxena et al, 2009).

In one such study, Winston et al (2010) describe a mandatory intervention at a large Caribbean medical school, in which students who fail and repeat their first semester are required, as a condition of their academic probation, to participate in a carefully designed remediation programme (Winston et al, 2010). This intervention programme draws upon a blend of complementary theoretical perspectives (Reynolds et al, 2002; Cobb, 1999; Jörg et al, 2007): it is primarily based upon a constructivist, student-centred approach that focuses on learning through collaboration, dialogue, self-direction and reflection (Loyens et al, 2007; Vygotsky, 1978; Bruner, 1999), while the effort to enculturate students into medical discourse and build their identity as medical students draws on sociocultural theories of learning (Lave and Wenger, 1991). Stable, faculty-facilitated groups of six students meet weekly throughout the semester to work through a syllabus that attends to various study and reasoning skills, including time management, pre-reading techniques, strategies for working with and integrating basic science course material, testtaking, and critical thinking. The key themes of this remediation course include: self-regulation, metacognition and reflection; discourse and making reasoning explicit; active learning; giving and receiving feedback; application and relevance to basic science course content; care with language; accuracy of thinking; and attention to affect and motivation (Winston et al, 2010). Participants have performed significantly better than students who repeated first semester at the school prior to the introduction of this mandatory programme: 
pass rates for exams taken at the end of the repeat first semester have increased by $64 \%(n=377, p<0.0001)$, and by $55 \%$ for the national exams taken five semesters later $(n=113, p<0.0001)$ (Winston et al, 2010).

In this study, we aim to clarify how and why the intervention works, by heeding the call to include student voice in understanding remediation strategies (Saxena et al, 2009; Young, 2005). Indeed, student beliefs about learning are known to affect course outcomes (Loyens et al, 2007; Kozanitis et al, 2007), with reflective, positive views typically resulting in better performance (McQueen and Webber, 2009).

Education researchers have found mixed student responses to skills-based pedagogy (Star and Hammer, 2007), noting resistance to change (Goldfinch and Hughes, 2007; Saltmarsh, 2008; Sahlström, 2009), with weaker students most likely to feel that academic support is unhelpful (Tekian et al, 2000). However, if students gain trust in a programme (Geertsma, 1977) and perceive its relevance, they may respond more positively (McQueen and Webber, 2009; Allan and Clarke, 2007). The following explores the perceptions of students who participated in our mandatory intervention for first semester repeaters (Winston et al, 2010), in order to provide more clarification on how remediation works effectively.

\section{Aims}

The principal aims of the current work are to answer the following questions:

1 How does participation in the programme change students' beliefs about what is required of them as medical students? Does the programme affect their study habits and their perceptions of themselves as medical students? If so, how? Which aspects of the programme do the students find most effective?

2 How do the students' perspectives inform our knowledge of the theory and practice of remediation? We expect to use emergent themes from the students' responses to improve our understanding of the optimal blend of remediation strategies for at-risk medical students.

\section{Methods}

To explore the complex process of remediation of students in difficulty, we used a mixed methods approach, incorporating the collection of both qualitative and quantitative data (Schifferdecker and Reed, 
2009). The combination of surveys at two time points with subsequent focus groups enables a broad range of perspectives to be gathered, and then enhanced by in-depth elaboration and clarification. Each method was approved by the school's Institutional Review Board (research ethics committee), and all participants gave informed consent.

\section{Surveys}

We administered anonymous surveys to each of nine cohorts at the end of their repeating semester. The survey consisted of likert-type questions canvassing students' attitudes towards the programme, and open-ended questions, asking: which elements of the programme were most helpful, and how; whether the programme helped to change the way they think about course work, and how; and an opportunity to provide other comments. A second survey was administered to five cohorts of students when they reached the third of their basic science semesters, to find out how their perceptions of the program may have changed with hindsight. This survey included open-ended questions asking: which elements of the programme they still use, and how; what did not help; suggestions for improvement; and space for other comments.

\section{Focus groups}

Focus groups are invaluable for uncovering why participants think as they do (Barbour, 2005), and for comprehending students' perceptions on different aspects of a program (Hassanien, 2007). Previous participants in the mandatory programme who were still studying in semesters 2, 3 and 4 of the basic sciences were invited to participate in focus groups of 4 to 6 students, moderated by the first author and a colleague. 16 students volunteered, 8 male and 8 female, with equal representation from each basic science semester. Prior to the sessions, participants were invited to reflect on their personal experience of the programme. Three focus groups each met for one session of about $1 \frac{1}{2}$ hours. The moderators, following standard focus group guidelines (Barbour, 2005; McNamara, 1997; Krueger, 2002), provided ground rules, and, through a series of open-ended questions, set the tone for an open discussion of students' experiences and attitudes to the programme. The sessions were recorded and transcribed verbatim. 


\section{Data Analysis}

Quantitative data was analysed using simple percentages and means (Greene et al, 2008), while qualitative responses to open-ended survey questions were analysed in conjunction with focus group data.

Focus group transcripts were analysed using a grounded-theory approach (Kennedy and Lingard, 2006), by iterative coding of utterances, and grouping into categories. The analysis for each group was cross-checked and verified by both the assistant moderator and the student participants. The codes and categories were compared across focus groups, along with responses to open-ended survey questions, and several common themes emerged. Because no new themes were emerging at the end of the third focus group session, it was decided that saturation had been reached and no further groups were scheduled (Stalmeijer et al, 2009).

While acknowledging that categories are artificial abstractions, perhaps indicating researchers' perspectives rather than descriptions of actual phenomena (Bateson, 1972; Greasley and Ashworth, 2007), and that the authors' own conceptual framework, used to design the programme itself, as described above, unavoidably colours our interpretation of the data (Bordage, 2009), we have attempted to integrate the emergent themes into a fledgling theory of remediation for at-risk medical students.

\section{Results}

The response rate for the end-of-course survey was $73 \%$ (275 of 377 participants). The majority of participants felt the programme was beneficial (mean likert score of 4.31 , where $1=$ strongly negative views and $5=$ strongly positive views), and $93 \%$ of respondents felt the programme changed the way they think about course material. Responses to the later, follow-up survey ( $37 \%$ response rate, $n=158$ ) suggest that students continued to believe that the programme was helpful, and continued to use the methods they learned.

Quantitative results showing which aspects of the programme students considered most helpful are shown in tables 1 and 2. Noteworthy here is the similarity in the students' immediate and hindsight views of what helps most: working with practice questions, creation of organized notes ('study products') and previewing before lectures, along with time management, language, critical thinking and general active study skills. The main difference is perhaps a growing appreciation of the importance of group work. However, these simple listings do not show how and why students found these ideas helpful. The 
qualitative data from both surveys and focus groups enables us to understand and extend what is shown in these tables.

Table 1: Semester 1 survey, most useful aspects of the programme

\begin{tabular}{|c|c|c|c|c|}
\hline $\begin{array}{l}\text { Favourite } \\
\text { element }\end{array}$ & Brief description & $\begin{array}{l}\text { No. of } \\
\text { responses }\end{array}$ & $\begin{array}{l}\% \text { of all } \\
\text { responses }\end{array}$ & $\begin{array}{l}\% \text { of } \\
\text { respondents }\end{array}$ \\
\hline $\begin{array}{l}\text { Working with } \\
\text { handouts }\end{array}$ & $\begin{array}{l}\text { Actively working with lecture } \\
\text { material, making study products, } \\
\text { concept maps, organizing course } \\
\text { material }\end{array}$ & 129 & $24 \%$ & $47 \%$ \\
\hline $\begin{array}{l}\text { Working with } \\
\text { MCQs }\end{array}$ & $\begin{array}{l}\text { Learning from MCQs, writing } \\
\text { MCQs, practice questions, test- } \\
\text { taking skills }\end{array}$ & 120 & $22 \%$ & $44 \%$ \\
\hline Preview & $\begin{array}{l}\text { Key word lists, activating prior } \\
\text { knowledge, attention to } \\
\text { definitions }\end{array}$ & 72 & $13 \%$ & $26 \%$ \\
\hline Time management & $\begin{array}{l}\text { effective scheduling, switching } \\
\text { subjects frequently, minimizing } \\
\text { inefficiency }\end{array}$ & 52 & $10 \%$ & $19 \%$ \\
\hline General study skills & Review, active learning, memory & 37 & $7 \%$ & $13.5 \%$ \\
\hline Group work & Discussion, peer support & 35 & $6.5 \%$ & $13 \%$ \\
\hline Language & $\begin{array}{l}\text { Medical terminology, definitions, } \\
\text { summary }\end{array}$ & 35 & $6.5 \%$ & $13 \%$ \\
\hline Critical thinking & $\begin{array}{l}\text { Asking questions, explicit } \\
\text { reasoning, analogy, inference }\end{array}$ & 34 & $6.3 \%$ & $12.5 \%$ \\
\hline Other & $\begin{array}{l}\text { Math, listening skills, learning } \\
\text { styles, repetition, reflection }\end{array}$ & 22 & $4 \%$ & $8 \%$ \\
\hline
\end{tabular}

*some students list several items 
Table 2: Semester 3 follow-up survey, elements of the programme useful in the longer-term

\begin{tabular}{|c|c|c|c|c|}
\hline Still Use & Brief description & $\begin{array}{l}\text { No. of } \\
\text { responses }\end{array}$ & $\begin{array}{l}\text { \% of } \\
\text { responses }\end{array}$ & $\begin{array}{c}\% \text { of } \\
\text { respondents }\end{array}$ \\
\hline $\begin{array}{l}\text { Working with } \\
\text { handouts }\end{array}$ & $\begin{array}{l}\text { Organizing material/Concept } \\
\text { maps/charts, } \\
\text { Outlining/summary, Note- } \\
\text { taking/key-words }\end{array}$ & 46 & $30 \%$ & $79 \%$ \\
\hline $\begin{array}{l}\text { Working with } \\
\text { MCQs }\end{array}$ & $\begin{array}{l}\text { Approach to MCQs, } \\
\text { understanding questions, } \\
\text { practice MCQs, test-taking }\end{array}$ & 27 & $18 \%$ & $47 \%$ \\
\hline Preview & $\begin{array}{l}\text { Activating prior knowledge, } \\
\text { lecture preparation }\end{array}$ & 27 & $18 \%$ & $47 \%$ \\
\hline Group work & $\begin{array}{l}\text { Collaborative learning, group } \\
\text { discussion, Support from fellow } \\
\text { repeaters }\end{array}$ & 16 & $11 \%$ & $28 \%$ \\
\hline $\begin{array}{l}\text { Time } \\
\text { management }\end{array}$ & $\begin{array}{l}\text { effective scheduling, switching } \\
\text { subjects frequently }\end{array}$ & 12 & $8 \%$ & $21 \%$ \\
\hline Critical thinking & $\begin{array}{l}\text { Asking questions, Integrating } \\
\text { material }\end{array}$ & 11 & $7 \%$ & $19 \%$ \\
\hline $\begin{array}{l}\text { General study } \\
\text { skills }\end{array}$ & $\begin{array}{l}\text { Review, active learning skills, } \\
\text { flexible approach }\end{array}$ & 6 & $4 \%$ & $10 \%$ \\
\hline Language & $\begin{array}{l}\text { Definitions/Analogies, Medical } \\
\text { Terminology }\end{array}$ & 5 & $3 \%$ & $9 \%$ \\
\hline Self-confidence & & 2 & $1 \%$ & $3 \%$ \\
\hline
\end{tabular}

*some students list several items

From the students' perspective, the success of the programme is attributable to a blend of cognitive and affective factors, that can be grouped under several distinct, but deeply intertwined, themes.

The first of these relates to the changes in ways of thinking and studying brought about through the specific course elements listed in the tables. Students recognize that it is the combination of the skills explored in the programme that leads them to become more active learners. They claim to have moved beyond rote memorization and passive learning, and now understand concepts as relationships, becoming more able to integrate the content of their various courses and apply their knowledge in different contexts. For example, "being able to work through the concept from the very basic definition to application to multiple choice questions involves all the study tips and strategies that were presented." Students said that they "learned to understand concepts as relationships, not just as strings of minute details," and that the program "was wonderful in helping me understand the material, not just memorize what's in the lecture notes." 
These changes in habits are accompanied by their development as flexible, reflective learners. The students came to appreciate being shown how to recognize when they don't know the course material well enough, and how to adopt different ways to approach their studies. "Before it felt like you're just flooring the gas and just trying so hard, and someone taps on the window and says 'you know there's an easier way'." "So now, when we get this material, there's no panic, you know exactly what to do, you're trained properly." Students gained the confidence to "adapt different approaches for different subjects," and appreciated being "encouraged to make a lot of changes until you find something that works for you." Indeed, many reflected that, "Without this programme, I don't think I would have changed anything," but that afterwards, "I became more humble, and more willing to try different things, to make myself get better."

Students stressed the importance of attitude and motivation. They feel that failure was hard to accept, "repeating was definitely a downer," and commonly cited initial lack of motivation and resistance to both the need to repeat the semester and the mandatory programme, mentioning colleagues who could not get past this antipathy and subsequently failed out of the school. They recognise that the "individual has to accept the need for change", and has to "stop blaming myself and others, and start blaming the process that I was using." The program "didn't allow me to wallow" and "continually builds up our confidence," acting as "a springboard for my drive to master all that I need." This changing of attitude is summed up thus: "At the beginning I felt that I was required to go to these cognitive skills sessions. At the end I came because I wanted to, and that made a difference."

Many commented that the programme needs to be mandatory. "Mandatory cognitive skills is the most annoying thing in the world, but it really did help keep me focused. I know I wouldn't have attended if it wasn't mandatory, and I would have really missed out." Indeed, failure to enforce this can be problematic, since "if kids are not showing up and they don't care about it, the whole infrastructure starts breaking down."

Consequently, the role of the teacher matters, and requires a combination of rigorous expectations, facilitation skills and honesty. It's important that the teacher points out deficits in study habits, holds students accountable, and makes sure everyone participates. The teacher needs to build confidence, "He never gave up on us, even though we may have given up on ourselves," and yet have high expectations: "There's a discipline here and it's enforced; you have to explain why you think that person's wrong, or why you think 
you're right." Students felt that a key factor was "just being surrounded by an environment that teaches how to think."

A major part of that environment is the group, which provides essential emotional and cognitive support. "The nature of the group was incredibly important to the entire process." "The group was inspiring," as "they were the ones who kept me motivated throughout the semester." Students acknowledge that the stability of the group and participation of all members is invaluable. They frequently comment that the sharing of opinions exposes them to new ways of thinking: "I was able to understand a concept more clearly through different points of view of the group. Even just listening to them talking was very helpful in analysing how I think and how I learn." Indeed, many state that this is their most positive experience ever of group study.

Unavoidably, students do get labeled as repeaters. "The whole social aspect of the school is talking with your friends about what you're studying," but "they don't know what it feels like to fail something." Dealing with this identity as a repeater can be challenging, but the programme helps by introducing them to a support group of peers facing the same situation. Indeed, the students come to love the label: "We're the underdogs. I always root for the underdogs. If it makes me want to put in that extra $10 \%$, that extra hour, then sure, call me a repeater, but I'm getting my job done better than I would have if I didn't repeat."

There were very few negative comments, with the very occasional statement that "simply repeating first semester was enough", and that some of the suggested skills were "an irrelevant waste of time". Overall, though, it seems that the majority of participants appreciated the programme, and retained long-term benefits: "I have just taken and conquered the Step (United States Medical Licensing Exam). I definitely believe that those mandatory weekly sessions for repeaters were beneficial. It provided a very supportive and encouraging environment, in addition to great test taking and study strategies."

\section{Discussion}

The design of this programme drew upon multi-disciplinary educational principles (Winston et al, 2010), and applied them to a very specific group of students. For most at-risk medical students, failure at medical school comes as a shock after previously successful academic careers, and is initially confronted with some degree of denial, which is typical of weak students in most areas of education. However, they also represent a unique group: rarely does the "atrisk" educational literature focus on academically-oriented students of 
above-average intelligence, and this study into their perspectives of remediation provides valuable insights.

\section{Changing Students' Habits and Beliefs}

The results clearly answer the first aim of this study: this programme changes students' beliefs about what is required of them as medical students, and helps participants gain insight into how this change is attained. They are able to recognise that the elements of the programme overlap extensively: the cognitive and the affective, the individual and the group. The students say it is important to make participation mandatory, and most would not have attended otherwise. They recognize the need to address their identity as repeaters, to deal with self-esteem issues and to accept responsibility for failure. Students believe that teachers should maintain high expectations, both respecting and challenging learners, while the stable group of peers provides essential cognitive and emotional support. Over the course of the programme, students come to understand how they learn, explore why new ideas are effective, and perceive the relevance to their immediate situation. They see that critical thinking is used in answering multiple-choice questions, language and relationships are essential for understanding and integrating course material, and careful time management underlies all their efforts. All this enables students to overcome their initial resistance, and believe they can exert control over their own academic performance.

\section{Towards a Theory of Remediation}

An important outcome is that students appear to have absorbed and claimed as their own many of the views of learning the programme tries to teach, and that support for the students' views of what works for them can be found throughout the education literature. From these perspectives, we can move towards our second aim, a better understanding of the theory and practice of remediation.

For example, emotion and intellect are inseparable (Bateson, 1972; Vygotsky, 1986), and attribution of academic performance to controllable causes is known to be related to positive cognitive and affective outcomes (Ferla et al, 2008), both prerequisites for students to make constructive cognitive changes (Saxena et al, 2009; Geertsma, 1977). However, many students fail to reflect on performance unless required (Albanese, 2006), and emotional factors often prevent weak students from seeking help (Hattie and Timperley, 2007). By mandating that these students participate in a remedial programme that acknowledges both their vulnerability and their autonomous adult agency (Dahlberg et al, 2009), we create an 
opportunity for them to approach the challenges of medical school more effectively.

Medical students frequently have difficulties organizing and integrating large amounts of information (Paul et al, 2009), and applying this information to new contexts, especially exams. Given that generating classes and exposing conceptual relationships are fundamental cognitive acts (Dewey, 1910; Maturana and Varela, 1987), and that the testing effect (retrieval practice, answering test questions) is such a potent learning device (Pashler et al, 2007; Thalheimer, 2003), it is encouraging that our students perceive that this programme helps with this conceptual integration, by exposing them to various methods of working with basic science course material and practice exam questions.

Indeed, student cognitions about learning profoundly influence study strategies (Ferla et al, 2008), while consciousness of one's thinking and learning limitations creates the possibility for change (Vygotsky, 1986; Papadimos and Murray, 2008). Various researchers have found that overcoming initial resistance (McQueen and Webber, 2009; Star and Hammer, 2007) and engaging in new ways of learning (Geertsma, 1977; Torre et al, 2007) helps create an 'empowering awareness of previously unimagined capacities' (Nillsen, 2004). Thus, the positive shift in attitude shown over the duration of the programme is an example of the increase in intrinsic motivation, enthusiasm and commitment that is known to lead to growth in learner autonomy and positive academic outcomes (Vansteenkiste et al, 2009; Kannan and Miller, 2009).

The students are clear that the learning environment, which includes both the teacher and the group of learners, is essential in producing these changes. The teacher needs to understand both the students and their context (Dewey, 1910), respond adaptively to variations in both (Corno, 2008), maintain high expectations, and provide constructive feedback (Brown and Gray, 2008; Thalheimer, 2008).

A study group can either enhance or undermine motivation (van Etten et al, 2008). As our students pointed out, it is important to ensure participation, and allow time for the development of group cohesion (Brigman and Webb, 2007), to create the psychologically safe environment and sense of belonging conducive to reflection and sharing of experiences (Muraskin, 1997; Rimmershaw, 1999; van Gennip et al, 2009; Wald et al, 2009). It then becomes possible to take advantage of cognitive aspects of collaborative learning, whereby learners become aware that others think differently, through challenges, exchange of ideas and joint construction of knowledge, thus gaining insight into, and developing, their own thinking Dewey, 1910; Rogoff, 1999; Sampson and Clark, 2009). 'Language is a 
necessary tool for thinking' (Dewey, 1910; Mercer, 2000): making reasoning explicit helps remove misunderstandings (Dewey, 1910; Postholm, 2008), and reflection on use of language helps in cognitive development (Anderberg et al, 2008).

So, it is a complex interplay of elements that results in successful remediation practice, and any theory of remediation needs to account for this complexity. Because transformations of human beings and their educational and psychological processes remain unpredictable (Kauffman, 1995; Purdy and Morrison, 2009), and all conceptual frameworks have limitations (Bordage, 2009; Hofstadter, 1979), we are unlikely to find a "grand unified theory" (Alexander et al, 2009). Still, we can say that education and learning are complex processes (Jörg et al, 2007; Lonka et al, 2008), and that any theory must take into account the factors that influence the pedagogic setting (Dewey, 1916; Leach and Moon, 1999). Context shapes everything (Bateson, 1979), and here the context includes the thinking, feeling individuals, the group, the teacher, the specific course content, the wider school curriculum, and more; a complex, interwoven environment. Further, since the participants constitute part of each other's context, they are complexly interrelated in a continuous process of mutual shaping and changing. Neither the constructivist focus on individual transformation, nor the sociocultural view of participation in a group that subsumes the individual, seem adequate to describe these relationships (Hager, 2008). Perhaps complexity theory, whereby the student and her environment are 'structurally coupled and mutually specified' (Maturana and Varela, 1987), offers the best hope of a deeper understanding.

Perhaps, then, the key message from these students is that successful remediation requires learners to understand themselves and their environment, and to recognize that they affect and are affected by the whole context of learning. Educators need to facilitate this exploration.

\section{Limitations}

A potential weakness of this study is that the lead author is both designer of and a teacher on the programme. The benefit of additional insight gained from practitioner research can be compromised when one has a vested interest in successful outcomes. We have strived to maintain objectivity, and have elicited critique and corroboration from both colleagues and students. Another limitation of this study is that students who chose to return surveys and volunteer for focus groups may have a more favourable attitude to the programme (Stalmeijer et al, 2009). However, given the consistency of the views, we believe they are representative of those students who succeed, 
enabling us to comment on what does work, even if we are less sure about what doesn't work for some students. Finally, it is important to remember that the theory developed here is based on student perspectives, rather than empirically tested hypotheses.

\section{Conclusion}

The first aim of this study seems to be answered. Most participants in our mandatory programme for students repeating first semester agree that the programme has made a major contribution to their academic success, helping them to become more active, flexible and reflective learners. It appears they believe that it works because of the combination of elements in the programme, including that it is mandatory, in a group setting, and provides emotional and motivational support, cognitive challenges, and specific techniques for changing their ways of thinking about both the medical school course material and themselves as learners.

This blend of elements suggests that, just as with all education and learning, remediation is a complex process that must take into account both general and specific knowledge of learners and learning. Before it is possible to generalize beyond the immediate context, more work is needed, including detailed exploration of the role and perspectives of the teachers in this programme, fine-grained analyses of how different elements combine in the classroom, and application of the methods to other at-risk groups within and beyond medical education.

However, we are encouraged that the students' perspectives, when combined with previous research findings, can inform our theory and practice: remediation needs to challenge students' conception of learning (Mattick and Knight, 2007), works best in groups, with skilled facilitators (Saxena et al, 2009; Muraskin, 1997), and must take into account cognitive and affective factors (Kozanitis et al, 2007; Lonka et al, 2008) and the complex interplay of learner and environment. We are optimistic that this ongoing work will allow us to return an integrated theory of remediation to the various educational disciplines from which we have garnered so many ideas (Eva, 2008).

\section{References}

Albanese MA. 2006. Crafting the reflective lifelong learner: why, what and how. Med Educ; $40: 288-290$

Alexander R, Badenhorst E, Gibbs T. 2005. Intervention programme: a supported 
learning programme for educationally disadvantaged students. Med Teach;27(1):66-70

Alexander PA, Schallert DL, Reynolds RE. 2009. What is learning anyway? A topograph ical perspective considered. Educ Psychol; 44(3):176-192

Allan J, Clarke K. 2007. Nurturing supportive learning environments in higher educa tion through the teaching of study skills: to embed or not to embed? Int J Teach Learn Higher Educ;19(1):64-76

Anderberg E, Svensson L, Alvegård C, Johansson T. 2008. The epistemological role of language use in learning: a phenomenographic intentional-expressive approach. Educ Res Rev;3:14-29

Barbour RS. 2005. Making sense of focus groups. Med Educ;39:742-750

Bateson G. 1972. Steps to an ecology of mind. Chicago: University of Chicago Press

Bateson G. 1979. Mind and nature: a necessary unity. New York: Dutton

Bordage G. 2009. Conceptual frameworks to illuminate and magnify. Med Educ; 43:312-319

Brigman G, Webb L. 2007. Student success skills: impacting achievement through large and small group work. Group Dyn;11(4):283-292

Brown J, Gray LE. 2008. Helping students to gain confidence in personal performance. Med Educ; 42:517-518

Bruner J. 1999. Culture, mind and education. In Moon B, Murphy P, editors. Curriculum in context. The Open University, London: Paul Chapman Publishing; p. 148-178

Burns ER. 2006. Learning syndromes afflicting beginning medical students: identification and treatment - reflections after forty years of teaching. Med Teach;28(3):230233

Cao L, Nietfield J. 2007. College students' metacognitive awareness of difficulties in learning the class content does not automatically lead to adjustment of study strate gies. Aust J Educ Dev Psychol;7:31-46

Cleland J, Arnold R, Chesser A. 2005. Failing finals is often a surprise for the student but not the teacher: identifying difficulties and supporting students with academic difficulties. Med Teach;27(6):504-508

Cobb P. 1999. Where is the mind? In: Murphy P, editor. Learners, learning \& assess ment. The Open University, London: Paul Chapman Publishing; p135-150

Corno L. 2008. On teaching adaptively. Educ Psychol; 43(3):161 - 173

Dahlberg K, Todres L, Galvin K. 2009. Lifeworld-led healthcare is more than patient-led care: an existential view of well-being. Med Health Care Philos; 12(3):265-271

Devoe P, Niles C, Andrews N, Benjamin A, Blacklock L, Brainard A et al. 2007. Lessons learned from a study-group pilot program for medical students perceived to be 'at risk'. Med Teach;29(2):e37-e40

Dewey J. 1910. How we think. New York: DC Heath and Co 
Dewey J. 1916. Democracy and education: an introduction to the philosophy of education. New York: Macmillan

Dolan S, Mallott DB, Emery JA. 2002. Passive learning: a marker for the academically at risk. Med Teach;24(6):648-649

Eva KW. 2008. The cross-cutting edge: Striving for symbiosis between medical education research and related disciplines. Med Educ; 42:950-951

Ferla J, Valcke M, Schuyten G. 2008. Relationships between student cognitions and their effects on study strategies. Learn Individ Differ;18(2):271-278

Frellsen SL, Baker EA, Papp KK, Durning SJ. 2008. Medical school policies regarding struggling medical students during the internal medicine clerkships: results of a national survey. Acad Med ;83(9):876-881

Geertsma RH. 1977. A special tutorial for minority medical students: an account of a year's experience. J Med Educ; 52(5):396-403

Goldfinch J and Hughes M. 2007. Skills, learning styles and success of first-year undergraduates. Active Learning in Higher Education; 8(3):259-273

Greasley K, Ashworth P. 2007. The phenomenology of 'approach to studying': the university student's studies within the lifeworld. Br Educ Res J; 33(6):819 - 843

Greene JA, Azevedo R, Torney-Purta J. 2008. Modeling epistemic and ontological cognition: philosophical perspectives and methodological directions. Educ Psychol; 43(3): $142-160$

Hager P. 2008. Learning and metaphors. Med Teach; 30(7):679-686

Hassanien A. 2007. A qualitative student evaluation of group learning in higher education. Higher Education in Europe; 32(2):135 - 150

Hattie J, Timperley H. 2007. The power of feedback. Rev Educ Res;77(1):81-112

Hauer KE, Teherani A, Kerr KM, Irby DM, O'Sullivan PS. 2009. Consequences within medical schools for students with poor performance on a medical school standardized patient comprehensive assessment. Acad Med, 84(5):663-668

Hofstadter DR. 1979. Gödel, Escher, Bach: an eternal golden braid. Harmondsworth: Penguin Books

Jörg T, Davis B, Nickmans G. 2007. Towards a new, complexity science of learning and education. Educ Res Rev;2:145-156

Judd TP. 1985. A research based approach to students in academic difficulty: charac teristics and intervention. ASHE 1985 Annual Meeting Paper. Rockland NY

Kannan J, Miller JL. 2009. The positive role of negative emotions: fear, anxiety, conflict and resistance as productive experiences in academic study and in the emergence of learner autonomy. Int J Teach Learn Higher Educ; 20(2):144-154

Kauffman SA. 1995. At home in the universe: the search for the laws of selforganization and complexity. New York: Oxford University Press 
Kennedy TJT, Lingard LA. 2006. Making sense of grounded theory in medical educa tion. Med Educ; 40:101-108

Kozanitis A, Desbiens JF, Chouinard R. 2007. Perception of teacher support and reaction towards questioning: its relation to instrumental help-seeking and motivation to learn. Int J Teach Learn Higher Educ;19(3):238-250

Krueger RA. 2002. Designing and conducting focus group interviews. University of Minnesota. http://www.nrsweb.org/docs/Krueger-FocusGroupInterviews.pdf

Lave J, Wenger E. 1991. Situated learning: legitimate peripheral participation. Cambridge: Cambridge University Press

Leach J, Moon B. 1999. Recreating pedagogy. In: Leach J, Moon B, editors. Learners and pedagogy. The Open University, London: Paul Chapman Publishing; p. 265-276

Lonka K, Sharafi P, Karlgren K, Masiello I, Nieminen J, BirgegÅrd G, Josephson A. 2008. MED NORD - A tool for measuring medical students' well-being and study orientations. Med Teach; 30(1):72-79

Loyens SMM, Rikers RMJP, Schmidt HG. 2007. The impact of students' conceptions of constructivist assumptions on academic achievement and drop-out. Stud High Educ;32(5):581-602

Mattick K, Knight L. 2007. High-quality learning: harder to achieve than we think? Med Educ; 41:638-644

Maturana HR, Varela FJ. 1987. The tree of knowledge. Boston (MA): Shambhala Publications Inc

McNamara C. 1997. Basics of conducting focus groups. Free Management Library http://www.managementhelp.org/evaluatn/focusgrp.htm

McQueen $\mathrm{H}$ and Webber J. 2009. What is very important to learning? A student perspective on a model of teaching and learning. J Fur High Educ;33(3):241-253

Mercer N. 2000. Words \& minds - how we use language together. London: Routledge

Muraskin L. 1997. Best practices in student support services: a study of five exempla ry sites. Follow-up study of student support services programs. Washington DC: SMB Economic Research Inc, and US Dept of Education

Nillsen R. 2004. Can the love of learning be taught? J University Teaching \& Learning Practice; 1(1):1-9

Papadimos TJ, Murray SJ. 2008. Foucault's "fearless speech" and the transformation and mentoring of medical students. Philos Ethics Humanit Med; 3(12):2-26

Pashler H, Bain PM, Bottge BA, Graesser A, Koedinger K, McDaniel M, Metcalfe J. 2007. Organizing instruction and study to improve student learning. IES Practice Guide, US Dept Education. http://ies.ed.gov/ncee/wwc/pdf/practiceguides/20072004.pdf

Paul G, Hinman G, Dottl S, Passon J. 2009. Academic development: a survey of academic difficulties experienced by medical students and support services provided. Teach Learn Med;21(3):254 - 260 
Postholm MB. 2008. Group work as a learning situation: a qualitative study in a university classroom. Teachers and Teaching;14(2):143-155

Reynolds J, Caley L, Mason R. 2002. How do people learn? London: Chartered Institute of Personnel and Development

Rimmershaw R. 1999. Using conferencing to support a culture of collaborative study. J Comput Assist Learn; 15:189-200

Rogoff B. 1999. Cognitive development through social interaction: Vygotsky and Piaget. In: Murphy $\mathrm{P}$, editor. Learners, learning \& assessment. The Open University, London: Paul Chapman Publishing; p. 69-82

Sahlström F. 2009. Conversation analysis as a way of studying. Scand J Educ Res;53(2):103-111

Saltmarsh D and Saltmarsh S. 2008. Has anyone read the reading? Using assessment to promote academic literacies and learning cultures. Teach Higher Educ;13(6):621632

Sampson V, Clark D. 2009. The impact of collaboration on the outcomes of scientific argumentation. Sci Educ; 93(3):448-484

Saxena V, O'Sullivan PS, Teherani A, Irby DM, Hauer KE. 2009. Remediation tech niques for student performance problems after a comprehensive clinical skills assess ment. Acad Med;84(5):669-676

Sayer M, Chaput de Saintonge M, Evans D, Wood D. 2002. Support for students with academic difficulties. Med Educ;36:643-650

Schifferdecker KE and Reed VA. 2009. Using mixed methods research in medical education: basic guidelines for researchers. Med Educ; 43:637-644

Slotnick HB. 1981. Identifying and remediating specific deficiencies of entering medical students. J Med Educ;56(2):91-102

Stalmeijer RE, Dolmans DHJM, Wolfhagen IHAP, Scherpbier AJJA. 2009. Cognitive apprenticeship in clinical practice: can it stimulate learning in the opinion of students? Adv Health Sci Educ;14(4): 535-546

Star C and Hammer S. 2007. Teaching generic skills: eroding the higher purpose of universities, or an opportunity for renewal? Oxford Rev Educ; 34(2):237-251

Tekian A, Jalovecky MJ, Hruska L. 2000. A quantitative assessment of "at risk" students and medical school performance: the importance of adequate advising and mentorship. Paper presented at annual meeting of American Educational Research Association, New Orleans

Thalheimer W. 2003. The learning benefits of questions. http://www.work-learning.com/ma/PP_WP003.asp

Thalheimer W. 2008. Providing learners with feedback - part 1: research-based recommendations for training, education, and e-learning. 2008.

http://www.work-learning.com/catalog/

Torre DM, Daley B, Stark-Schweitzer T, Siddartha S, Petkova J, Ziebert M. 2007. A 
qualitative evaluation of medical student learning with concept maps. Med Teach; 29(9):949-955

Van Etten S, Pressley M, McInerney DM, Liem AD. 2008. College seniors' theory of their academic motivation. J Educ Psychol; 100(4):812-828

Van Gennip NAE, Segers MSR, Tillema HH. 2009. Peer assessment for learning from a social perspective: the influence of interpersonal variables and structural features. Educ Res Rev; 4(1): 41-54

Vansteenkiste M, Sierens E, Soenens B, Luyckx K, Lens W. 2009. Motivational profiles from a self-determination perspective: the quality of motivation matters. J Educ Psychol; 101(3):671-688

Vygotsky LS. 1978. Mind in society. Cambridge (MA): Harvard University Press

Vygotsky LS. 1986. Thought and language. Cambridge (MA): MIT Press

Wald HS, Davis SW, Reis SP, Monroe AD, Borkan JM. 2009. Reflecting on reflections: enhancement of medical education curriculum with structured field notes and guided feedback. Acad Med; 84(7):830-837

Weinsheimer J. 1998. Providing effective tutorial services. National Council of Educa tional Opportunity Associations, Department of Education, Washington DC

Winston KA, Van der Vleuten CPM, Scherpbier AJJA. 2010. An investigation into the design and effectiveness of a mandatory cognitive skills programme for at-risk medical students. Med Teach;32(3):236-243

Young KA. 2005. Direct from the source: the value of 'think-aloud' data in understand ing learning. J Educ Enquiry, 6(1):19-33 


\section{CHAPTER 4}

\section{The Role of the Teacher in Remediating At-Risk Medical Students}

Published as:

Winston KA, Van Der Vleuten CPM, and Scherpbier AJJA. 2012. "The Role of the teacher in remediating at-risk medical students", Medical Teacher, 34(11):e732-42 


\section{Introduction}

With the trend towards admission of students from diverse, nontraditional backgrounds to medical education (Howe et al. 2008; Jolly et al. 2008), comes increasing numbers of students who do not know what to expect or what will be expected of them (Fitzmaurice, 2010), and thus a need for increased academic support to help them succeed (Winston et al, 2010a). Common difficulties include organizing and integrating large amounts of information, test-taking and test anxiety (Paul et al, 2009), time management, ineffective study strategies, insufficient background and content knowledge, weakness in literacy and numeracy skills, and a general lack of self-regulatory, metacognitive and critical thinking skills (Winston et al, 2010b). However, these weaker students tend to avoid seeking assistance, (Devoe et al. 2007), and frequently fail a course in medical school (Winston et al, 2010b).

Students who fail are typically allowed to repeat, and yet repetition without remediation rarely leads to long term success (Mattick and Knight, 2007; Winston et al, 2010a). A handful of successful remediation programs have been reported in the medical education literature (McGrath and McQuail, 2004; Kies and Freund, 2005; Alexander et al. 2005; Saxena et al, 2009; Cleland et al, 2010), but there appears to be an absence of guidelines about how best to accomplish remediation, along with frequent calls for further research into details of effective, replicable strategies for remediation of struggling medical students (Kies and Freund, 2005; Saxena et al, 2009; Paul et al, 2009; Cleland et al, 2010).

Winston et al (2010a) describe the details of a mandatory remediation programme for students who fail their first semester at a large Caribbean medical school. Students repeating that first semester on probation, in addition to retaking basic science courses, must meet twice a week, for twelve weeks, in a small group of five or six students, with a faculty member from the school's Centre for Teaching and Learning. The key themes in the carefully designed syllabus of this remediation course, which draws on a blend of theories and research-proven techniques, include: self-regulation, metacognition and reflection; explicit, think-aloud discourse; active learning; giving and receiving feedback; application of learning processes to basic science course content; care with language; accuracy of thinking, and attention to affect and motivation. Participants have performed significantly better than students who repeated the first semester at the school prior to the introduction of this mandatory programme: pass rates have increased from $58 \%$ to $91 \%$ for examinations taken at the end of the repeated first semester $(n=511 ; p<0.0001,15$ cohorts over 5 years) and from $28 \%$ to $51 \%$ for national examina- 
tions (USMLE) taken five semesters later $(n=216 ; p<0.0001$; remaining 295 participants have yet to take USMLE).

Subsequent clarification research (Cook et al, 2008) showed that the participating at-risk medical students believe that successful remediation should be mandatory, works best in small stable groups supported by honest teachers with rigorous expectations and good facilitation skills, needs to challenge students' conceptions of learning, encourage their development as flexible, reflective learners, and must take into account a blend of cognitive and affective factors. Exploration of these students' perspectives made it clear that remediation is a complex, context-dependent process, in which elements of the learning environment - students, teachers, syllabus, school and more - all play major, mutually constitutive roles (Winston et al, 2010b).

In order for such a remediation programme to be used effectively in other contexts, it is essential to gain a deeper understanding of the role of the teachers and precisely how they affect the students' outcomes. Previous work has noted that teachers of remediation need a good understanding of the learning and assessment environment (Mattick and Knight, 2007), and should involve a teacher-student relationship that builds confidence while maintaining high expectations and challenging students' thinking (Winston et al, 2010b). However, we have found no literature at all on teachers' views of their role in effective remediation of students in difficulty in medical education, nor, indeed, in other areas of higher education. The goal here is to begin to address this literature gap, to identify the qualities of good teaching that most apply to remediation in medical education, and to relate these qualities to the broader literature on teaching expertise.

\section{The importance of the teacher}

Dewey (1938) says that the learning environment includes the conditions, materials, people and total social set-up with which an individual interacts, and teachers are certainly an element of any pedagogic setting. There seems little doubt that the quality of teaching influences student learning and achievement (Patel et al, 2009; McNeill, 2009; Thompson et al, 2008), that teachers are key factors in both small group learning (Jaarsma et al, 2008; Postholm, 2010) and successful student support programs (Muraskin, 1997), and that academic advising can impact student performance (Tekian et al, 2000). Students perceive teachers as having strong influence on their experience (Harris, 2010; Kreber et al, 2010), and both faculty and students rate intangible teacher variables, such as interest, enthusiasm and approachability, as having greatest importance for learning 
(Lammers and Smith, 2008). And yet, Foster (2010) found no association between specific tutors and either student attrition or improvement of weaker students. Indeed, there is considerable uncertainty about which teacher characteristics positively affect student achievement (Konstantopolous and Chung, 2011), and about the precise role of teachers in supporting at-risk students (Barkas, 2011).

Considerable work in education research has shown that teachers' beliefs and conceptions affect their teaching practice (Bolhuis and Voeten, 2004; Song et al, 2007; Mahlios et al, 2010; Feucht and Bendixen, 2010), which in turn influences students' help-seeking strategies (Kozanitis et al, 2007) and approaches to learning (Prosser et al, 2003; Kember et al, 2008), and, ultimately, student outcomes. Thus, in order to understand the attributes and practices of teachers required for excellence in assisting at-risk medical students, we need to explore teachers' beliefs (Pajares, 1992), using sources that include practitioners' own descriptions of their work (Kelchtermans, 2009; Fitzmaurice, 2010). Hopefully, by drawing upon the wisdom of practice (Shulman, 2007), we can develop a deeper understanding of the key elements that inform the pedagogical content knowledge important to remediation in medical education (Shulman, 1986, 1987).

\section{Aims}

The current work aims to build towards a practical theory of remediation in medical education, and, in particular, to examine the role of the teacher in this process. Thus, the main research question is:

What is the role of the teacher in remediation of struggling medical students?

This broad question can be broken down into sub-questions that allow for exploration of different perspectives that may steer us towards a deeper understanding of remediation. In previous work, student focus groups suggested that the teacher is one of several key factors in the complex process of remediation (Winston et al, 2010b). To probe deeper into the student view, we aim to answer the following question:

How do students believe the teachers influence student success?

The teachers' voice is essential to understanding their role, and thus we ask: 
How do remedial teachers in medical education see their role? What do they perceive to be the most effective elements in their remediation of at-risk medical students?

Finally, we look at the student performance data, asking:

Are there any differences in outcomes of students allocated to different teachers? If so, how can these be explained?

The results of these explorations will then be examined for links to theoretical perspectives in an effort to continue to build essential bridges between theory and practice (Sparapani et al, 1996; Kaufman, 2003). It is, of course, important to acknowledge our own perspectives (Dewey, 1938): theory building inevitably depends on the conceptual framework used by researchers. Since education and learning are inherently complex processes (Jörg et al, 2007; Winston et al, 2010b) in which all elements of the pedagogic setting are mutually constitutive (Varela et al, 1992), we take on a complexivist framework (Jörg et al, 2007), which we hope will enable us to go beyond the limitations of any single conceptual framework and draw upon a series of conceptual lenses (Bordage, 2009) to develop a deeper understanding of the complexity of remediation.

\section{Methods}

A complexity framework requires developing understanding through the interactions between the related components of a system (Thomas, 2006), so the study of complex interactions benefits from a mixed methods approach (Kennedy and Lingard, 2006; Schifferdecker and Reed, 2009). Here we attempted the triangulation of some quantitative and considerable qualitative data to seek a valid balance of stakeholders' voices (Denzin and Lincoln, 2005).

Firstly, a brief survey was sent electronically to 310 students who had successfully completed our remediation programme when they repeated their first semester at our medical school (Winston et al, 2010a). These were all current students at the school (in semesters 2 through 10), many of whom had moved on to clinical rotations by the time of this study. The survey asked students to name their teacher during the programme, to what extent that teacher had influenced the outcome of their participation (likert-type scale), and to describe what that teacher did that was helpful and how that influenced their learning. A limitation of this approach is that, lacking contact details of those who failed out of the school, the views of unsuccessful students are not represented. However, given the appreciative nature 
of this part of the enquiry, we feel these successful students' views contribute to our understanding of what makes remediation work.

At the time of this research six faculty members had been teachers on the programme, and all students included in the data here were members of a group taught by one of these six teachers. One declined to participate, and one is the first author of this paper (henceforth simply ' $\mathrm{KW}$ '). The remaining four were sent questionnaires, which asked for demographic data, and included a series of open-ended questions inviting views on the remediation programme and their role within it. The teachers were then invited to participate in one-hour flexible semi-structured interviews (Feucht and Bendixen, 2010), for which the questions were formulated to explore and clarify the questionnaire responses: three interviews were conducted, while one teacher chose to engage in written dialogue to answer the interview questions. $\mathrm{KW}$ also completed responses to both the questionnaire and interview questions.

The inclusion of data from KW requires some explanation. The attempt to understand the teachers' views is a phenomenological approach, an exploration of lived experience aiming to discover, describe and classify the teachers' conceptions of their reality (Varela et al, 1991; Allan and Clarke, 2007). In all qualitative research, results are suffused with researcher perspectives (Denzin and Lincoln, 2005): the researcher is an intrinsic part of the method, upon whose understanding of the field the outcomes of interviews depend (Kvale, 1996). Further, there is a need for insider understanding, for selfstudy research that is essential for the development of practical wisdom (Postholm, 2008; Lunenberg and Korthagen, 2009). Thus, given that $\mathrm{KW}$ is both designer of and teacher in this programme, any attempt to claim objectivity would surely ring hollow: neither data collection nor analysis can be neutral (Mauthner and Doucet, 2003), both are influenced by the researchers, and here we admit and embrace the inevitable inclusion of researcher perspectives.

We believe that this does not exclude analytical rigour. The phenomenological method involves looking for constants among varieties of experienced phenomena to construct descriptive categories of collective understanding (Kvale, 1996; Greasley and Ashworth, 2007). The qualitative data from both students and teachers was initially subjected to bottom-up analysis, with comments coded and grouped into pools of related meaning (Harris, 2010). These pools were then further abstracted and refined to derive themes that could be analysed top-down for comparison of new findings with previous research and the extant literature. Finally, the findings were crosschecked and verified by the participants (Kitto, 2008).

The third method in this triangulation approach was a quantitative analysis of the short- and longer-term outcomes of the students, 
grouped according to which teacher they worked with during their participation in the program, the goal being to determine whether any differences in perspectives could be correlated with differences in objective performance.

The School's IRB has approved this research project. All participants signed an informed consent form. Identities have been kept confidential and removed from all the presented data.

\section{Results}

In qualitative research, where procedural rigour and reflexivity are essential (Mauthner and Doucet, 2003; Kitto, 2008), and boundaries between data collection and analysis are blurred (Pope, 2000), there is inevitably some overlap between methods and results. So, in an attempt to render the interpretative process a little more visible, our results are presented in the order they were found.

\section{Students' views}

It is important to note that allocation of students to groups in the remediation course (and thus to specific teachers) is essentially random: for scheduling purposes, we make use of their laboratory group designations, which are random. The 188 students who responded to the survey (61\% response rate) were spread in approximate proportion to the number of students taught by each teacher. When asked whether their teacher influenced their outcomes, the responses were: strongly positive influence, $76 \%$; somewhat positive influence, 20\%; no influence at all, 3\%; somewhat negative influence, $1 \%$; strongly negative influence, $0 \%$. Clearly, then, the students believe that their teacher makes a difference, and for the better.

For all six teachers, students' made similar comments on how their teachers helped their learning. The terms encouragement and motivation featured prominently, as did approachability and honesty. These students had failed, and appreciated the support their teachers provided:

"She was very supportive and encouraged us to succeed despite minor setbacks."

"He always managed to help me bring my self-esteem and confidence level up."

They stressed the importance of listening and advising, of simply being interested in them: 
"He consistently asked us how we were doing, was interested in our progress, and showed a sincere desire to help us pass."

Facilitation skills were acknowledged by many respondents:

"She always made sure everyone participated," and "gave the group the opportunity to discuss the answers and possible explanations, guiding us so the session does not go off topic," while remaining "sensitive to our individual needs, identifying weaknesses and suggesting changes to overcome them."

There were many comments about specific elements of the course, and the teachers' role in enforcing them, while also allowing some student flexibility:

"He required us to work outside of our comfort zone and try techniques we weren't accustomed to, and provided the foundation for me to figure out what worked best for me."

Frequently mentioned was the importance of challenging students' thinking and holding them accountable for details:

"He expected us to perform at a high level and led us very far in our thinking in a very short time. Making us pay attention to all details and pick out words we didn't understand was very beneficial because now I don't let other things slide."

"He makes you explain things step by step, and asks questions that keep you focused on the problem. It allows you to see flaws you wouldn't have otherwise."

\section{Teachers' views}

The teachers' questionnaire and interview responses conveyed a rich description of a complex role consisting of a broad range of behaviours and attitudes. All five participants shared similar views, and all followed the same course syllabus and handbook (available by request from first author) with their students. The following description provides a flavour of these teachers' shared conceptions of the essential aspects of their work.

There was a shared sense of purpose, a common belief in the value of the course for repeating students: 
"We have to believe in what we're doing, enjoy what we're doing, take responsibility for putting everything that we have agreed upon in front of them."

"There was a sense of collegiality, of mutual trust among us that I think allowed us to meet the students fully focused on what we thought we could do for them, and I don't doubt that was communicated to the students."

Key to the success of this programme is an emphasis on studentcentredness, on active learning, critical thinking, dialogue, reflection, and relevance:

"Teaching is about allowing people to discover truths through inquiry, experimentation and reflection."

"We provide a space for questioning assumptions and making them explicit, for sharing ideas and developing communication skills. The use of illustrations, analogies, examples and stories makes the process more active and enjoyable."

"Use of (medical science) curricular content as a vehicle for all exercises is fundamental to creating acceptance from students."

It seems that for this course, medical science content knowledge is helpful but not essential, whereas teaching and context expertise are both considered indispensable:

"Knowledge of how people learn, of pedagogical theory, is needed to explain why the ideas are important, and to probe deeper into methods that help them."

"Contextual knowledge is very important - the curriculum format, not necessarily details, (though content knowledge is helpful, and also helps earn students' respect), rules and regulations, the set of behaviours needed for success in this school, and medical school in general."

To successfully convey the core programme to the students, the teachers described five multi-faceted, overlapping roles that encompass and expand the behaviours described by the students. The first of these is as active facilitator, akin to 'Socrates' midwife' (Plato, 1997), key for eliciting student talk and providing a dynamic, nonintimidating learning environment that encourages both cognitive and emotional support:

"Facilitation skills are essential - enables the group to work together, ensures everyone feels their needs are met, and prevents non-beneficial discussions on unrelated topics." 
"It's a hard-working process, you're constantly working at them to maintain order and direction. You have to establish, and maintain, basic ground rules from the start."

"Facilitating - do not re-teach the content. Ask probing questions and expect students to give and explore meaningful answers."

The next role might be described as nurturing mentor, which involves advising, counseling, and demonstrating empathy, kindness and belief in the students. The students are dealing with failure and exposed vulnerability in the high-functioning environment of medical school, and this role is crucial to student trust, acceptance and motivation:

"I am a friendly, concerned, accessible, and firm mentor. I have belief in them and let them see that I have this, and care about their performance."

"I foster an atmosphere that encourages the students to feel at ease in the sessions. The fact that this program exists shows the students that we care about them, so they see it as a positive thing and they accept it."

"I should not tell them to work harder unless I know they are not diligent. I should remember that the students who are performing worst are typically working hardest."

"The students need relationships that they can trust here. I am not above discussing some of my own problems, past or present, with students, and believe it helps our relationship to do so."

However, this needs to be tempered by the disciplinarian, the strict teacher who has high expectations and demands diligence:

"Successful learning is largely a matter of self-discipline. Don't allow them to indulge in denial or half-reasoned answers; don't accept unjustified excuses."

"Ultimately, my role is to hold students accountable for their thinking and reasoning, to enable the students to become independent learners, to attain self-mastery."

"If they report things as going well, I require them to elaborate on what this means, specifically with regards to the activities that we propose."

"I believe that many students have been misled by being taught study strategies they can employ without much mental effort. There is a serious communication problem in describing just what that mental effort consists of, and successful teaching of these skills consists of overcoming that communication problem." 
Although this course is quite prescriptive, and most students have problems in common, they are still individuals, and this requires the teacher to be a keen diagnostician, who observes and listens attentively, and provides clear, honest feedback:

"I must learn to know the students, be astute, knowledgeable and observant enough to be able to identify student weaknesses and provide "remedies" as much as possible."

"Know when to ask questions, when to ask why. It's partly knowing the content, partly feeling for when they're floundering, partly recognizing body language, and watching the group, seeing what's happening."

"I have to listen carefully to what the students say, to point out alternative ways of thinking. And it's not just what's happening in the classroom, or what's happening in study time, it's what's happening at home, the boyfriend, that sort of thing."

"Provide feedback, clear and specific feedback. Comment on specific positives in their discussions, point out very specific errors in logical reasoning. You also have to catch them doing things right."

"Occasionally, I must engage in difficult conversations, in which I advise on pursuit of an altogether different career path to which they may be better suited."

Finally, these teachers talked about being a model for the behaviours they are trying to teach, the need to embody enthusiasm for learning, curiosity, critical thinking, reflective acceptance of feedback. You have to enjoy the work to do it well:

"I model ways of thinking and learning. I feel that my biggest contribution is in the area of making connections. There is an essential pleasure in seeing someone suddenly light up with understanding."

"I enjoy the relationships that form in the group, and the stability of the group, over the extended time that we get to meet with them."

"It's socially responsible work. Helping students to become physicians impacts their lives and the lives of countless people I will never know. I think that doing the job well is a very worthy aim." "Show them how to find joy and interest in the material - demonstrate a thrill at the concepts, awe at medical science. This is our gift to them, that sense of 'isn't this amazing! "' 


\section{Quantitative performance data}

The outcomes of students allocated to different teachers are presented in table 1. Teachers are labeled t 1 through t6. The fifth semester marks the beginning of the clinical part of the school's curriculum, so passing fourth semester, completion of the basic science curriculum, is taken as a long-term measure of the success of the remedial programme taken when students repeat first semester.

Table 1: Performance of students allocated to different teachers

\begin{tabular}{lccccccc}
\hline $\begin{array}{l}\text { Teac- } \\
\text { her }\end{array}$ & $\begin{array}{c}\text { teaching } \\
\text { experience }\end{array}$ & $\begin{array}{c}\text { Qualifi- } \\
\text { cations }\end{array}$ & $\begin{array}{c}\text { No. of } \\
\text { students }\end{array}$ & $\begin{array}{c}\text { MCAT } \\
\text { mean }\end{array}$ & $\begin{array}{c}\text { Mean } \\
\text { fails }\end{array}$ & $\begin{array}{c}\text { Pass } \\
\text { sem 1 }\end{array}$ & $\begin{array}{c}{ }^{*} \text { Pass } \\
\text { sem 4 }\end{array}$ \\
\hline t1 & $40+\mathrm{yrs}$ & M.Ed & 112 & 21.5 & 1.85 & $90 \%$ & $65 \%$ \\
$\mathbf{t 2}$ & $3 \mathrm{yrs}$ & MD & 39 & 22.1 & 1.71 & $80 \%$ & $49 \%$ \\
$\mathbf{t 3}$ & $39 \mathrm{yrs}$ & Phd & 25 & 20.8 & 1.76 & $92 \%$ & $60 \%$ \\
$\mathbf{t 4}$ & $3 \mathrm{yrs}$ & DVM & 90 & 21 & 1.84 & $88 \%$ & $54 \%$ \\
$\mathbf{t 5}$ & $25+\mathrm{yrs}$ & M.Ed & 124 & 20.6 & 1.84 & $93 \%$ & $69 \%$ \\
t6 & $4 \mathrm{yrs}$ & PhD & 39 & 22.3 & 1.67 & $92 \%$ & $54 \%$ \\
\hline
\end{tabular}

*Prior to this programme, $38 \%$ passed semester 4 . With the programme, overall, $61 \%$ passed sem 4. For full details see Winston et al 2010a,b

$* *$ Students may have failed $1,2,3$ or 4 courses in first semester originally. Long term success correlates with number of fails, $\mathrm{p}<0.014$.

(MCAT = Medical College Admissions Test, standardized US medical school entrance exam; sem = semester)

Short-term success of students was similar with all teachers, appeared to be unrelated to teacher qualifications ( $t 2, \mathrm{t} 3$ and $\mathrm{t} 4 \mathrm{have}$ recognized basic science content expertise), and students of all teachers performed significantly better than students without the aid of the program (Winston et al, 2010a). The one striking difference seems to be teacher experience: Pearson correlation between experience and long-term outcomes is 0.78 . Table 2 shows this clearly, and significantly. Indeed, given the measures of prior knowledge (mean number of fails during first semester and MCAT scores), one would not have expected outcomes to favour the experienced teachers. 
Table 2: Experienced vs inexperienced teachers

\begin{tabular}{lcccc}
\hline Teachers & $\begin{array}{c}\text { No. of } \\
\text { students }\end{array}$ & $\begin{array}{c}\text { MCAT } \\
\text { mean }\end{array}$ & $\begin{array}{c}\text { Mean } \\
\text { fails }\end{array}$ & $\begin{array}{c}\text { Pass } \\
\text { sem 4 }\end{array}$ \\
\hline Experienced $(\mathrm{t} 1, \mathrm{t} 3, \mathrm{t} 5)$ & 261 & 21 & 1.84 & $66 \%$ \\
Inexperienced $(\mathrm{t} 2, \mathrm{t} 4, \mathrm{t} 6)$ & 168 & 21.7 & 1.76 & $53 \%$ \\
\hline
\end{tabular}

$\mathrm{x} 2, \mathrm{p}<0.007$ that difference in passing sem 4 is due to chance.

This finding prompted us to look back at the qualitative data for any differences we may have missed. Some isolated comments hint at possible differences. For example, students described experienced teachers as 'friendly', 'pushed us outside of our comfort zone' and 'required us to try techniques'; in contrast, inexperienced teachers 'became a friend,' 'could have been meaner,' 'made us feel comfortable,' and 'allowed us to try different techniques.' The experienced teachers more strongly stressed the importance of discipline and of verbal and non-verbal language; they also expressed more uncertainty about what works best, and sought feedback from the students. The less experienced failed to mention seeking feedback, one acknowledged difficulty in providing feedback, and one discussed a growing realization of the need to push students harder.

However, the similarities between the teachers' views far outweigh any differences, and the sample size is much too small to generalize from. Still, it is worth noting that contradictions between qualitative and quantitative findings are not uncommon, and, while disconcerting, do suggest areas for further work (Schifferdecker and Reed, 2009).

\section{Discussion}

The fact that both students and teachers agree on what makes this remediation programme work exemplifies one of its greatest strengths: a shared message successfully conveyed. Drawing together the results, we can summarize the role of the teacher in remediation of at-risk medical students, as experienced by both students and teachers. These teachers need to support their students' cognitive and affective development, applying teaching expertise and contextual knowledge to a constructivist, student-centred approach that promotes self-efficacy and independence. They need to engage, motivate, observe, critique, challenge and advise their learners; they need to be curious, rigorous, flexible thinkers who are interested in their students' growth and enjoy teaching. These teachers perform five broad, interrelated roles that embody these behaviours: facilitator, nurturing mentor, disciplinarian, diagnostician and modeller of 
the skills these students need to turn failure into a successful medical school career. Unsurprisingly, the ability to play all these roles seems to improve with experience.

A broad range of extant literature documents the value of these attributes in education. The cognitive and affective are inseparable (Vygotsky, 1986; Lakoff and Johnson, 1999): engagement, motivation, and the will to learn are dependent on emotion and, when fostered, result in deep learning (Vansteenkiste et al, 2009; Taylor, 2010; McCune and Entwistle, 2011). There is good agreement that the ability to motivate, engage, explain, challenge, and connect with students are core elements of good teaching (Trigwell et al, 1999; Bartram and Bailey, 2009). Effective teachers have patience, enthusiasm, high expectations and genuine interest in their students (Hull et al, 1991; Thompson et al, 2008; Jaarsma et al, 2008; Rosenfeld and Rosenfeld, 2008). Enjoyment of teaching, conveyed to the students, matters (Confucius, 1979; Frenzel et al, 2009). In this nurturing mentor role, the teacher acts as a friendly companion who provides the psychological safety, healthy intimacy and advice that nurtures this safe environment conducive to reflection and learning (Reeve, 2009; Sibii, 2010).

Context gives meaning to words and actions (Bateson, 1979), and awareness of contextual effects on learning, especially the interconnected relationships between various parts of the curriculum, pedagogy, learners and content is essential to effective teaching (Shulman, 1986; Stooksberry et al, 2009). In constructivism, where other students are part of this context, the focus on collaboration, dialogue, metacognition and articulation of meaning enhances creative thinking and self-regulation, and thus improves student performance (Dewey, 1910; Mercer, 2000; Kaufman, 2003; Postholm, 2008; McCune and Entwistle, 2011), and this is especially important for weaker students (Brigman and Webb, 2007; Kistner et al, 2010). This combining of autonomy support and structure by studentcentred teachers is known to increase conceptual change, selfefficacy and independence (Prosser et al, 2003; Kaufman, 2003; Reeve, 2009; Mitchell, 2010): more distributed power results in more productive argument and discourse (Bloom and Volk, 2007) and enhanced pedagogical efficacy (Hmelo-Silver and Barrows, 2008).

It is the role of the facilitator to enable these constructivist dialogues, to ensure all group members are heard, to join in the discussion by challenging ideas and asking probing, Socratic questions (Martin and Arendale, 1992; Plato, 1997; Postholm, 2010; Taylor, 2010) that foster the curiosity central to reasoning (Dewey, 1910; Dyche and Epstein, 2011). The facilitator is an active participant who helps create a community of inquiry by asking for clarification, identifying connections between ideas, summarizing, and posing 
different views; the facilitator should be a disruptive influence who prevents groupthink and premature convergence of opinions by promoting wider exploration (Stoyanova and Kennedy, 2010; Sayama et al, 2011), especially important with less successful students who tend to readily agree without consideration of alternative explanations.

Many similar skills are also needed by the expert diagnostician. Teachers have to study their students, to carefully observe nuances of language, gesture and interaction to detect signs of misunderstanding (Dewey, 1910; Dewey, 1938; Mercer, 2000; Boudreau et al, 2009). A hallmark of expert educators is the ability to problematize, take significant facts as evidence, cherish error as opportunity, and to act on their diagnoses to provide feedback (Dewey, 1910; Tsui, 2009; Davidoff, 2011). Accurate, timely, specific feedback facilitates the development of self-efficacy and self-regulation, and particularly helps lower-achieving students (Harlen, 2003; Hattie and Timperley, 2007; Fenollar et al, 2007; Carless et al, 2011). It takes considerable discipline to act on feedback and change habits, so the compassion of the nurturing mentor has to be applied judiciously (Jonas, 2010), tempered by the strict disciplinarian who critiques candidly (Lim and Seet, 2007) stretches learners with required, scaffolded activities (Vygotsky, 1986; Mercer, 2000; Wilson and Bai, 2010) and demands explicit, non-vague use of language for training rigorous thinking (Dewey, 1910).

The skills required for these teacher roles overlap those the learners need to be successful students, and, ultimately, good physicians: doctors need to be trusted by their patients, critically consider evidence, context and patients' lifeworlds, and be willing to jointly construct explanations and interventions (Groopman, 2008; Fuks et al, 2009; Dahlberg et al, 2009). The relationship between a teacher and remediating students parallels the doctor-patient relationship in many ways: authentically modelling skills, attitudes and behaviours is an integral part of this work (Kreber et al, 2010; Dyche and Epstein, 2011).

To combine all these roles, an educator needs the capacity to handle complex emotional and cognitive tasks (Steiner and Peifer, 1990), to be highly adaptive, able to draw on both physical and everchanging social surroundings (Dewey, 1938; Corno, 2008). Expertise in any complex domain takes extended practice (Alexander et al, 2009), and experience is known to correlate positively with student performance (Darling-Hammond and Youngs, 2002). Inexperienced teachers may overvalue affective over cognitive student outcomes (Pajares, 1992), even while convinced of underlying principles (Bolhuis and Voeten, 2004). Understanding and practical wisdom are not the same (Aristotle, 2008): becoming an expert teacher is a 
lifelong process (Hultberg et al, 2008) requiring not only skills and competencies but also development of personal practical knowledge derived from experience of many particular situations (Aristotle, 2008; Field and Latta, 2001; Ben-Peretz, 2011). In this study, the three experienced teachers have taught a wide range of disciplines in various institutional contexts, so, although the data may be an artefact of individual differences within a small sample, the literature suggests experience should count.

This brief literature survey suggests that the teaching of remediation requires similar skills to teaching in general. However, given the skills deficits and vulnerabilities of at-risk students, especially in the context of a high pressure, fast-paced medical school environment that demands extremely high functioning, we would suggest that remediation of struggling medical students needs teachers who can bring a unique, flexible combination of roles to their daily practice. These students have previously struggled in largely anonymous, lecture-based courses, and our work suggests that the teaching of remediation cannot be considered as somehow subordinate to teaching (Barkas, 2011), nor left to the most junior faculty or student tutors, as is frequently the case, but rather requires considerable teaching expertise.

Thus far, we have given a rich description of the roles of the teachers, rather than provided a theoretical model; Wittgenstein (1967) would say we should stop there, that 'explanation' adds nothing to description. Nevertheless, drawing 'fox-like' on several theories has been shown to be applicable to the real world (Tetlock, 2005, Chinn and Samarapungavan, 2009), so here we reflect on ideas that may help towards our construction of a theory of remediation.

Previous work has shown that successful remediation is a complex, context-dependent process, ideally delivered as a mandatory course to small groups. It should be based upon a blend of constructivist, student-centred techniques that acknowledge the importance of both cognitive and affective factors in the development of selfregulation, metacognition and critical thinking (Winston et al, $2010 a, b)$. Now we can add the five teacher roles that mediate this process: facilitator, nurturing mentor, disciplinarian, diagnostician and role model. The cognitive part of this is reflected in the 'cognitive apprenticeship model', in which teachers model, coach and scaffold learning using questioning (articulation), reflection and exploration within a positive learning climate, gradually withdrawing support as students progress (Collins et al. 1989; Stalmeijer et al, 2009).

In remediation, we suggest that this apprenticeship plays out within a 'community of inquiry' (Stoyanova and Kennedy, 2010), a methodology that considers education as a complex dynamic system 
in which components are structurally coupled and mutually constitutive (Maturana and Varela, 1987; Jörg et al, 2007). A community of inquiry provides a safe environment for a group of students to learn critical thinking through dialogue, where members build on each other's ideas to reconstruct their understandings, guided by a facilitator who provides the optimal amount of 'noise', feedback and challenges that allow enough space for student exploratory talk while preventing groupthink and provoking discussion (Stoyanova and Kennedy, 2010; Proulx, 2010).

The teacher is thus an integral component of this community (Dewey, 1938; Proulx, 2010), performing complex roles that require 'presence' (Rodgers and Raider-Roth, 2006). Teaching presence involves the whole self, fully alert and connected to the individual students and the group, their cognition and emotion, the subject matter and all interactions within the classroom context, responded to with compassionate, flexible, intelligent action (Dewey, 1910; Rodgers and Raider-Roth, 2006; Stooksberry et al, 2009). Presence develops with reflection and experience (Rodgers and Raider-Roth, 2006), much like practical wisdom. Perhaps it is this combination of presence and practical wisdom that provides the artistry, the feeling, that 'just know' factor, that allows teachers to go beyond competency to attain excellence (Dewey, 1910; Eisner, 2002; Lunenberg and Korthagen, 2009; Fitzmaurice, 2010).

\section{Limitations and further work}

Categories are abstractions imposed by researchers for tidiness (Bateson, 1972; Ricca, 2009), conceptual understandings trail life (Thomas, 2006), and all words come laden with prior meanings (Bakhtin, 1986), which will inevitably affect our understanding of our subjects, and our readers' understanding of us. Objectivity is never easy, especially so for practitioner researchers, and we acknowledge that our own perspectives suffuse our work. Of course, given the added value of practitioner-researcher viewpoint, this could be considered both strength and limitation.

Most people are poor at self-assessment (Kruger and Dunning, 1999; Sui and Reiter, 2009), and what they tell researchers may be new to themselves, ambiguous and not fully representative of underlying conceptions (Roth, 2007; Mauthner and Doucet, 2003). There is also uncertainty about the relationship between teachers' beliefs about their actions and their actual practice (Norton et al, 2005; Peeraer et al, 2011; Ben-Peretz, 2011), hinted at by the similarity of teachers according to our qualitative findings when compared to the differences in the quantitative results. Thus we are unable to directly link these qualitatively described attributes of good remediation to 
students' success and failure rates. Additionally, complex systems might be better studied at the level of their emergence, where interactions are visible (Jörg et al, 2007; Radford, 2008; Kauffman, 2008). This suggests that a fruitful area for further work would be direct observation of classroom teaching, which would allow comparison of perceptions with more objective reality (Wittgenstein, 2006; Ben-Peretz, 2011), may help us identify the most important attributes for student success, and could also result in more specific guidance for supporting novice teachers' development of practical wisdom (Lunenberg and Korthagen, 2009). Indeed, both the teaching and the remediation course itself may benefit from direct observation of the enactment of the different lessons included in the course handbook (Winston et al, 2010a), since observation of and learning from small changes may be the best way to improve an intervention (Morris and Hiebert, 2011).

\section{Conclusion}

Although human functioning in complex systems is unpredictable (Kauffman, 1995), and absolute educational laws may never be established (Eva, 2008), we are now able to offer a tentative theory of remediation applicable to one particular context of at-risk medical students. Remediation should support emotional needs and foster cognitive and metacognitive skills for self-regulation and critical thinking. This is best done through a cognitive apprenticeship within a small community of enquiry that motivates and challenges the students. This community should foster curiosity and joy for learning, using collaborative exploratory dialogue that revolves around their experiences of failure, success and deep engagement with the subject matter of their courses. Teachers of remediation can mediate these processes through embodiment of five core roles: facilitator, nurturing mentor, disciplinarian, diagnostician and modeller of desired skills, attitudes and behaviours. This combination demands high levels of teaching presence and practical wisdom to flexibly manage a complex and uncertain remediation process.

While broader applicability remains to be tested before we can generalize, this practical theory draws together elements of teaching excellence supported by a wide range of literature to create a unique blend tailored to the high cognitive and affective demands of remediation in medical education, and promises value in remediation in other higher educational contexts. 


\section{References}

Alexander R, Badenhorst E, Gibbs T. 2005. Intervention programme: A supported learning programme for educationally disadvantaged students. Med Teach 27(1):66-70

Alexander PA, Schallert DL, Reynolds RE. 2009. What is learning anyway? A topographical perspective considered. Educ Psychol 44(3):176-92

Allan J, Clarke K. 2007. Nurturing supportive learning environments in higher education through the teaching of study skills: to embed or not to embed? Int J Teach Learn High Educ 19 (1):64-76

Aristotle 2008. Nicomachean Ethics, Translated by W. D. Ross, MobileReference kindle edition

Bakhtin MM. 1986. Speech Genres and Other Late Essays, Translated by Vern W. McGee. Edited by Caryl Emerson and Michael Holquist, Austin, University of Texas Press

Barkas LA. 2011. 'Teaching' or 'support'? The poisoned chalice of the role of Students' Skills Centres. J Further and Higher Education 35(2):265-286

Bartram B, Bailey C. 2009. Different students, same difference?: A comparison of UK and international students' understandings of 'effective teaching'. Act Learn High Educ 10(2):172-184

Bateson G. 1972 Steps to an Ecology of Mind. Chicago, IL: University of Chicago Press 469-70

Bateson, G. 1979. Mind and Nature: A Necessary Unity. New York, NY: Dutton

Ben-Peretz M. 2011. Teacher knowledge: What is it? How do we uncover it? What are its implications for schooling? Teach Teacher Educ 27(1):3-9

Bloom JW, Volk T. 2010. The Use of Metapatterns for Research into Complex Systems of Teaching, Learning, and Schooling. 4(1):45-68

Bolhuis S, Voeten MJM. 2004. Teachers' conceptions of student learning and own Learning. Teachers and Teaching, 10(1):77-98

Bordage G. 2009. Conceptual frameworks to illuminate and magnify. Med Educ 43:312-9

Boudreau JD, Cassell EJ. Fuks A. 2009. Preparing medical students to become attentive listeners. Med Teach 31(1):22-29

Brigman G, Webb L. 2007. Student success skills: Impacting achievement through large and small group work. Group Dyn: Theory Res Pract 11(4):283-292

Carless D, Salter D, Yang M, Lam J. 2011. Developing sustainable feedback practices. Studies Higher Educ 36(4):395-407

Chinn CA, Samarapungavan ALA. 2009. Conceptual Change-Multiple Routes, Multiple Mechanisms: A Commentary on Ohlsson. Educ Psych 44(1):48-57 
Cleland J, Mackenzie RK, Ross S, Sinclair HK, Lee AJ. 2010. A remedial intervention linked to a formative assessment is effective in terms of improving student performance in subsequent degree examinations. Med Teach 32(4):e185-e190

Collins A, Brown JS, Newman SE. 1989. Cognitive apprenticeship: Teaching the crafts of reading, writing, and mathematics. In L. B. Resnick (Ed.), Knowing, learning, and instruction: Essays in honor of Robert Glaser (pp. 453-494). Hillsdale, New Jersey: Lawrence Erlbaum Associates, Inc

Confucius 1979 Analects of Confucius. Translated by Lau, D. C. Penguin Books, London, England

Cook DA, Bordage G, Schmidt HG. 2008. Description, justification and clarification: a framework for classifying the purposes of research in medical education. Med Educ 42: $128-133$

Corno L. 2008. On teaching adaptively. Educ Psychol 43(3):161-73

Dahlberg K, Todres L, Galvin K. 2009. Lifeworld-led health care is more than patientled care: an existential view of well-being. Med Health Care Philos 12(3):265-71

Darling-Hammond L, Youngs P. 2002. Defining "Highly Qualified Teachers": What Does "Scientifically-Based Research" Actually Tell Us? Educ Researcher 31(9):13-25

Denzin NK, Lincoln YS. 2005. The Sage Handbook of Qualitative Research, $3^{\text {rd }}$ edition. Sage Publications, California

Devoe P, Niles C, Andrews N, Benjamin A, Blacklock L, Brainard A, Colombo E, Dudley B, Koinis C, Osgood M. 2007. Lessons learned from a study-group pilot program for medical students perceived to be 'at risk'. Med Teach 29(2):e37-e40

Dewey J. 1910. How We Think. New York, NY: DC Heath \& Co

Dewey J. 1938. Experience And Education. Kappa Delta Pi, Touchstone, NY

Davidoff F. 2011. Music Lessons: What Musicians Can Teach Doctors (and Other Health Professionals). Ann Intern Med 154(6):426-429

Dyche L, Epstein RM. 2011. Curiosity and medical education. Med Educ 45:663-668 Eisner EW. 2002. From episteme to phronesis to artistry in the study and improvement of teaching. Teaching Teacher Educ 18(4):375-385

Eva KW. 2008. The cross-cutting edge: Striving for symbiosis between medical education research and related disciplines. Med Educ 42:950-951

Fenollar P, Roman S, Cuestas PJ. 2007. University students' academic performance: An integrative conceptual framework and empirical analysis. Br J Educ Psychol 77:873891

Feucht FC, and Bendixen LD. 2010. Exploring Similarities and Differences in Personal Epistemologies of U.S. and German Elementary School Teachers. Cognition and Instruction 28(1):39-69

Field JC, Latta MM. 2001. What constitutes becoming experienced in teaching and learning? Teach Teacher Educ 17(8):885-895 
Fitzmaurice M. 2010. Considering teaching in higher education as a practice. Teach Higher Educ, 15(1):45-55

Foster G. 2010. Teacher effects on student attrition and performance in mass-market tertiary education. High Educ 60(3):301-319

Frenzel AC, Goetz T, Lüdtke O, Pekrun R, Sutton RE. 2009. J Edu Psych 101(3):705716

Fuks A, Boudreau JD, Cassell EJ. 2009. Teaching clinical thinking to first-year medical students. Med Teach 31(2):105-111

Greasley K, Ashworth P. 2007. The phenomenology of 'approach to studying': the university student's studies within the lifeworld. Br Educ Res J 33(6):819-43

Groopman J. 2008. How doctors think. New York: Mariner Books

Harlen W. 2003. Enhancing Inquiry Through Formative Assessment. San Francisco, CA: Institute for Inquiry Exploratorium. Available from:

http://www.exploratorium.edu/ifi/resources/harlen_monograph.pdf

Harris L. 2010. Delivering, modifying or collaborating? Examining three teacher conceptions of how to facilitate student engagement. Teachers and Teaching, 16(1):131-151

Hattie J, Timperley H. 2007. The power of feedback. Rev Educ Res 77(1):81-112.

Hmelo-Silver CE, Barrows HS. 2008. Facilitating Collaborative Knowledge Building. Cognition and Instruction, 26(1):48-94

Howe A, Campion P, Searle J, Smith H. 2008. New perspectives - Approaches to medical education at four new UK medical schools. BMJ 329: 327-32

Hull G, Rose M, Fraser KL, Castellano M. 1991. Remediation as Social Construct: Perspectives from an Analysis of Classroom Discourse. Center for the Study of Writing, Berkeley, CA, Technical Report no. 44

Hultberg J, Plos K, Hendry GD, Kjellgren KI. 2008. Scaffolding students' transition to higher education: parallel introductory courses for students and teachers', J Fur Higher Educ 32(1):47-57

Jaarsma ADC, de Grave WS, Muijtjens AMM, Scherpbier AJJA, van Beukelen P. 2008. Perceptions of learning as a function of seminar group factors. Med Educ 42: 11781184

Jolly P, Garrison G, Boulet JR, Levitan T, Cooper RA. 2008. Three pathways to a physician career: Applicants to U.S. MD and DO schools and U.S. citizen applicants to international medical schools. Acad Med 83(12):1125-1131

Jonas ME. 2010. When Teachers Must Let Education Hurt: Rousseau and Nietzsche on Compassion and the Educational Value of Suffering. J Phil Educ 44(1):45-60

Jörg T, Davis B, Nickmans G. 2007. Towards a new, complexity science of learning and education. Educ Resh Rev 2:145-156 
Kaufman DM. 2003. ABC of learning and teaching in medicine: Applying educational theory in practice. BMJ 326:213-216

Kauffman SA. 1995. At Home in the Universe: the Search for the Laws of SelfOrganization and Complexity. New York, NY: Oxford University Press

Kauffman SA. 2008. Reinventing the Sacred: A New View of Science, Reason, and Religion. New York, Basic Books

Kelchtermans G. 2009. 'Who I am in how I teach is the message: self-understanding, vulnerability and reflection', Teachers and Teaching, 15(2):257-272

Kember D, Leung DYP, McNaught C. 2008. A workshop activity to demonstrate that approaches to learning are influenced by the teaching and learning environment. Active Learn Higher Educ 9(1):43-56

Kennedy TJT, Lingard LA. 2006. Making sense of grounded theory in medical education. Med Educ 40:101-8

Kies SM, Freund GG. 2005. Medical Students who Decompress During the M-1 Year Outperform Those who Fail and Repeat it: A Study of M-1 Students at the University of Illinois College of Medicine at Urbana-Champaign 1988-2000. BMC Med Educ Available from: http://www.pubmedcentral.nih.gov/articlerender.fcgi?artid1/41166556

Kistner S, Rakoczy K, Otto B, Dignath-van Ewijk C, Büttner G, Klieme E. 2010. Promotion of self-regulated learning in classrooms: investigating frequency, quality, and consequences for student performance. Metacog Learn 5(2):157-171

Kitto SC, Chesters J, Grbich C. 2008. Quality in qualitative research: Criteria for authors and assessors in the submission and assessment of qualitative research articles for the Medical Journal of Australia. MJA 188:243-246

Konstantopoulos S, Chung V. 2011. The Persistence of Teacher Effects in Elementary Grades. American Educ Res J 48(2)361-386

Kozanitis A, Desbiens JF, Chouinard R. 2007. Perception of Teacher Support and Reaction Towards Questioning: Its Relation to Instrumental Help-seeking and Motivation to Learn. Int J Teach Learn Higher Educ 19(3):238-250

Kreber C, McCune V, Klampfleitner M (2010) Formal and implicit conceptions of authenticity in teaching, Teaching in Higher Education, 15(4):383 - 397

Kruger J, Dunning D. 1999. Unskilled and Unaware of It: How Difficulties in Recognizing One's Own Incompetence Lead to Inflated Self-Assessments. J Personality Social Psych 77(6):121-1134

Kvale S. 1996. Interviews: An Introduction to Qualitative Research Interviewing. Sage Publications, California

Lakoff G, Johnson M. 1999. Philosophy in the Flesh: The Embodied Mind and Its Challenge to Western Thought. Basic Books, NY

Lammers WJ and Smith SM. 2008 Learning Factors in the University Classroom:

Faculty and Student Perspectives. Teaching of Psychology, 35: 61-70 
Lim ECH, Seet RCS. 2007. Stop! In the Name of Love! (Before You Fail, Not Pass!). Teach Learn Med 19(2):198-199

Lunenberg M, Korthagen F. 2009. Experience, theory, and practical wisdom in teaching and teacher education. Teachers and Teaching 15(2):225-240

Mahlios M, Massengill-Shaw D, Barry A. 2010. Making sense of teaching through metaphors: a review across three studies. Teachers and Teaching 16(1):49-71

Martin DC, Arendale DR, 1992. Supplemental Instruction: Improving First Year Student Success in High Risk Courses. The Freshman Year Experience: Monograph Series Number 7. National Resource Center for the Freshman Year Experience, University of South Carolina

Mattick K, Knight L. 2007. High-quality learning: Harder to achieve than we think? Med Educ 41:638-644

Maturana HR, Varela FJ. 1987. The Tree of Knowledge. Boston, MA: Shambhala Publications

Mauthner NS, Doucet A. 2003. Reflexive Accounts and Accounts of Reflexivity in Qualitative Data Analysis. Sociology 37(3): 413-431

McCune V, Entwistle N. 2011. Cultivating the disposition to understand in 21st century university education. Learning and Individual Differences, 21(3):303-310

McGrath B, McQuail D. 2004. Decelerated medical education. Med Teach 26(6):510513

McNeill KL. 2009. Teachers' Use of Curriculum to Support Students in Writing Scientific Arguments to Explain Phenomena. Sci Ed 93:233 - 268

Mercer N. 2000. Words \& Minds: How we use language to think together. London: Routledge

Mitchell I. 2010. The Relationship Between Teacher Behaviours and Student Talk in Promoting Quality Learning in Science Classrooms. Res Sci Educ 40(2):171-186

Morris AK, Hiebert J. 2011. Creating Shared Instructional Products : An Alternative Approach to Improving Teaching. Educ Researcher 40(1):5-14

Muraskin L. 1997. "Best practices" in student support services: A study of five exemplary sites. Followup study of student support services programs. SMB Economic Research Inc. and US Department of Education

Norton L, Richardson JTE, Hartley J, Newstead S, Mayes J. 2005. Teachers' beliefs and intentions concerning teaching in higher education. Higher Educ 50(4):537-571

Pajares MF. 1992. Teachers' Beliefs and Educational Research: Cleaning up a Messy Construct. Rev Educ Res, 62(3)307-332

Patel VL, Yoskowitz NA, Arocha JF 2009. Towards effective evaluation and reform in medical education: a cognitive and learning sciences perspective. Adv in Health Sci Educ 14(5):791-812 
Paul G, Hinman G, Dottl S, Passon J. 2009. Academic development: a survey of academic difficulties experienced by medical students and support services provided. Teach Learn Med 21(3):254-60

Peeraer G, Donche V, De Winter BY, Muijtjens AMM, Remmen R, Van Petegem P, Bossaert L, Scherpbier AJJA. 2011. Teaching conceptions and approaches to teaching of medical school faculty: The difference between how medical school teachers think about teaching and how they say that they do teach. Med Teach 33(7): e382-e387

Plato 1997. Theaetetus, in Plato Complete Works, ed Cooper JM, p166-7. Hackett Publishing Co. Indiana

Pope C, Ziebland S, Mays N. 2000. Qualitative research in health care: Analysing qualitative data. BMJ 320:114-116

Postholm MB. 2008. Group work as a learning situation: a qualitative study in a university classroom. Teachers and Teaching: Theory Pract 14(2):143-55

Postholm MB. 2010. Self-regulated pupils in teaching: teachers' experiences. Teachers and Teaching 16:(4)491-505

Prosser M, Ramsden P, Trigwell K, and Martin E. 2003. Dissonance in Experience of Teaching and its Relation to the Quality of Student Learning. Studies Higher Educ 28:(1)37-48

Proulx J. 2010. Is "Facilitator" the Right Word? And on What Grounds? Some Reflections and Theorizations. Complicity: Int J Complexity Educ 7(2):52-65

Radford M. 2008. Prediction, control and the challenge to complexity. Oxf Rev Educ 34(5):505-520

Reeve JM. 2009. Why Teachers Adopt a Controlling Motivating Style Toward Students and How They Can Become More Autonomy Supportive, Educ Psych 44(3):159-175

Ricca B. 2009. The Imposition of Boundaries: A Response to Ton Jörg's Programmatic View. Complicity: Int J Complexity Educ 6(1):56-61

Rodgers CR, Raider-Roth MB. 2006. Presence in teaching. Teachers and Teaching, 12(3)265-287

Rosenfeld S, Rosenfeld M. 2008. Developing effective teacher beliefs about learners: the role of sensitizing teachers to individual learning differences. Educ Psych, 28(3):245-272

Roth WM. 2007. The nature of scientific conceptions: A discursive psychological perspective. Educ Res Rev 3(1):30-50

Saxena V, O'Sullivan PS, Teherani A, Irby DM, Hauer KE. 2009. Remediation techniques for student performance problems after a comprehensive clinical skills assessment. Acad Med 84(5):669-76

Sayama H, Farrell DL, Dionne SD. 2011. The Effects of Mental Model Formation on Group Decision Making: An Agent-Based Simulation. Complexity 16(3):49-57

Schifferdecker KE, Reed VA. 2009. Using mixed-methods research in medical education: basic guidelines for researchers. Med Educ 43:637-44 
Shulman LS. 1986. Those Who Understand: Knowledge Growth in Teaching. Educational Researcher, 15(2)4-14

Shulman LS. 1987. Knowledge and teaching: foundations of the new reform, Harvard Educational Review, 57(1)1-23

Shulman LS. 2007. Practical Wisdom in the Service of Professional Practice. Educational Researcher, 36(9)560-563

Sibii R. 2010 Conceptualizing teacher immediacy through the 'companion' metaphor. Teach High Educ 15(5):531-542

Skelton, A. 2005. Understanding teaching excellence in higher education. London: Routledge

Song L, Hannafin MJ, Hill JR. 2007. Reconciling beliefs and practices in teaching and learning. Educ Tech Res Dev 55:27-50

Sparapani EF, Abel FJ, Easton SE, Edwards P, Herbster DL. 1996. Action research: A strategy for bridging the gap between theory and practice, paper presented at the association of teacher educators 76th annual meeting, St Louis, MO

Stalmeijer RE, Dolmans DHJM, Wolfhagen IHAP, Scherpbier AJJA. 2009. Cognitive apprenticeship in clinical practice: can it stimulate learning in the opinion of students? Adv Health Sci Educ 14(4):535-46

Steiner DD, Peifer JH. 1990. Teaching the At-Risk Student: A Guide for Teacher Educators. Eastern Mennonite College, Commonwealth Center for the Education of Teachers, Harrisonburg, VA

Stooksberry LM, Schussler DL, Bercaw LA. 2009. Conceptualizing dispositions: intellectual, cultural, and moral domains of teaching. Teachers and Teaching 15(6):719-736

Stoyanova N, Kennedy D. 2010. Between Chaos and Entropy: Community of Inquiry from a Systems Perspective. Complicity: Int J Complexity Educ 7(2):1-15

Sui E, Reiter HI. 2009. Overview: what's worked and what hasn't as a guide towards predictive admissions tool development. Adv Health Sci Educ 14(5):759-775

Taylor JS. 2010. Learning With Emotion: A Powerful and Effective Pedagogical Technique. Acad Med, 85(7):1110

Tekian A, Jalovecky MJ, Hruska L. 2000. A quantitative assessment of "at risk" students and medical school performance: The importance of adequate advising and mentorship, paper presented at annual meeting of American educational research association, New Orleans, MS

Tetlock PE. 2005. Expert political judgment: How good is it? How can we know? Princeton, NJ: Princeton University Press.

Thomas P. 2006. General Medical Practitioners Need to Be Aware of the Theories on Which Our Work Depends. Ann Fam Med 2006;4:450-454 
Thompson GL, Warren SR, Foy T, Dickerson C. 2008. What Makes a Teacher Outstanding? A Contrast of Teachers' and African American High School Students' Perspectives. J Urban Learn Teach and Res 4:122-134

Trigwell K, Prosser M, Waterhouse F. 1999. Relations between teachers' approaches to teaching and students' approaches to learning. Higher Education 37:57-70

Tsui ABM. 2009. Distinctive qualities of expert teachers. Teachers and Teaching 15(4):421-439

Vansteenkiste M, Sierens E, Soenens B, Luyckx K, Lens W. 2009. Motivational profiles from a self-determination perspective: the quality of motivation matters. J Educ Psychol 101 (3):671-88

Varela FJ, Thompson ET, Rosch E. 1991. The Embodied Mind: Cognitive Science and Human Experience. Cambridge, MA, MIT Press

Vygotsky LS. 1986. Thought and Language. Cambridge, MA: MIT Press

Wilson NS, Bai H. 2010. The relationships and impact of teachers' metacognitive knowledge and pedagogical understandings of metacognition. Metacognition Learning 5(3):269-288

Winston KA, van der Vleuten CPM, Scherpbier AJJA. 2010a. An investigation into the design and effectiveness of a mandatory cognitive skills programme for at-risk medical students. Med Teach, 32(3):236-43

Winston KA, Van Der Vleuten CPM, Scherpbier AJJA. 2010b. At-risk medical students: implications of students' voice for the theory and practice of remediation. Med Educ, 44:1038-1047

Wittgenstein L. 1967. Philosophical Investigations, $3^{\text {rd }}$ ed. Blackwell, Oxford Wittgenstein L. 2006 Tractatus Logico-Philosophicus kindle edition Public Domain Books 


\section{CHAPTER 5}

\section{Prediction and Prevention of Failure: An Early Intervention to Assist At-Risk Medical Students}

Published as:

Winston KA, Van Der Vleuten CPM, and Scherpbier AJJA. 2013. "Prediction and Prevention of Failure: An Early Intervention to Assist At-Risk Medical Students," Medical Teacher, online first, $1^{\text {st }}$ October. 


\section{Introduction}

In a context of widening participation throughout higher education, and large resource investment by all stakeholders, there exists a moral imperative to assist struggling students in order to improve their success and their institutions' retention rates. The challenge is that these students typically fail to seek help (Winston et al, 2010a), and continue to underperform throughout their education (Cleland et al. 2005, 2008). Although there is a growing consensus that early identification and intervention provide the best chance of improving these students' skills (Paul et al, 2009), the most effective way to break this 'cycle of underperformance' (Cleland et al, 2005) remains an active area of enquiry (Cleland et al, 2013).

Essentially, there are two approaches to assisting these students: prediction and prevention of failure, or remediation after failure. Within medical education, many attempts at remediation have had only short-term effects (Cleland et al, 2013), setting these students up for further failure later in their careers. However, interventions lasting a full year have reported more success (Ficklin et al. 1985; Alexander et al. 2005). In particular, recent work has shown significant long-term gains in student outcomes after participation in a 14week course that provides a cognitive and affective apprenticeship using self-regulatory, metacognitive, and dialogic techniques within a small community of inquiry (Winston et al, 2010a, 2010b, 2012). These successful efforts at remediation have been preferred to prevention because of the difficulty of predicting exactly who will struggle, the risks of labelling students incorrectly, and the necessity for students to admit their need for help before it can be fully effective. Indeed, most reported efforts at preventing failure have shown no significant effect (Tekian and Hruska, 2004; Devoe et al. 2007), or short-term but no long-term effect (Stegers-Jager et al, 2013). Nevertheless, accurate prediction and targeted prevention of failure, if possible, has the potential for more effective use of limited resources.

Accurate prediction of failure is challenging: student difficulty and attrition have complex causes (Hall, 2001), and the real social world is inherently too unpredictable for straightforward modelling (Kahneman, 2011). The best pre-admission predictor appears to be a combination of prior GPA and cognitive tests such as the US Medical College Admission test (MCAT), which account for around $20 \%$ of the variance in medical school performance (Donnon et al, 2007; Callahan et al, 2010). However, these measures seem unable to predict either failure or dropout (Shulruf et al, 2012). Inclusion of personality and study skills inventories may be useful for predicting later 'noncognitive' clinical performance but add little to prediction of the basic 
science performance that serves as a gatekeeper for those later years (Haight et al, 2012; McLaughlin, 2012); besides, such self-report inventories are susceptible to faking, and should be used with caution (Griffin and Wilson, 2012).

Unsurprisingly, the more similar the prediction task is to subsequent performance assessment tasks, the more accurate the prediction turns out to be (Tanilon et al, 2011). Second year performance is highly predictive of final performance (Cleland et al, 2008; Rich et al, 2012), and students who struggle or fail in the first year continue to have difficulty later in the same course (Yates, 2011; Stegers-Jager et al, 2013). It seems likely that the most effective predictor for 'atrisk-ness' is students' performance early in their programmes. Finding an appropriate early measure, and then targeting these students with a carefully designed intervention, would be a worthy goal for effective use of resources for maximizing student outcomes.

\section{Aims}

In this paper we describe an attempt to take ideas from a successful remediation programme (Winston et al, 2010a) and apply them to a short course aimed at prevention of failure. We provide a detailed description of our specific context, our practice, and its consequences (Regehr, 2010), and thereby address calls for further research into duration, timing and structure of interventions to help students in difficulty (Cleland et al, 2013). We address the following questions:

- Can a new early exam improve our ability to predict which students will fail courses at our medical school?

- What kind of early intervention can we provide to reduce the failure rate of these students in our own context?

Answering the second of these questions could reduce delay and cost for the students, and the burden on our own remediation programme (Winston et al, 2010a), while potentially offering ideas on how to assist strugglers in other professional education contexts.

\section{Methods}

\section{Context}

This research was carried out by the first author, KW, a faculty member in the Centre for Teaching and Learning (CTL) of a Caribbean-based US medical school, with ethical approval from the school's Institutional Review Board. The school admits up to 400 new students, three times per year, to follow an accelerated curriculum, 
spending four 4-month basic science semesters on island before advancing to their clinical rotations in mainland USA. Students have diverse backgrounds, with mean MCAT scores of 23 (range is 12 to 36): most have failed to gain entry into mainland US medical schools, where the mean MCAT of matriculants is 31 (AAMC, 2012). Lower MCAT scores have been shown to correlate with lower USMLE pass rates (Tekian and Hruska, 2004): we have a $25 \%$ to $30 \%$ attrition rate. Prediction of success and failure at these MCAT ranges has proven difficult: MCAT, prior college GPA, age, gender and ethnicity combine to predict only $8.7 \%$ of our students' attrition, and $13.4 \%$ of variance in their basic science grades (Meisenberg, 2012).

In September 2010 the school shifted to a system-based curriculum. During the first semester, students take 3 sequential modules, taught largely through lectures (20 hours per week) and labs. Each module is assessed through multiple choice exams: $45 \%$ of the module grade from an exam at the end of the module, and $45 \%$ from a final exam at the end of the semester; the remaining $10 \%$ coming from labs. For the first module (Fundamentals, of histology, biochemistry, physiology and anatomy), amid fears of too much weight on students' first medical school exam, the exam was split into two sections: the first part (henceforth referred to as 'week-2-exam') is taken after the first two weeks and accounts for $19 \%$ of the module grade; the second after 5 weeks, constitutes $26 \%$. The pass mark for all modules is $60 \%-65 \%$.

\section{Data Collection and Analysis}

Initially, we looked at student performance in the new week-2-exam for three cohorts. For those who failed (scored below 65\%), we tracked whether they went on to fail courses at the end of that first semester or in any subsequent semester. After a year, the numbers and percentages were so clear that we felt no need for further statistical analysis (Gorard, 2010): many students were failing the week-2exam, and this was predictive of later failure (see results). Something had to be done, but any intervention needed to fit around the overcrowded schedules of both the students and the CTL faculty.

For the next three cohorts, students who failed the week-2-exam were invited by email to participate in our intervention. This email included a description of the intervention, and data pertaining to the predictive value of this exam drawn from those first three cohorts. Attendance and subsequent performance each semester were tracked, both for those who chose to participate, and those who did not. Pass/fail outcomes were compared with the three cohorts prior to this intervention, and between participating/non-participating students. Given the categorical pass/fail data, chi-squared tests were 
used to determine the significance of varying levels of attendance. We also performed forced order of entry multiple regression analyses, using SPSS version 19, 2010 edition (SPSS, Inc., Chicago, IL, USA), to determine the effect of likely predictor variables on the number of modules failed at the end of first semester: score on week-2-exam, MCAT score, attendance at the intervention sessions, attendance at other voluntary CTL activities and demographic data. Participating students were also asked four Likert-type questions about the value of the intervention, using the anonymous survey tool SurveyMonkey ${ }^{\circledR}$.

\section{Intervention Design}

Given existing demands on students' time, the large number of struggling students, and the small number of overworked CTL faculty, we decided to offer a short series of three large group workshops, in the only open time slots available in the two weeks between obtaining the week-2-exam results, and the second exam at the end of the fifth week. Each workshop lasted two hours, and was held in a large classroom with tables for seating smaller groups of six students. At the conclusion of the workshop series, participants could sign up for weekly small group meetings with a faculty facilitator for the remainder of the semester.

This compromise design was based on our Essential Lifelong Learning Skills (ELLS) course, which draws on a blend of constructivist, sociocultural and complexivist theories to focus on self-regulation, metacognition and reflection while applying active learning skills to basic science content (Winston et al, 2010a). Through discourse, explicit reasoning, and mutual feedback, small groups of repeating students, guided by a faculty facilitator, support each other's cognitive and affective development (Winston et al, 2010a, 2010b, 2012). Although we did not have the resources to offer this intervention in small groups, or over a full semester, we felt that presenting key ideas and then using the majority of workshop time for small group assignments had the potential to replicate some of the findings from the team-based learning (TBL) model, in which weaker students are reported to have attained the largest performance gains (Koles et al, 2010).

Each workshop included large group introduction to, and discussion of, key ideas, small group activities with circulating CTL faculty facilitators, followed by whole-class plenary to share insights. At the end of each workshop students were assigned tasks for applying the learned ideas to basic science course material, and asked to bring back completed assignments for further discussion. 
The first workshop included small and large group discussion of the emotions related to the just-failed week-2-exam, with activities focused on students' current study strategies, exploration of their perception of the meanings of terms like 'study', 'learn' and 'review'. After providing a brief overview of self-regulated learning theory (Zimmerman, 2000), students were engaged in time-management and lecture-previewing activities, with careful attention to language use and definitions of previously learned terms that were about to appear in upcoming lectures, to demonstrate the importance of linking new learning to prior knowledge (Dewey, 1929). The second workshop involved organization and critical appraisal of lecture material, with groups working on asking higher order questions and the creation of study products such as concept maps. The final workshop revolved around techniques for answering and learning from multiple-choice questions, including rephrasing of question stems, explanation of answer choices, and the use of confidence marking for judgments of learning and identification of specific knowledge gaps. In the follow-up small group (4-7 ss/group) meetings, each facilitated by one of six CTL faculty, these ideas were elaborated upon, along with introduction of other activities drawn from the ELLS course (Winston et al, 2010a).

\section{Results}

For the first three cohorts of students in the new curriculum, $27 \%$ $(276 / 1010)$ of all those entering the school, failed the week-2-exam. As shown in table $1,65 \%(178 / 275)$ of students who failed week-2exam, went on to fail either semester 1,2 , or 3 . This was our strongest early predictor of failure yet. For the next 3 cohorts, $32 \%$ $(333 / 1109)$ of all those entering the school failed the week-2-exam, and were invited to attend the intervention workshop. As shown in table 1, whether or not students who failed the week-2-exam were offered our intervention, two thirds had failed a module by the end of semester 3 - offering the intervention made no overall difference to outcomes. The mean MCAT for students failing the first exam was 22.3, while for those passing it was 23.4: a small, non-significant difference.

Table 2 shows the effects of attending the workshops. 268 of those offered the intervention attended at least one workshop, while 101 attended three workshops. Over the three iterations of this intervention, each workshop had between 30 and 100 students, with numbers decreasing from the first to the third in the series. Workshop attendance also appears unrelated to outcomes. 
Over the three intervention cohorts, 91 students signed up to attend the follow-up small group sessions, but only 21 students attended more than two of these sessions, despite having been shown the data demonstrating a strong dose effect for the ELLS course, where increased attendance correlates with better long-term outcomes (Winston, 2010a). Table 3 shows that attendance at more than two follow-up sessions correlates with higher pass rates, and is statistically significant for semester 2 pass rates. Also noteworthy is that the experience of the teacher ( $>25$ years for two teachers, compared to $<6$ years for the other four) appears to be strongly related to persistence in attending these voluntary sessions, despite having allocated students according to score on the week-2-exam to ensure an even distribution of 'prior knowledge' in each group.

Table 1: Comparison of students failing week-2-exam from cohorts offered and not offered the intervention

\begin{tabular}{lccc}
\hline & $\begin{array}{c}\text { \% students } \\
\text { passing } \\
\text { semester 1 }\end{array}$ & $\begin{array}{c}\text { \% students } \\
\text { passing } \\
\text { semester 1 and 2 }\end{array}$ & $\begin{array}{c}\text { \% students } \\
\text { passing semester } \\
\mathbf{1 , 2} \text { and 3 }\end{array}$ \\
\hline $\begin{array}{l}\text { Cohorts not offered } \\
\text { intervention, } \mathrm{n}=275\end{array}$ & $50 \%$ & $40 \%$ & $35 \%$ \\
$\begin{array}{l}\text { Cohorts offered } \\
\text { intervention, } \mathrm{n}=333\end{array}$ & $53 \%$ & $41 \%$ & $34 \%$ \\
$\mathrm{X} 2$ & $\mathrm{P}=0.456$ & $\mathrm{P}=0.833$ & $\mathrm{P}=0.801$ \\
\hline
\end{tabular}

Table 2: Outcomes for the intervention cohorts, by workshop attendance

\begin{tabular}{lcccc}
\hline & n & $\begin{array}{c}\text { \% students } \\
\text { passing } \\
\text { semester 1 }\end{array}$ & $\begin{array}{c}\text { \% students } \\
\text { passing } \\
\text { semester 1 and 2 }\end{array}$ & $\begin{array}{c}\text { \% students } \\
\text { passing semester } \\
\mathbf{1} \text {, 2 and 3 }\end{array}$ \\
\hline $\begin{array}{l}\text { Attend no } \\
\text { workshops }\end{array}$ & 65 & $45 \%$ & $38 \%$ & $30 \%$ \\
$\begin{array}{l}\text { Attend 1 workshop } \\
\text { Attend 2 }\end{array}$ & 105 & $57 \%$ & $43 \%$ & $33 \%$ \\
$\begin{array}{l}\text { workshops } \\
\begin{array}{l}\text { Attend 3 } \\
\text { workshops }\end{array}\end{array}$ & 62 & $56 \%$ & $35 \%$ & $32 \%$ \\
X2 & 101 & $51 \%$ & $42 \%$ & $38 \%$ \\
\hline
\end{tabular}


Table 3: Effect of attendance at small group, post-workshop, followup sessions

\begin{tabular}{lccccc}
\hline & n & $\begin{array}{c}\text { \% with } \\
\text { experienced } \\
\text { teachers }\end{array}$ & $\begin{array}{c}\text { \% students } \\
\text { passing } \\
\text { semester 1 }\end{array}$ & $\begin{array}{c}\text { \% students } \\
\text { passing } \\
\text { semester 1 } \\
\text { and 2 }\end{array}$ & $\begin{array}{c}\text { \% students } \\
\text { passing } \\
\text { semester 1, } \\
\text { 2 and 3 }\end{array}$ \\
\hline $\begin{array}{l}\text { Attend 3 - 6 } \\
\text { sessions }\end{array}$ & 21 & $86 \%$ & $67 \%$ & $67 \%$ & $48 \%$ \\
$\begin{array}{l}\text { Attend 1 or 2 } \\
\text { sessions }\end{array}$ & 50 & $26 \%$ & $50 \%$ & $36 \%$ & $37 \%$ \\
$\begin{array}{l}\text { Attend 0 } \\
\text { sessions }\end{array}$ & 262 & $\mathrm{n} / \mathrm{a}$ & $53 \%$ & $41 \%$ & $34 \%$ \\
$\mathrm{X} 2$ & $\mathrm{P}<0.001$ & $\mathrm{P}=0.414$ & $\mathrm{P}=0.047$ & $\mathrm{P}=0.43$ \\
\hline
\end{tabular}

Multiple regression analysis revealed that only two factors were significant predictors for the number of modules failed in semester 1: the actual score on the week-2-exam ( $F$ change $=69.1, p<0.001$ ) and attendance at the small group sessions ( $F$ change $=9.56$, $\mathrm{p}<0.002$ ). All other factors (MCAT score, workshop attendance, attendance at other activities and demographics) were non-significant ( $F$ change $<0.4, p>0.5$ ). Changing the order of forced entry for the regression analyses yielded the same results. Thus, the score on the week-2-exam combined with attendance at the small group sessions to explain $18.4 \%$ variance in the number of failed modules in first semester.

There was a $44 \%$ response rate to the surveys of workshop participants, with outcomes quite different to the objective data: overall $64 \%(183 / 286)$ of the students agreed or strongly agreed that the workshops were helpful (figure 1), while only $10 \%(30 / 286)$ disagreed or strongly disagreed with this notion. 
Figure 1: Student survey results, likert-type questions

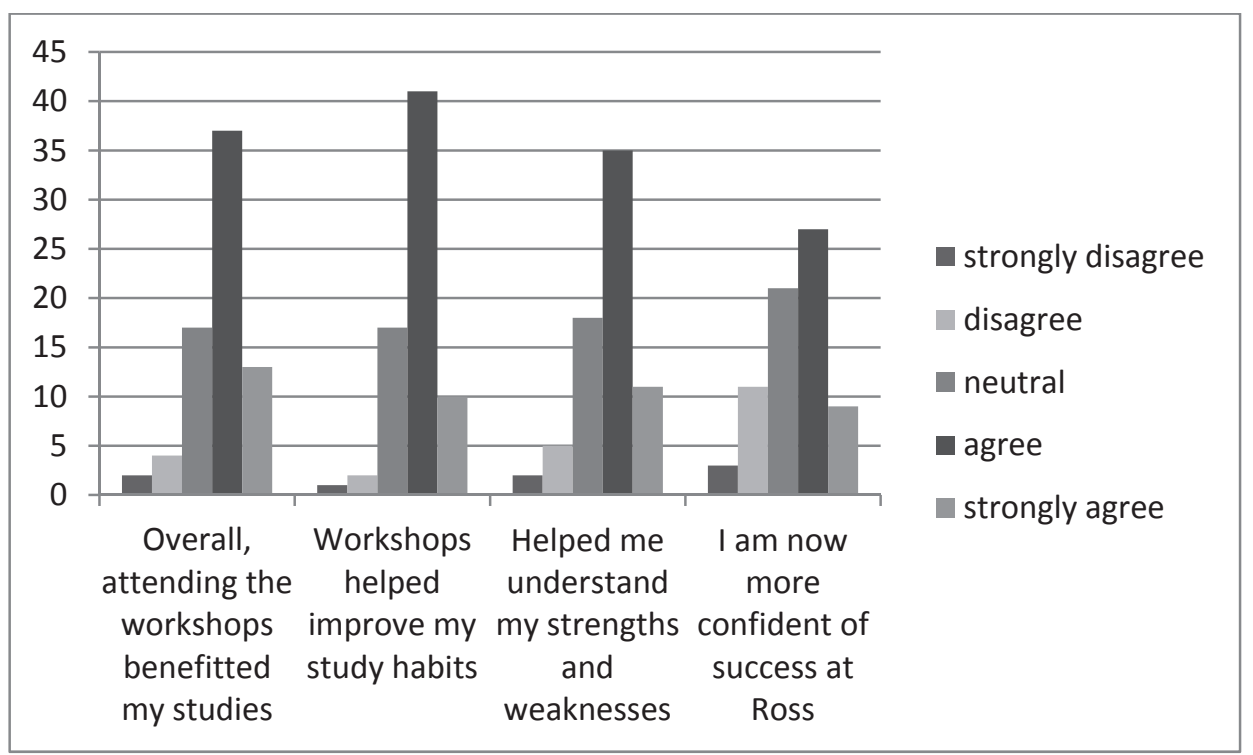

\section{Discussion}

Our first aim of finding an improved predictor of failure was certainly achieved for our specific population of medical students. This link between early and late performance within the same school mirrors the findings of others, from undergraduate education studies (Tanilon et al, 2011), to medical schools in the UK (Yates, 2011) and Netherlands (Stegers-Jager et al, 2013), so perhaps measures of early medical school performance are our best indicators of future medical school performance. It may be possible to search for additional variables to improve this level of prediction, but we need to be aware of the inherent unpredictability of complex systems such as education (Mennin, 2010), and should, perhaps, focus our efforts on how best to adapt our programmes to help those most likely to struggle.

In educational research, unintended outcomes allow us to explore our assumptions, understand our mistakes and inform future practice (Regehr, 2010). The fact that this intervention did not work as well as we hoped provides an opportunity to advance our understanding of how to (and not to) help struggling students. For the remainder of this discussion, we consider aspects of this particular intervention, offer some answers to our second research question of how to reduce the failure rate in our own context, and make a number of sugges- 
tions that may help to improve interventions to prevent failure in broader contexts.

Firstly, the diminishing attendance as the workshop series progressed, and minimal take-up of the ensuing, and more effective, small group sessions, is in keeping with the commonly reported limited help-seeking of weaker students (Devoe et al. 2007; Winston et al, 2010a). Others have found that students dislike exercises that have improved their performance (Leggett et al, 2012) and that selfreport measures are unrelated to objective outcomes (Bowman, 2010). Given that the skills required for competence are similar to the skills required to evaluate that competence (Kruger and Dunning, 1999), it is unsurprising that struggling students are not the best judges of the help provided for them. This reinforces the need for such interventions to be mandatory. Previous work showed that effective remediation with voluntary participation remained equally effective after participation was required (Winston et al, 2010a): it takes time for students to develop the skills and make the commitment of effort for real behaviour change. Students' attitudes to remediation become more positive as the programme progresses (Winston et al, 2010b), so it makes sense to require participation in attempts at prevention of failure to afford students the opportunity to appreciate and understand the value of such interventions.

Despite positive student surveys, our large group workshops made no statistical difference to overall pass rates, while the small group sessions appear to have had some effect. Large classes can be alienating and de-motivating (Van Etten et al, 2008), while smaller classes promote development of thought and attitude (Edmunds and Brown, 2010) and allow for more interaction and teacher attention (Blatchford et al, 2011). Affect is an important element of both reasoning and student engagement (Taylor, 2010). Confronted with the prospect of failure, it was difficult for our workshop participants to address the affective aspect of their situation before such a large audience of unfamiliar colleagues. The objective arguments faculty can deliver to a large group in a few meetings may not affect behaviours (Jonas, 2010): the positive mood that emerges from familiarity and trust is often a prerequisite for change (Geertsma 1977). Such trust emerges from the relationships that develop in stable groups over time, as students provide mutual motivation and support, and come to appreciate each other's contributions (Winston et al, 2010b). The feeling of group membership and familiarity can result in contagion of positive goals (Eren, 2009), and provides the social regulatory foundation for effective cognitive work and collaborative learning (Volet et al, 2009). None of this is readily achievable in a large group setting with variable attendance, and suggests that increasing time and reducing group size may be helpful to our intervention efforts. 
Even if supportive relationships among students could be created in large group settings through regular meetings with stable teams, there remains the issue of building students' relationships with teachers, which are often undervalued (ten Cate et al, 2011). The teacher-student relationship that develops over time is a significant factor in student learning, engagement and motivation (Hauer et al, 2012). Small group settings afford the space for communication that both enables and evolves from mutual confidence and trust between teachers and students, which in turn heavily influences the way feedback is received (Eva et al, 2010). Feedback from expert teachers is a key component of the development of self-regulation and successful remediation (Winston et al, 2012), and the provision of useful feedback requires the teacher to understand her learners, diagnose specific difficulties and offer generalizations for improvement of learning processes. However, in this intervention critique of student learning was left to the student teams, while teachers circulated and offered occasional comments. This is problematic because students do not spontaneously produce high-level, critical discussions (Gillies, 2011), and need guidance and challenges from expert facilitators to provoke them out of their comfort zones into deeper, exploratory talk (Stoyanova and Kennedy 2010; Winston et al, 2012). The careful listening that is required for such facilitation is extremely difficult in a large group situation, where many student concerns are neither raised nor challenged. Thus, we might expect the small group follow-up sessions to make more long-term difference to outcomes than the large-group workshops. The results also suggest that teacher experience matters in maintaining attendance and engagement of students, reinforcing the findings from our earlier work (Winston et al, 2012) that outcomes of remediation are significantly better for experienced than for inexperienced teachers. The implication is that trusting teacher-student and student-student relationships are an important ingredient of both successful remediation and prevention of failure, and that stable small groups may offer the most effective environment for developing these relationships.

Our results also add to the growing evidence that the practice of remediation and prevention of failure needs to account for a dose effect. Previously, we found that students who attended more than fifteen ELLS sessions were twice as likely to achieve long-term success than students who attended fewer than ten sessions (Winston et al, 2010a). Here, the maximum dose, with workshops and small group sessions combined, was just nine, and only very few students reached this. Others have similarly found that increased attendance at support programmes correlates with better outcomes (Muraskin 1997; Stegers-Jager et al, 2013), and that short programmes do not produce long-term improvements (Pell et al, 2012). 
Isolated, brief interventions rarely succeed (McLaughlin, 2012), since behaviour change, development of critical thinking dispositions, and acquisition of new skills necessarily take time (Paul et al, 2009), requiring extended interaction with consecutive discourse and feedback in a regular environment (Dewey, 1910; Kahneman, 2011). A handful of meetings is clearly inadequate for fundamental change in skills and dispositions, and we would suggest that meeting twice each week for one semester would be a good place to start exploration of the most effective dose for an intervention to prevent failure in atrisk professional students.

Finally, a successful programme probably needs a systemic perspective with clear administrative support (Lieberman et al, 2010), flexible curricular options, and dedicated time for self-study, classwork, and participation in carefully designed support programmes.

\section{Limitations and Further Work}

Perhaps the main limitation of any research is the difficulty of accounting for complexity, and we acknowledge that since all contexts with many variables are unique, generalizations can only be tentative (Dewey, 1929), particularly given the uncommon nature of our school and student population.

A further limitation is the non-random, voluntary nature of student participation, which means that motivation could be acting as a moderating variable. However, for the large group workshops, if motivation was a factor in increased attendance, it did not result in better outcomes. For the small group follow-up sessions, it may well be that motivation was a factor, but, given the differential attendance at groups led by experienced and inexperienced teachers, and that mandatory participation in our remediation course was as effective as voluntary participation (Winston et al, 2010a), improved motivation is perhaps more likely to be consequence than cause. Again, since our results for teacher experience and dose effects in this intervention are based on limited numbers, we should be cautious to generalize.

Additionally, the possible reasons for non-significant research findings can be numerous. While our discussion selects and rationalizes some likely possibilities for improving efforts at preventing failure, these ideas still need empirical verification, both in this and other contexts. We believe that continued programmatic research, testing each of the various possibilities discussed above, can lead to deeper understanding and improved interventions. Given these limitations, and that no grand theory of education that covers all dimensions and variations is possible (Alexander et al, 2009), we offer the following conclusions for future confirmation or refutation. 


\section{Conclusions}

An exam after the first two weeks of medical school seems wellsuited to our aim of finding an early predictor for our target population of students likely to struggle, confirming the notion that close similarity between predictor task and target task provides sufficient accuracy for targeted early interventions.

For prevention of failure, as with remediation, the type and details of intervention are likely to matter. Compromise solutions present serious challenges, and it is essential that systemic issues, such as workload and curricular flexibility, are addressed if we are to maximise the likelihood of successfully supporting our increasingly diverse student populations. Preventive interventions will need to be tailored for specific contexts, but it seems likely that a series of at least a dozen meetings over a minimum of one whole semester, following a flexible syllabus that teaches self-regulatory and metacognitive skills through application to content, would be necessary ingredients for success. In our own context, for example, this might involve offering a de-accelerated track to students who fail the first exam, thus providing enough time and space for attentive participation. Our results suggest that, ideally, this would happen through mandatory attendance in small stable groups led by experienced, mindful faculty facilitators, in which emotionally supportive relationships allow for sufficient academic rigour and timely constructive feedback for students to develop and apply their skills over time.

\section{References}

AAMC. 2012. MCAT Scores and GPAs for Applicants and Matriculants to U.S. Medical Schools, 2001-2012, American Association of Medical Colleges, website: https://www.aamc.org/download/321494/data/2012factstable17.pdf

Alexander R, Badenhorst E, Gibbs T. 2005. Intervention programme: A supported learning programme for educationally disadvantaged students. Med Teach 27(1):66-70

Alexander PA, Schallert DL, Reynolds RE. 2009. What is learning anyway? A topographical perspective considered. Educ Psychol 44(3):176-192

Blatchford P, Bassett P, Brown P. 2011. Examining the effect of class size on classroom engagement and teacher-pupil interaction: Differences in relation to pupil prior attainment and primary vs. secondary schools. Learning and Instruction, 21(6):715730

Bowman NA. 2010. Can 1st-year college students accurately report their learning and development? Amer Educ Res J, 47(2):466-496 
Callahan CA, Hojat M, Veloski J, Erdmann JB, Gonella JS. 2010. The predictive validity of three versions of the MCAT in relation to performance in medical school, residency, and licensing examinations: A longitudinal study of 36 classes of Jefferson Medical College. Acad Med, 85(6):980-987

Cleland J, Arnold R, Chesser A. 2005. Failing finals is often a surprise for the student but not the teacher: Identifying difficulties and supporting students with academic difficulties. Med Teach 27(6):504-508

Cleland J, Milne A, Sinclair H, Lee AJ. 2008. Cohort study on predicting grades: Is performance on early $\mathrm{MBChB}$ assessments predictive of later undergraduate grades? Med Educ 42:676-683

Cleland J, Leggett H, Sandars J, Costa MJ, Patel R, Moffat M. 2013. The remediation challenge: theoretical and methodological insights from a systematic review. Med Educ, $47: 242-251$

Devoe P, Niles C, Andrews N, Benjamin A, Blacklock L, Brainard A, Colombo E, Dudley B, Koinis C, Osgood M. 2007. Lessons learned from a study-group pilot program for medical students perceived to be 'at risk'. Med Teach 29(2):e37-e40

Dewey J. 1910. How we think. New York, NY: DC Heath \& Co

Dewey J. 1929. Experience and Nature. George Allen and Unwin Ltd, London. (Kindle edition)

Donnon T, Paolucci EO, Violato C. 2007. The predictive validity of the MCAT for medical school performance and medical board licensing examinations: a meta-analysis of the published research. Acad Med, 82(1):100-106

Edmunds S, Brown G. 2010. Effective small group learning: AMEE Guide No. 48. Med Teach, 32(9):715-726

Eva KW, Munoz J, Hanson MD, Walsh A, Wakefield J. 2010. Which factors, personal or external, most influence students' generation of learning goals? Acad Med, 85(10):S102-S105

Eren A. 2009. Exploring the relationships among mirror neurons, theory of mind, and achievement goals: Towards a model of achievement goal contagion in educational settings. Educ Res Rev, 4(3):233-247

Ficklin FL, Hazelwood JD, Carter JE, Shellhamer RH. 1985. The reduced load as a remedial program to increase retention of first-year medical students. J Med Educ 60(5):406-408

Geertsma RH. 1977. A special tutorial for minority medical students: An account of a year's experience. J Med Educ, 52(5):396-403

Gillies RM. 2011. Promoting thinking, problem-solving and reasoning during small group discussions. Teachers and Teaching, 17(1):73-89

Gorard S. 2010. All evidence is equal: the flaw in statistical reasoning. Ox Rev Educ, 36(1):63-77

Griffin B, Wilson IG. 2012. Faking good: self-enhancement in medical school applicants. Med Educ, 46(5):485-490 
Haight SJ, Chibnall JT, Schindler DL, Slavin SJ. 2012. Associations of Medical Student Personality and Health/Wellness Characteristics With Their Medical School Performance Across the Curriculum, Acad Med 87(4):476-485

Hall JC. 2001. Retention and Wastage in FE and HE. Scottish Council for Research in Education

Hauer KE, O'Brien BC, Hansen LA, Hirsh D, Ma IH, Ogur B, Poncelet AN, Alexander EK, Teherani A. 2012. More Is Better: Students Describe Successful and Unsuccessful Experiences With Teachers Differently in Brief and Longitudinal Relationships. Acad Med, 87(10):1389-1396

Jonas ME. 2010. When teachers must let education hurt: Rousseau and Nietzsche on compassion and the educational value of suffering. J Philos Educ 44(1):45-60

Kahneman D. 2011. Thinking, Fast and Slow. Farrar, Straus and Giroux, New York

Koles PG, Stolfi A, Borges NJ, Nelson S, Parmelee DX. 2010. The impact of team-based learning on medical students' academic performance. Acad Med, 85(11):1739-1745

Kruger J, Dunning D. 1999. Unskilled and Unaware of It: How Difficulties in Recognizing One's Own Incompetence Lead to Inflated Self-Assessments. J Personality and Soc Psych, 77(6):121-113

Leggett H, Sandars J, Burns P. 2012. Helping students to improve their academic performance: A pilot study of a workbook with self-monitoring exercises. Med Teach, 34(9):751-753

Lieberman SA, Ainsworth MA, Asimakis GK, Thomas L, Cain LD, Mancuso MG, Rabek JP, Zhang N, Frye AW. 2010. Effects of comprehensive educational reforms on academic success in a diverse student body. Med Educ, 44(12):1232-1240

McLaughlin K. 2012. Navigating in the fog of medical school admissions data. Adv in Health Sci Educ, 17:627-629

Meisenberg G. 2012. Analysis of student data, February 2012. In-house data analysis, personal communiqué

Mennin S. 2010. Self-organisation, integration and curriculum in the complex world of medical education. Med Educ, 44(1):20-30

Muraskin L. 1997. "Best practices" in student support services: A study of five exemplary sites. Followup study of student support services programs. SMB Economic Research Inc. and US Department of Education

Paul G, Hinman G, Dottl S, Passon J. 2009. Academic development: A survey of academic difficulties experienced by medical students and support services provided. Teach Learn Med 21(3):254-260

Pell G, Fuller R, Homer M, Roberts T. 2012. Is short-term remediation after OSCE failure sustained? A retrospective analysis of the longitudinal attainment of underperforming students in OSCE assessments. Med Teach, 34(2):146-50

Regehr G. 2010. It's NOT rocket science: rethinking our metaphors for research in health professions education. Med Educ, 44(1):31-39 
Rich AM, Ayers KMS, Thomson WM, Sinclair RJ, Rohan MJ, Seymour GJ. 2012. Does performance in selection processes predict performance as a dental student? Eur J Dent Educ, 16(1):27-34

Shulruf B, Poole P, Wang GY, Rudland J, Wilkinson T. 2012. How well do selection tools predict performance later in a medical programme? Adv in Health Sci Educ, 17(5):615626

Stegers-Jager KM, Cohen-Schotanus J, Themmen APN. (2013). The effect of a short integrated study skills programme for first-year medical students at risk of failure: $A$ randomised controlled trial. Med Teach, 35(2):120-126

Stoyanova N, Kennedy D. 2010. Between chaos and entropy: Community of inquiry from a systems perspective. Complicity: Int J Complexity Educ 7(2):1-15

Tanilon J, Vedder P, Segers M, Tillema H. 2011. Incremental validity of a performancebased test over and above conventional academic predictors. Learn Indiv Diff, 21(2):223-226

Taylor JS. 2010. Learning with emotion: A powerful and effective pedagogical technique. Acad Med 85(7):1110

Tekian A, Hruska L. 2004. A Review of Medical School Records to Investigate the Effectiveness of Enrichment Programs for "At Risk" Students, Teach Learn Med, 16(1):28-33

ten Cate OTJ, Kusurkar RA, Williams GC. 2011. How self-determination theory can assist our understanding of the teaching and learning processes in medical education. AMEE Guide No. 59. Med Teach, 33(12):961-973

van Etten S, Pressley M, McInerney DM, Liem AD. 2008. College seniors' theory of their academic motivation. J Educ Psychol, 100(4):812-28

Volet S, Vauras M, Salonen P. 2009. Self- and Social Regulation in Learning Contexts: An Integrative Perspective, Educ Psych, 44(4):215-226

Winston KA, Van der Vleuten CPM, Scherpbier AJJA. 2010a. An investigation into the design and effectiveness of a mandatory cognitive skills programme for at-risk medical students. Med Teach 32(3):236-243

Winston KA, Van Der Vleuten CPM, Scherpbier AJJA. 2010b. At-risk medical students: Implications of students' voice for the theory and practice of remediation. Med Educ 44:1038-1047

Winston KA, Van Der Vleuten CPM, Scherpbier AJJA. 2012. The Role of the Teacher in remediating at-risk medical students, Med Teach, 34(11):e732-42

Yates J. 2011. Development of a 'toolkit' to identify medical students at risk of failure to thrive on the course: an exploratory retrospective case study. BMC Med Educ, $11(1): 95$

Zimmerman BJ. 2000. Attaining self-regulation: A social cognitive perspective. In M. Boekaerts, P. R. Pintrich, \& M. Zeidner (Eds.), Handbook of self-regulation (pp. 13-39). San Diego, CA: Academic Press 


\section{CHAPTER 6}

\section{Remediation of At-Risk}

Medical Students: Theory in Action

Published as:

Winston KA, Van Der Vleuten CPM, and Scherpbier AJJA. 2013. "Remediation of At-Risk Medical Students: Theory in Action," BMC Medical Education, 13:132, http://www.biomedcentral.com/1472-6920/13/132 


\section{Background}

Throughout higher education, the current increase in both numbers and diversity of students brings with it concerns about maintaining retention rates (Thomas, 2012). When combined with commonlyvoiced concerns that many students entering higher education are illequipped for the rigour of academic work, the need for active efforts to support these at-risk students is clear. However, there is considerable uncertainty about how best to provide this support, and about the precise roles of study skills centres and teachers in these efforts (Barkas, 2011). Within medical education, likewise experiencing an upsurge in enrolment (AAMC, 2012), this has been accompanied by increased research into the efficacy of remediation for underperforming students, with a recent review noting the need for further development and examination of the details of complex interventions (Cleland et al, 2013).

This link between widening access and high attrition is exemplified in our own context, a Caribbean-based US medical school which accepts students from diverse ethnic and socioeconomic backgrounds, most of whom have already failed to gain entry into mainland US medical schools. Our lower admissions criteria (mean MCAT (Medical College Admissions Test) of 23, compared to US mean of 31) contribute to an attrition rate of almost $30 \%$. In attempting to address this challenge, we have developed an Essential Lifelong Learning Skills (ELLS) course, a programme drawing on a blend of constructivist, sociocultural and complexity theories that has resulted in significantly improved long-term outcomes for medical students who fail and repeat their first semester (Winston et al, 2010a). The ELLS course involves faculty-facilitated groups of six students meeting throughout a semester to work through a syllabus that integrates learning study skills and critical thinking with the content of basic science course material (Winston et al, 2010a). Exploration of student and teacher perspectives (Winston et al, 2010b, 2012) enabled us to build a theory of successful remediation: participation needs to be mandated (Winston et al, 2010b), and should provide cognitive and affective support within a small community of inquiry that motivates and challenges the students using a syllabus engendering selfregulatory, metacognitive, and dialogic techniques in small stable groups that meet a sufficient number of times to establish the trusting relationships necessary for the provision and acceptance of effective feedback and the development of more effective academic practices. This community needs a student-centred environment that fosters curiosity and joy for learning with teachers capable of performing a unique combination of roles: facilitator, mentor, disciplinarian, diagnostician and role model (Winston et al, 2012). 
The opinions of all participants converged upon the aforementioned elements of remediation: students and teachers agreed on the ingredients required for success, and that all the teachers were performing these roles. And yet, while groups facilitated by all the programme's teachers statistically outperformed historical controls, highly significant differences were found between those working with experienced and inexperienced teachers in retention and pass rates four semesters after taking this course (Winston et al, 2012). This led to the conclusion that effective negotiation of the complex, contextdependent remediation process demands high levels of teaching presence and practical wisdom - the teaching and contextual expertise that comes with long experience. That teachers are key to educational success is not new (Jaarsma et al, 2008; Postholm, 2010), and neither is the finding that experience matters (DarlingHammond and Youngs, 2002), since development of expertise, practical wisdom and teaching presence is a lifelong process (Aristotle, 2008; Alexander et al, 2009; Rodgers and Raider-Roth, 2006). The significance lies in the fact that it is typical to delegate remediation work to inexperienced teachers or student tutors, despite lack of improved long-term outcomes in such ventures (Devoe et al, 2007; Stegers-Jager et al, 2013) and evidence that experience may be required to maximize the effect of academic support (Winston et al, 2012). However, when teachers themselves use similar language to interpret their own behaviours while their students attain differing outcomes, and when so many studies substitute self-report measures of satisfaction or belief for measures of performance, how are practitioners and administrators to distinguish who and what is most likely to be effective?

Many have questioned the relationship between teachers' beliefs and their actions (Norton et al, 2005; Ben-Peretz, 2011), noting the challenge of accurately articulating practice (Shulman, 1987) and of enacting beliefs and principles (Bolhuis and Voeten, 2004; Bloom, 2011; van de Pol et al, 2012). Furthermore, researchers can only impose their own artificial categories on their findings (Bateson, 1972; Greasley and Ashworth, 2007), and, no matter how carefully the vocabulary they choose is explicitly operationalized (Sfard, 2010), readers can only interpret from their own perspectives (Dewey, 1929). Thus it is no surprise that the education community has trouble pinning down and disseminating what counts as good teaching, and the kinds of questions we have received at workshops on underperforming students have served to underline the wide gap between what is described and what is understood.

Since education is complex (St Julien, 2009), and small groups are complex systems (Winston et al, 2010b; Mennin, 2007), it is from interactions that characteristics emerge (Thomas, 2006; Jörg et al, 
2007; Kauffman, 2008). And so, having generated ideas about a theory of remediation (Winston et al, 2010a, 2010b, 2012), for clarification of exactly how it works (Cook et al, 2008) we must look carefully at classroom life to verify our findings (Dewey, 1929; Shulman, 2007) by exploring actual behaviour in practice (BenPeretz, 2011; van de Pol et al, 2012; Wittgenstein, 2006; Pope and Mays, 2009).

\section{Aims}

The current study examines events in the classrooms of the remediation course for at-risk medical students previously described by Winston et al (2010a). In doing so, we have two intertwined aims. The first is to use the interplay between our theory of remediation and our practice (Freire, 2000; Misawa, 2011; Gibbs et al, 2011) both to verify and test what we have described (Dewey, 1929), and to illuminate and extend our understanding of how remediation works. By illustrating and exploring more deeply the context of our efforts (Regehr, 2010) and documenting examples of our practice (Shulman, 1987), we hope that others can come to fully appreciate this work, and then test and extend the ideas in their own contexts. Thus, our first research question is:

To what extent can examples of remediation practice be used to illuminate and extend the theory of remediation?

The second aim is to seek out differences between experienced and inexperienced teachers' classroom interactions. If differences are identified, they may help explain the noted variation in outcomes (Winston et al, 2012), and provide valuable tools for training novice teachers and promoting development of their practical wisdom (Lunenberg and Korthagen, 2009). Indeed, this should feed into the first aim by informing our theoretical knowledge: as Shulman (1987) so eloquently stated, "The neophyte's stumble becomes the scholar's window." So, our second research question is:

What are the differences between experienced and inexperienced teachers of remediation, and how can these differences deepen our understanding of effective remediation?

Answers to this second research question will, by extension, help answer the first, by providing clear examples of variation in remediation practice. 


\section{Methodology}

Given these aims, this research is necessarily mostly qualitative, as we attempt to provide a rich contextual description that elaborates details of our intervention (Cresswell and Miller, 2000; Gill and Griffin, 2009). Still, we have also continued to track quantitative performance data reported previously (Winston et al, 201a, 2012), specifically the students' basic science completion rates, four semesters after participation in our Essential Lifelong Learning Skills (ELLS) course for students repeating a semester at our medical school.

The lead author, KW, observed and audio-recorded twelve small group sessions led by six different teachers (including KW) working with 49 different students during their participation in ELLS. Eight separate groups of five to seven students were studied (four groups were observed twice), and each small group session lasted approximately 90 minutes. The work was ethically approved by Ross University's Institutional Review Board, and all participants gave informed consent. The resultant nineteen hours of recordings were then transcribed, with repeated careful listening revealing ever more detail (Postholm, 2010), to yield 564 pages of transcript.

Audio-recordings were preferred to video recordings for three main reasons: firstly, participants were more comfortable with less intrusive audio-recording (van Kruiningen, 2013); secondly, one small digital sound recorder enables inclusive capture of all participants' speech, whereas multiple cameras and angles are required to include everyone via video; and, while gesture, gaze and facial expression are undoubtedly important elements of group dynamics, focusing on dialogue allowed us to keep the scope of the project manageable. Indeed, dialogue is the essence of education: it is through dialogic interaction that knowledge emerges (Freire, 2000; Proulx, 2008), through discourse that we think and create meaning (Dewey, 1910; Kuper and Hodges, 2011). There is evidence that the way talk is used in classrooms affects learning (Mercer, 2010), and analysis of classroom talk is core to understanding the effects of remedial interventions (Hull et al, 1991).

Of course, one's choice of method for talk analysis is not neutral, and inevitably affects one's findings (Mauthner and Doucet, 2003). Since our aim is to disambiguate, rather than proliferate, the categories that are evidently open to different interpretations, we have chosen not to create and enumerate codes that divorce the content of talk from its functional context (Mercer, 2010; Roth, 2007). Instead, we treat discourse as a situated, action-oriented tool for the construction of interaction and shared understanding (Edwards and Potter, 2001; Benwell and Stokoe, 2002). Just as seeing a tool in use enables clearer understanding than merely hearing a description, we 
provide representative samples of classroom talk in context as integral to comprehending the application of remediation theory in practice: the medium is very much part of the message. We take a pragmatic approach, drawing on sociocultural discourse analysis (Mercer, 2010), in which the content and function of language are analysed and interpreted, in order to understand how participants' learning and behaviours shape and are shaped by classroom interactions (Mercer, 2010; Bell, 2011).

With such a large amount of data, selections have to be made. Through multiple readings of the transcripts, talk samples have been chosen to illustrate some of the thematic categories previously described in our theory of remediation, samples that seem most suitable for crystallizing understanding. We have also identified talk samples that exemplify newly emergent ideas about differences between experienced and inexperienced teachers (Dewey, 1929; Kennedy and Lingard, 2006; Mitchell, 2010; Seltzer-Kelly et al, 2011). In our results, the talk samples are numbered as TS1, TS2, etc; turns at talk, which, as the basis of dialogue (Sidnell, 2010; Boyd and Markarian, 2011), we take as our fundamental unit of analysis, are numbered as Utterances (U). Students within each group are labelled as S1, S2, etc, while teachers are labelled according to table 1.

In such an analysis, the researcher, as interpreter of discourse, is very much part of the method (Kvale, 1996), and objectivity is clearly a challenge when the principal investigator (KW) is also one of the subjects. However, 'objectivity is a chimera' (Denzin and Lincoln, 2005): all observers bring their own paradigms to their perceptions (Dewey, 1929; Kuhn, 1996), and outsider researchers' unfamiliarity with the context of their subjects often leads to misunderstandings (van Kruiningen, 2013; Maso, 2001) that can ultimately serve to distance researchers from practitioners. Hence the many calls for practitioner research, which affords the opportunity for insider exploration of one case study in enough detail for others to draw lessons applicable to their own contexts (Regehr, 2010), and may thus foster generalization and integration of theory and practice (Baird et al, 1987; Postholm, 2008). So, while the analysis admittedly follows an interpretivist approach suffused with a practitioner-researcher's thoughts, opinions and experience (Bunniss and Kelly, 2010) in one specific context, hopefully some clarity emerges for the broader practice of supporting at-risk students in their academic work. 


\section{Results}

Table 1 presents some data pertaining to the teachers involved in the study. The final column shows the percentage of students who, having worked with a particular teacher during their repeat of first semester, went on to successfully complete the basic science curriculum at the end of their fourth semester. The correlation between context experience, operationalized as number of years teaching at this school, and long-term pass rate is 0.81 . The correlation between total teaching experience and long-term pass rate is 0.72 . These are high, suggesting that $51 \%-65 \%$ of the variance in student outcome could be due to teacher experience. While many other factors must be involved, this is worth exploring.

Table 1: Teachers' experience and their students' long term outcomes

\begin{tabular}{l|cccc}
\hline Teacher & $\begin{array}{c}\text { Highest } \\
\text { Qualification }\end{array}$ & $\begin{array}{c}\text { Teaching } \\
\text { Experience } \\
\text { (yrs) }\end{array}$ & $\begin{array}{c}\text { Context } \\
\text { Experience } \\
\text { (yrs) }\end{array}$ & $\begin{array}{c}\text { \% students } \\
\text { passing 4 } \\
\text { semester }\end{array}$ \\
\hline T1 & MSc & 4 & 2 & $35 \%(\mathrm{n}=20)$ \\
T2 & PhD & 5 & 1 & $36 \%(11)$ \\
T3 & MD & 5 & 3 & $44 \%(66)$ \\
T4 & MBBS & 15 & 3 & $50 \%(14)$ \\
T5 & MEd & 28 & 10 & $70 \%(162)$ \\
T6 & MEd,MA & $40+$ & 7 & $62 \%(139)$ \\
T7* & DVM & 3 & 3 & $54 \%(90)$ \\
T8* & PhD & 4 & 2 & $51 \%(72)$ \\
T9* & PhD & 39 & 12 & $60 \%(25)$ \\
\hline
\end{tabular}

*left the school prior to this study, but was included in the previous study, Winston et al, 2012

A number of sharp differences between teachers emerged from the recordings and observations. For example, one of the students' favourite exercises (Winston et al, 2010b) is working with practice multiple-choice questions (MCQ). After reading the question stem, the experienced teachers ( $\mathrm{T} 5$ and $\mathrm{T} 6$ ) insist that their groups rephrase the question and discuss it in detail, typically spending around ten minutes exploring definitions and relations between terms, thoroughly eliciting ideas before allowing their groups to consider the answer choices. The other teachers averaged about one minute doing this. This difference is reminiscent of the way experts slow down and take more time planning their approach to problems than novices (Zimmerman, 2002; Eva and Regehr, 2011). Talk Sample 1 (TS1) 
demonstrates how this can play out in the classroom. Note the lengthy silence at Utterance 3 (TS1.U3): expecting answers to questions, and waiting for them, is a key element of rigorous facilitation. At TS1.U6 the teacher observes the difference between the two responses, a move that required attentive listening from the teacher, and exposes a clear misunderstanding. On the rare occasions that inexperienced teachers required rephrasing of the question, they did not go on to press the students to explore differences between their versions. In U8 we see a diagnostic intervention, a challenge for specificity, a query that is reiterated in U16: this tenacity, the refusal to let a question go unanswered, seems to be a hallmark of the expert teachers rarely displayed by their less experienced counterparts. In $\mathrm{U} 12$ we see a deliberate attempt to draw another group member into the conversation, and likewise in U26, where other group members are asked to verify the accuracy of S2's contribution: noteworthy here is that the facilitator neither provides the answers, nor acts as the verifier of content accuracy. This typically results in the group resolving their own understanding, self-correcting (U11, U14) and supporting each other's ideas (U13, U27), especially when invited to predict the answer (U24). The sequence at U19 to U22 shows the student asked to finally reformulate the question indulging in light-hearted mimicry, playfulness that is encouraged by the teacher and aids group cohesion, a type of behaviour that actually occurred in the groups of all the teachers: the nurturing mentor role seems much easier for the inexperienced teachers than the roles of disruptive facilitator, disciplinarian and diagnostician.

Talk Sample 1 - T5, Working with a multiple choice question (MCQ), $7^{\text {th }}$ group meeting:

1. T5: Ok, so read the question for us.

2. S1: Okay, so Phosphoinositide-3-kinase forms inositol phospholipids that are phosphorylated in position 3. Normally, this phosphate group is removed by the lipid phosphatase PTEN. When a cell loses PTEN through somatic mutations, the most likely effect of this will be?

3. T5: Okay, so let's rephrase the question. [20 seconds silence]

4. S2: Okay, when a cell cannot remove a phosphate group, this would most likely lead to?

5. S3: When the cell can't remove the phosphoinos 3 kinase that will result into?

6. T5: Okay, those are very different.

7. S3: Yes. I just figured if you can't remove the phosphate you can't get rid of the phosphoinositol-3-kinase.

8. T: What is it you can't remove the phosphate from? 
9. S3: From PI3 kinase, you have to remove it, it has a phosphate on the third position, right?

10. $T$ : Is there a problem reading it that way?

11. S3: No, it's not that, I'm sorry. It forms phospholipids that are phosphorylated on the third position, because of the kinase. I'm sorry.

12. T5: So how would you rephrase this? [turning to s4; another long silence ensues]

13. S4: I would do the same way she did, if you can't remove the phosphate group, what happens?

14. S2: But I made a mistake too, because it has to be IP3 pathway, because if it's anywhere else, it's different.

15. S3: So it's a different pathway.

16. T5: So if you don't remove the phosphate group from what, I think that's the piece that we're missing.

17. S3: It's from the IP3?

18. S4: Same thing as she said, just remember it's the IP3 pathway.

19. T5: So say it again then, but include that piece.

20. S4: IP3 comma [others laughing]

21. T5: Absolutely, go for it, yes.

22. S4: IP3, if you, what was it, um, if you can't remove the phosphate, what happens?

23. S2: Yes, that's right.

24. T5: So then before reading the choices, what do you think would happen, what do you know about this pathway?

25. S2: First I know, no matter what it is, it's going to be an active pathway because sometimes when you phosphorylate things, it inactivates it, but this cascades, definitely something that will occur, something will be like stimulated, not inhibited.

26. T5: Yes, no?

27. S4: Yes, it's just the two things that get, the IP3 phosphorylates them, the PKB or the AKT, just keeps getting phosphorylated, so it constantly kicks them onto the cascade, like nonstop.

28. T5: Okay. So now let's go through the choices one at a time.

Talk Sample 2 - T5, After answering the MCQ from TS1, later in $7^{\text {th }}$ group meeting:

1. T5: But again, it's important to be clear what the question is getting at, because it was very densely worded, wasn't it?

2. S4: Yeah, it was, like I have no idea what PT and EN means.

3. S2, S5: Me too

4. T5: But you didn't need to know, because it told you what it does. 
5. S6: That's when I like, because I have it all the time, like I see a word that I've never seen before and I freak out.

6. T5: This is why this exercise of rephrasing is so important. In the previous question we were talking about with seizures, you haven't done seizures really yet, but it told you what seizures are in the question. Here, he's told you what PTEN does, so you went straight to the point and said, okay, we're not removing the phosphate, that was good.

TS2 is a sequence occurring after discussion of the answer choices has led to resolution of the question. Before allowing the group to move on, there is a recap of what happened. In $U 1$, the challenge they faced at the beginning is noted, with the 'dense wording' offered as an explanation. This ploy allows group members the space to admit difficulties, a prerequisite for improvement: we see three students voice agreement about the problem (U2, U3), and this encourages S6 to elaborate on his anxiety (U5). The teacher then summarizes the importance of the skill and reminds them of a similar example from which they can begin to generalise, while also finding a way to praise, very specifically, what they did well. These 'metacognitive time-outs' for attending to process happened multiple times in the classrooms of experienced teachers, but almost never with the inexperienced teachers.

TS3 and TS4 offer a contrast to the previous two samples. As before, a student has just read a multiple choice question written by that student as a homework assignment. TS3.U1 is a good opening move, inviting discussion of the question format, as is the follow-up question (U4). However, accepting that it is clear to everyone on the response of one student (U5) is a missed opportunity to uncover any misunderstandings in the group: she could then have asked others to rephrase the question stem, or probed them to predict the answer before examining the answer choices, moves that elicit careful thought and expose uncertainty. Likewise, the initial moves in TS4 are positive (U1, U3), eliciting student reflection on the construction of the question (U4). The teacher then nurturingly validates the student's framing of her approach to learning - the unproductive classroom game of guessing what the lecturer wants (Hutchison and Hammer, 2010), going as far as to suggest that this is their goal (U7). Yet this should most definitely not be their long-term goal. The real challenge is to inculcate a curiosity, an approach to learning that will carry them throughout their careers. Indeed, even if the object were to 'get inside the lecturer's head', the best way to guess how an expert thinks is surely to learn to think as an expert. In this example, there was an excellent opportunity to press this point. In TS3, the students have agreed that this is a straight recall question, but in 
TS4.U4 the student claims her aim was to create a secondary question. A really helpful move would have been to call them on this, and then get the group to re-create the question together, to discuss what a secondary question actually looks like, and implement the wording collaboratively. In this particular example they could easily have replaced the answer choices stating anatomical structures for choices describing clinical deficits ensuing from damage to those structures. Indeed, T6, when dissatisfied with the questions produced by her group, had the students step back, identify the organisational structure and key points of the relevant lecture, and then produce a question together on the whiteboard. Seeing this opportunity in the moment of classroom action partly depends on a kind of contextual expertise, on having seen discussion of enough questions to know the type students struggle with, and partly on the adaptability and presence to follow through on those teaching moments that arise spontaneously as students expose their knowledge and shortcomings.

Talk Sample $3-T 2$, Working with an MCQ, $7^{\text {th }}$ group meeting:

1. T2: How does that question sound before you go on answering it?

2. S1: It's a memorization question.

3. S3: Recall.

4. T2: Is it clear though?

5. S3: Yes, it's pretty clear.

6. T2: Then looking at the choices, what about a)?

Talk Sample $4-T 2$, After answering the MCQ from TS3, later in $7^{\text {th }}$ group meeting:

1. T2: And S1, how was it going through the man being stabbed?

2. S1: I tried to hit three different topics so I did anatomy, then did one embryo, and then one on neural tissue so I was just trying to spread it out evenly.

3. T2: But then how you actually wrote it though, taking that ...?

4. S1: I tried to make it similar to a secondary question they would ask on a mini because I know Dr.X loves those questions about a man was shot here, stabbed here or fell on this portion of his arm, what would be the deficit seen?

5. T2: So you got into her head a little bit with how she props up the questions...

6. S1: Tried to, yeah.

7. T2: That's our goal as a practice, right? All right. 
Talk Sample $5-T 6,22^{\text {nd }}$ group meeting

1. S1: I'll tell you what, Y's lecture was heavy yesterday. Really heavy.

2. S5: I like her lecture though.

3. S1: I don't like developmental for some reason. Embryology is like, so we came about, we're here, now what. I mean we've got to learn it.

4. T6: Does anyone love the embryology?

5. S4: I do.

6. T6: What do you see in it, that she's hating.

7. S4: I don't know. I mean it's just, a lot of diseases that we can't cure yet are congenital, embryological

8. S1: Yeah

9. S4: And if you can't repair it surgically, then there's really no cure for it. Or it's an enzyme defect, so, I don't know. It's like a frontier, it's like neurology, people don't really know everything about it.

10. S1: I think it's because we can't do as much about it too, you know what I mean?

11. T6: It's also very hard to visualize

12. S1: It is, it's very hard to visualize

13. S2: Embryology? Yes. I've been looking for embryology videos since first semester.

TS5 is an example of how one can help foster curiosity, the joy of learning for its own sake, so absent in TS4. After the comment about disliking embryology (U3), there was a danger of the group focusing on unhelpful negativity, but this is expertly refocused towards appreciative enquiry (U4), especially when S4 is encouraged to elaborate on his love of embryology (U6). Engaging the group in this kind of positive social regulation (Volet et al, 2009) is invaluable for students struggling with the stigma of failure, especially when displays of intellectual enthusiasm are so often disparaged among modern students (Benwell and Stokoe, 2002). At the same time the teacher manages to validate the challenge they face (U11), which draws in another student to the conversation (U13). This last comment provides a space for sharing of resources - it just so happens that this teacher has been collecting links to embryology videos for several years, another facet of her contextual experience.

TS6, on the other hand, shows one student interacting with the teacher in a conversation about their time-management assignment. This sample exemplifies the initiation-response-feedback (IRF) format of classroom dialogue that positions the teacher as the authority in the classroom (Hicks, 2003). This was the dominant form of discourse in the groups of less experienced teachers, with students taking turns 
to engage with the teacher. Although there was some studentstudent interaction in discussions of content, conversations about process (with T1 - T4) were almost exclusively in this IRF format that does so little to promote the social-regulatory group dynamic of a genuine enquiry-based classroom. In TS6.U3 the teacher does a good job of checking whether the student attempted to stick to the schedule he made, but then, after hearing the student's explanation (U4), the suggestion is to simply try more of the same (U5), which gets a predictable non-committal response (U6). Instead, T4 could have picked up on the fact that the student has twice said his schedule is too dense (U2, U4), and asked him to point out a specific example. If they had then focused on this, and other group members had been invited to offer potential solutions, everyone would have been more engaged. The comment at U8, however, implies that perhaps his schedule was not so dense after all, and indeed the student appears somewhat defensive, positioning himself in opposition to 'you guys'. Although the teacher then does well to validate his stance and behaviours (U9), he could, for example, have gone on to highlight one section of his schedule, and then asked the group to help re-work it towards something more realistic for him. And then, when the student reveals he has produced a new version for the coming week (U10), the teacher doesn't ask him to share or compare this new version with the one they have discussed, but simply moves on to the next student, thus missing the opportunity to further practice the self-regulatory processes of reflection and planning.

\section{Talk Sample 6 - T4, time management, $3^{\text {rd }}$ group meeting}

1. T4: And how about yours?

2. S1: I'm not good with the schedule thing. I mean, I wrote stuff out, but it's too dense and there's no way I can stick to the schedule that I made.

3. T4: You tried that?

4. S1: Yeah, I tried, I mean I tried, it's just impossible cos I think I make it too dense. And I want to do all this stuff and it's like, well I'm gonna add another hour to that, and I'm gonna add another hour to that, and this and that, but I'm better off listing what I'm going to get done during the day and having my blocks of study.

5. T4: I think, you have only made two weeks that you have completed this way, so you can give a try again and see how it goes.

6. S1: Ok.

7. T4: So in that whole one week you could not achieve what you wanted in that week?

8. S1: Well I mean I study, I touch on everything, but it's just like a matter of, you know, how successful you can be. That's why I do 
it in two hour blocks. You guys say to do it in one hour blocks, but I give myself 2 hours because I know in that 2 hours I might take a break or I might, not like take a break as in go off to eat, but take a break mentally, or you know, just kind of add in some leeway here.

9. T4: That's ok. You need those things, I don't disagree at all. His schedule is even more detailed, he has filled it with minute things every hour. Really great if you can follow this actually.

10. S1: I think it would be, that's why I tried. Last night I did the one for this week.

Talk Sample 7 - T5, drawing, $21^{\text {st }}$ group meeting

1. S2: That was the point I was going to bring up after you answered this question because all, when these, the development of all these vessels, it's like it's just pretty much memorisation. I was just wondering if you guys have any easier way to memorise all that or not memorise but remember all that.

2. S6: I just like drew it out.

3. S2: Yes, I drew it out last semester, but it didn't help.

4. T5: Let's see it.

5. S2: I didn't actually draw it out. I just wrote it out.

6. T5: You drew it out? [Directed at S6]

7. S6: Yes, like this one's really easy. You either know it or you don't. Like, her pictures are really small, but they make a lot of sense. [And he gets up, starts drawing on board, and explaining as he goes (cardinal veins, etc), with others chipping in to add to his explanation. It takes less than a minute.] ...

8. S5: Yeah, you just have to figure out if it's left or right, and then you can remember pictures.

9. S2: Yeah, that would have helped me, cos it just broke it down.

10. T5: That picture was good.

11. S2: I guess I can try that. But this is going to take time for me.

12. T5: How long did it take him to draw that? [ss laughing]

13. S2: I don't know. I just... Because I would have to sit down for all these other things, draw it out.

14. T5: Do you remember that conversation we had a couple of weeks ago?

15. S6: Well, like, this is what I'm saying, if you draw it out, the SSVC, then this one makes sense. I had to draw it out, otherwise I won't remember it.

16. S5: It only took me thirty minutes. I maximised the screen as much as I could, and then I drew it out. The pictures are really good.

17. S2: Yeah. 
18. S5: Like the same thing with the superior mediastinum. There's a lot of information. It took me 20 minutes to do this thing because I can't draw but I have to like draw it properly. It took me only 15 minutes to draw and after that I just knew where it is. Because you draw it based on what it says, like in words, but I can't memorize the words.

19. T5: It's twice in a session we've had a drawing suddenly make it clear. That was really quick and clear. And then, when you drew your arrows, that was the moment when everyone goes "oh yeah". [laughter, general agreement] It doesn't take long to do it, and it doesn't have to be beautiful.

20. S2: Yeah, no, I know.

Some effects of promoting group discussion and reflection on process are illustrated in TS7. We join the group after a question on embryological development of blood vessels has been resolved. At this late stage of the semester, students have become comfortable raising questions about both content and process in the group, as we see in TS7.U1. After S6 responds with his method of drawing (U2), we see U3 claim that drawing didn't help. At U4, the teacher asks to see his earlier work, a suggestion with a powerful purpose: struggling students frequently claim that a method didn't work for them, typically because of either ineffective or non-existent implementation. In the former case, displaying his drawing would have enabled the group to examine it and identify ways to improve it. In this case, however, we see the latter outcome, affording the opportunity to enlist a group effort (U6). For the remainder of this segment, we see the efforts that S2's colleagues make to persuade him of the value of drawing, spontaneously creating a drawing on the board, and reinforcing each other's explanation. Note, for example, how S5 (in U16) picks up on S6's earlier comment about the small size of the image in the lecture (U7), provides a solution, and even praises the quality of the material. This last point is a real achievement: getting students who failed to appreciate the positives in lecture material, and find workarounds for the less effective parts, is an important attitudinal shift from the common starting point of blaming the poor quality of the teaching for their struggles. After the teacher has praised these efforts (U10), S2 is still hedging (U11). This is common - a student agreeing a method is a good idea, but then quickly rationalising why perhaps he still might not do it. It's important to call them on this, as T5 does in U12, a move lent support by the subsequent contributions of S5 and S6. In response to further resistance (U13), the gentle reminder of an earlier discussion (U14) about the importance of fully exploring ideas and adapting them to their own needs is a pointer to the importance of group continuity and stability, and is part of the disciplinary and 
mentorial aspects of the teacher's role. The sample ends with another example of the metacognitive generalisation by experienced teachers mentioned earlier, with T5 highlighting how effective S2's earlier drawing to explain blood flow through the heart had been in creating group understanding. Indeed, this particular student, s2, was, eventually, so thoroughly convinced that when he reached his fourth semester he volunteered to speak to the new batch of repeating first semesters about the importance of fully participating in the course.

Talk samples 8 and 9 highlight the kinds of confusion that can develop when students are pressed to explore content in detail. In TS8, the group has settled on an answer to a biochemistry question they have been discussing. The teacher's response (U2) to the opening question (U1) effectively problematizes an issue the students had earlier sidestepped - they had been unable to find a clear reason to eliminate one of the wrong answer choices, ferrochelatase. However, instead of affirming the correct answer with 'yeah', she could have invited the whole group to consider their confidence in their chosen answer choice, and to identify for themselves what they were unsure of: earlier in the course the students are introduced to confidence marking (Caleon and Subramaniam, 2010; Leggett et al, 2012) and encouraging regular practice of this calibration technique aids development of students' self-regulatory habits. Nevertheless, T1 has successfully exposed a major misunderstanding of the structure of hemoglobin that goes way beyond the function of this particular enzyme (ferrochelatase). Allowing this confusion to play out between the students is certainly reasonable, but sometimes facilitator intervention is helpful. For example, when S4 disagrees (U9) with the preceding statement, it may have been wise to flag this disagreement and ask them to make their positions explicit. More troubling is the failure to challenge the inconsistency of S4's statements at U6 and $\mathrm{U} 12$, both of which receive support from other group members. The logic of the two statements taken together could imply that protoporphyrin and iron are the same thing, and yet the group would certainly not agree with that proposition. Drawing the group's attention to this would have caused them to rethink their argument much more carefully; doing this repeatedly through a whole semester can go a long way towards helping them to hone their critical thinking skills. The ability to catch these errors often appears, to observers, to be about the teacher's content knowledge, but in fact it depends more on attentiveness, curiosity, and the ability to follow the logic of students' argument; in this study, the two most experienced teachers (T5 and T6) have 'lower' content-related qualifications than their colleagues. 
Talk Sample 8 - T1, $10^{\text {th }}$ group meeting

1. S2: Is $C$ the right answer then?

2. T1: Yeah, but back to ferrochelatase. Tell me what it does.

3. S1: So you have like your iron molecule, and like your heme molecule, which is also called protoporphyrin 9.

4. S3: Yeah

5. S1: And then that combines the two together. That's like the iron to the heme, and it makes, like, hemoglobin. No, not hemoglobin. Is it?

6. S4: You're adding heme to protoporphyrin, so it is hemoglobin.

7. S2: Yeah, so it is hemoglobin.

8. S1: No, heme is the same thing as protoporphyrin.

9. S4: No.

10. S1: Iron is put into heme. Heme and iron make up

11. S3: Heme and iron make up hemoglobin.

12. S4: Yes. So four subunits of heme plus an iron make up hemoglobin.

13. S5: Yeah.

14. S4: Okay, so this guy, ferrochelatase, makes, you said, heme plus

15. S1: I'm pretty sure, it's like the last step, right? Do you know?

16. S3: I don't remember.

17. S1: It's either that one or the one before. I'll check. I just looked at it too.

18. T1: You just looked at it?

19. S1: Yeah. And now I'm second guessing myself.

20. T1: Well, when you review, then you'll never forget.

TS8 ends with another major missed opportunity, as T1 optimistically hopes that a later review (which may or may not happen) will suffice (U20), instead of unpacking what has just happened and pursuing an alternative approach to understanding. Early in the course there are sessions in which the explicit focus is on language and medical terminology, with assignments on definitions, analogy, and word roots. As with the confidence marking, T1 fails to link back to these longitudinal course themes. In this sequence, she could have directed the students to break down these terms into their roots (proto, heme, globin, chelate, etc), a technique that most likely would have been enlightening. In the classrooms of experienced teachers, language becomes a major thread throughout the course, and they continuously raise students' awareness of loose jargon, ambiguous pronouns, confused direction of causation, and unnoticed common word roots, thus enhancing both their content and process understanding.

TS9 illustrates this difference between teachers. The group has just read through a handout that introduces the importance of asking 
questions, and takes them through an exercise in which they ask each other questions about one lecture of their choice, using primary, secondary and tertiary questions. One of the students has asked how Parkinson's disease might appear in a 65-year-old patient, and, as in TS8, the group have talked themselves into a thorough groupthink misunderstanding by U13. At U14, the teacher asks a really simple question, which is pressed at U16 and U20 and further simplified at U23, with justification for this probing given at U18. Notice how this elicits the admission that they don't know the meaning of this term (U17, U21): everyday English can be as problematic as technical jargon. Then, when S2 actually draws and demonstrates, we get an in-class eureka moment (U25 - U29). This took less than a minute (from U14 to U25), and is clearly more effective than the way it was left hanging at the end of TS8.

Talk Sample 9 - T5, asking questions, $3^{\text {rd }}$ group meeting

1. S5: I think there's the gait

2. S1: cog-wheel

3. S2: It's called cog-wheel rigidity.

4. S3: The gait is the shuffling gait.

5. S1: and there's the pill-rolling. What's the name for pill-rolling?

6. S5: It's called pill-rolling

7. S1: That's the cog-wheel?

8. S2: No, no, the cog wheel is like...

9. S1: so what is the pill-rolling?

10. S5: that is after. The first one is the patient won't even know it, but the doctor will pick up on it when they come in, like he'll notice a lack of...

11. S2: the cog-wheel rigidity, right?

12. S4: Yeah, that's what cog-wheel rigidity is, the doctor notices but the patient is unaware.

13. S1: good deal.

14. T5: What is a cog-wheel?

15. S5: rigidity

16. T5: What is a cog-wheel?

17. S5: I don't know exactly what a cog-wheel is.

18. T5: You keep skipping the fundamental questions, but I think they're the most important.

19. S1: It's the, er, I want to say it's the reduced range of motion in the arm. That's the cog-wheel rigidity.

20. T5: What is a cog-wheel? Or a cog?

21. S1: I have no idea.

22. S2: A cog is in a machine

23. T5: Exactly what is it? 
24. S2: It's er, you know the big old clocks? And then they have little rivets [draws a cog wheel on the board]. You know, and then they move, like this [demonstrates jerky movement]

25. Ss: oh [sudden understanding all around]

26. S4: That worked!

27. S3: Now I'll never forget it.

28. S1: So it's gonna move like a clock.

29. S5: Like a clock.

The remaining three talk samples, all taken from a single session in which the group is collaboratively creating a concept map of a challenging biochemistry lecture, draw out a number of the preceding themes. As preparation, students were asked to prepare a key word list for the lecture, but none had actually done so. The teacher responds adaptively, suggesting an alternative approach by inviting them to summarize the lecture, while noting, throughout the ensuing process, the points where the original approach would have been beneficial, as exemplified in TS10.U1. In this initial phase (TS10), it is often necessary to be somewhat directive, as at U9, and to ensure clarity, as with the reformulation offered in U12. Indeed, there were a couple of times during the session when the teacher went to the whiteboard to demonstrate how a just-discussed link or idea might be represented, revealing the possibilities of the technique. This level of interference is valuable in early stages of concept map training, as long as it is used sparingly, and is simply another example of facilitative reformulation and modelling. It is, of course, important to draw everyone in to the process, making $\mathrm{U} 6$ a key comment. The sequence from U13 to U19 is especially helpful with respect to this development of group ownership of the task. S2 has raised an objection (U13) to what has just gone on to the board, which despite apparent acknowledgement from S1 (U14), is ignored by S5 and is not being reflected in the drawing. The teacher's reformulation at U17 works to establish ground rules and promote teamwork skills, validating the contribution from a quieter voice, and giving her the confidence and space to restate her point with clarity in U19. This noticing, of a quiet voice, tentative disagreement, or even just a puzzled facial expression, and then drawing that student to voice, or re-voice, her concern, is essential to building trust and a group dynamic where all contributions are valued, and willingly offered.

Talk Sample 10 - T5, concept mapping initiation, $6^{\text {th }}$ group meeting

1. T5: So, if you're gonna... this is the piece, for me the most important piece is to get an overall organisation, a structure to it. So, I've always found it easiest to see all the words in one space, 
but if you don't want to do that, is it all one? Are there sections you can divide it into?

2. S4: The different types of receptors, and the different types of signalling cascades.

3. T5: Ok. That's it? That's the whole thing?

4. S4: That's how I would divide it, is into the specific types

5. S6: And the pathways of the signals. Like divide into the specific types, then under each types you write the pathway that type takes in order to have an effect.

6. T5: Does everyone agree with that structure?

7. S3: Yeah.

8. S6: Cos that's what he talked about, receptors, and, you know, how they respond to hormones. Like you have the receptor that is responding to hormone, but it just don't respond, it has to go through a pathway, so he spent most of his time talking about those signalling pathways that it goes through, and what can happen. Like if this goes through three different steps, maybe if you stop it on this step, what's going to happen.

9. T5: Ok. So if you were going to present this as a concept map to me, to show me this broad outline of the lecture, how would it look? Could we put that on the board?

10. S1: He divides them first, between the soluble receptors and the insoluble receptors, those that can come into the cell and those that cannot

11. S5: right

12. T5: So there's two broad classes then. Ok, so write 'receptor' right in the middle there.

13. S2: Wouldn't it be hormones that are soluble or insoluble. The receptors are, like, membrane bound or not

14. S1: Yeah. So soluble hormones would get into the cell

15. S2: right but

16. S5: but like location of receptors you could put

17. T5: But what $\mathrm{S} 2$ is saying is that it's not receptors that are soluble, it's the hormones

18. Ss: It's the hormones.

19. S2: So I just mean that instead of having 'receptors' up there, shouldn't that be 'hormones'?

The group then gets involved in constructing their concept map, classifying, structuring, and thinking carefully about similarities and differences between pathways. Talk Sample 11 occurs about an hour into the process, when discussion has turned to the effects of cholera toxin. By this time, we see the group largely self-directing their work, providing their own suggestions about how best to represent their ideas (U2, U6), and prompts towards deeper exploration (U7) that 
are actively taken up (U8). Still, the teacher continues to ensure the students take care about the accuracy of their work (U4): pointing out the need for self-disciplined thinking, whether that is through verbal or physical representation, remains an essential element of rigorous facilitation. This demand for high expectations is exemplified at $\mathrm{U} 10$ and $\mathrm{U} 12$. Although the group has already agreed on how cholera toxin exerts its effect, the teacher inserts two disruptive questions to challenge their comfortable consensus. This again highlights the value of attentive listening, contextual expertise and group stability: in the previous week, this group had briefly mentioned cholera when discussing a question from a histology lecture. Here, after the problematization of their discussion (U12), we see the group in genuine collaborative knowledge construction, completing each other's sentences (U13 - U24) as they work through the details of the process, culminating in $\mathrm{S} 1$ explicitly making the link between the two lectures (U22, U25). This realisation was followed by discussion about differences in level of detail between the two lectures, and proposals for bridging concepts across the two disciplines. Getting 'weak' students to make these kinds of links is real achievement, and is not uncommon in the groups of experienced teachers. In another example, a group was struggling with the concepts of preload and afterload in cardiac physiology: they were trying to solve a question about the left atrium, and were convinced the terms could only be applied to the ventricles, in relation to which the terms had been taught. A simple question from the teacher, "So there's no pressure and volume in the atrium?" prompted lengthy discussion resulting in "I mean we learned about preload, afterload and contractility with just muscles. Yes, I think it can be applied to atrium as well." For students who have been struggling, these carefully timed prompts have the power to transform their thinking and enhance the likelihood of knowledge transfer occurring.

Talk Sample 11 - T5, concept mapping, $6^{\text {th }}$ group meeting

1. T5: Ok. So how are you going to capture that?

2. S2: You could write, like, cholera, and then write like a whole bunch of increase arrows to $\mathrm{G}_{\mathrm{s}}$

3. S5: Ok, so [writing on whiteboard]

4. T5: To $G_{s}$, not to just $G$. where you point it matters, doesn't it? You can't allow yourself to make that slight inaccuracy.

5. S5: Oh....cholera

6. S2: and just write some up arrows, there

7. S1: Do you want to write how exactly it has an effect? Cos he mentions that. 
8. S5: ..to $G_{s}$, and it causes high CAMP, which makes sense, and then high CAMP, should I say equals diarrhoea? Or high cAMP is watery diarrhoea?

9. S2, S3: Yeah

10. T5: Well, why does it give you watery diarrhoea?

11. S5: Cos you have too much cAMP.

12. T5: CAMP is watery?

13. S4: No, it erm

14. S1: it's the way it acts on the intestine.

15. S3, S2: yeah

16. S1: Too much cAMP on the tissue itself

17. S5: causes

18. S1, S3: diarrhoea

19. S2: It's cos er electrolyte

20. S5: imbalance.

21. S2: Just like the release of electrolytes into fluids

22. S1: But even, think about cholera, go back to epithelium.

23. S4: Yeah, with the zona pellucida

24. S3: with the junctions

25. S1: Yeah, when it breaks the junction, and by breaking the cells the water comes in, so these two are related.

Shortly after TS11, an hour and seven minutes into this session, the teacher asks how much of the lecture has been covered. The group members reach consensus that they are only a quarter way through this three-hour lecture topic and feel that there is still a lot left to cover. At this point, the teacher presses them to be explicit about what is missing from their concept map. This final sample, TS12, occurs 14 minutes later.

Talk Sample 12 - T5, concept mapping reflection, $6^{\text {th }}$ group meeting

1. T5: Ok. Now how far have we got in the lecture?

2. S5: I think we're done.

3. T5: Ok. So when you said we were only a quarter done, about ten minutes ago, we must have been considerably more than a quarter done.

4. S5: Or we worked really fast. [ss laughter]

5. T5: Or we worked really fast. So which was it?

6. S5: A little bit of both, I think.

7. T5: Well, how is it that we worked faster?

8. S3: Cos a lot of the things

9. S6: were organized.

10. S4: We had a certain ending 
11. T5: We had something going. It takes times to get started, and I think that's okay. Okay, so now an obvious next question is what happened in this session?

12. S1: We found out that we need to be organized, I found out, I'll speak for myself.

13. S5: There's weak areas, where we had a hard time

14. S3: And also doing it like this make me see the big picture more clearly.

15. T5: Are we missing details?

16. S3: Yeah.

17. S5: This is kind of like an overview, you're still going have to study on your own.

18. S1: But not the itty bitty details though, cos we covered pretty much, like $G_{i}, G_{s}$,

19. S5: That's true. Um, what else?

20. S1: The cyclic AMP can have an effect on the smooth muscle, can it?

21. S3: $\mathrm{mhm}$.

22. S4: It's up there, we got that already.

23. S1: Exactly, so ... that's not bad. And it's still part of that, like a big picture, it's already there.

24. S5: Yeah. I guess. Was it beneficial? Do you guys understand it better now?

25. S3: I could

26. S6: I think so. It's clearer.

27. S4: Yeah, I think so.

28. S6: I think the best is to study with someone, cos there's maybe a lot of things I thought I knew here, and it's like, whoa...

29. S4: I think one good thing about this that I noticed, is that leaving out the details forces you to remember, and to recall, and I never do that, I always write down all the little details.

30. T5: But you can trust yourself.

31. S4: Yeah

32. T5: Cos actually it's quite interesting how many details you do know. I think, you know a lot of details, if you can use triggers. And how much more detail do we need than this, I wonder, really? I bet, when you do the practice questions, you'll discover one or two details that we did miss and should have been in, but not many.

The comment at TS12.U3 stems from contextual knowledge of at-risk medical students, and is used to elicit discussion on a common issue: the overestimation of how much they have to do often leads to paralysis, making it worth pressing them to objectively account for the volume of work confronting them, so that it can then be divided 
and managed. When S5 jokingly offers an alternative explanation (U4), the teacher embraces his implicit challenge and expects elaboration (U5, U7), leading into thoughtful, collaborative response (U8 $\mathrm{U} 10)$ that is aided by a further prompt to reflect on the whole session (U11). The question about missing details (U15) similarly displays strong knowledge of the learners: fear of missing details that might feature on exams, and inability to select what is important, is overwhelming for students, and results in copious unmanageable notes, often blindly copied from the lecture handouts. The sequence from U16 to U29 shows the group grappling with this difficulty, and by a process of social regulation they reach the explicit conclusion (U29) that excluding detail brings its own benefits. Note also how S5, who had been a prime doubter of this process, takes on the role of facilitator (U24), an example, perhaps, of goal contagion (Eren, 2009), whereby group members become infected with each other's goals, so that the glow of successful task completion spills over into positive affect that imbues subsequent work. The last comment (U32) generalizes the students' conclusion, and links back to a previously taught method of identifying and plugging knowledge gaps, a metacognitive linking moment that we have seen to be a hallmark of teaching expertise in this context.

Further examples could undoubtedly reveal additional insights into remediation of at-risk medical students, but these dozen talk samples hopefully provide adequate flavour of the patterns of interaction in these classrooms. We finish this section with one brief, final example:

\section{Talk sample $13-T 5$, at the beginning of $21^{\text {st }}$ session}

1. T5: Okay, so any questions or comments or problems or anything? [4 sec pause]

2. S3: Oh, I have a comment. I was just finding it interesting yesterday some of my friends from second semester were telling me things about the GI and renal things and stuff, and I just kept asking them so why does it do that or why is it like that and they were like we don't know, it just does, and it was just funny because I feel like, now I'm curious about it and I'm asking questions.

\section{Discussion}

Before offering a summary of the key points raised in the results section, and discussing how they relate to our original aims and developing theory, we sound a brief note of caution. Having drawn on education theory to create a remediation programme (Winston et al, 
2010a), and then extended remediation theory based on participant perspectives and descriptions of practice (Winston et al, 2010b, 2012), we discovered that although participants offered similar views of their experience, their outcomes differed considerably (Winston et al, 2012). In this paper we have sought to disambiguate the language of that theory by sharing exemplars of classroom talk. In attempting to summarise our findings, we are in danger of re-creating that ambiguity by replacing the source of our understanding with descriptive labels and generalization (Wittgenstein, 1967; Bateson, 1979). But the function of talk is embedded in its context (Bell, 2011; Boyd and Markarian, 2011), language and knowledge are inseparable from the interactions in which they emerge (Dewey, 1938; Varela et al, 1991). Abstracting to theory from practice always risks producing a false dichotomy, as the two can only be fully understood in conjunction, through experience (Dewey, 1929; Misawa, 2011). The following needs to be understood in light of this caveat, as a linear presentation, due to the constraints of language, of fundamentally interconnected ideas. 
Table 2: Summary of key differences between experienced and inexperienced teachers

\begin{tabular}{|l|l|l|}
\hline Trait/behaviour & $\begin{array}{l}\text { Experienced } \\
\text { teachers }\end{array}$ & Inexperienced teachers \\
\hline Nurturing mentor & $\begin{array}{l}\text { High expectations; model and } \\
\text { expect appreciative inquiry, } \\
\text { curiosity and intellectual } \\
\text { enthusiasm }\end{array}$ & $\begin{array}{l}\text { Over-value affect; allow } \\
\text { unproductive framing }\end{array}$ \\
\hline $\begin{array}{l}\text { Challenging, } \\
\text { disruptive facilitation }\end{array}$ & $\begin{array}{l}\text { Problematize; challenge } \\
\text { claims; flag disagreements } \\
\text { and inconsistencies; promote } \\
\text { cognitive conflict }\end{array}$ & $\begin{array}{l}\text { Sometimes probe and ask } \\
\text { questions; trust student } \\
\text { understanding; allow } \\
\text { premature closure of } \\
\text { discussion }\end{array}$ \\
\hline Diagnostician & $\begin{array}{l}\text { Note inaccurate language use; } \\
\text { query student uncertainty; } \\
\text { expect answers to questions }\end{array}$ & $\begin{array}{l}\text { overlook critical details; under- } \\
\text { appreciate importance of } \\
\text { language }\end{array}$ \\
\hline $\begin{array}{l}\text { Management of group } \\
\text { dynamic }\end{array}$ & $\begin{array}{l}\text { Dialogic stance; demand } \\
\text { student-student interaction; } \\
\text { draw-in quieter voices }\end{array}$ & $\begin{array}{l}\text { IRF typical, especially for } \\
\text { process discussion }\end{array}$ \\
\hline Metacognitive voice & $\begin{array}{l}\text { Frequent metacognitive time- } \\
\text { outs; explicit generalization of } \\
\text { process; links course } \\
\text { elements; links curriculum } \\
\text { elements }\end{array}$ & $\begin{array}{l}\text { Cursory attention, little } \\
\text { probing into depth of process } \\
\text { use }\end{array}$ \\
\hline $\begin{array}{l}\text { Pedagogical context } \\
\text { knowledge }\end{array}$ & $\begin{array}{l}\text { Practical wisdom; timing, } \\
\text { format and content of } \\
\text { interventions; knowledge of } \\
\text { learners, institutional context } \\
\text { and classrooms }\end{array}$ & $\begin{array}{l}\text { Less adaptive, less able to } \\
\text { deliver course flexibly, less } \\
\text { improvisation }\end{array}$ \\
\hline
\end{tabular}

The clear differences in the practice of experienced and inexperienced teachers that have emerged from this analysis are summarized in table 2; discussion of these will lead us towards our primary aim of revisiting our theory of remediation with new appreciation. While a direct causal link cannot be proven, the conclusion that differences in classroom behaviours contribute to differences in student outcomes seems intuitively, and theoretically, probable. All the teachers made efforts to validate the challenges these students face, to promote attribution of these difficulties to controllable behaviours (Sandars and Cleary, 2011), to encourage higher self-expectations (Dickhauser et al, 2009), and to nurture the trust and positive attitude necessary for successful learning (Geertsma, 1977; Efklides, 2012). However, 
the less experienced teachers typically tended to overvalue compassion and affect (Pajares, 1992; Jonas, 2010), to trust too much, to inadvertently endorse unproductive framing of learning as the classroom game of passing the next exam (Hutchison and Hammer, 2010). Given that the short-term outcomes for both groups of teachers are similar (Winston et al, 2012), this risks potentially setting up many of these students for future difficulty, a failing of many remediation efforts (Cleland et al, 2013). In contrast, we saw the more experienced teachers foster genuine curiosity and will to learn (Dewey, 1910, 1938; McCune and Entwistle, 2011), in part by refocusing discussion towards appreciative enquiry of specific behaviours and encouraging displays of intellectual enthusiasm, an approach more likely to have long term effect.

Another difference arose in the way the teachers challenged their students. When left to themselves, students tend to avoid cognitive conflict (Yew and Schmidt, 2009; van Velzen, 2012), display faulty logic, produce inconsistent arguments, and, as newcomers to medical discourse, frequently misuse language (Sfard, 2010; Dewey, 1910; Anderberg et $\mathrm{al}, 2008$ ). The inexperienced teachers often did not notice or challenge unjustified claims, unacknowledged disagreements, and inaccurate language use, and, when they did, failed to insist on immediate pursuit of the problem, resulting in unhelpful premature closure of discussion Dyche and Epstein, 2011). Requiring students to elaborate and articulate meaning is valuable for reducing misunderstanding and eliciting new insights (Dewey, 1910; Vygotsky, 1986; Mercer, 2000), while probing and problematizing to create cognitive conflict are core to development of critical thinking and learning (Dewey, 1929; Freire, 2000; Mennin, 2007). The experienced teachers consistently posed disruptive, 'noisy' questions (Hmelo-Silver and Barrows, 2008; Stoyanova and Kennedy, 2010), flagging student uncertainty, inconsistency and disagreement for further exploration. Notably, the format of the intervention, whether it was a closed or open question, simple or complex, subtle or overtly directive, a statement, or even non-verbal, was less important than the timing and context (Boyd and Markarian, 2011; Morris and Hiebert, 2011), the intent of the challenge and the tenacious expectation of a considered student response. These are features of a dialogic stance on teaching (Freire, 2000; Boyd and Markarian, 2011) in which careful listening, attention to detail (Boudreau et al, 2009; Gawande, 2011) and the ability to follow the logic of, and diagnose errors in, students' argument all contribute to the creation of a knowledge-building conversation. Whether or not these are skills that grow with a teacher's experience or are coincidentally due to individual characters, they certainly appeared as differences in the classrooms of the teachers in this study. 
Of course, these ways of constructing knowledge create and are created by interaction and effective dialogue (Postholm, 2008; Mennin, 2010), and we saw this as variation in the dynamics of different groups. A key advantage of group work is the opportunity for students to be confronted with multiple viewpoints, to think together and scaffold each other's learning (Mercer, 2000), especially important for students in academic difficulty (Winston et al, 2010b; Muraskin, 1997). The initiation-response-feedback (IRF) dialogue format that typified the less experienced teachers' classrooms tends to locate authority in the teacher and reduces student-student interaction (Hicks, 2003; Berland and Reiser, 2009). In contrast, the experienced teachers insisted that students comment on each other's ideas and take ownership of the conversation, creating a discourse community of shared regulation (Stoyanova and Kennedy, 2010; Järvelä, 2011). Given the challenges of self-assessment Kruger and Dunning, 1999), this promotion of social regulation offers students the chance to learn how to self-regulate through critiquing others (Volet et al, 2009). It seems likely that fostering dynamic group interaction not only enables immediate collaborative learning, but also supports more independent self-regulation for improved longerterm outcomes.

The experienced teachers also put much more emphasis on 'metacognition', regularly inviting the students to examine and summarize their learning processes and classroom events, while frequently linking elements of the course and offering generalizations of techniques. The lack of this from inexperienced teachers misses a key objective of the course: raising awareness of the value of these skills (Murdoch-Eaton and Whittle, 2012) through explicit abstraction to new domains (Vygotsky, 1986) is vital in persuading these students of the relevance of changing their behaviours, a necessary prerequisite for the long-term development of self-regulatory dispositions (ten Cate et al, 2011). The way the experienced facilitators take on the role of the metacognitive, self-regulatory voice of their groups serves as a model for the students and appears to generate genuine shifts in attitudes and behaviours.

It seems that contextual expertise may tie together all the above techniques of experienced teachers. Knowledge of this course and the wider curricular and institutional context allows them to uncover links between disciplines, processes and concepts; knowledge of these students, and their particular struggles, enables them to induce students to make and appreciate these links, and to engage them in seeking behavioural change. For the practice of remediation, these are aspects of what we might call 'pedagogical context knowledge' (Barnett and Hodson, 2001): understanding of learners, their experience, misconceptions and language use (Shulman, 1987; van de Pol 
et al, 2012; Dewey, 1910, 1938); understanding of content (Shulman, 1986), which for remediation includes the processes of learning, both cognitive and affective, as well as the content of the remediation course and its links to the whole curriculum; and understanding of the classroom (Barnett and Hodson, 2001), as action unfolds, complexly, moment by moment. Thoughtful application of this contextual knowledge is essential to the provision of effective support and requires teaching presence and practical wisdom (Winston et al, 2012). Presence includes mindful awareness of and engagement with all the elements of classroom life (Rodgers and Raider-Roth, 2006), reflecting in action (Schon, 1983) to respond adaptively and flexibly to student needs as they emerge through interactions (Barnett and Hodson, 2001; Corno, 2008; Van Driel and Berr, 2012). This ability to improvise (Maheux and Lajoie, 2010) requires the practical wisdom to know when and how to act (Shulman, 1987; Lunenberg and Korthagen, 2009), a finely tuned contextual expertise necessarily borne of experience (Aristotle, 2008; Dewey, 1938; Day and Goldstone, 2012).

Thus, we feel that examination of these examples of classroom talk, and the differences between experienced and inexperienced teachers, has enabled us to address our initial aims, and offer a description of the theory/practice of successful remediation of at-risk medical students. Remediation, as with any form of education, is situated within complex pedagogic settings where details matter and small perturbations can have significant effects (Mennin, 2007; Durning and Artino, 2011). Since most learning is through language, the 'tool of tools' (Dewey, 1929), small, stable groups can provide an ideal climate for students to support each other, for dialogue that develops self-regulatory skills through social regulation. This can happen when experienced teachers combine artistry (Eisner, 2002), presence, practical wisdom and a dialogic stance (Boyd and Markarian, 2011) to create space for their group to become a community of inquiry (Stoyanova and Kennedy, 2010) that expects high level interaction and critical thinking.

\section{Limitations and Further Work}

There are, of course, a number of limitations with this work. To start with, education is inherently uncertain, and all descriptions can only be incomplete (Kuhn, 1996; Purdy and Morrison, 2009). Furthermore, since small groups are complex dynamic systems, always changing because they are dependent on interactions (Dewey, 1929; Mennin, 2007), our recordings could only be transient moments in their unfolding evolution; further reducing those recordings to a 
handful of snapshots for this paper, through selection by one participant, inevitably weakens ability to generalize from these findings. Additionally, we have examined the work of only six teachers, all in the same institutional context; further work would need to explore similar work in other contexts. Although the correlation between experience and outcomes is strong, experience alone is unlikely to be enough: the experienced teachers in this study all chose to work in this context, and it is likely that desire and particular pedagogical beliefs are also required for successful remedial teaching.

Another limitation, that has the potential for interesting development, is the use of only audio recording. The use of video recording, not only for further research, but also as a tool for faculty development, has the potential to provide direct feedback to less experienced teachers drawn from their own classrooms (Eva, 2006; van Es, 2012). One cannot know what one has failed to notice, unless it is pointed out. Classroom video recordings, used in collaborations between experienced and inexperienced teachers, could help inexperienced teachers learn to respond more adaptively to emerging classroom interactions and thus provide tangible long-term benefits to many struggling students. Such work may also enable further exploration of the mechanisms of social regulation, into how it might be developed and how it might result in improved self-regulation (Volet et al, 2009; Brydges and Butler, 2012).

\section{Conclusion}

Undoubtedly, reflection on personal experience of remediation teaching is the best way to understand it (Dewey, 1929). Lacking this, careful inspection and analysis of classroom discourse, which is an essential vehicle for teaching and learning in any context, can provide insight into the kinds of behaviours that embody effective remediation.

Such work is effectively carried out in a small, stable community of inquiry that requires participation of all group members in the generation of dialogue for collaborative knowledge construction and social regulation. Such a learning climate can evolve in groups led by experienced teachers with extensive pedagogical context knowledge and expertise. When these teachers pay attention to details of both content and process, they can use timely interventions to foster curiosity and the will to learn. These teachers should actively challenge students' language use, logical inconsistencies and uncertainties, problematize their assumptions, and provide a metacognitive regulatory voice that can generate attitudinal shifts and nurture the development of independent critical thinkers. 
This is no small task, but, if the large differences in outcomes are found in other contexts, then, in order to maximise the effectiveness of limited resources, it must be worth putting experienced teachers to work with the students who need them most.

\section{References}

AAMC. 2012. Results of the 2011 Medical School Enrollment Survey. AAMC Centre for Workforce Studies. https://www.aamc.org/download/281126/data/enrollment2012.pdf

Alexander PA, Schallert DL, Reynolds RE. 2009. What is learning anyway? A topographical perspective considered. Educ Psych 2009, 44(3):176-192

Anderberg E, Svensson L, Alvegård C, Johansson T. 2008. The epistemological role of language use in learning: A phenomenographic intentional-expressive approach. Educ Res Rev, 3(1):14-29

Aristotle. 2008. Nicomachean ethics. Translated by Ross WD. Kindle edition. Stillwell, KS

Baird J, Mitchell I, Northfield J. 1987. Teachers as researchers: the rationale; the reality. Res Sci Educ, 17(1):129-138

Barkas LA. 2011. Teaching' or 'support'? The poisoned chalice of the role of students' skills centres. J Fur High Educ, 35(2):265-286

Barnett J, Hodson D. 2001. Pedagogical context knowledge: Toward a fuller understanding of what good science teachers know. Sci Educ, 85(4):426-453

Bateson G. 1972. Steps to an Ecology of Mind. Chicago, IL: University of Chicago Press

Bateson G. 1979. Mind and nature: A necessary unity. New York, NY: Dutton

Bell A. 2011. Re-constructing Babel: Discourse analysis, hermeneutics and the interpretive arc. Discourse Studies, 13(5):519-568

Ben-Peretz M. 2011. Teacher knowledge: What is it? How do we uncover it? What are its implications for schooling? Teach Teach Educ, 27(1):3-9

Benwell B, Stokoe E. 2002. Constructing discussion tasks in university tutorials: shifting dynamics and identities. Discourse Studies, 4(4):429-453

Berland LK, Reiser BJ. 2009. Making sense of argumentation and explanation. Sci Educ, 93(1):26-55

Bloom JW. 2011. Investigating Relationships: Thoughts on the Pitfalls and Directions. Complicity: Int J Complexity Educ, 8(1):38-43

Bolhuis S, Voeten MJM. 2004. Teachers' conceptions of student learning and own learning. Teach Teach, 10(1):77-98 
Boudreau JD, Cassell EJ, Fuks A. 2009. Preparing medical students to become attentive listeners. Med Teach, 31(1):22-29

Boyd MP, Markarian WC. 2011. Dialogic teaching: talk in service of a dialogic stance, Lang and Educ, 25(6):515-534

Brydges R, Butler D. 2012. A reflective analysis of medical education research on selfregulation in learning and practice. Med Educ, 46(1):71-79

Bunniss S, Kelly DR. 2010. Research paradigms in medical education research. Med Educ, 44:358-366

Caleon IS, Subramaniam R. 2010. Do students know what they know and what they don't know? Using a four-tier diagnostic test to assess the nature of students' alternative conceptions. Res Sci Educ, 40(3):313-337

Cleland J, Leggett H, Sandars J, Costa MJ, Patel R, Moffat M. 2013. The remediation challenge: theoretical and methodological insights from a systematic review. Med Educ, $47: 242-251$

Cook DA, Bordage G, Schmidt HG. 2008. Description, justification and clarification: A framework for classifying the purposes of research in medical education. Med Educ, 42:128-133

Corno L. 2008. On teaching adaptively. Educ Psychol, 43(3):161-173

Creswell JW, Miller DL. 2000. Determining Validity in Qualitative Inquiry. Theory Into Practice, 39(3): 124-130

Darling-Hammond L, Youngs P. 2002. Defining "highly qualified teachers": What does "scientifically-based research" actually tell us? Educ Researcher, 31(9):13-25

Day SB, Goldstone RL. 2012. The Import of Knowledge Export: Connecting Findings and Theories of Transfer of Learning. Educ Psych, 47(3):153-176

Denzin NK, Lincoln YS. 2005. The Sage handbook of qualitative research. 3rd edition. Thousand Oaks, CA: Sage

Devoe P, Niles C, Andrews N, Benjamin A, Blacklock L, Brainard A, Colombo E, Dudley B, Koinis C, Osgood M. 2007. Lessons learned from a study-group pilot program for medical students perceived to be 'at risk'. Med Teach, 29(2):e37-e40

Dewey J. 1910. How We Think. New York, NY: DC Heath \& Co

Dewey J. 1929. Experience and Nature. London, George Allen \& Unwin Ltd

Dewey J. 1938. Experience and Education. Touchstone, NY: Kappa Delta Pi

Dickhäuser O, Reinhard M, Diener C, Bertrams A. 2009. How need for cognition affects the processing of achievement-related information. Learn Indiv Diff, 19(2):283-287

Durning SJ, Artino AR. 2011. Situativity theory: A perspective on how participants and the environment can interact: AMEE Guide no. 52. Med Teach, 33(3):188-199

Dyche L, Epstein RM. 2011. Curiosity and medical education. Med Educ, 45:663-668 
Edwards D, Potter J. 2001. Discursive psychology. In How to analyse talk in institutional settings: A casebook of methods, edited by McHoul AW, Rapley M. London: Continuum International

Efklides A. 2012. Commentary: How readily can findings from basic cognitive psychology research be applied in the classroom? Learn Instr, 22:290-295

Eisner EW. 2002. From episteme to phronesis to artistry in the study and improvement of teaching. Teach Teach Educ, 18(4):375-385

Eren A. 2009. Exploring the relationships among mirror neurons, theory of mind, and achievement goals: Towards a model of achievement goal contagion in educational settings. Educ Res Rev, 4(3):233-247

Eva KW. 2006. Whither the need for faculty development? Med Educ, 40(2):99-100

Eva KW, Regehr G. 2011. Exploring the divergence between self-assessment and selfmonitoring. Adv Health Sci Educ Theory Pract, 16(3):311-29

Freire P. 2000. Pedagogy of the Oppressed, 30th Anniversary Edition. New York, Continuum

Gawande, A. 2011. Personal Best: Top athletes and singers have coaches. Should you? New Yorker, Oct 3 http://www.newyorker.com/reporting/2011/10/03/111003fa_fact_gawande

Geertsma RH. 1977. A special tutorial for minority medical students: An account of a year's experience. J Med Educ, 52(5):396-403

Gibbs T, Durning S, Van Der Vleuten C. 2011. Theories in medical education: Towards creating a union between educational practice and research traditions. Med Teach, 33(3): $183-187$

Gill D, Griffin AE. 2009. Reframing medical education research: let's make the publishable meaningful and the meaningful publishable. Med Educ, 43(10):933-935

Greasley K, Ashworth P. 2007. The phenomenology of 'approach to studying': the university student's studies within the lifeworld. Br Educ Res J, 33(6):819-43

Hicks D. 2003. Discourse, teaching and learning. In Language, Literacy and Education: a reader, edited by Goodman et al. Stoke-on-Trent: Trentham Books:3-23

Hmelo-Silver CE, Barrows HS. 2008. Facilitating collaborative knowledge building. Cogn Instr, 26(1):48-94

Hull G, Rose M, Fraser KL, Castellano M. 1991. Remediation as social construct: Perspectives from an analysis of classroom discourse. Technical Report no. 44. Berkeley, CA: Center for the Study of Writing

Hutchison P, Hammer D. 2010. Attending to student epistemological framing in a science classroom. Science Education, 94(3):506-524

Jaarsma ADC, de Grave WS, Muijtjens AMM, Scherpbier AJJA, van Beukelen P. 2008. Perceptions of learning as a function of seminar group factors. Med Educ, 42:11781184 
Järvelä, S. 2011. How does help seeking help?-New prospects in a variety of contexts. Learn Instr, 21(2):297-299

Jonas ME. 2010. When teachers must let education hurt: Rousseau and Nietzsche on compassion and the educational value of suffering. J Philos Educ, 44(1):45-60

Jörg T, Davis B, Nickmans G. 2007. Towards a new, complexity science of learning and education. Educ Res Rev, 2:145-156

Kauffman SA. 2008. Reinventing the sacred: A new view of science, reason, and religion. New York, NY: Basic Books

Kennedy TJT, Lingard LA. 2006. Making sense of grounded theory in medical education. Med Educ, 40:101-108

Kruger J, Dunning D. 1999. Unskilled and Unaware of It: How Difficulties in Recognizing One's Own Incompetence Lead to Inflated Self-Assessments. J Personality and Soc Psych, 77(6):121-113

Kuhn T. 1996. The structure of scientific revolutions. $3^{\text {rd }}$ edition. University of Chicago Press

Kuper A, Hodges B. 2011. Medical education in its societal context. In Medical education: theory and practice. Edited by Dornan T et al. Edinburgh, Elsevier:39-49

Kvale S. 1996. Interviews: An introduction to qualitative research interviewing. Thousand Oaks, CA: Sage

Leggett $H$, Sandars J, Burns P. 2012. Helping students to improve their academic performance: A pilot study of a workbook with self-monitoring exercises. Med Teach, 34(9):751-753

Lunenberg M, Korthagen F. 2009. Experience, theory, and practical wisdom in teaching and teacher education. Teach Teach, 15(2):225-240

Maheux JF, Lajoie C. 2010. On Improvisation in Teaching and Teacher Education. Complicity: Int J Complexity Educ, 8(2):86-92

Maso I. 2001. Phenomenology and ethnography. In Handbook of ethnography, edited by Atkinson et al. LA: Sage Publications Limited:136-144

Mauthner NS, Doucet A. 2003. Reflexive accounts and accounts of reflexivity in qualitative data analysis. Sociology, 37(3):413-431

McCune V, Entwistle N. 2011. Cultivating the disposition to understand in 21st century university education. Learn Indiv Differ, 21(3):303-310

Mennin S. 2007. Small-group problem-based learning as a complex adaptive system. Teach Teach Educ, 23(3):303-313

Mennin S. 2010. Self-organisation, integration and curriculum in the complex world of medical education. Med Educ, 44(1):20-30

Mercer N. 2000. Words and minds: How we use language to think together. London: Routledge 
Mercer N. 2010. The analysis of classroom talk: Methods and methodologies. Brit J Educ Psych, 80(1):1-14

Misawa K. 2011. The Hirst-Carr Debate Revisited: Beyond the Theory-Practice Dichotomy. J Phil Educ, 45(4):689-702

Mitchell I. 2010. The relationship between teacher behaviours and student talk in promoting quality learning in science classrooms. Res Sci Educ, 40(2):171-186

Morris AK, Hiebert J. 2011. Creating shared instructional products: An alternative approach to improving teaching. Educ Researcher, 40(1):5-14

Muraskin L. 1997. "Best practices" in student support services: A study of five exemplary sites. Follow-up study of student support services programs. SMB Economic Research Inc. and US Department of Education

Murdoch-Eaton D, Whittle S. 2012. Generic skills in medical education: developing the tools for successful lifelong learning. Med Educ, 46(1):120-128

Norton L, Richardson JTE, Hartley J, Newstead S, Mayes J. 2005. Teachers' beliefs and intentions concerning teaching in higher education. High Educ, 50(4):537-571

Pajares MF. 1992. Teachers' beliefs and educational research: Cleaning up a messy construct. Rev Educ Res, 62(3):307-332

Pope C, Mays N. 2009. Critical reflections on the rise of qualitative research. BMJ, 339:737-739

Postholm MB. 2008. Group work as a learning situation: A qualitative study in a university classroom. Teach Teach: Theory Pract, 14(2):143-155

Postholm MB. 2010. Self-regulated pupils in teaching: Teachers' experiences. Teach Teach, 16(4):491-505

Proulx J. 2008. Some Differences between Maturana and Varela's Theory of Cognition and Constructivism. Complicity: Int J Complexity Educ, 5(1):11-26

Purdy N, Morrison H. 2009. Cognitive neuroscience and education: unravelling the confusion. Oxf Rev Educ, 35(1):99-109

Regehr G. 2010. It's NOT rocket science: rethinking our metaphors for research in health professions education. Med Educ, 44(1):31-39

Rodgers CR, Raider-Roth MB. 2006. Presence in teaching. Teach Teach, 12(3):265-287

Roth WM. 2007. The nature of scientific conceptions: A discursive psychological perspective. Educ Res Rev, 3(1):30-50

Sandars J, Cleary TJ. 2011. Self-regulation theory: Applications to medical education: AMEE Guide No. 58. Med Teach, 33(11):875-886

Schon DA. 1983. The reflective practitioner: How professionals think in action. New York: Basic Books 
Seltzer-Kelly DL, Cinnamon-Morrison S, Cunningham CA, Gurland ST, Jones K, Toth SL. 2011. (Re)Imagining Teacher Preparation for Conjoint Democratic Inquiry in Complex Classroom Ecologies. Complicity: Int J Complexity Educ, 8(1):5-27

Sfard A. 2010. A Theory Bite on Infinity: A Companion to Falk. Cogn and Instr, 28(2):210-218

Shulman LS. 1986. Those who understand: Knowledge growth in teaching. Educ Researcher, 15(2):4-14

Shulman LS. 1987. Knowledge and teaching: Foundations of the new reform. Harvard Educ Rev, 57(1):1-23

Shulman LS. 2007. Practical wisdom in the service of professional practice. Educ Researcher, 36(9):560-563

Sidnell J. 2010. Conversation Analysis: An Introduction (Language in Society). WileyBlackwell, Chichester

Stegers-Jager KM, Cohen-Schotanus J, Themmen APN. 2013. The effect of a short integrated study skills programme for first-year medical students at risk of failure: A randomised controlled trial. Med Teach, 35(2):120-126

St Julien J. 2009. Expanding Complexity: A Meditation. Complicity: Int J Complexity Educ, 6(2):40-45

Stoyanova N, Kennedy D. 2010. Between chaos and entropy: Community of inquiry from a systems perspective. Complicity: Int J Complexity Educ, 7(2):1-15

Ten Cate OTJ, Kusurkar RA, Williams GC. 2011. How self-determination theory can assist our understanding of the teaching and learning processes in medical education. AMEE Guide No. 59. Med Teach, 33(12):961-973

Thomas L. 2012. Building student engagement and belonging in Higher Education at a time of change: final report from the What Works? Student Retention \& Success programme. Paul Hamlyn Foundation, HEA

Thomas P. 2006. General medical practitioners need to be aware of the theories on which our work depends. Ann Fam Med, 4:450-454

Van de Pol J, Volman M, Beishuizen J. 2012. Promoting teacher scaffolding in smallgroup work: A contingency perspective. Teach Teach Educ, 28(2):193-205

Van Driel JH, Berry A. 2012. Teacher professional development focusing on pedagogical content knowledge. Educ Researcher, 41(1):26-28

Van Es EA. 2012. Examining the development of a teacher learning community: The case of a video club. Teach Teach Educ, 28(2):182-192

Van Kruiningen JF. 2013. Educational design as conversation: A conversation analytical perspective on teacher dialogue. Teach Teach Educ, 29:110-121

Van Velzen JH. 2012. Teaching metacognitive knowledge and developing expertise. Teach Teach: Theory and Practice, 18(3):365-380 
Varela FJ, Thompson ET, Rosch E. 1991. The embodied mind: Cognitive science and human experience. Cambridge, MA: MIT Press

Volet S, Vauras M, Salonen P. 2009. Self- and Social Regulation in Learning Contexts: An Integrative Perspective. Educ Psych, 44(4):215-226

Vygotsky LS. 1986. Thought and language. Cambridge, MA: MIT Press

Winston KA, Van der Vleuten CPM, Scherpbier AJJA. 2010a. An investigation into the design and effectiveness of a mandatory cognitive skills programme for at-risk medical students. Med Teach, 32(3):236-243

Winston KA, Van Der Vleuten CPM, Scherpbier AJJA. 2010b. At-risk medical students: Implications of students' voice for the theory and practice of remediation. Med Educ, 44:1038-1047

Winston KA, Van Der Vleuten CPM, Scherpbier AJJA. 2012. The Role of the Teacher in remediating at-risk medical students. Med Teach, 34(11):e732-42

Wittgenstein L. 1967. Philosophical investigations, 3rd edition. Oxford: Blackwell

Wittgenstein L. 2006. Tractatus logico-philosophicus. London: Public Domain Books, Kindle edition

Yew EH, Schmidt HG. 2009. Evidence for constructive, self-regulatory, and collaborative processes in problem-based learning. Adv in Health Sci Educ, 14(2):251-273

Zimmerman BJ. 2002. Becoming a Self-Regulated Learner: An Overview. Theory Into Practice, 41(2):64-70 

CHAPTER 7

Discussion 
This research has employed design-based methodology to follow a case study of an Essential Lifelong Learning Skills (ELLS) course for at-risk medical students. We have endeavoured to develop an understanding of the theory and practice of remediation by asking questions about the ingredients of successful remediation and exploring how these elements work to improve outcomes for participating students. The ELLS course, a mandatory intervention for students who fail and repeat their first semester at Ross University School of Medicine, draws upon a blend of complementary theoretical perspectives: it is primarily based upon a constructivist, student-centred approach that focuses on learning through collaboration, dialogue and self-regulation, while the effort to enculturate students into medical discourse and build their identities as medical students draws on sociocultural theories of learning. Stable, faculty-facilitated groups of six students meet throughout a semester to work through a syllabus that integrates learning the processes of various study and reasoning skills with the content of basic science course material. The outcomes in terms of student performance have shown strongly significant and long-term improvement. Indeed, continued data collection shows that now, three years since the publication of chapter 2, and with a much larger sample size, the results for passing first semester remain identical, while the longer term results for passing fourth semester with ELLS have improved by $6 \%$ (table 7.1).

Table 7.1:

Academic progress of programme participants, compared with historical controls, $2007-2012$

\begin{tabular}{lcc}
\hline & Pass sem 1 & Pass sem 4 \\
\hline w/out ELLS & $\mathbf{5 8 \%}$ & $\mathbf{3 8 \%}$ \\
with ELLS & $(413 / 715)$ & $(274 / 715)$ \\
Significance $\left(\boldsymbol{X}^{2}\right)$ & $\mathbf{9 1 \%}$ & $\mathbf{6 1 \%}$ \\
& $(536 / 588)$ & $(326 / 537)$ \\
\hline
\end{tabular}

Another key finding was that more attendance correlates with better long term results. Again, I continued to track this, and table 7.2 shows that this clear trend persisted. Consequently, the school has since mandated that all students attend two sessions per week, and this change may well have contributed to the aforementioned improvement in long term outcomes, although given our subsequent findings on the effect of teacher experience (see below), along with minor adjustments to the course syllabus (see Course Design section below), this claim is hard to verify confidently. 
Table 7.2:

Academic progress of participants by no. of ELLS sessions attended

\begin{tabular}{lccc}
\hline ELLS Attendance & $\begin{array}{c}\text { No. of } \\
\text { students }\end{array}$ & $\begin{array}{c}\text { Pass sem } \\
\mathbf{4}\end{array}$ & $\begin{array}{c}\text { Dismissed/withdrew } \\
\text { by } \text { end of sem 4 }\end{array}$ \\
\hline Attend $>\mathbf{1 5}$ & 89 & $82 \%$ & $18 \%$ \\
Attend 10-15 & 140 & $63 \%$ & $37 \%$ \\
Attend $<\mathbf{1 0}$ & 73 & $45 \%$ & $55 \%$ \\
\hline
\end{tabular}

Significance $(x 2)$ : yes, $p<0.0001$

Subsequent examination of student and teacher perspectives yielded agreement that remediation is complex, should be mandatory, and needs to focus on students' affective, cognitive and metacognitive development. This can be achieved within a small community of inquiry that motivates and challenges the students, with teachers performing the roles of facilitator, mentor, disciplinarian, diagnostician and role model. However, a strong correlation (0.81) was found between teacher experience and long-term student outcomes. Analysis of classroom talk revealed that, despite students' and teachers' convergent claims, the extensive pedagogical context knowledge of experienced teachers leads to clear differences in classroom interactions that positively impact long-term student outcomes. This qualitative work illuminated the essential ingredients of successful remediation practice, which are elaborated in the ensuing discussion.

\section{Lessons Learned}

In this section I draw together a number of themes that have emerged across the five studies, offering tentative answers to my original research question through discussion of some of the key ingredients of successful remediation.

\section{Methodology}

Before exploring the theory and practice of remediation, I briefly summarize lessons learned about the methodologies used in this project.

Firstly, the discrepancy between the qualitative data from surveys, focus groups and interviews and the quantitative outcome data is revealing. In the prediction and prevention study (chapter 5) the student surveys suggested that the workshops were effective in improving performance, while the numbers showed no difference. 
This could, of course, be merely an artefact of students' choice to respond: the surveys were anonymous, so we cannot know if the majority of respondents were those who saw improvement - quantitative data are, after all, aggregated and presented as averages, and some students certainly did improve. A parallel explanation could be that motivation to respond to surveys coincides with motivation to succeed, but if, indeed, survey respondents' personalities are skewed in this way, that would still leave us questioning the validity of survey results. However, others have also found that self-report measures are unrelated to objective outcomes (Bannert and Mengelkamp, 2008; Bowman, 2010; Leggett et al, 2012; Kirschner and van Merriënboer, 2013), and are susceptible to faking (Credé and Kuncel, 2008; Huws et al, 2009; Griffin and Wilson, 2012). The same issues arise from the fact that the students viewed all the teachers similarly, and that teachers described their own behaviours in the same terms, despite the divergence of outcomes and classroom actions. Again, many others have commented on the difference between teachers' beliefs and behaviours (Greensfeld and Elkad-Lehman, 2004; Norton et al, 2005; Ben-Peretz 2011), noting the challenge of accurately articulating practice (Shulman, 1987) and of enacting beliefs and principles (Bolhuis and Voeten, 2004; Bloom, 2011; van de Pol et al, 2012). There may also be some lack of self-awareness: novices, be they students or teachers, may lack the competence to evaluate their own behaviours (Kruger and Dunning, 1999). Issues of social desirability may play a part too, with some teachers saying what the researcher wants to hear (Ferla et al, 2009), especially in this case of practitioner-research, where the researcher is also a colleague.

These challenges to the validity of phenomenological research are compounded by the researcher's creation of categories to classify people's descriptions, which may or may not accurately convey subjects' meanings (Bateson, 1972; Greasley and Ashworth, 2007): inevitably "discourse about experience fails to capture the richness of experience" (Varela et al, 1991). Despite all these reservations, gathering participant perspectives is a valuable place to start, which, when combined with suitable quantitative data, offers researchers a substantial basis for the formulation of the appropriate questions to guide further research. Then, in order to get closer to 'truth', the picture built up from participants viewpoints must be compared to reality (Wittgenstein, 2006). This is why direct observation and analysis of classroom action is an essential component of educational research, providing insight into what actually happens rather than what people say or believe happens (Perry et al, 2002; Pope and Mays, 2009; Ben-Peretz, 2011).

So, in the final paper I focused on classroom talk, since dialogue is at the heart of education: it is through dialogic interaction that 
knowledge emerges (Freire, 2000; Proulx, 2008), through discourse that we think and create meaning (Dewey, 1910; Kuper and Hodges, 2011). The samples of classroom talk presented in that paper are integral to comprehending the application of remediation theory in practice: the medium is very much part of the message. Every step away from the action towards description and abstraction of that talk involves an interpretative act on my part, and this interpretation is a step towards ownership of meaning (Bell, 2011). But if I make that interpretation, that is my ownership of meaning, not the reader's: this view through a practitioner-researcher lens has the advantage of adding insider insight for the reader, but also risks creating distance, and perhaps simplification of complex phenomena.

Similarly, a long case study following design-based research methodology ends up being an interaction between intervention and context (Design-Based Research Collective, 2003): there has been the space to tweak, to adapt the intervention to the needs of the institution and its members, and to follow emergent themes as the research progressed, but it is hard to know if this is at the expense of the ability to transfer the findings to other contexts. Still, when we are dealing with complex systems, even the most carefully controlled, statistically sound experiment conducted by an impartial observer cannot be easily generalized, since even the slightest change in initial conditions can have far reaching consequences (Prigogine, 1997; Jörg et al, 2007). In the end, I think this balance of objectivity and subjectivity, and the trade-off between context-specificity and the ability to generalize, is part of all research, whether explicitly stated or not, and an extended case study using design-based practitioner research offers a perspective at least as valid as any other.

\section{Remediation Theory-Practice}

Given the complexity and context-specificity of any educational process (Bateson, 1979; Jörg et al, 2007; Lonka et al, 2008), we cannot expect to find an overarching, fully generalizable theory of remediation (Alexander et al, 2009; Regehr, 2010). Instead, I pragmatically offer lessons learned from one specific context and a range of literature as a basis from which others can think about the practice of remediation within their own contexts (Regehr, 2010). I first give a broad overview of key ingredients of successful remediation, and then explore some of those elements in further detail.

Firstly, it is clear that from a complexity perspective context shapes everything (Bateson, 1979), so any theory must take into account the various factors that influence the pedagogic setting (Dewey, 1916; Leach and Moon, 1999). Here, that context includes 
the individual students, the group, the teacher, the specific course design and content, the wider school curriculum, the institutional system and beyond. Further, as the participants, materials and environment constitute part of each other's contexts, they are interrelated in a continuous process of mutual shaping and changing (Maturana and Varela, 1987).

Undoubtedly, the primary locus of change is the learners themselves, and successful remediation should support their affective, cognitive and metacognitive development. Failure has emotional and attitudinal consequences, and it is essential to engage with and explore these, while recognizing that the goal is not to simply make the students feel better about themselves (Nillsen, 2004), but to encourage reflection, to (re)kindle their curiosity, intrinsic motivation and desire to learn (Dewey, 1938; Vansteenkiste et al, 2009; Dyche and Epstein, 2011). At the same time, their cognition, their capacity for critical thinking, needs to be nurtured. Indeed, the cognitive and affective are inseparable (Vygotsky 1986; Lakoff and Johnson 1999), and motivation can be enhanced by setting tasks that appropriately challenge their thinking (Eva and Regehr, 2011; Guadagnoli et al, 2012), and promote intellectual playfulness and active sense-making (Berland and Reiser, 2009; Hutchison and Hammer, 2010; Larsson and Dahlin, 2012). This cognitive element is encapsulated in the cognitive apprenticeship model, in which teachers model, coach and scaffold students towards independent learning (Collins et al. 1989; van Merrienboer et al, 2002; Stalmeijer et al. 2009). This independence requires self-regulation, which for these 'weaker' students needs to be taught explicitly, so that they learn to habitually plan, monitor and reflect on their learning, and become aware of how their beliefs and behaviours affect their performance (Zimmerman, 2002; Sandars and Cleary, 2011).

The acquisition of these practices requires adequate time, a regular environment, and clear feedback. In remediation, a small, stable community of inquiry (Stoyanova and Kennedy, 2010) provides a safe space for students to learn these attitudes and behaviours: members can support each other emotionally and cognitively, and build on each other's ideas to reconstruct their understandings. This community should be led by an experienced teacher with extensive pedagogical context knowledge who guides the group in collaborative knowledge construction and social regulation. Within these groups, trusting relationships are central to the often uncomfortable work of mutual critique and constructive feedback that are necessary accompaniments to genuine conceptual change.

For sustained success, such a programme of remediation is aided by a systemic perspective with clear institutional support (Lieberman et al, 2010): sufficient human and physical resources, and firm 
policies provide a framework for implementation. However, systemic changes typically occur too slowly to help students needing assistance immediately, and in this case, the administrative support followed our ability to provide data showing the effectiveness of this approach. I now turn to some of the more practical elements that enable these outcomes.

\section{Course design}

The course itself certainly plays a major role in improving student outcomes: even students taught by inexperienced teachers saw greatly improved long term outcomes ( $48 \%$ vs $38 \%$ passing semester $4, \mathrm{x} 2$ significant, $\mathrm{p}<0.004)$. Important to this success was coming to the design with a strong contextual understanding of the institution, the curriculum and the learners, and the difficulties caused by interactions between all three. Although I oversaw the design and production of the course materials, much of the work was collaborative, with all faculty members in the Centre for Teaching and Learning (CTL) invited to contribute to writing, selection and improvement of the teaching materials. Such joint creative endeavour, with regular interaction between faculty for discussing details of handouts and their application in the classroom, can result in a sense of ownership that is beneficial to the delivery of any course (Morris and Hiebert, 2011).

One fundamental guiding principle is that learning process is inseparable from learning content (Friedman et al, 2010). Skills and processes are best learned first in one specific situation and then from application to and generalization from a variety of further examples (Adey et al, 2007; Norman, 2009; Day and Goldstone, 2012), provided the similarities and differences are made explicit (Patel et al, 2009; Day and Goldstone, 2012). Furthermore, these students invariably fear the large volume of basic science course material they are required to master, and worry that the effort needed for any change in their learning strategies will waste their precious time, so the relevance of ELLS materials to other curricular content must, at least initially, be really obvious if they are to engage.

Thus, every technique in the course handbook is first demonstrated with an example from one of the basic science disciplines, and then applied, through homework and in-class assignments, to other material from those disciplines. For example, when teaching students to prepare for lectures by activating prior knowledge, an essential first step in learning anything (Dewey, 1910; Vygotsky, 1986; Kaufman, 2003), we require them to list vocabulary from the next day's lectures that they are supposed to know from earlier lectures. When 
students are then pressed to define those terms, they invariably run into difficulties, and this cognitive dissonance shatters illusions of knowing (Pashler et al, 2007), forcing them to admit knowledge gaps, attend to meaning, and at least entertain the possibility of previewing for future lectures. Similarly, the basic cognitive acts of categorization (Maturana and Varela, 1987) and identifying relationships (Dewey, 1910) are made explicit when concept-mapping a challenging lecture; the value of self-explanation (Day and Goldstone, 2012) is demonstrated when floundering and then learning from the provision of explanations for peers; the value of retrieval practice (Pashler et al, 2007; Thalheimer, 2003) from repeated analysis of multiple-choice questions; and the importance of asking questions for critical thinking (Dewey, 1929; Pashler et al, 2007) is shown through quizzing peers on lecture content and writing their own multiple-choice questions.

We have also continually tweaked the course content to meet students' needs as our own understanding of those needs crystallized. A good example is the Personal Improvement Project (PIP), introduced since publication of chapter 2, (but included in the current ELLS handbook that is appended to that chapter), a quality improvement task (Morrison and Headrick, 2008) that extends through the whole semester. For their PIP students select two concrete things (ranging from managing sleep patterns to measuring performance on practice test questions) on which to work throughout the semester; they have to set goals, collect data, monitor progress, reflect on their performance, and adapt the goals and targets as needed. Having shared their plans with the group at the outset, they tend to inquire after each other's progress and hold each other accountable, and this has been a really good way to approach the explicit teaching of selfregulation. This aspect of the course design, this sharing of plans and reflections, thinking aloud in front of the group, drawing or showing working on the whiteboard, amounts to a constructionist 'performance of understanding' (Papert and Harel, 1991; Wiske, 1999) that not only allows essential teacher feedback-provision (Harlen, 2003), but also enables students to practice the skills of giving and receiving feedback. An important part of the whole process is this treatment of deficit as virtue (McDermott, 1999) - not knowing is not only allowed, but appreciated as opportunity to teach and learn.

Another challenge in course design is striking the right balance between learner autonomy and teacher control. The problem arises from the conflict between the necessary goal of cultivating independent learners, while acknowledging that what people prefer is often not what is best for them (e.g. candy, cigarettes, answers to the next test), especially in this situation where students who have failed courses are usually far from experts in self-regulation. In this course, we practice a form of shared control (Kirschner and van Merriënboer, 
2013), whereby the course handbook specifies the skill or process to be practiced each week, while the students choose what specific basic science course material to apply it to, with encouragement to work with material they have previously found challenging. This flexibility creates a way of balancing individual and group needs, and students' feeling of autonomy is further enhanced when they are encouraged to explore, adapt and blend learning strategies to suit their own purposes. This practice also affords unanticipated opportunities for learning: a student may, for example, bring to the table a multiple-choice problem around a physiology concept they have struggled with, only to find that discussion exposes misunderstandings in other students who had previously confidently claimed full comprehension.

Of course, much of this is not new - I have simply drawn together educational ideas for which there is good evidence and created a course to meet the needs of at-risk medical students in one specific context. However, the following sections highlight some findings of this work that are also likely to be key ingredients of successful remediation.

\section{Timing}

It is useful to ask whether the timing of this kind of intervention matters. The conventional wisdom is that the earlier the intervention the better (Weinsheimer 1998; Devoe et al. 2007; Johnson et al, 2009), since this gives more time to work on improvement (Cleary, 2008). However, this premise could be challenged on the basis that the further a student has progressed along the path to a medical career, the more they have invested and the more they have to lose, thus making later semester participants potentially more receptive to new ideas. The work on preventative intervention described in chapter 5 gives little indication either way: the large group format was not a success, but the results from the follow-up sessions suggested that a small group format, in sufficient dose with experienced teachers could well be effective.

The school's data show that a failure in any of the four basic science semesters is equally predictive of ultimate failure to graduate as a physician, so, given the success of ELLS for first semester repeaters, in 2011 we started to require the course for students who failed and repeated second and third semesters. We used the same format as with semester 1 ELLS, and the course handbook was largely the same, with minor changes to reflect differences in curricula for upper semester students. The outcomes are shown in table 7.3, using the same endpoint as with the first semester - the successful completion of basic sciences at the end of $4^{\text {th }}$ semester, which is two semesters 
later for those repeating semester 2 , but only one semester (4 months) later for those repeating semester 3.

Table 7.3:

$4^{\text {th }}$ semester pass rates for at-risk students taking ELLS in $2^{\text {nd }}$ or $3^{\text {rd }}$ semester

\begin{tabular}{|c|c|c|c|c|c|c|}
\hline & $\begin{array}{l}\text { Without } \\
\text { ELLS }\end{array}$ & $\begin{array}{l}\text { With } \\
\text { ELLS }\end{array}$ & $\begin{array}{c}x^{2} \\
\text { significance }\end{array}$ & $\begin{array}{c}\text { Experienced } \\
\text { teachers }\end{array}$ & $\begin{array}{c}\text { Inexpe- } \\
\text { rienced } \\
\text { teachers }\end{array}$ & $\begin{array}{c}x^{2} \\
\text { significance }\end{array}$ \\
\hline Sem 2 & $\begin{array}{c}39 \% \\
(n=84)\end{array}$ & $\begin{array}{c}60 \% \\
(n=99)\end{array}$ & $\begin{array}{c}\text { Yes, } \\
p<0.004\end{array}$ & $\begin{array}{c}71 \% \\
(n=65)\end{array}$ & $\begin{array}{c}38 \% \\
(n=34)\end{array}$ & $\begin{array}{c}\text { Yes, } \\
p<0.002\end{array}$ \\
\hline Sem 3 & $\begin{array}{c}72 \% \\
(n=123)\end{array}$ & $\begin{array}{c}78 \% \\
(n=123)\end{array}$ & $\begin{array}{c}\text { No, } \\
p=0.301\end{array}$ & $\begin{array}{c}85 \% \\
(n=47)\end{array}$ & $\begin{array}{c}74 \% \\
(n=76)\end{array}$ & $\begin{array}{c}\text { No, } \\
p=0.137\end{array}$ \\
\hline
\end{tabular}

(Data are given for 2 years prior to the intervention, and 2 years with the intervention. Percentages are pass rates for semester 4, two and one semester after the sem 2 and 3 interventions respectively)

The fact that this involved the same teachers, within the same institution, allows for comparison with earlier results for semester 1 ELLS. Overall, the results for semester 2 ELLS show a major impact of the course, but this only holds for students who worked with experienced teachers; working with an inexperienced teacher appears to make no difference at all. While the statistical results for semester 3 ELLS suggest no significant effect, we need to remember that these are shorter-term data, and it is possible that with time, for example at USMLE Step 1, there could be a difference, especially if the numerical trend that favours ELLS students continues. Indeed, when comparing only those semester 3 students who worked with experienced teachers to those who received no intervention, the $x 2$ test already approaches significance $(p=0.082)$ more closely than other relationships.

All this suggests that the precise timing may be less important than previously thought. Certainly, if inexperienced teachers are involved, the earlier the better still seems safest; however, an intervention at semester 2 is as effective as at semester 1 , as long as that provision is of the right kind and involves teachers with plenty of experience.

\section{Dose effect}

One of the results from chapter 2, extended in table 7.2 above, suggests that there is a dose effect with this intervention: those who attended more than 15 sessions were twice as likely to attain longterm success as those who attended fewer than 10 sessions. 
No doubt a good deal of this difference is attributable to motivation, with those choosing to attend more than required likely to have put in more effort. However, since requiring attendance at two meetings per week, raising the average number of attendances to twenty-one per student, the overall long-term outcome has improved 6\%. Given the number of other variables, this cannot be solely attributable to the increase in dose, but it is, at least, suggestive. Further evidence comes from chapter 5, where attendance at more than two small group follow-up sessions correlates with higher pass rates, and is just about statistically significant for pass rates in the subsequent semester. Here, the maximum dose, with workshops and small group sessions combined, was just nine, only very few students reached this, and again it is not possible to disentangle this from other key variables, most notably the effect of teacher experience.

Still, other evidence is also suggestive of a dose effect. StegersJager et al (2013) found those who attended four or five sessions had better outcomes than those attending fewer sessions, while $\mathrm{Mu}$ raskin's (1997) study of exemplary college support programmes found a linear relation between dose and grade increase, claiming that twelve contacts per year is not enough. On the whole, it seems that short, isolated programmes do not produce long-term improvements (Pell et al, 2012; McLaughlin, 2012), while more successful programmes typically include a large number of activities and run for a bare minimum of one whole semester (Brigham et al, 1994; Alexander et al, 2005; Tuckman and Kennedy, 2011).

The idea of a dose effect also makes some theoretical sense. In any endeavour, practice leads to improvement, so it comes as no surprise that students perform better if they are given longer to practice study skills (Carroll and Feltham, 2007). Behaviour change and development of critical thinking dispositions necessarily take time (Kaufman, 2003; van Schalkwyk, 2010), and require extended interaction with consecutive discourse and feedback in a regular environment (Dewey, 1910; Sibii, 2010; Kahneman, 2011). It takes time for new ideas to settle (Hinchliffe, 2011), to notice 'coincidences' as we go about our daily lives, to see further examples of recently encountered ideas that enable us to flesh out and appreciate new concepts. Time is also required to build trust: students are more comfortable voicing uncertainty to teachers and peers with whom they have sustained relationships (ten Cate et al, 2011; Hauer et al, 2012), and the quality of dialogue improves with familiarity (Bricker and Bell, 2008).

This is why there have been suggestions that a full year is needed for successful remediation (Whitehead, 2012), with additional support in subsequent years (Hays, 2012). While there is not yet a conclusive answer to the question of how much support is necessary, and it will 
certainly vary according to context and individuals, this work adds weight to a growing body of evidence. It seems likely that an initial intensive intervention of 20 sessions across one semester, followed by infrequent follow-up meetings in subsequent semesters, would be a sound basis from which to investigate further.

\section{Mandatoriness}

The decision about whether or not such a programme should be compulsory is not without opponents. After all, these are young adults capable of making their own choices, and we are aiming to produce independent lifelong learners. I would argue, though, that reaching that end product is a process, and not a place to start.

As stated in chapter 2, we initially piloted the course for two semesters as a voluntary option, taken up by thirty-seven students, and $83 \%$ of these passed. Fifty-three did not come: $58 \%$ of these passed, which is the same percentage as our historical controls. This latter result is interesting in itself: if only the less-motivated students chose not to attend, and that is the main reason they were less successful as a group, they ought to have done worse than the historical group which must have included many motivated students who were simply not given the option of a remedial intervention. When the course became mandatory, the success rate of $91 \%$ passing the repeat semester was even better than in the pilot study, which again is evidence that success is not simply down to motivation: students were clearly benefitting from doing something that they would not have chosen to do. The students themselves also say it is important to make participation mandatory and most would not have attended the programme otherwise: the strong positive shift in attitude from the beginning to the end of the course noted in chapter 3 contributing to the idea that students need to be pushed into the opportunity to appreciate and understand the value of such interventions. In chapter 5 , we saw that only 21 students out of 333 who failed the first exam $(6.3 \%)$ attended more than two of the small group follow-up sessions, despite having been shown the data demonstrating the strong dose effect for the ELLS course. This minimal uptake of a voluntary programme is in keeping with the commonly reported limited help-seeking of weaker students (Judd 1985; Weinsheimer 1998; Devoe et al. 2007).

As noted above, there is no evidence for a relationship between student preferences for learning and their learning outcomes (Kirschner and van Merriënboer, 2013), and weak students typically overestimate their likelihood of success (Kruger and Dunning, 1999), even in the face of evidence to the contrary. It is also, perhaps, unsurprising that students would not choose to put themselves into a 
situation designed to expose their weakness: children (and many adults) do not like the taste of medicine even with full knowledge that it may help them. Furthermore, overcoming initial resistance has been described as valuable for later success, with a positive change in affect actually leading to increased commitment and autonomy (Kannan and Miller, 2009) - an example, perhaps, of the enthusiasm of the convert.

Thus, I think that educators have a responsibility to mandate attendance in remedial programmes for those students who, by their failure, have been proven to need help. Students pay for an education because they have much to learn, and for some this is as much true for learning process as for learning content. George Elliot (1985/1874) wrote, "The mistakes that we mortals make when we have our own way might fairly raise some wonder that we are so fond of it." I think there is a strong case for requiring that at-risk students at least experience the opportunity to not get their own way.

\section{Language \& Discourse}

A thread running through the whole ELLS course is the importance of language in learning medical science, and attention to language and discourse emerged as a key difference between experienced and inexperienced teachers. In chapter 6 we saw how experienced teachers elicited new understanding by pressing for the exact meaning of technical terms, by constantly reminding students to notice word roots, and by demanding precision in the use of common language, words such as 'cog' and 'from'. Experienced teachers also took a more dialogic stance, framing and conducting discourse in the classroom in ways that prompted all group members to participate and engage critically, with an expectation of high quality exploratory talk that includes questioning, clear reasoning and explicit justification of rationale (Mercer, 2000).

This attention to language is crucial throughout education, but especially so for struggling students, who commonly use technical language as if they know the meanings, but who cannot define terms when asked, and tend not to look them up when they encounter them on their own. Furthermore, this very weakness makes them less likely to speak up, to question meaning, or to use the words publicly themselves; and yet languages, of which medicine is one, are only truly learned from talking them, and the meanings of words and concepts can only be owned and appreciated through usage (Dewey, 1910; Vygotsky, 1986). It is when learners are forced to be explicit, to reflect on language, to explain themselves and articulate their understanding, that they recognize their knowledge gaps and take command of concepts (Dewey, 1910; Anderberg et al, 2008; Stal- 
meijer et al, 2008). Often it is through communication that knowledge is constructed (Freire, 2000; Wahlström, 2010): when we engage in dialogue others can know our understanding and offer feedback (Mercer, 2000), and it is when our ideas are challenged that our opinions are transformed (Mackenzie, 2007).

Learning can be considered as the ability to understand and use language in specialized ways. When teachers and learners accept the core role of educational talk (Stokoe, 2000), it becomes a transformative intellectual tool (Dewey, 1910). Language and discourse lie at the core of remediation.

\section{Small Groups}

If discourse is core, then group settings make sense for remediation, and in this study both students and teachers all felt the group was an important ingredient for the success of the programme. Of course, not all groups produce discourse of equal quality: group dynamics influence outcomes (Sampson and Clark, 2009), and size does matter (Spruijt et al, 2013). In chapter 5, we saw that our large group workshops made no difference to overall pass rates, while the small group sessions appeared to have had some effect. This is not an unusual finding: large classes can be alienating and de-motivating (Van Etten et al, 2008; Palmer et al, 2009), too daunting for weaker students to venture contributions (Askell-Williams and Lawson, 2005). Smaller classes provide space for less confident voices, and allow for more interaction and teacher attention (Blatchford et al, 2011). Five or six members is, perhaps, the most effective group size for collaborative learning (Kooloos et al, 2011); certainly, from my experience of remedial group work, if all students are to express themselves fully, seven is the maximum viable group size.

Nevertheless, some commentators have argued that because struggling students present with a variety of self-reported causes for their failure, they should receive individual, tailored support (Sayer et al, 2002; Yates, 2011; Cutting and Saks, 2012). While I would agree that there are certain very personal issues that merit individual attention, those individual discussions should occur as an adjunct to, rather than a replacement for, group remediation. Group teachers need to be approachable by individual students, and be vigilant for signs of specific individual issues that merit a separate one-to-one meeting. However, it turns out to be quite rare that a student has such a unique problem, and equally rare that their problems are due to a single cause (Saxena et al, 2009). When students report their reasons for failure in their group, they quickly discover that others share similar concerns; when they hear others' reasons for failure, they discover that many of those issues also apply to themselves, 
even though they would have remained unrealised and unacknowledged without a group context.

This sharing sits in a reciprocal relationship to a positive group dynamic: as students share their concerns and experiences, they receive emotional support and constructive ideas from their peers and teacher, while at the same time the very acts of sharing and supporting create an environment conducive to further sharing, and the group becomes steadily more close-knit. Thus, we see the value of mandatory attendance and an adequate dose, since without these there is no group stability, no time for the emergence of group cohesion, for building the trusting relationships necessary for the creation of a psychologically safe environment and the sense of belonging conducive to reflection and acceptance of feedback (Muraskin, 1997; van Gennip et al, 2009; Eva et al, 2010; Price et al, 2011; ten Cate et al, 2011). This can in turn result in an effect of positive goal contagion, whereby group members adopt and pursue educational goals of their peers (Eren, 2009), an effect simply not possible in a one-to-one setting. Indeed, friendships form that continue after completion of the ELLS course - these students often maintain these support networks throughout and beyond their basic science programme on island.

The value of a small group extends further than the reduction of the stigma associated with failure and the provision of affective support: the trusting relationships lay the foundation for difficult cognitive work and collaborative learning. Students often fail to appreciate that others may think differently (Dewey, 1910), so a key advantage of group work is the opportunity for students to be confronted with multiple and diverse viewpoints (Askell-Williams and Lawson, 2005; Jordan, 2010), to think together (Mercer, 2000), to be challenged, to exchange ideas and scaffold each other's learning, and thus gain insight into, and develop, their own thinking (Dewey, 1910; Sampson and Clark, 2009). Furthermore, in an atmosphere that encourages mutual feedback and critique, the students learn to call out each other's mistakes, to make metacognitive suggestions, to regulate each other. It is often easier to correct others than ourselves, so this social regulation (Volet et al, 2009; Järvelä, 2011) turns out to be a valuable tool in the training of the self-regulatory behaviours that seem so hard for low-achievers to master.

Such shared regulation does not occur without effort, especially as weaker students tend to be less willing to voice challenges and explore disagreements (Sampson and Clark, 2011), so the guidance of a teacher who promotes student-student dialogue is essential. When this is done skilfully, the group can become a genuine community of inquiry (Stoyanova and Kennedy, 2010), engaging in critical discourse, the deconstruction and reconstruction of understanding 
that results in conceptual change and deep learning. The small group is a key ingredient in the learners' enculturation into medical discourse and their growing identity as successful medical students.

\section{The Teachers}

Throughout this work it has become increasingly clear that the teacher matters, with strong evidence that what the teacher does, and who the teacher is, make very significant differences to longterm student outcomes. Many educational researchers have noted that the teacher is the most significant factor affecting student achievement (Darling-Hammond and Youngs, 2002; Eva, 2006), and the difficulty of working with struggling students who present a complex array of challenges makes the teacher even more important in a remedial context. These teachers need to support their students' cognitive, affective and metacognitive development, applying teaching expertise and contextual knowledge to a constructivist, studentcentred approach that promotes self-efficacy and independence.

Teachers of remediation need to motivate, critique, challenge and advise their learners, through embodiment of five core roles: facilitator, nurturing mentor, disciplinarian, diagnostician and role model. These are represented in figure 7.1, which would ideally have many cross-links between the various branches to show the interconnectedness of these roles (but including these would have made it far too messy and complex). The challenge is balancing these roles, knowing when to intervene, and when to stay silent, when to disrupt and when to nurture. The teacher has to be adaptive, following the lesson wherever it leads, and attending carefully to nuances of classroom action, so that the timing and type of intervention are tailored to the moment for the greatest effect (Dewey, 1910, 1938). Essential to all of this is a dialogic stance (Boyd and Markarian, 2011): the classroom is a conversation, students' voices matter, and feedback is rooted in the teacher's appreciation of their understanding. When these roles are carried out with enthusiasm, when it is obvious to the students that the teacher is striving for their benefit, a community of inquiry is created that enables work towards long-lasting improvement in student performance.

Figure 7.2 captures key attributes of teachers of remediation. Effective teachers believe the students can improve, and, while they value their teacher-student relationships, they value the relationships between the students even more. Deep pedagogical context knowledge is fundamental (Barnett and Hodson, 2001): these teachers need understanding of learners, (Dewey, 1910, 1938; Shulman, 1987), understanding of content (Shulman, 1986), which for remediation includes the content and processes of learning, and understand- 
ing of the classroom as action unfolds. Such contextual expertise develops with practical wisdom gained through reflected-upon experience, and is effected through teaching presence that includes mindful awareness of and engagement with all the elements of classroom life (Rodgers and Raider-Roth, 2006). Experience, which has been shown to correlate with student performance (Darling-Hammond and Youngs 2002; Carrell and West, 2010), is necessary, but not sufficient: it is the complex interplay of all the elements in both concept maps that contributes to the effectiveness of a good teacher of remediation. Further, believing all of this is also not enough: acting on those beliefs, and reflecting on those actions, is key to implementation. 


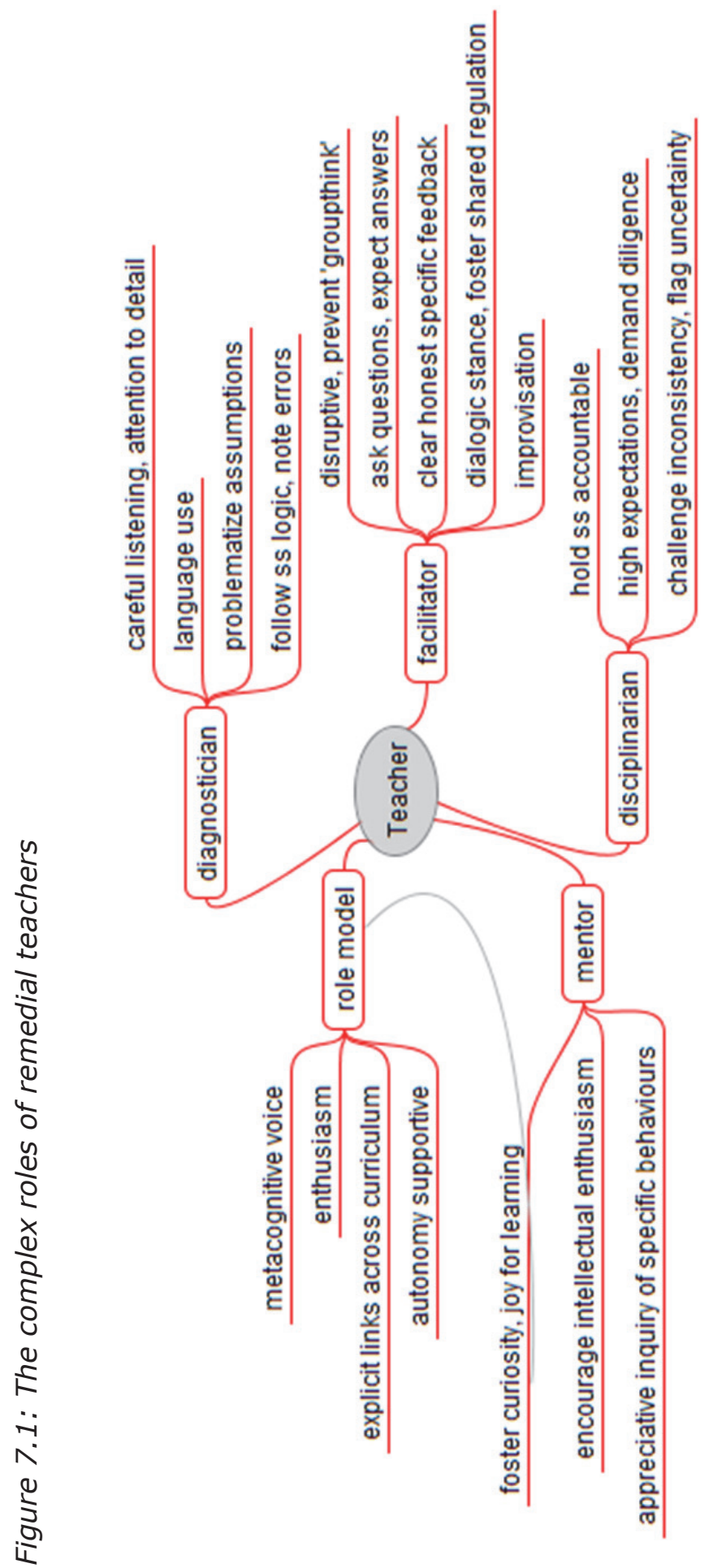


๙ึ

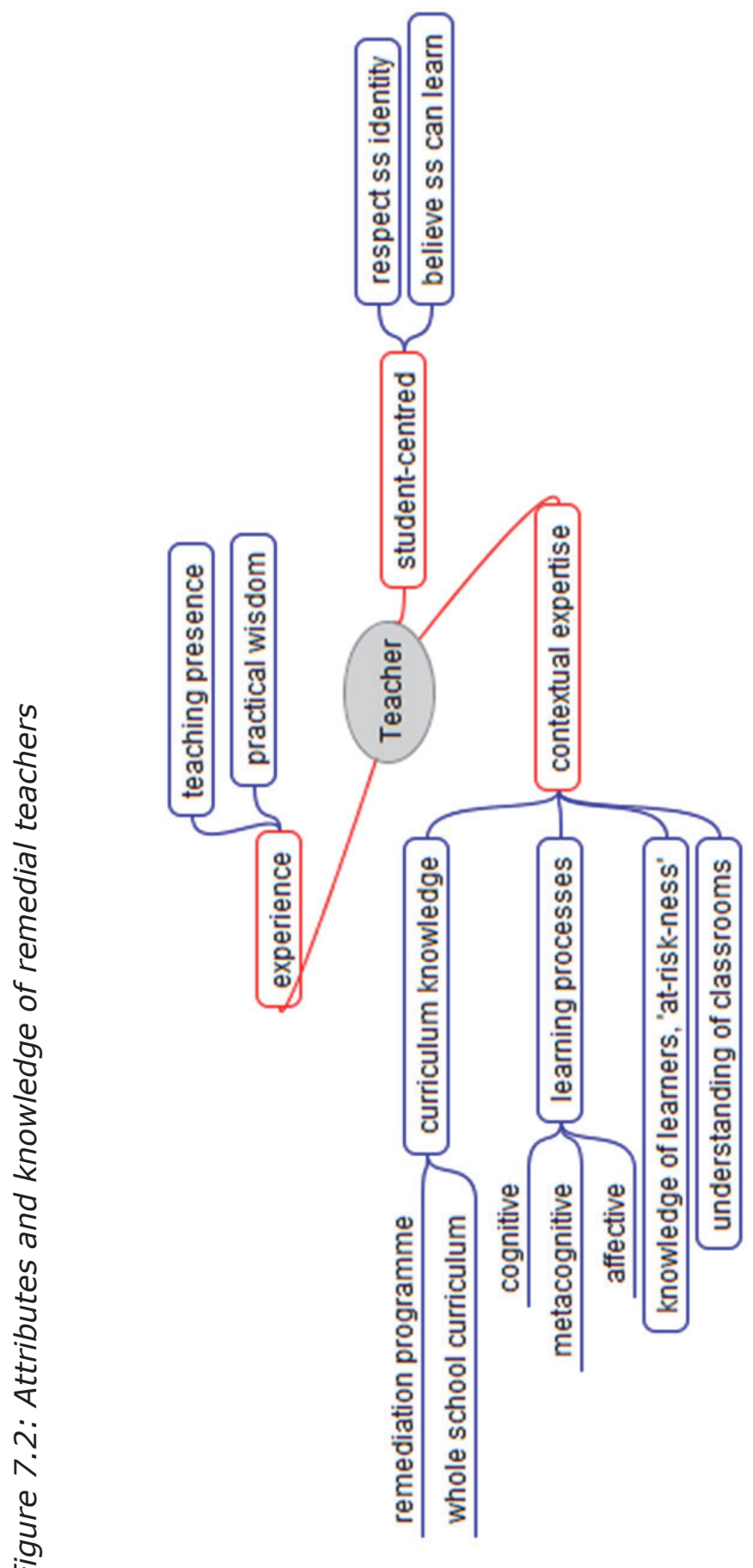


All of the above facets of remediation are, of course, situated within a wider context that exerts influence on the outcome of any programme, and successful remediation needs a systemic perspective with clear administrative support (Lieberman et al, 2010), and provision of adequate human and physical resources. Administrators need to appreciate the complexity of the work (Barkas, 2011), and those involved in remediation need to have some influence over policy (Muraskin, 1997). In our own case, we were in direct discussion with various committees, including curriculum and promotions, and this enabled us to mandate attendance, enforce consequences (although this was rarely needed), and eventually, after proving efficacy, offer credit for completion of the ELLS course. It was also important that we had access to student data, including exam performance, and the sensitive sharing of key information is an important element of helping students (Cleary, 2008). Transparency is also imperative: all stakeholders, especially the students, need to be clear from the outset what the school's policies are, and what kind of support to expect.

When all of this comes together, it is possible to maximise the likelihood that at-risk students will be able to turn around their performance.

\section{Strengths, Limitations and Further Work}

One of the key strengths of this work is the methodology: the use of a mixture of qualitative and quantitative methods to explore a remediation intervention in a single context has delivered an in-depth case study from which others can draw ideas to adapt to their own contexts. My insider perspective as a practitioner researcher is, as stated earlier, both strength and weakness, but then all research must come from some point of view, so I see this as more strength than limitation.

The large numbers of students involved in this study, over 500, compared to less than 50 for other studies of remediation in medical education, has allowed us to have some confidence in our results. The extended time-frame also contributes to this certainty: it is not unusual for a new pedagogic intervention to have a large impact early on, but for that impact to wane over time (Radford, 2008). This work has been ongoing for six years, allowing the course to be repeated many times ( 3 times per year), and also enabling exploration of longer-term effects not often examined in the rush to publication. 
Indeed, without inclusion of the longer-term outcomes, the effect of teacher experience could not have been uncovered.

The use of self-report data in chapters three and four could have been a limitation, had this not been combined with performance data and then followed up with the observational study in chapter six. Nevertheless, any use of survey and focus group data has to be acknowledged as a limitation, since participation is voluntary, and the views of those who refuse to contribute are always lacking. Another key limitation is the small number of teachers - drawing firm conclusions from a sample size of nine is risky, and it may be that the identified attributes were down to characteristics of the individual teachers, rather than experience itself. While the results were corroborated by findings from a broad range of literature, this work needs to be extended to include more teachers, of varying experience levels, and in multiple contexts.

Since no finite work can cover every angle, other limitations necessarily follow from this incompleteness, giving scope for considerable further work. In any complex system, small changes can have far-reaching effects (Durning and Artino, 2011; Morris and Hiebert 2011), so more fine-grained analyses of the different ingredients of remediation could be instructive. For example, there are many handouts in the ELLS handbook, and any of those could be examined in detail, looking at the effect of small changes, or how they are applied differently across teachers and time. Each of these has a written assignment, and how these are treated by the students, as well as the kind of written feedback given by different teachers, could prove revealing if compared to outcomes. Physical space is another interesting variable: I always ensure all group members can see each other clearly, and believe this makes a difference, but a systematic study of seating arrangements and classroom layout could show whether and how this affects outcomes. Likewise, this course has made no use of instructional technology, and how IT could be used in remediation remains poorly understood.

In the analysis of classroom talk, I observed and recorded several classrooms, but only saw each group of students either once or twice. But single lessons do not happen in isolation, and another study might explore the evolution of groups over the course of a whole semester. Such work might also include a more careful look at dialogue, the precision of student talk as it evolves over time, and how that relates to performance outcomes. Similarly, following specific groups over longer periods might afford understanding of relationships within the groups, and whether the formation of stable friendships affects long-term outcomes, as it would appear to do anecdotally. Combining these longitudinal studies might also reveal a 
deeper understanding of the mechanisms of social regulation, and their relationship to self-regulation.

Another area for interesting work would be to determine how much experience is enough to make a difference, and to identify a way to accelerate the learning of inexperienced teachers. Since what is observed typically reflects the views of the observer (Perry et al, 2002), an inexperienced teacher and an experienced mentor could together watch and discuss video-recordings of them both in action. They would inevitably notice different things, and exploration of those differences, along with reflection on how they frame their behaviours in the spirit of advocacy inquiry (Rudolph et al, 2006), if used as a sustained faculty development tool, could make a real difference to teacher behaviours and ultimately to student outcomes.

Of course, the other main area for further work is to explore remediation in similar detail in other contexts. How far do all these ideas apply in other medical schools, in other fields of professional education, and even in other higher and further education contexts? That, I think, is work with the potential for real impact on wider society.

\section{Last Word}

Language matters, and it has become clear that when people use the same words to describe their beliefs and behaviours, they may not be talking about the same thing. Even when people clearly agree on the language of their descriptions, there is often a belief/action mismatch which has implications for the theory and practice of remediation, and educational research in general: you have to see it and feel it to know what it is.

Indeed, the term 'remediation' is considered by some to be problematic in itself. Much the same can be said for any number of other terms (e.g. 'at-risk', 'low-achieving', 'weak', etc) used to categorize a group of students not performing as well as we, or they, would like. Regardless of the political correctness of the terminology, we need to recognize that some students need more support than others, and pretending this is not so will exacerbate rather than help resolve the problem. If students we have accepted onto courses subsequently struggle, we have a duty to try to help them, with a caring intent that will overcome whatever labels we choose to use. And, since teaching those who find learning most challenging is difficult work, we also need to acknowledge that it needs the involvement of our best teachers.

In conclusion, stated within the constraints of language noted above, I think that remediation should be mandatory, and of suffi- 
cient dose and intensity to fully explore a student-centred course designed to blend the learning of content and process. This work should be carried out in a small, stable community of inquiry that requires participation of all group members in the generation of dialogue for collaborative knowledge construction and social regulation. Such a learning climate can evolve in groups led by teachers with extensive pedagogical context knowledge and expertise. When these teachers pay attention to learners, the details of their thoughts and actions, they can use timely interventions to foster development of affective, cognitive, and metacognitive practices. Teachers of remediation thus need to embody the core roles of facilitator, nurturing mentor, disciplinarian, diagnostician and role model. This combination demands high levels of teaching presence and practical wisdom, gained through experience, to flexibly manage complex remediation processes, to produce attitudinal shifts and nurture the development of independent, well-regulated, critical, lifelong learners.

\section{References}

Adey P, Csapó B, Demetriou A, Hautamäki J, Shayer M. 2007. Can we be intelligent about intelligence?: Why education needs the concept of plastic general ability. Educ Res Rev, 2(2):75-97

Alexander R, Badenhorst E, Gibbs T. 2005. Intervention programme: A supported learning programme for educationally disadvantaged students. Med Teach 27(1):66-70

Alexander PA, Schallert DL, Reynolds RE. 2009. What is learning anyway? A topographical perspective considered. Educ Psychol 44(3):176-192

Anderberg E, Svensson L, Alvegård C, Johansson T. 2008. The epistemological role of language use in learning: A phenomenographic intentional-expressive approach. Educ Res Rev 3(1):14-29

Askell-Williams H, Lawson MJ. 2005. Students' knowledge about the value of discussions for teaching and learning. Social Psych Educ, 8(1):83-115

Bannert M, Mengelkamp C. 2008. Assessment of metacognitive skills by means of instruction to think aloud and reflect when prompted. Does the verbalisation method affect learning? Metacogn and Learn, 3(1):39-58

Barkas LA. 2011. 'Teaching' or 'support'? The poisoned chalice of the role of students' skills centres. J Fur High Educ 35(2):265-286

Barnett J, Hodson D. 2001. Pedagogical context knowledge: Toward a fuller understanding of what good science teachers know. Science Education, 85(4):426-453

Bateson G. 1972. Steps to an Ecology of Mind. Chicago, IL: University of Chicago Press 469-70 
Bateson G. 1979. Mind and nature: A necessary unity. New York, NY: Dutton

Bell A. 2011. Re-constructing Babel: Discourse analysis, hermeneutics and the interpretive arc. Discourse Studies, 13(5):519-568

Ben-Peretz M. 2011. Teacher knowledge: What is it? How do we uncover it? What are its implications for schooling? Teach Teach Educ 27(1):3-9

Berland LK, Reiser BJ. 2009. Making sense of argumentation and explanation. Sci Educ, 93(1):26-55

Blatchford P, Bassett P, Brown P. 2011. Examining the effect of class size on classroom engagement and teacher-pupil interaction: Differences in relation to pupil prior attainment and primary vs. secondary schools. Learning and Instruction, 21(6):715730

Bloom JW. 2011. Investigating Relationships: Thoughts on the Pitfalls and Directions. Complicity: Int J Complexity Educ, 8(1):38-43

Bolhuis S, Voeten MJM. 2004. Teachers' conceptions of student learning and own learning. Teach Teach 10(1):77-98

Bowman NA. 2010. Can 1st-year college students accurately report their learning and development? Amer Educ Res J, 47(2):466-496

Boyd MP, Markarian WC. 2011. Dialogic teaching: talk in service of a dialogic stance, Lang and Educ, 25(6):515-534

Bricker LA, Bell P. 2008. Conceptualizations of argumentation from science studies and the learning sciences and their implications for the practices of science education. Sci Educ, 92(3):473-498

Brigham TA, Moseley SA, Sneed S, Fisher M. 1994. Excel: An intensive and structured program of advising and academic support to assist minority freshmen to succeed at a large state university. J Behavioral Education, 4(2):227-242

Carrell SE, West JE. 2008. Does professor quality matter? Evidence from random assignment of students to professors (No. w14081). National Bureau of Economic Research

Carroll S, Feltham M. 2007. Knowledge or Skills - The Way to a Meaningful Degree? An Investigation Into The Importance of Key Skills Within an Undergraduate Degree and The Effect This Has On Student Success. Bioscience Education 10

Cleary L. 2008. "Forward Feeding" About Students' Progress: The Case for Longitudinal, Progressive, and Shared Assessment of Medical Students. Acad Med, 83(9):800

Collins A, Brown JS, Newman SE. 1989. Cognitive apprenticeship: Teaching the crafts of reading, writing, and mathematics. In: Resnick LB, editor. Knowing, learning, and instruction: Essays in honor of Robert Glaser. Hillsdale, NJ: Lawrence Erlbaum Associates, Inc. pp 453-494

Credé M, Kuncel NR. 2008. Study habits, skills, and attitudes: The third pillar supporting collegiate academic performance. Persp on Psych Sci, 3(6):425-453 
Cutting MF, Saks NS. 2012. Twelve tips for utilizing principles of learning to support medical education. Medical Teacher, 34(1):20-24

Darling-Hammond L, Youngs P. 2002. Defining "highly qualified teachers": What does "scientifically-based research" actually tell us? Educ Researcher 31(9):13-25

Day SB, Goldstone RL. 2012. The Import of Knowledge Export: Connecting Findings and Theories of Transfer of Learning, Educ Psych, 47(3):153-176

Design-Based Research Collective. 2003. Design-based research: An emerging paradigm for educational inquiry. Educational Researcher, 5-8

Devoe P, Niles C, Andrews N, Benjamin A, Blacklock L, Brainard A, Colombo E, Dudley B, Koinis C, Osgood M. 2007. Lessons learned from a study-group pilot program for medical students perceived to be 'at risk'. Med Teach 29(2):e37-e40

Dewey J. 1910. How We Think. New York, NY: DC Heath \& Co

Dewey J. 1916. Democracy and Education: an Introduction to the Philosophy of Education. New York, NY: Macmillan

Dewey J. 1929. Experience and Nature. London, George Allen \& Unwin Ltd

Dewey J. 1938. Experience and Education. Touchstone, NY: Kappa Delta Pi

Durning SJ, Artino AR. 2011. Situativity theory: A perspective on how participants and the environment can interact: AMEE Guide no. 52. Med Teach, 33(3):188-199

Dyche L, Epstein RM. 2011. Curiosity and medical education. Med Educ 45:663-668

Eliot G. 1985. Middlemarch (1874), New York, Bantam Classics

Eren A. 2009. Exploring the relationships among mirror neurons, theory of mind, and achievement goals: Towards a model of achievement goal contagion in educational settings. Educ Res Rev, 4(3):233-247

Eva KW. 2006. Whither the need for faculty development? Med Educ, 40(2):99-100

Eva KW, Munoz J, Hanson MD, Walsh A, Wakefield J. 2010. Which factors, personal or external, most influence students' generation of learning goals? Acad Med, 85(10):S102-S105

Eva KW, Regehr G. 2011. Exploring the divergence between self-assessment and selfmonitoring. Adv Health Sci Educ Theory Pract. 16(3):311-29

Ferla J, Valcke M, Schuyten G. 2008. Relationships between student cognitions and their effects on study strategies. Learn Indiv Differ, 18(2):271-8

Freire P. 2000. Pedagogy of the Oppressed, 30th Anniversary Edition. New York, Continuum

Friedman DB, Crews TB, Caicedo JM, Besley JC, Weinberg J, Freeman ML. 2010. An exploration into inquiry-based learning by a multidisciplinary group of higher education faculty. Higher Education, 59(6):765-783 
Greasley K, Ashworth P. 2007. The phenomenology of 'approach to studying': the university student's studies within the lifeworld. Br Educ Res J 33(6):819-43

Greensfeld H, Elkad-Lehman I. 2004. How do we think? Teachers in education colleges reflect on the thinking in their respective disciplines: science and literature, Teach and Teach, 10(5):527-551

Griffin B, Wilson IG. 2012. Faking good: self-enhancement in medical school applicants. Med Educ, 46(5):485-490

Guadagnoli M, Morin MP, Dubrowski A. 2012. The application of the challenge point framework in medical education. Medical education, 46(5):447-453

Harlen W. 2003. Enhancing Inquiry Through Formative Assessment. San Francisco, CA: Institute for Inquiry Exploratorium. Available from:

http://www.exploratorium.edu/ifi/resources/harlen_monograph.pdf

Hauer KE, O'Brien BC, Hansen LA, Hirsh D, Ma IH, Ogur B, Poncelet AN, Alexander EK, Teherani A. 2012. More Is Better: Students Describe Successful and Unsuccessful Experiences With Teachers Differently in Brief and Longitudinal Relationships. Acad Med, 87(10):1389-1396

Hays RB. 2012. Remediation and re-assessment in undergraduate medical school examinations. Med Teach, 34(2):91-92

Hinchliffe G. 2011. What is a Significant Educational Experience? J Philos of Educ, 45(3):417-431

Hutchison P, Hammer D. 2010. Attending to student epistemological framing in a science classroom. Science Education, 94(3):506-524

Huws N, Reddy PA, Talcott JB. 2009. The effects of faking on non-cognitive predictors of academic performance in University students. Learn Indiv Diff, 19(4):476-480

Järvelä S. 2011. How does help seeking help?-New prospects in a variety of contexts. Learning and Instruction, 21(2):297-299

Johnson CW, Johnson R, McKee JC, Kim M. 2009. Using the personal background preparation survey to identify health science professions students at risk for adverse academic events. Adv health sci educ, 14(5):739-752

Jordan ME. 2010. Mathematics as a Complex System: Learning in Complex Adaptive Systems, Complicity: Int J Complexity and Educ, 7(1):70-76

Jörg T, Davis B, Nickmans G. 2007. Towards a new, complexity science of learning and education. Educ Res Rev 2:145-156

Judd TP. 1985. A research based approach to students in academic difficulty: Characteristics and intervention. ASHE 1985 annual meeting paper

Kahneman D. 2011. Thinking, Fast and Slow. Farrar, Straus and Giroux, New York

Kannan J, Miller JL. 2009. The positive role of negative emotions: fear, anxiety, conflict and resistance as productive experiences in academic study and in the emergence of learner autonomy. Int J Teach Learn High Educ, 20(2):144-54 
Kaufman DM. 2003. ABC of learning and teaching in medicine: Applying educational theory in practice. BMJ 326:213-216

Kirschner PA, van Merriënboer JJ. 2013. Do Learners Really Know Best? Urban Legends in Education. Educ Psych, online first:

http://dx.doi.org/10.1080/00461520.2013.804395

Kooloos JG, Klaassen T, Vereijken M, Van Kuppeveld S, Bolhuis S, Vorstenbosch M. 2011. Collaborative group work: Effects of group size and assignment structure on learning gain, student satisfaction and perceived participation. Med Teach, 33(12):983988

Kruger J, Dunning D. 1999. Unskilled and Unaware of It: How Difficulties in Recognizing One's Own Incompetence Lead to Inflated Self-Assessments. J Personality and Soc Psych, 77(6):121-113

Kuper A, Hodges B. 2011. Medical education in its societal context, Chap 3 in Medical education: theory and practice, Dornan et al (Eds). Edinburgh, Elsevier

Lakoff G, Johnson M. 1999. Philosophy in the flesh: The embodied mind and its challenge to western thought. New York, NY: Basic Books

Larsson J, Dahlin B. 2012. Educating far from Equilibrium: Chaos Philosophy and the Quest for Complexity in Education. Complicity: Int J Complex Educ, 9(2)

Leach J, Moon B. 1999. Recreating pedagogy. In: Leach J, Moon B, eds. Learners and Pedagogy. London: Open University / Paul Chapman Publishing pp265-76

Leggett $H$, Sandars J, Burns P. 2012. Helping students to improve their academic performance: A pilot study of a workbook with self-monitoring exercises. Med Teach, 34(9):751-753

Lieberman SA, Ainsworth MA, Asimakis GK, Thomas L, Cain LD, Mancuso MG, Rabek JP, Zhang N, Frye AW. 2010. Effects of comprehensive educational reforms on academic success in a diverse student body. Med Educ, 44(12):1232-1240

Lonka K, Sharafi P, Karlgren K, Masiello I, Nieminen J, Birgegård G, Josephson A. 2008. 'MED NORD - A tool for measuring medical students' well-being and study orientations. Med Teach 30(1):72-79

Mackenzie J. 2007. Conceptual learning in higher education: Some philosophical points. Oxf Rev Educ, 34(1):75-87

Maturana HR, Varela FJ. 1987. The tree of knowledge. Boston, MA: Shambhala

McDermott, RP. 1999. On Becoming Labelled - the story of Adam, in Murphy (ed) Learners, Learning \& Assessment, The Open University, Sage, London

McLaughlin K. 2012. Navigating in the fog of medical school admissions data. Adv in Health Sci Educ, 17:627-629

Mercer N. 2000. Words \& Minds: How we use language to think together. London: Routledge

Morris AK, Hiebert J. 2011. Creating shared instructional products: An alternative approach to improving teaching. Educ Researcher 40(1):5-14 
Morrison LJ, Headrick LA. 2008. Teaching residents about practice-based learning and improvement. Joint Commission Journal on Quality and Patient Safety, 34(8):453-459

Muraskin L. 1997. "Best practices" in student support services: A study of five exemplary sites. Follow-up study of student support services programs. SMB Economic Research Inc. and US Department of Education

Nillsen R. 2004. Can the love of learning be taught? J Univ Teach Learn Pract 1(1):1-9

Norman G. 2009. Teaching basic science to optimize transfer, Med Teach,31(9):807811

Norton L, Richardson JTE, Hartley J, Newstead S, Mayes J. 2005. Teachers' beliefs and intentions concerning teaching in higher education. High Educ 50(4):537-571

Palmer M, O'Kane P, Owens M. 2009. Betwixt spaces: student accounts of turning point experiences in the first-year transition. Studies in High Educ, 34(1):37-54

Papert S, and Harel I. 1991. Situating constructionism. Constructionism, 1-11. Westport, CT, US: Ablex Publishing

Pashler H, Bain PM, Bottge BA, Graesser A, Koedinger K, McDaniel M, Metcalfe J. 2007. Organizing Instruction and Study to Improve Student Learning. IES Practice Guide. US Department of Education

Patel VL, Yoskowitz NA, Arocha JF. 2009. Towards effective evaluation and reform in medical education: A cognitive and learning sciences perspective. Adv Health Sci Educ 14(5):791-812

Pell G, Fuller R, Homer M, Roberts T. 2012. Is short-term remediation after OSCE failure sustained? A retrospective analysis of the longitudinal attainment of underperforming students in OSCE assessments. Med Teach, 34(2):146-50

Perry NE, Van de Kamp KO, Mercer LK, Nordby CJ. 2002. Investigating teacher-student interactions that foster self-regulated learning. Educational Psychologist, 37(1):5-15

Pope C, Mays N. 2009. Critical reflections on the rise of qualitative research. BMJ 339:737-739

Price M, Handley K, Millar J. 2011. Feedback: focusing attention on engagement, Studies in Higher Educ, 36(8):879-896

Prigogine I. 1997. The End of Certainty, The Free Press, New York

Proulx J. 2008. Some Differences between Maturana and Varela's Theory of Cognition and Constructivism. Complicity: Int J Complexity Educ, 5(1):11-26

Radford M. 2008. Prediction, control and the challenge to complexity. Oxf Rev Educ 34(5):505-520

Regehr G. 2010. It's NOT rocket science: rethinking our metaphors for research in health professions education. Med Educ, 44(1):31-39

Rodgers CR, Raider-Roth MB. 2006. Presence in teaching. Teach Teach 12(3):265-287 
Rudolph JW, Simon R, Dufresne RL, Raemer DB. 2006. There's no such thing as "nonjudgmental" debriefing: a theory and method for debriefing with good judgment. Simulation in Healthcare, 1(1):49-55

Sampson V, Clark D. 2009. The impact of collaboration on the outcomes of scientific argumentation. Sci Educ, 93(3):448-84

Sampson V, Clark DB. 2011. A comparison of the collaborative scientific argumentation practices of two high and two low performing groups. Research in Science Education, 41(1):63-97

Sandars J, Cleary TJ. 2011. Self-regulation theory: Applications to medical education: AMEE Guide No. 58. Med Teach, 33(11):875-886

Saxena V, O'Sullivan PS, Teherani A, Irby DM, Hauer KE. 2009. Remediation techniques for student performance problems after a comprehensive clinical skills assessment. Acad Med 84(5):669-676

Sayer M, Chaput de Saintonge M, Evans D, Wood D. 2002. Support for students with academic difficulties. Med Educ 36:643-650

Shulman LS. 1986. Those who understand: Knowledge growth in teaching. Educ Researcher 15(2):4-14

Shulman LS. 1987. Knowledge and teaching: Foundations of the new reform. Harvard Educ Rev 57(1):1-23

Sibii R. 2010. Conceptualizing teacher immediacy through the 'companion' metaphor. Teach High Educ 15(5):531-542

Spruijt A, Wolfhagen I, Bok H, Schuurmans E, Scherpbier A, van Beukelen P, Jaarsma D. 2013. Teachers' perceptions of aspects affecting seminar learning: a qualitative study. BMC Med Educ, 13(1):22

Stalmeijer RE, Dolmans DHJM, Wolfhagen IHAP, Scherpbier AJJA. 2009. Cognitive apprenticeship in clinical practice: Can it stimulate learning in the opinion of students? Adv Health Sci Educ 14(4):535-546

Stegers-Jager KM, Cohen-Schotanus J, Themmen APN. 2013. The effect of a short integrated study skills programme for first-year medical students at risk of failure: A randomised controlled trial. Med Teach, 35(2):120-126

Stokoe E. 2000 Constructing Topicality in University Students' Small-group Discussion: A Conversation Analytic Approach, Language and Education, 14(3):184-203

Stoyanova N, Kennedy D. 2010. Between chaos and entropy: Community of inquiry from a systems perspective. Complicity: Int J Complexity Educ 7(2):1-15

ten Cate OTJ, Kusurkar RA, Williams GC. 2011. How self-determination theory can assist our understanding of the teaching and learning processes in medical education. AMEE Guide No. 59. Med Teach, 33(12):961-973

Thalheimer W. 2003. The Learning Benefits of Questions. http://www.worklearning.com/ma/PP_WP003.asp

Tuckman BW, Kennedy GJ. 2011. Teaching Learning Strategies to Increase Success of First-Term College Students, J Experimental Education, 79(4):478-504 
van Gennip NAE, Segers MSR, Tillema HH. 2009. Peer assessment for learning from a social perspective: the influence of interpersonal variables and structural features. Educ Res Rev, 4(1):41-54

van de Pol J, Volman M, Beishuizen J. 2012. Promoting teacher scaffolding in smallgroup work: A contingency perspective. Teach Teach Educ 28(2):193-205

van Etten S, Pressley M, McInerney DM, Liem AD. 2008. College seniors' theory of their academic motivation. J Educ Psychol, 100(4):812-28

Van Merriënboer JJ, Clark RE, De Croock MB. 2002. Blueprints for complex learning: The 4C/ID-model. Educational Technology Research and Development, 50(2), 39-61

van Schalkwyk S. 2010. Early assessment: using a university-wide student support initiative to effect real change. Teach High Educ, 15(3):299-310

Vansteenkiste M, Sierens E, Soenens B, Luyckx K, Lens W. 2009. Motivational profiles from a self-determination perspective: The quality of motivation matters. J Educ Psychol 101(3):671-688

Varela FJ, Thompson ET, Rosch E. 1991. The embodied mind: Cognitive science and human experience. Cambridge, MA: MIT Press

Volet S, Vauras M, Salonen P. 2009. Self- and Social Regulation in Learning Contexts: An Integrative Perspective, Educ Psych, 44(4):215-226

Vygotsky LS. 1986. Thought and language. Cambridge, MA: MIT Press

Wahlström N. 2010. Learning to communicate or communicating to learn? A conceptual discussion on communication, meaning, and knowledge, J Curriculum Studies, 42(4):431-449

Weinsheimer J. 1998. Providing effective tutorial services. Washington DC: Department of Education, National Council of Educational Opportunity Associations

Whitehead D. 2012. Do we give them a fair chance? Attrition among first year tertiary students, J Fur High Educ, 36(3):383-402

Wiske, MS. 1999. What is Teaching for Understanding, in Leach and Moon (eds) Learners and Pedagogy, The Open University, Sage, London

Wittgenstein L. 2006. Tractatus logico-philosophicus. London: Public Domain Books, Kindle ed

Yates J. 2011. Development of a 'toolkit' to identify medical students at risk of failure to thrive on the course: an exploratory retrospective case study. BMC Med Educ, 11(1):95

Zimmerman BJ. 2002 Becoming a Self-Regulated Learner: An Overview, Theory Into Practice, 41(2):64-70 


\section{Summary}

Chapter 1 provides an introduction to the topic of remediation in medical education. The widening participation agenda brings with it an increasing number of diverse students who struggle to succeed in medical school. Although the causes for students' academic difficulties are multi-faceted and complex, a careful appraisal of the literature reveals a number of recurring, inter-related reasons for students failing at medical school. These generally include weakness in literacy, numeracy, study skills, test-taking strategies, background knowledge, critical thinking, domestic and emotional problems, confidence and self-esteem. However, there has been relatively little work on strategies for effective remediation of struggling students, particularly within medical education. There is uncertainty about what kind of remediation works best, and the work that has been done has typically shown only short-term improvements in student performance. This has resulted in calls for further research into the components of effective remediation, how they work, and how they might be combined into an effective intervention.

The aim of this research project is to develop a practical theory of remediation for at-risk medical students, with the main research question being, 'What are the ingredients of successful remediation, and how do these work to improve outcomes for at-risk medical students?' This research project has employed mixed quantitative and qualitative methodologies to follow an extended case study of a design-based remedial intervention in one medical school. We have endeavoured to develop an understanding of the theory and practice of remediation by asking questions about the ingredients of successful remediation and exploring how these elements work to improve outcomes for participating students.

Chapter 2 gives a detailed description of the Essential Lifelong Learning Skills (ELLS) course design, and presents data on performance outcomes of the participating students. The ELLS course, a mandatory intervention for students who fail and repeat their first semester at Ross University School of Medicine, draws upon a blend 
of complementary theoretical perspectives: it is primarily based upon a constructivist, student-centred approach that focuses on learning through collaboration, dialogue and self-regulation, while the effort to enculturate students into medical discourse and build their identities as medical students draws on sociocultural theories of learning. Stable, faculty-facilitated groups of six students meet throughout a semester to work through a syllabus that integrates learning study skills and critical thinking with the content of basic science course material. The outcomes in terms of student performance have shown strongly significant and long-term improvement. Of the 588 participants, $91 \%$ passed their repeat semester, compared to $58 \%(n=715)$ for controls $(p<0.0001)$. This significant effect persisted for progression through the school for the subsequent three semesters, with $61 \%$ completing their basic science courses three semesters later (compared to $38 \%$ prior to the intervention, $\mathrm{p}<0.0001$ ). Another key finding was that more attendance correlates with better long term results. The conclusions drawn from this work are that a mandatory programme that draws on a blend of theories and research-proven techniques clearly makes a positive difference to the outcomes for atrisk medical students.

Chapter 3 presents the perspectives of the students who have participated in ELLS, as shared through surveys and focus groups. The majority of participants $(89 \%)$ felt the programme had been beneficial, and, when asked about their attitude towards mandatory attendance, reported a marked positive shift (from 3.2 to 4.1 on a 5point likert scale), representing increases in intrinsic motivation, enthusiasm and commitment. It is encouraging that students appear to have absorbed and claimed as their own many of the views of learning the course tries to teach. They believe the programme works because of a combination of elements, including its mandatory status, respect for their identity as repeaters, and the way that it fosters changes in their ways of thinking and their development as flexible, reflective learners. Working in stable groups provides essential emotional and academic support, especially when supported by honest teachers with rigorous expectations and good facilitation skills. Ultimately, they conveyed that successful remediation needs to take into account a blend of cognitive and affective factors and the complex interplay between learner and environment.

Chapter 4 explores the role of the teacher in the remediation process by canvassing student opinions and exploring the teachers' perspectives. Almost all responding students said their teacher positively influenced their outcomes, with all teachers apparently equally proficient at balancing core facilitation skills of listening and advising, 
being interested in the students, enforcing course elements, allowing some student flexibility, challenging students' thinking, holding them accountable, offering encouragement, providing motivation, and being approachable and honest.

Likewise, the teachers shared similar views of the ingredients of successful remediation, namely that it should support emotional needs and foster cognitive and metacognitive skills for self-regulation and critical thinking. They all agreed that teachers of remediation need to motivate, critique, challenge and advise their learners, applying teaching and contextual expertise in a constructivist, student-centred small-group environment that fosters curiosity and joy for learning. Teachers of remediation should mediate these processes through embodiment of five core roles: facilitator, nurturing mentor, disciplinarian, diagnostician and role model.

Despite these convergent opinions, a look at quantitative performance data for students, sorted by which teachers facilitated their group, revealed striking and unexpected differences. Although shortterm success of students was similar with all teachers, and appeared to be unrelated to teacher qualifications, there was a correlation of 0.78 between teacher experience and long-term student outcomes.

The paper concludes that remediation of struggling medical students can be achieved through a cognitive apprenticeship within a small community of inquiry that motivates and challenges the students. Such a community needs teachers capable of performing a unique combination of roles that demands high levels of teaching presence and practical wisdom borne of experience.

Chapter 5 shows that a new exam taken two weeks into first semester at the medical school increased our ability to predict which students may struggle: $71 \%$ of students who performed poorly in the new exam subsequently failed a course, leading to either dismissal or repetition of a semester, suggesting that close similarity between predictor task and target task is important for accurate prediction of failure.

The paper goes on to describe a short, preventative, voluntary intervention designed using ideas from the ELLS course material, but heavily constrained by institutional context. Attendance at a series of three large group workshops made no difference to short- or longterm pass rates, despite participants' survey responses expressing beliefs that the intervention did help. However, attendance at more than three follow-up small group sessions significantly improved pass rates two semesters later. Interestingly, the experience of the small group teacher appears to strongly influence students' persistence in attending these voluntary sessions. 
The paper concludes that early identification of at-risk students is possible, but, as with remediation, the type and details of preventative interventions are likely to matter, and need to be tailored for specific contexts. In particular, these results support giving consideration to dose effect, class size, and teacher experience. Ideally, intervention/remediation programmes need strong administrative support, and should involve at least one semester of mandatory, weekly small group meetings with experienced teachers.

Chapter 6 picks up on the emergent theme of the teachers' role in remediation, with the inclusion of additional data still showing the strong correlation (0.81) between long-term student outcomes and teacher experience. Analysis of twenty hours of classroom talk exemplifies how remediation processes play out in the classroom and exposes clear differences between the behaviours of experienced and inexperienced teachers.

The less experienced teachers typically tended to overvalue compassion and affect, and to inadvertently endorse unproductive framing of learning. Much of their classroom dialogue followed the initiation-response-feedback (IRF) format that tends to locate authority in the teacher and reduces student-student interaction, and they often did not challenge unjustified claims, unacknowledged disagreements, or inaccurate language use, and, when they did, failed to insist on immediate pursuit of the problem, resulting in unhelpful premature closure of discussion.

By contrast, the experienced teachers provided more challenging, disruptive facilitation, expertly diagnosing cognitive errors and consistently flagging student uncertainty, inconsistency and disagreement for further exploration. They took a dialogic stance that encouraged more collaborative group dynamics, insisting that students comment on each other's ideas and take ownership of the conversation, thus creating a discourse community of shared regulation. They provided frequent metacognitive time-outs, both as a model self-regulatory voice and enforcer of student reflection, and they used their extensive contextual knowledge to help students make and appreciate explicit links between disciplines, processes and concepts.

This study concludes that remediation work is effectively carried out in a small, stable community of inquiry that requires participation of all group members in the generation of dialogue for collaborative knowledge construction and social regulation. Such a learning climate can evolve in groups led by experienced teachers with extensive pedagogical context knowledge and expertise. When these teachers pay attention to details of both content and process, they can use timely interventions to foster curiosity and the will to learn. These 
teachers should actively challenge students' language use, logical inconsistencies and uncertainties, problematize their assumptions, and provide a metacognitive regulatory voice that can generate attitudinal shifts and nurture the development of independent critical thinkers.

Chapter 7 discusses the findings from the five studies, draws together emergent themes and offer some conclusions. Through this work it has become clear that language matters: when people use the same words to describe their beliefs and behaviours, they may not be talking about the same thing. Even when people clearly agree on the language of their descriptions, there is often a belief/action mismatch which has implications for the theory and practice of remediation, and educational research in general: you have to see it and feel it to really know what it is.

Indeed, the term 'remediation' is itself considered, by some, to be problematic. Much the same can be said for any number of other terms (e.g. 'at-risk', 'low-achieving', 'weak', etc) used to categorize a group of students not performing as well as we, or they, would like. Regardless of the political correctness of the terminology, we need to recognize that some students need more support than others, and pretending this is not so will exacerbate rather than help resolve the problem. If students we have accepted onto courses subsequently struggle, we have a duty to try to help them, with a caring intent that will overcome whatever labels we choose to use. And, since teaching those who find learning most challenging is difficult work, we also need to acknowledge that it needs the involvement of our best teachers.

In conclusion, it seems that remediation should be mandatory, and of sufficient dose and intensity to fully explore a student-centred course designed to blend the learning of content and process. This work should be carried out in a small, stable community of inquiry that requires participation of all group members in the generation of dialogue for collaborative knowledge construction and social regulation. Such a learning climate can evolve in groups led by teachers with extensive pedagogical context knowledge and expertise. When these teachers pay attention to learners, the details of their thoughts and actions, they can use timely interventions to foster development of affective, cognitive, and metacognitive practices. Teachers of remediation thus need to embody the core roles of facilitator, nurturing mentor, disciplinarian, diagnostician and role model. This combination demands high levels of teaching presence and practical wisdom, gained through experience, to flexibly manage complex remediation processes, to produce attitudinal shifts and nurture the development of independent, well-regulated, critical, lifelong learners. 



\section{Samenvatting}

Hoofdstuk 1 geeft een inleiding tot het onderwerp van dit proefschrift, het remediëren van studenten met studieproblemen. De toegenomen diversiteit van deelnemers aan het medisch onderwijs heeft tot gevolg dat steeds meer geneeskundestudenten met verschillende achtergronden problemen ondervinden tijdens hun studie. Ondanks de zeer diverse en complexe oorzaken van studieproblemen laat een zorgvuldige bestudering van de literatuur zien dat er een aantal onderling samenhangende en steeds terugkerende reden is waarom studenten mislukken, zoals onvoldoende lees- en rekenvaardigheid, studievaardigheden, examenstrategieën, achtergrondkennis, kritisch denken, privé- en emotionele problemen, zelfvertrouwen en eigenwaarde. $\mathrm{Er}$ is echter vooral binnen het geneeskundeonderwijs weinig onderzoek gedaan naar methoden om studenten met studieproblemen te helpen. Onduidelijk is welke aanpak de beste is en van het weinige dat op dit gebied gedaan is, weten we dat de resultaten hoofdzakelijk beperkt blijven tot kortdurende verbetering van studentenprestaties. Dit heeft geleid tot de behoefte aan meer onderzoek naar de onderdelen van effectief remediëren, hun werking en hoe zij gecombineerd kunnen worden tot effectieve interventies.

Het onderzoek in dit proefschrift had tot doel om een praktische theorie te ontwikkelen voor het remediëren van geneeskundestudenten bij wie een grote kans bestaat op het ontstaan van studieproblemen. De belangrijkste onderzoeksvraag is: Wat zijn de ingrediënten van succesvol remediëren en wat is het onderliggende mechanisme waardoor deze ingrediënten de studieresultaten van probleemstudenten kunnen verbeteren? Een mix van kwantitatieve en kwalitatieve methoden is gebruikt in een uitvoerige case-studie van een 'designbased' remediëringsinterventie in één medisch curriculum. $\mathrm{Er}$ is gestreefd naar inzicht in de theorie en praktijk van remediëren door het bevragen van betrokkenen over onderdelen van een succesvolle interventie en door onderzoek naar de manier waarop deze onderdelen leidden tot verbeterde prestaties van de deelnemende studenten. 
In Hoofdstuk 2 wordt een onderwijsontwerp, genaamd Essential Lifelong Learning Skills (Essentiële Vaardigheden voor Levenslang Leren, (ELLS)), gedetailleerd beschreven en worden gegevens gepresenteerd over de prestaties van de hieraan deelnemende studenten. Het ELLS-programma is een verplicht onderwijsonderdeel voor studenten die gezakt zijn en hun eerste semester aan de Ross University School of Medicine over moeten doen. Het programma is gebaseerd op een mengeling van complementaire theoretische uitgangspunten met als belangrijkste een constructivistische, studentgerichte aanpak met nadruk op samenwerkend leren, discussie en zelfregulering. Daarnaast worden studenten op basis van sociaalculturele leertheorieën vertrouwd gemaakt met de medische cultuur en het medisch taalgebruik en geholpen een identiteit te ontwikkelen als geneeskundestudent. Vaste groepen van zes studenten onder begeleiding van een docent komen regelmatig bijeen gedurende een semester voor een programma waarin studievaardigheden en kritisch denken geïntegreerd zijn met de inhoud van onderwijsmateriaal van de basisvakken.

De uitkomsten in de vorm van studentenprestaties gaven een zeer significante verbetering te zien op de lange termijn. $91 \%$ van de 588 deelnemende studenten sloten het herhaalde semester af met een voldoende resultaat tegenover $58 \%(n=715)$ van de studenten in de controlegroep $(p<0.0001)$. Dit significante resultaat bleef gehandhaafd tijdens de volgende drie semesters aan het eind waarvan $61 \%$ slaagde voor de basisvakken, vergeleken met een slaagpercentage van $38 \%$ voor de implementatie van de interventie $(p<0.0001)$. Een andere belangrijke uitkomst was dat meer aanwezigheid bij het onderwijs gerelateerd was met betere resultaten op de lange termijn. Hieruit kan geconcludeerd worden dat een verplicht programma gebaseerd op een combinatie van theorie en in onderzoek effectief bevonden technieken een duidelijk positief effect heeft op de resultaten van studenten met studieproblemen.

In Hoofdstuk 3 staat de mening centraal van de studenten die deelnamen aan de ELLS-interventie. Enquêtes en focusgroepen lieten zien dat de meeste deelnemers (89\%) het programma zinvol vonden. De mening van de deelnemers over verplichte deelname liet een duidelijk positieve verschuiving te zien (van 3,2 tot 4,1 op een vijfpunts-Likertschaal), hetgeen wijst op een verbetering van intrinsieke motivatie, enthousiasme en inzet. Het is bemoedigend om te zien dat studenten veel van de inzichten over leren uit het programma overgenomen en zich eigengemaakt hebben. Volgens de studenten is het programma effectief door een combinatie van elementen zoals verplichte deelname, respect voor hun identiteit als recidivisten en de manier waarop het programma hun manier van denken veran- 
dert en hen stimuleert om flexibel en reflectief te leren. Het werken in vaste groepen biedt de benodigde emotionele en academische steun, vooral wanneer docenten betrouwbaar zijn, hoge verwachtingen van studenten hebben en beschikken over goede begeleidingsvaardigheden. Het belangrijkste inzicht dat naar voren kwam uit de opmerkingen van de studenten was dat een effectief remediëringsprogramma rekening dient te houden met een mengeling van cognitieve en affectieve factoren en met de complexe interactie tussen studenten en hun omgeving.

Hoofdstuk 4 betreft een onderzoek naar de mening van studenten en de visie van docenten ten aanzien van de rol van de docent bij het begeleiden van studenten met problemen. Bijna alle studenten die deelnamen aan het onderzoek gaven aan dat hun docent een positieve invloed had op hun resultaten. Dit wekte de indruk dat alle docenten de kernvaardigheden voor studentenbegeleiding even goed beheersten, zoals luisteren, adviseren, belangstelling tonen voor studenten, elementen van het onderwijs versterken, studenten enige ruimte geven, studenten aanzetten tot denken, ter verantwoording roepen, stimuleren en motiveren, en toegankelijk en betrouwbaar zijn.

De docenten bleken een vergelijkbare opvatting te hebben over de ingrediënten voor succesvolle begeleiding: gericht op het ondersteunen van emotionele behoeften en het bevorderen van cognitieve en metacognitieve vaardigheden voor zelfregulering en kritisch denken. Er was algemene overeenstemming dat docenten die probleemstudenten begeleiden studenten moeten motiveren, bekritiseren, uitdagen en adviseren, waarbij docenten hun onderwijskundige en contextuele expertise toepassen in een omgeving gekenmerkt door een constructivistische benadering in studentgerichte kleine groepen waarin nieuwsgierigheid en plezier in het leren bevorderd worden. Docenten die probleemstudenten begeleiden, dienen deze processen te mediëren door middel van vijf kernrollen: begeleider, stimulerende mentor, strenge docent, diagnosticus en rolmodel.

Hoewel de meningen van studenten en docenten sterk overeenkwamen, laat een blik op de kwantitatieve gegevens betreffende studentenresultaten, geordend naar groepsdocent, opvallende en onverwachte verschillen zien. Hoewel de resultaten van de studenten op de korte termijn vergelijkbaar waren voor alle docenten en er geen relatie was met docentenkwaliteiten was er een correlatie van 0.78 tussen de ervaring van de docent en de resultaten op de lange termijn. Hieruit wordt geconcludeerd dat studenten met studieproblemen succesvol begeleid kunnen worden door middel van een 'cognitive apprenticeship' in een kleine leergemeenschap waarin studenten gemotiveerd en uitgedaagd worden. Een dergelijke ge- 
meenschap heeft docenten nodig die een unieke combinatie van rollen kunnen vervullen die een sterke aanwezigheid van de docent vereisen evenals door ervaring verkregen praktische wijsheid.

Het onderzoek in Hoofdstuk 5 laat zien dat een nieuw examen dat afgenomen werd na de tweede week van het eerste semester ons in staat stelde om te voorspellen bij welke studenten er een kans bestond op studieproblemen: $71 \%$ van de studenten met een slecht resultaat op dit nieuwe examen bleken uiteindelijk te zakken voor een cursus, met als gevolg dat zij uitgesloten werden van deelname aan verder onderwijs of een semester over moesten doen. Dit wijst erop dat een sterke overeenkomst tussen de voorspellende taak en de doeltaak belangrijk is voor een juiste voorspelling van een slecht resultaat.

Vervolgens wordt een korte, preventieve, facultatieve interventie beschreven op basis van ideeën uit het ELLS-programma, zij het sterk beperkt door de institutionele context. Deelname aan een reeks van drie workshops voor grote groepen leidde niet tot een verschil in slagingspercentage op korte en lange termijn, hoewel de deelnemers in een enquête aangaven dat de interventie nuttig was. Echter, deelname aan meer dan drie follow-up bijeenkomsten in een kleine groep leidde twee semesters later tot een significante verbetering van het slaagpercentage. Opvallend was dat blijvende deelname van studenten aan deze facultatieve bijeenkomsten sterk beïnvloed bleek te worden door de mate van ervaring van de groepsdocent.

Geconcludeerd wordt dat vroege opsporing van probleemstudenten mogelijk is, maar dat, evenals bij remediëringsprogramma's, de methode en de elementen van de preventieve interventie van belang zijn en toegesneden moeten worden op de specifieke omstandigheden. Deze resultaten onderstrepen vooral de noodzaak om aandacht te geven aan frequentie, groepsgrootte en de ervaring van de docent. Bij voorkeur is er een uitstekende administratieve ondersteuning voor interventies/ remediëringsprogramma's, die dienen te bestaan uit verplichte, wekelijkse groepsbijeenkomsten gedurende minstens één semester onder begeleiding van een ervaren docent.

Hoofdstuk 6 gaat verder in op het thema van de rol van de docent, waarvan het belang naar voren kwam in de eerdere studies. Het onderzoek behelst een analyse van gegevens die een sterke correlatie te zien gaven (0.81) tussen studentenresultaten op de lange termijn en de ervaring van de docent. Een analyse van twintig uur opnames van discussies tijdens groepsbijeenkomsten laat zien hoe remedieringsprocessen verlopen in groepen en brengt duidelijke verschillen aan het licht tussen het gedrag van ervaren en onervaren docenten. 
De minder ervaren docenten waren geneigd te veel nadruk te leggen op medeleven en affect, waardoor zij ongewild bijdroegen aan een onproductieve inkadering van het leren. Een groot deel van de discussie in de groep verliep volgens het patroon initiatie-reactiefeedback (IRF), dat er doorgaans toe leidt dat autoriteit bij de docent wordt gelegd en dat er minder interacties optreden tussen studenten. De onervaren docenten gingen vaak niet in op onterechte aannames, niet erkende verschillen van mening of verkeerd taalgebruik, en als ze dit wel deden, drongen ze vaak niet aan op een onmiddellijke aanpak van het probleem, hetgeen leidde tot een voortijdige beëindiging van de discussie zonder dat er veel geleerd was.

De ervaren docenten daarentegen boden studenten meer uitdaging en pasten een verstorende benadering toe om de discussie te stimuleren. Met hun deskundigheid legden zij de vinger op cognitieve fouten en signaleerden zij onzekerheden bij studenten, inconsistenties en verschillen van mening waarbij zij erop aandrongen dat de groep hier dieper op inging. Hun houding ten aanzien van de discussie stimuleerde een sfeer van samenwerking in de groep, doordat zij studenten dwongen commentaar te geven op elkaars ideeën en verantwoordelijkheid te nemen voor de discussie. Hiermee creëerden zij een 'discourse community' met gedeelde leiding. Zij lasten veel metacognitieve pauzes in, waarbij zij als rolmodel fungeerden voor zelfregulering en studenten tot reflectie aanzetten. Ook maakten zij gebruik van hun brede contextuele kennis om studenten verbanden tussen disciplines, processen en concepten te laten leggen en op waarde te schatten.

De conclusie uit dit onderzoek is dat remediëring succes kan hebben mits toegepast in een kleine, stabiele leergemeenschap waarin alle groepsleden geacht worden deel te nemen aan de discussie om zo samen te werken aan kennisconstructie en sociale regulering. Een dergelijk leerklimaat kan ontstaan in groepen die begeleid worden door een ervaren docent met brede kennis en expertise ten aanzien van de pedagogische context. Als deze docenten aandacht besteden aan inhoud en proces kunnen zij tijdig interveniëren om de nieuwsgierigheid en de bereidheid tot leren van studenten te bevorderen. Deze docenten dienen actieve sturing te bieden ten aanzien van het taalgebruik van studenten, logische inconsistenties en onzekerheden, aannames ter discussie te stellen en een metacognitieve regulerende stem te laten horen om zo de houding van studenten om te buigen en hun ontwikkeling tot onafhankelijke kritische denkers te stimuleren.

In Hoofdstuk 7 worden de bevindingen uit de vijf onderzoeken besproken en wordt een synthese gemaakt van de belangrijke thema's. Ook worden enkele conclusies besproken. Uit het onderzoek is 
gebleken dat taal belangrijk is: als mensen dezelfde woorden gebruiken om zowel ideeën als gedrag te beschrijven, is niet uit te sluiten dat ze dezelfde woorden gebruiken voor verschillende zaken. Zelfs als er overeenstemming bestaat over de taal van de beschrijvingen kan er toch vaak een verkeerde relatie gelegd worden tussen idee en handeling met gevolgen voor theorie en praktijk van remediëring en voor onderzoek van onderwijs in het algemeen: je moet het zien en voelen om echt te begrijpen wat het is.

Sterker nog, de term remediëring zelf wordt door sommigen als problematisch beschouwd. Hetzelfde geldt voor veel andere termen, zoals risicolopend, slechtpresterend, zwak, etc., die gebruikt worden met betrekking tot studenten die niet zo goed presteren als wij, of zij, graag zouden willen. Afgezien van de vraag of dergelijke terminologie politiek correct is, moeten wij ons ervan bewust zijn dat sommige studenten meer ondersteuning nodig hebben dan anderen. Pretenderen dat dit niet zo is, zal het probleem eerder verergeren dan oplossen. Als studenten die wij toegelaten hebben tot ons onderwijs vervolgens studieproblemen blijken te hebben, is het onze plicht hen te helpen, met de expliciete intentie ervoor te zorgen dat zij hun problemen kunnen overwinnen, ongeacht de etiketten die wij hen opplakken. Onderwijs geven aan studenten met de grootste leerproblemen is moeilijk, maar we dienen ons er rekenschap van te geven dat dit de inzet verdient van onze beste docenten.

Ten slotte kunnen wij concluderen dat remediëring verplicht moet zijn en van voldoende frequentie en intensiteit om een studentgericht onderwijsontwerp toe te kunnen passen waarin inhoudelijk en procesgericht leren samen kunnen gaan. Dit onderwijs dient plaats te vinden in een kleine, stabiele leergemeenschap waarin alle groepsleden geacht worden actief samen te werken in discussies gericht op kennisconstructie en sociale regulering. Een dergelijk leerklimaat kan ontstaan in groepen die begeleid worden door docenten met een brede pedagogische contextuele kennis en expertise. Als deze docenten aandacht hebben voor studenten en hun gedachten en handelingen, zullen zij in staat zijn tijdig in te grijpen om de ontwikkeling van affectieve, cognitieve en metacognitieve praktijken te bevorderen. Het is daarom van groot belang dat voor remediëringsprogramma's docenten worden ingezet die de kernrollen kunnen belichamen van begeleider, stimulerende mentor, strenge docent, diagnosticus en rolmodel. Deze combinatie vereist een hoog niveau van aanwezigheid van de docent en op ervaring gestoelde praktische wijsheid om het complexe proces van remediëring flexibel te kunnen sturen, om de instelling van studenten te kunnen veranderen en om te bevorderen dat studenten zich ontwikkelen tot onafhankelijke, zelfstandige, kritische, levenslang lerende professionals. 


\section{Acknowledgments}

I would like to thank my supervisors, Cees van der Vleuten and Albert Scherpbier, for their encouragement and patience throughout this process. I met Albert when attending the RESME course at the AMEE conference in Trondheim, in 2007, and this PhD project is a result of the research proposal submitted as part of that course. When the idea of taking that forward for a PhD was suggested, I had little idea how much I would learn. It has been a valuable journey, in so many ways, and I am extremely grateful for the wisdom, guidance and friendship that both Albert and Cees have offered along the way.

The work at Ross University could not have been accomplished without the collaboration of Catherine Schipul, my long-time colleague in the Centre for Teaching and Learning. Our daily discussions about the ELLS course, the details of the materials, the students and the logistics, as well as endless conversations about teaching, language and life, have provided the space for me to test out ideas, and given me the support to carry them out. It is rare that a working relationship is so inspirational.

Above all, I want to thank my wife, Diana Callender. It was her influence that convinced me that a PhD was worth pursuing and her wisdom and understanding that has enabled me to persist, to sustain focus over these years. Without her, I am quite sure this thesis would not have been written. 



\section{Biosketch}

Kalman Winston was born in 1965 in Southend-on-Sea, Essex, England, where he was raised and schooled. He has lived in a number of places, principally the UK, Taiwan, and Dominica, mostly working as a teacher, of English, mathematics, study skills and critical thinking, to students of a wide range of ages and levels. He was awarded the degrees of BSc and Masters in Education from the Open University, UK, in 2001 and 2007 respectively. His projects have included the development of an English language school in Hualien, Taiwan and the founding of an eco-resort in Rosalie, Dominica. He worked for ten years at Ross University School of Medicine, Dominica, directing their $\mathrm{PBL}$ program for five years, chairing the Institutional Review Board for four years, and founding and developing a Centre for Teaching and Learning, which was the main locus of this research. He currently works as a Study Adviser at Bangor University, North Wales. He is married, has one adult son, and enjoys reading, learning, walking, and being. 


\section{SHE Dissertation Series}

The SHE Dissertation Series publishes dissertations of PhD candidates from the School of Health Professions Education (SHE) who defended their PhD theses at Maastricht University. The most recent ones are listed below. For more information go to:

www.maastrichtuniversity.nl/she.

Duvivier, R. J. (12-12-2012) Teaching and Learning Clinical Skills. Mastering the Art of Medicine.

De Feijter, J.M. (09-11-2012) Learning from error to improve patient safety.

Prescott, L. (09-11-2012) Ensuring the Competence of Dental Practitioners through the Development of a Workplace-Based System of Assessment.

Cilliers, F.J. (05-09-2012) The Pre-assessment Learning Effects of Consequential Assessment: Modelling how the Examination Game is Played.

Spanjers, I. A.E. (05-07-2012) Segmentation of Animations: Explaining the Effects on the Learning Process and Learning Outcomes.

Al-Kadri, H.M.F. (28-06-2012) Does Assessment Drive Students' Learning?

Leppink, J. (20-06-2012) Propositional manipulation for conceptual understanding of statistics.

Van Zundert, M.J. (04-05-2012) Conditions of Peer Assessment for Complex Learning.

Claramita, M. (30-03-2012) Doctor-patient communication in a culturally hierarchical context of Southeast Asia: A partnership approach.

Kleijnen, J.C.B.M. (21-03-2012) Internal quality management and organizational values in higher education.

Persoon, M.C. (19-01-2012) Learning in Urology; The influence of simulators and human factors. 
Pawlikowska, T.R.B. (21-12-2011) Patient Enablement; A Living Dialogue.

Sok Ying Liaw, (14-12-2011) Rescuing A Patient In Deteriorating Situations (RAPIDS): A programmatic approach in developing and evaluating a simulation-based educational program.

Singaram, V.S. (7-12-2011) Exploring the Impact of Diversity Factors on Problem-Based Collaborative Learning.

Balslev, T. (24-11-2011) Learning to diagnose using patient video cases in paediatrics: Perceptive and cognitive processes.

Widyandana, D. (19-10-2011) Integrating Pre-clinical skills training in skills laboratory and primary health care centers to prepare medical students for their clerkships.

Durning, S.J. (09-09-2011) Exploring the Influence of Contextual Factors of the Clinical Encounter on Clinical Reasoning Success (Unraveling context specificity).

Govaerts, M.J.B. (08-09-2011) Climbing the Pyramid;Towards Understanding Performance Assessment.

Stalmeijer, R. E. (07-07-2011) Evaluating Clinical Teaching through Cognitive Apprenticeship.

Malling, B.V.G. (01-07-2011) Managing word-based postgraduate medical education in clinical departments

Veldhuijzen, J.W. (17-06-2011) Challenging the patient-centred paradigm: designing feasible guidelines for doctor patient communication.

Van Blankenstein, F. (18-05-2011) Elaboration during problem-based, small group discussion: A new approach to study collaborative learning.

Van Mook, W. (13-05-2011) Teaching and assessment of professional behavior: Rhetoric and reality.

De Leng, B. (8-12-2009). Wired for learning. How computers can support interaction in small group learning in higher education.

Maiorova, T. (29-05-2009). The role of gender in medical specialty choice and general practice preferences.

Bokken, L. (04-03-2009). Innovative use of simulated patients for educational purposes.

Wagenaar, A. (18-09-2008). Learning in internships. What and how students learn from experience. 
Driessen, E. (25-06-2008). Educating the self-critical doctor. Using portfolio to stimulate and assess medical students' reflection.

Derkx, H. (18-06-2008). For your ears only. Quality of telephone triage at out-of-hours centres in the Netherlands.

Niessen, Th. (30-11-2007). Emerging epistemologies: making sense of teaching practice.

Budé, L. (05-10-2007). On the improvement of students' conceptual understanding in statistics education.

Niemantsverdriet, S. (26-07-2007). Learning from international internships: $A$ reconstruction in the medical domain.

Marambe, K. (20-06-2007). Patterns of student learning in medical education - A Sri Lankan study in traditional curriculum.

Pleijers, A. (19-01-2007). Tutorial group discussion in problem-based learning.

Sargeant, J. (21-09-2006). Multi-source feedback for physician learning and change.

Dornan, T. (12-06-2006). Experience-based learning.

Wass, V. (12-05-2006). The assessment of clinical competence in high stakes examinations.

Prince, K. (21-04-2006). Problem-based learning as a preparation for professional practice. 